\title{
Environmental health risk assessment : evaluation of some default assumptions
}

Citation for published version (APA):

Albering, H. J. (1998). Environmental health risk assessment : evaluation of some default assumptions. [Doctoral Thesis, Maastricht University]. Rijksuniversiteit Limburg.

https://doi.org/10.26481/dis.19980626ha

Document status and date:

Published: 01/01/1998

DOI:

10.26481/dis.19980626ha

Document Version:

Publisher's PDF, also known as Version of record

\section{Please check the document version of this publication:}

- A submitted manuscript is the version of the article upon submission and before peer-review. There can be important differences between the submitted version and the official published version of record.

People interested in the research are advised to contact the author for the final version of the publication, or visit the DOI to the publisher's website.

- The final author version and the galley proof are versions of the publication after peer review.

- The final published version features the final layout of the paper including the volume, issue and page numbers.

Link to publication

\footnotetext{
General rights rights.

- You may freely distribute the URL identifying the publication in the public portal. please follow below link for the End User Agreement:

www.umlib.nl/taverne-license

Take down policy

If you believe that this document breaches copyright please contact us at:

repository@maastrichtuniversity.nl

providing details and we will investigate your claim.
}

Copyright and moral rights for the publications made accessible in the public portal are retained by the authors and/or other copyright owners and it is a condition of accessing publications that users recognise and abide by the legal requirements associated with these

- Users may download and print one copy of any publication from the public portal for the purpose of private study or research.

- You may not further distribute the material or use it for any profit-making activity or commercial gain

If the publication is distributed under the terms of Article $25 \mathrm{fa}$ of the Dutch Copyright Act, indicated by the "Taverne" license above, 


\title{
Environmental health risk assessment
}

\author{
Evaluation of some default assumptions
}


(c) Albering, Harmina Jannette

ISBN 90-9011740-7
Vormgeving:
Rea Croes
Omslagillustratie Joan Bruggink
Diuk
: Datawyse/ Universitaire Pers Maastricht 


\title{
Environmental health risk assessment
}

\author{
Evaluation of some default assumptions
}

\section{PROEFSCHRIFT}

ter verkrijging van de graad van doctor aan de Universiteit Maastricht,

op gezag van de Rector Magnificus, Prof. dr. A.C. Nieuwenhuijzen Kruseman, volgens het besluit van het College van Decanen, in het openbaar te verdedigen op vrijdag 26 juni 1998 om 14.00 uur

$$
\text { door }
$$

Harmina Jannette Albering

geboren te Smilde op 21 februari 1965 


\section{Promotor:}

Prof. dr. J.C.S. Kleinjans

\section{Beoordelingscommissie:}

Prof dr. J.A. Knottnerus (voorzitter)

Prof. dr. P.G. Knipschild

dr. W.F. Passchier (Gezondheidsraad)

Prof. dr. T.J.F. Savelkoul (Universiteit Utrecht)

Prof. dr. ir. O.J. Vrieze 
Wie geen slechte tijden kan verdrager, zal geew goede tijder beleven

Joods spreekwoord 


\section{Contents}

Abbreviations $\quad 8$

Chapter 1 General Introduction 11

1.1 Introduction 11

1.2 Environmental health chain 12

$1.3 \quad$ Risk Assessment and Risk Management 13

1.3.1 Risk Assessment 14

1.3.2 Risk Management $\quad 22$

1.3.2.1 Risk Assessment/management in environ-

1.4 Uncertainties 25

1.4.1 Defaults 26

$1.5 \quad$ Research and research requires $\quad 27$

1.5.1 Exposure Assessment 29

1.5.2 Dose-Response Assessment 30

1.6 Aim and outline of the thesis 31

\section{Part I: $\quad$ Exposure Assessment}

\section{A: The case of dioxins and PCBs}

Chapter 2 Waste incineration and health risks:

the dioxin case revisited

Chapter 3 Health risk by consuming contaminated fish from brooks in the south-west part of The Netherlands

\section{B: The case of the river Meuse}

Chapter 4 Evaluating environmental health risks after the flooding of the river Meuse during the winter of 1993-1994

Chapter 5 Human health risk assessment in relation to environmental pollution in two artificial freshwater lakes in The Netherlands 


\section{Part II:}

Chapter 6

Chapter 7

Chapter 8

Chapter 9

\section{Dose-response Assessment}

The case of radon

Survey of ${ }^{222} \mathrm{Rn}$ concentrations in dwellings and soils in the Dutch-Belgian border region

Indoor Radon exposure and cytogenetic damage

Genetic biomarkers indicative for DNA damage in relation to indoor Radon exposure

Indoor Radon exposure and extrapulmonary genetic risk

Chapter 10 Summary and General Discussion

Samenvatting

Dankwoord

Curriculum vitae

List of publications 


\section{Abbreviations}

\begin{tabular}{|c|c|}
\hline AAS & Atomic Absorption Spectrometry \\
\hline ADI & Acceptable daily intake \\
\hline ALARA & As Low as Reasonable Achievable \\
\hline ANOVA & Analysis of variance \\
\hline As & Arsenic \\
\hline$B(a) P$ & Benzo(a)pyrene \\
\hline$B C F$ & Bioconcentration factor \\
\hline $\mathrm{Bq}$ & Bequerel \\
\hline bw & Body weight \\
\hline CA & Chromosomal aberrations \\
\hline$C B$ & Cytokinesis blocked \\
\hline $\mathrm{Cd}$ & Cadmium \\
\hline $\mathrm{CG}-\mathrm{ECD}$ & Capillary gas chromatography with electron capture detection \\
\hline Cr & Chromium \\
\hline CRAM & Committee of Risk Assessment Methodology \\
\hline CRARM & Commission on Risk Assessment and Risk Management \\
\hline $\mathrm{Cu}$ & Copper \\
\hline DDT & Dichloro-diphenyl-tri-chloroethane \\
\hline EC & European Community \\
\hline ECETOX & European Centre for Ecotoxicology and Toxicology and Chemicals \\
\hline ELA & Environmental Impact Assessment \\
\hline $\mathbb{E O X}$ & Extractable organic halogen compounds \\
\hline EPA & Environmental Protection Agency \\
\hline $\mathrm{Eq}$ & Equation \\
\hline $\mathrm{Fe}$ & Iron \\
\hline GSD & Geometric standard deviation \\
\hline hat & Hectare \\
\hline HESP & Human Exposure to Soil Pollutants \\
\hline hprt & hypoxanthine guanine phosphoribosyltransferase \\
\hline IPCS & International Programme on Chemical Safety \\
\hline IUPAC & International Union of Pure and Applied Chemistry \\
\hline$K_{d}$ & partition coefficient \\
\hline Kow & octanol/water partition coefficient \\
\hline LMS & Linear multi stage \\
\hline LOAEL & Lowest observed adverse effect level \\
\hline Gy & Gray \\
\hline $\mathrm{Mg}$ & Magnesium \\
\hline MHS & Municipal Health Services \\
\hline MN & Micromuclei \\
\hline Mn & Manganese \\
\hline mo & Month \\
\hline $\mathrm{MPC}$ & Maximum permissible concentration \\
\hline $\mathrm{MPR}$ & Maximum permissible risk \\
\hline So & Silivert \\
\hline NAS & National Academy of Science \\
\hline NEN & Netherlands Normalisation Institute \\
\hline $\mathrm{Ni}$ & Nickel \\
\hline $\mathrm{NNE}$ & North-North-East \\
\hline
\end{tabular}




\begin{tabular}{|c|c|}
\hline NOEL & No observed effect level \\
\hline NR & Negligible nisk \\
\hline NRC & National Research Council \\
\hline OECD & Organization of Economic Co-operation and Development \\
\hline OTA & Office of Technology Assessment \\
\hline $\mathrm{PAH}$ & Polycyclic aromatic hydrocarbon(s) \\
\hline $\mathrm{Pb}$ & Lead \\
\hline PBPK & Physiologically based pharmacokinetic \\
\hline $\mathrm{PBPD}$ & Physiologically based pharmacodynamic \\
\hline $\mathrm{PCB}$ & polychlorinated biphenyl \\
\hline PCDD & polychlorinated dibenzo-p-dioxin \\
\hline PCDF & polychlorinated dibenzofuran \\
\hline $\mathrm{PEC}$ & Predicted environmental concentration \\
\hline PNEC & Predicted no effect concentration \\
\hline ppm & Parts per million \\
\hline QSAR & Quantitative structure-activity relationship \\
\hline $\mathrm{Ra}$ & Radium \\
\hline RTVM & $\begin{array}{l}\text { Rijksinstituut woor Volksgezondheid en Milieu (National Institute of Public } \\
\text { Health and the Environment) }\end{array}$ \\
\hline RTVO & $\begin{array}{l}\text { Rijksinstituut voor Visserij Onderzoek (National Institute for Fisheries } \\
\text { Research) }\end{array}$ \\
\hline $\operatorname{Rn}$ & Radon \\
\hline rpm & Round per minute \\
\hline$R_{5}$ & Spearman rank correlation coefficient \\
\hline SCE & Sister chromatid exchange. \\
\hline sd & Standard deviation \\
\hline $\mathrm{SE}$ & Standard error \\
\hline TCDD & Tetrachloordibenzo-p-dioxin \\
\hline TDI & Tolerable daily intake \\
\hline TEF & Toxicity equivalence factor \\
\hline TEQ & Toxic equivalents \\
\hline $\mathrm{U}$ & Uranium \\
\hline USES & Uniform system for the evaluation of substances \\
\hline WHO & World health organization \\
\hline WI & Waste incineration \\
\hline yt & Year \\
\hline $\mathrm{Zn}$ & Zinc \\
\hline
\end{tabular}





\section{Chapter 1}

\section{General Introduction}

\subsection{Introduction}

Public concern about the potential health effects resulting from exposure to environmental pollutants via air, drinking water, soil and food, has led to a demand for protection against environmental risks. The environmental health chain as well as the risk assessment framework provide clues to estimate and evaluate human health risks in relation to environmental pollution. The environmental health chain represents a sequence of events from the release of a pollutant into the environment, via contact betweem the pollutant with the human body, to the related health effects.

The risk assessment process provides a format for estimating the likelihood of adverse health effects of human exposure in relation to an environmental agent. In general, the process consists of four steps: hazard identification, doseresponse assessment, exposure assessment and risk characterization. By a combination of dose-response assessment and exposure assessment, the human health risk can be estimated. The results of the risk assessment in combination with political, social, economic and engineering information are used for risk management decisions on measures to be taken in order to protect public health.

Most environmental health risk assessments are associated with a high degree of uncertainty, which can be grouped into two major categories: uncertainty resulting from the lack of scientific understanding to interpret the available data, and from the lack of available and appropriate information and data. In order to deal with uncertainty in health risk assessment studies, often default assumptions have been used. Default assumptions/approaches are generic in the sense that they are based on general knowledge if specific knowledge is not avallable. There are some advantages and disadvantages in using default assumptions. An important disadvantage is that most default assumptions appear to be conservative. However, consistency and predictability are major advantages of default assumptions.

Research is necessary to reduce uncertainty and replace default assumptions. Scientific research forms the basis for the assessment framework and by different authors a feedback loop has been postulated interrelating research, risk assessment and risk management. The output of the risk assessment also identifies the uncertainties and thereby directs the research needs. Specifically, mechanistically oriented research which provides insight into the source- 
exposure-effect continuum, has to be improved, and the results should be effectively incorporated into the risk assessment process.

In the following paragraphs, the environmental health chain and the risk assessment framework will be described as well as the risk management process, in relation to risk assessment and in particular, to the environmental policy in The Netherlands. Furthermore, uncertainty as a main problem in most environmental health studies will be described and a summary of research needs for exposure assessment as well as dose-response assessment will be given. In the last section of this Introduction, the outline of the thesis will be summarized.

\subsection{Environmental health chain}

When a pollutant is released into the environment from for instance an industrial source, it may be transported via air, soil, food, and water to the immediate environment of humans. Via ingestion, inhalation and dermal uptake the environmental contaminant enters the body (internal dose) (1). The contaminant undergoes metabolism and elimination, and interacts with target cells and molecules by which it may produce adverse effects. For relating internal dose to adverse health effects, the target dose and the biologically effective dose are important parameters. The target dose represents the part of the internal dose that reaches the tissue of interest. The biologically effective dose is the dose of a contaminant or metabolite that reaches the site of toxic action and induces an altered physiological function (2).

Environmental health risks in relation to exposure are frequently expressed as a product of the emission term, the exposure function, the organ or tissue dose and the adverse effects associated with the delivered dose (toxic potency factor) $(3,4)$. This suggests that the health risks of an environmental pollutant largely are a function of two primary factors: exposure and dose. The continuum of events from the emission from a source into the environment to the ultimate health effects represented by the environmental health chain as illustrated in Fig. 1.1, can be used as a framework to evaluate and estimate environmental health risks (5).

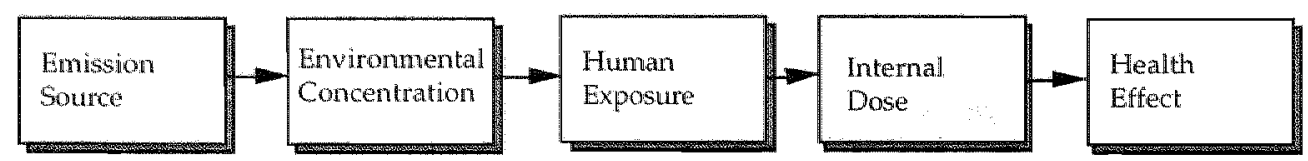

Fig 1.1: Environmental health chain (5) 
The environmental health chain is successive in composition, which means that the input into the next module is the result from the previous module. The lack of scientific information on any part of the chain influences the assessment of health risk related to the environment (6). This chain from source to exposure to effect is a simplified representation. Important information on for instance transport, fate, metabolism and bioavailability is required for a good understanding of the risk chain (7). Furthermore, exposure will vary over time, and health effects vary in term of frequency and severity. Ad ditionally, there may be a time delay between exposure and adverse health effect (8).

Another method for the evaluation of health risks in relation to environmental pollution is the effect approach, in contrast to the dose approach as described above. Epidemiological research is an example of this approach.

Although each element of the chain is important in order to determine the risk for the general public associated with environmental pollution, much attention has been paid to the last part of the chain (6,9-11). Various studies. have related exposure to dose to effects in animals and humans. Frequently, actual exposure in relation to environmental pollution has not been determined. Until the 1980s, exposure assessment has been primarily based on measurements or on model predictions of concentrations in the environment of human populations, generally exposed via single exposure pathways $(9,10,12,13)$. An example of this is the measurement of human exposure to air pollutants by centrally located air monitoring stations. But many human exposures to environmental pollutions, for instance pesticides, dioxins and PCBs, cadmium, polycyclic aromatic hydrocarbons and benzene, appear to follow multiple environmental pathways (air, food, soil, water) and multiple routes (dermal transport, ingestion and inhalation). At present, much attention is directed to the assessment of total exposure of environmental pollutants by multiple exposure pathways (10).

Alternatively to the analysis of the environmental health chain, the risk assessment framework can be used to evaluate health risks in relation to environmental exposure.

\subsection{Risk Assessment and Risk Management}

Risk assessment is the process of describing the likelihood that potentially adverse health effects are caused by a chemical, biological or physical agent. In the literature, there is some discussion about the term 'risk assessment'. There is some disagreement on how to make the distinction between risk assessment and risk management. Some authors use the term 'risk assessment" for the entire risk management process, others see 'risk assessment' merely as a part of the management process, and some use "risk assessment' to characterize threats 
to human health and the environment as a part of the regulatory decision making framework (14-17). Risk assessment and risk management are connected, be it by different methods, different objectives, information and results.

In general, risk assessors estimate risks while risk managers have to determine a safe level, or to decide whether risks are unacceptable and if so, what do about these risks (5). The concept of risk plays an important role in the evaluation of health effects in relation to exposure by environmental pollution. The national government in The Netherlands has defined risk as "the undesirable consequences of a particular activity in relation to the likelihood that it occurs", and comprises two aspects: the significance of the effects and the probability that these effects occur (18).

The type and detail of the risk assessment are frequently affected by the type of the risk management decision $(14,16)$. Since research serves as an input for both risk assessment and management, risk assessment can be seen as a function to link science to decision making $(17,19)$. In this introductory chapter, a distinction has been made between risk assessment, risk management and research.

\subsubsection{Risk Assessment}

Historically, risk assessments have been performed many decades before general consensus on the process had been achieved. By the mid 1970s, risk assessment had been recognized as a way of evaluating the potential harm from the environment $(20,21)$. Lowrance provided the first conceptual framework of environmental risk assessment for human health in 1975 (22). The framework includes an identification of the condition of exposure to an agent, the adverse effect of the agent, a determination of a quantitative relationship between exposure and adverse effect, and ultimately, an estimation of the health risk by a combination of the condition of exposure to the agent and the dose-response relationship. The estimated risks are used for policy making and management decision, taking into account other aspects, for instance, social values (22).

The U.S. National Research Council Committee of the National Academy of Science has played an important role with regard to the institutional means for assessment of risks to public health by publishing the book Risk Assessment in the Federal Government, in 1983 popularly quoted as "The Red Book" (14). The emphasis of this study has been on the problem of increased cancer risk resulting from environmental exposure to chemicals. In the committee's view, the basic shortcoming of risk assessment is the uncertainty and lack of scientific knowledge of the health hazards (21). It codifies what has become a common view, that risk assessment is a scientific task, and the committee defines risk assessment as "estimating the magnitude, likelihood and uncertainties of 
environmentally induced health effects" (21). The risk assessment process as shown in Figure 1.2, includes one or all of the following four steps: hazard identification, dose-response assessment, exposure assessment and risk characterization. This framework or scheme provides a conceptual understanding that enhances the uniformity and clarity of human health risk assessment $(14,23)$.

The U.S. Environmental Protection Agency for instance has adopted the NAS/NRC risk assessment framework for their risk assessments.

Risk Managennent

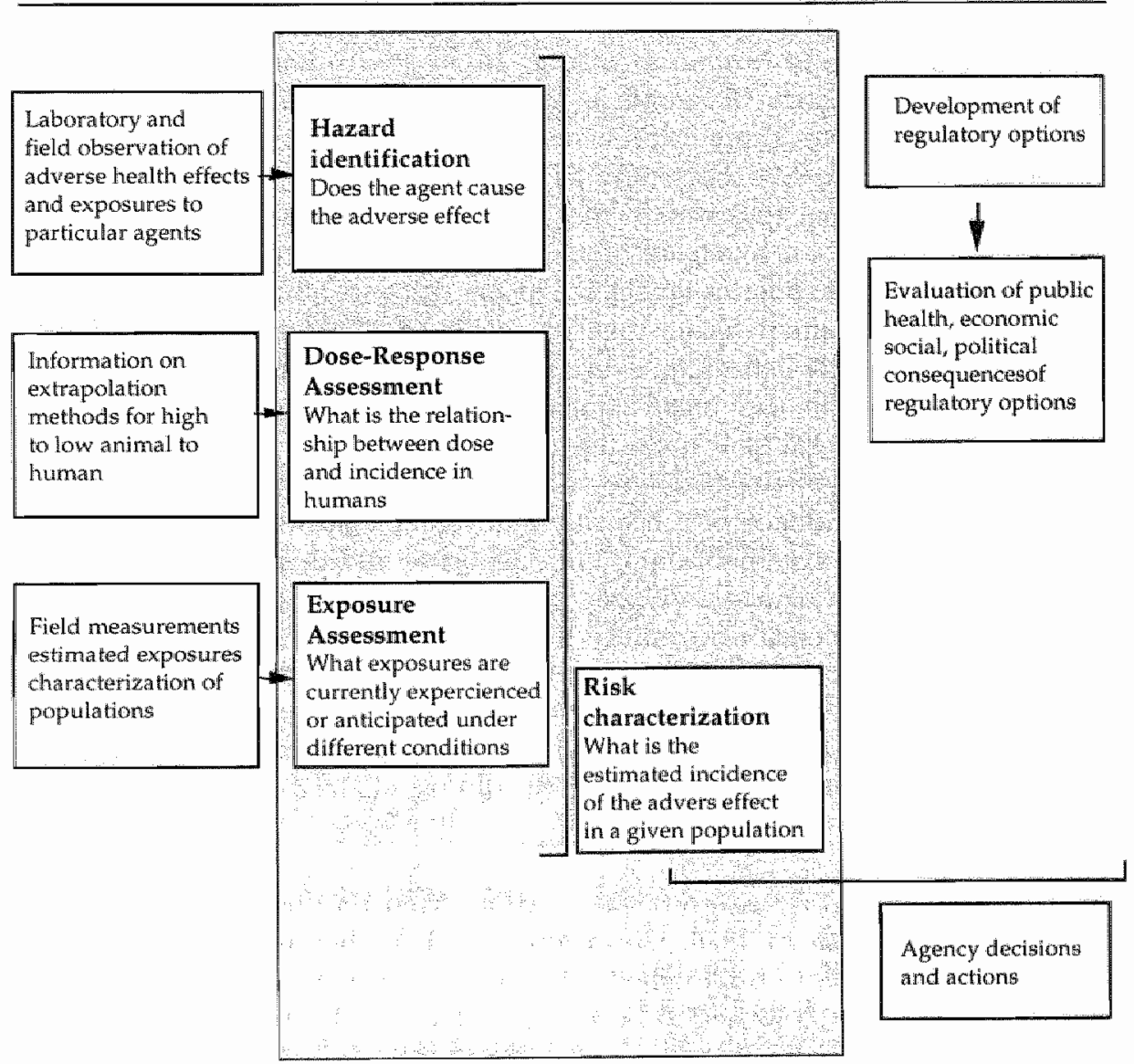

Figure 1,2: Risk assessment framework according to the NAS/NRC (21) 
The goal of hazard identification is to determine whether the avallable scientific data describe a causal relationship between exposure to an (environmental) agent and the toxic health effects that an agent produces, as well as the level of exposure at which these occur. Information on the agent responsible for the effect, may come from animal bioassays, epidemiological data, short term studies like mutagenicity assays, and QSAR (quantitative structure-activity relationship) studies (21).

Dose-response assessment is designed to establish a quantitative relationship between exposure (dose) and adverse health effects which have been observed. The dose-response assessment is based mainly on two important extrapolations: from high-to-low dose and from animals to humans.

Exposure assessment focuses on measuring or estimating the magnitude, frequency and duration of human exposures to an environmental agent, or on estimating future exposure of agents to be introduced into the environment (23). In general, there are three approaches for the quantification of exposure; each approach has different shortcomings and strengths (10,24-26). The direct approach measures actual exposure at the exterior of the human body. Personal exposure monitors are an example of this approach. The reconstructive approach estimates past exposure levels based on reconstruction of the internal dose observed from human tissue measurements (e.g. exposure biomarkers). The predictive approach estimates exposure by using different mathematical scenario models and is the most commonly used method for estimating exposure in environmental health studies $(1,10,26-30)$.

Risk characterization, the final step in the risk assessment process, deals with estimating the incidence of a health effect under various circumstances of human exposure. It is a combination of both exposure and dose-response assessment, in which the uncertainties with regard to the exposure and dose-response assessments, and the overall uncertainty in the final step are described. Within this respect, risk characterization represents the interface between the scientist and the risk manager. The known uncertainties from the first three steps are clearly expressed in order to assist the decision maker and is furthermore a guide for the scientist to plan new research aiming at decreasing the level of uncertainty (21).

The NAS/NRC framework insignificantly differs from the first risk assessment framework by Lowrance in 1975 . Uncertainty analysis has been added to the four steps of the process and furthermore, the committee has recommended that a conceptual distinction has to be made between risk assessment and risk management (22).

Over the last decades, several schemes for environmental health risk analysis have become available. These schemes clarify the main elements in risk assessment and risk management. The frameworks presented in this paragraph follow the framework devised by the NAS in 1983, although the 
degree of similarity and level of detail varies. The basic four elements of the framework have been improved during the last decades.

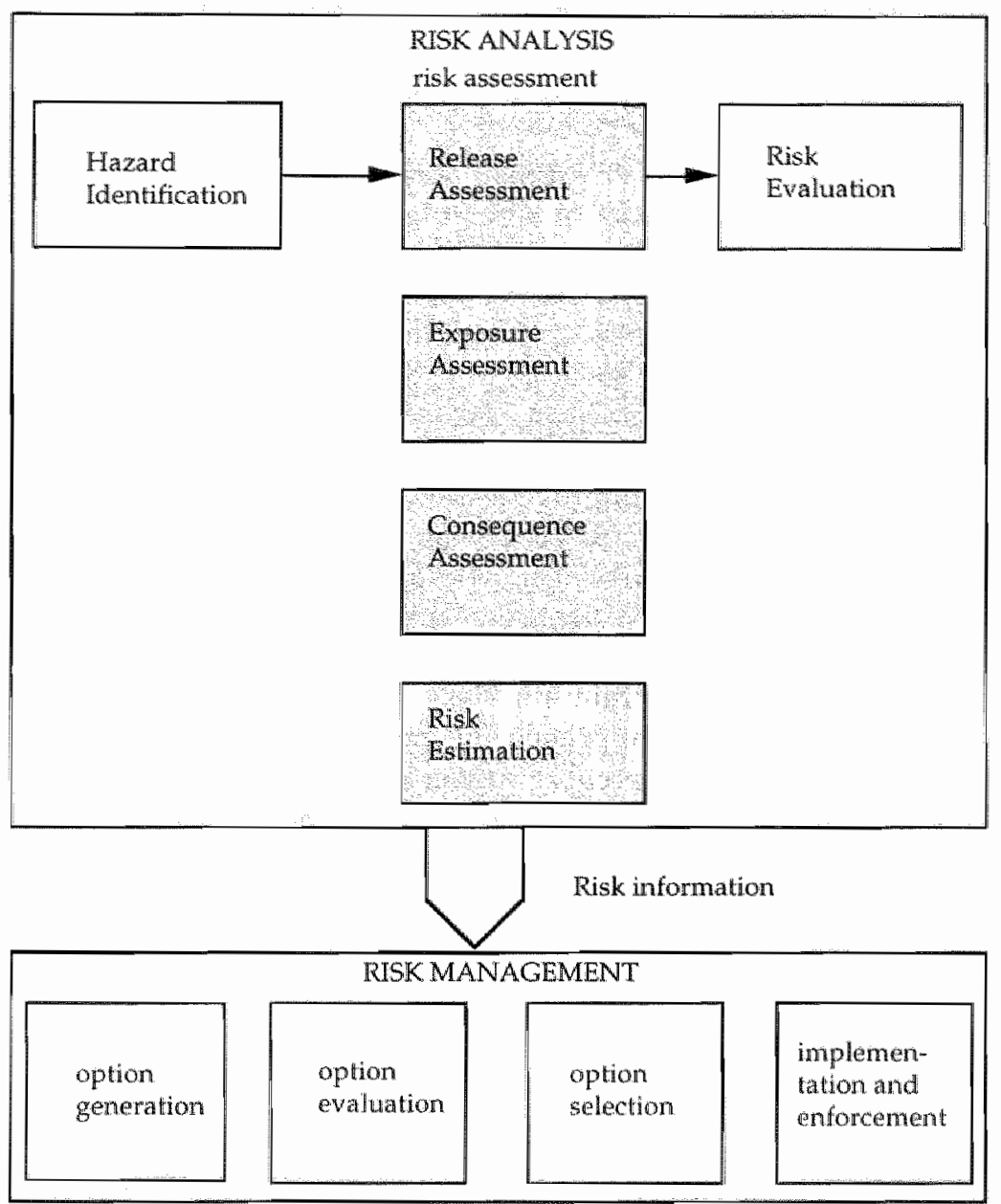

Figure 1.3: Risk assessment framework according to Covello and Merkhofer (8)

In 1993, Covello and Merkhofer have formulated an alternative model for risk assessment, as shown in Figure 1.3 (8). The authors have decided that hazard identification, the first step in the NAS/NRC model, is an essentiall step that necessarily takes place before the assessment process. It is a process of equal importance as the quantitative process of risk assessment. Furthermore, release assessment has been included as the first step in the risk assessment process. It is designed to establish a quantification of the possibility of an environmental 
source to release or to introduce agents into the environment, for instance as a consequence of industrial accidents or fallures of technological systems. Exposure assessment is similar as formulated in the NAS/NRC model, but it is performed before dose-response assessment, which has been described as consequence assessment in the Covello and Merkhofer model. Ecological and human consequences have additionally been included into this assessment (8).

In 1994, a follow up report from the National Academy of Science and the National Research Council entitled Science and Judgement in Risk Assessment has been written, generally referred to as CAPRA (31). This committee has reviewed the quantitative carcinogenic risk assessment procedures by the EPA with concern to the exposure to hazardous air pollutants from sources under the Clean Air Act Amendments of 1990 (31). The CAPRA report does not intend to change the traditional process of risk assessment/management as postulated and described in 1983, but it intends to improve the various steps in the risk assessment process (32). The improvements can be summarized by four central themes. A conservative default-based approach of risk assessment should be retained for screening analysis in standard setting. In addition, an iterative approach of risk assessment has been proposed, which starts with relatively simple analyses and then focus on more intensive analyses for chemicals suspected of exceeding minimum risks. This approach allows for improvements in the default-based approach by improving both models and data used in the analysis. Finally, the report suggests not only to present point estimates of risk but also the sources and magnitudes of uncertainty associated with the estimated health risks have to be described and clearly summarized in order to become understandable for decision makers and the public (31).

Originally, the NAS/NRC risk assessment scheme has been used to evaluate the carcinogenic risks from exposure to environmental toxicants, but also other health related effects like reproductive and developmental disorders can be evaluated by this framework (33). Since the 1990s, ecological risk assessment has moved to the front to join human health risk assessment in terms of usefulness for environmental policy. In 1992, the U.S. Environmental Profection Agency has modified the original NAS/NRC framework to evaluate the ecological risks due to chemicals and other stressors (e.g. deforestation, excessive energy consumption) in relation to environmental pollution (33).

The framework includes the following steps: problem formulation, risk analysis and risk characterization. In the course of problem formulation, the type and details of the risk assessment are determined according to the state of the art of the scientific knowledge and to the relevance for the decision making process. Characterizations of exposure and effect are determined during the risk analysis step. The output of the risk assessment are discussed with the decision 
maker, who has to make a decision about the acceptability of the estimated risks and who furthermore, has to communicate with the public (23).

The Committee of Risk Assessment Methodology (CRAM) of the National Academy of Science has reconciled ecological risk assessments with the original NAS/NRC framework (Figure 1.4), which will serve as a methodological scheme for both ecological and health risk assessments in environmental policy (23). The ultimate goal for both models (CRAM and EPA) is to provide a conceptual scheme that can increase the merits of ecological risk assessment (23).

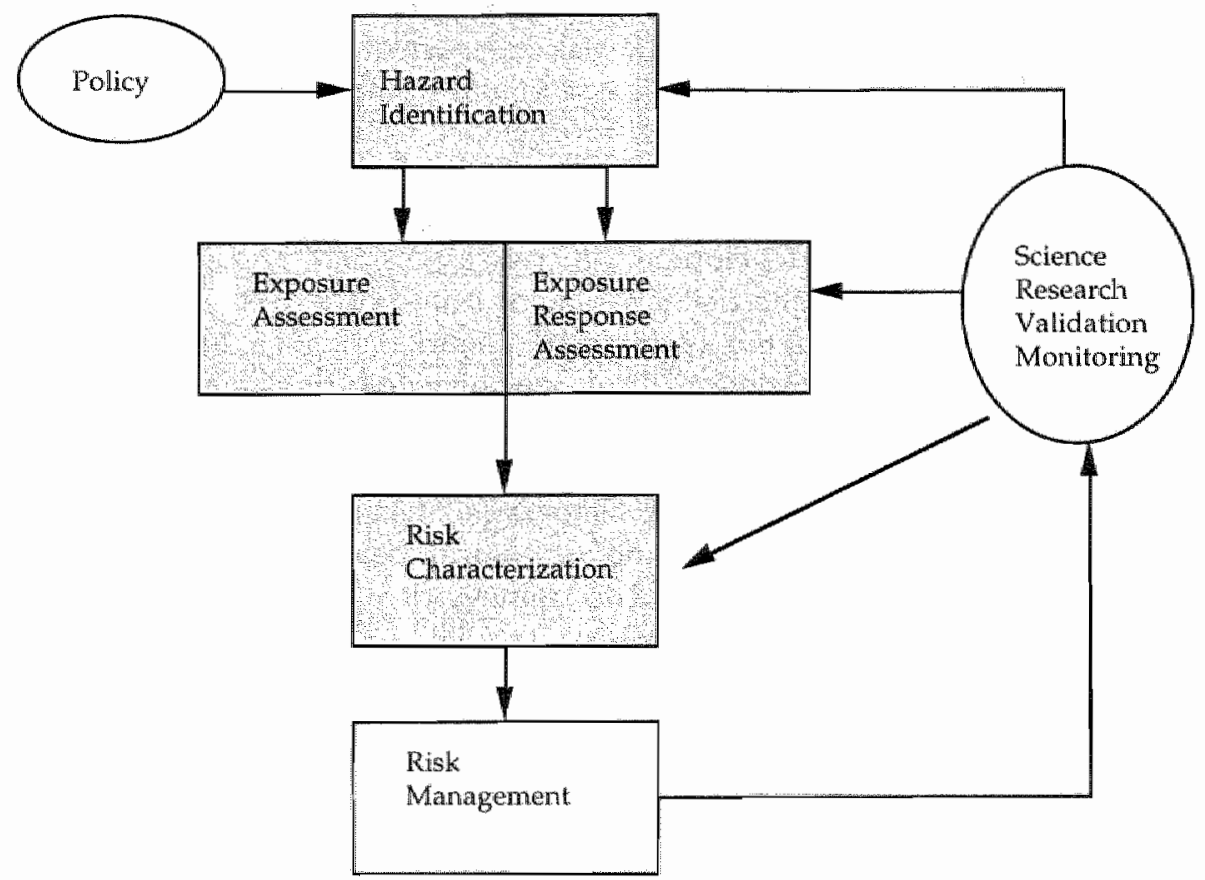

Figure 1.4: Health/Ecological risk assessment framework proposed by the CRAM committee (23)

The framework proposed a conceptual scheme for human and ecological risk assessment consisting of the following components; hazard identification, exposure assessment, exposure-response assessment and risk characterization.

The dose term in dose-response assessment has been replaced by an exposure term, because the concept of "dose" cannot correctly be applied to nonchemical endpoints. The CRAM committee acknowledges that policy decisions affect the hazard identification. Furthermore, the committee notes the need to create a relationship between the output of the assessment and the scientific 
foundation for new risk assessments (see research paragraph). According to CRAM, an important aspect of understanding the risks, particularly in ecological risk assessment, is effective communication with decision makers and the public (23). This viewpoint has also been recommended by the U.S. Office of Technology Assessment (OTA) in 1993 and the NAS committee in $1994(20,31)$.

Risk assessment is a young and evolving area in environmental health science and the process of risk assessment is under development. The concept regarding a basic principle of a separation between risk assessment from risk management, as suggested in the NAS/NRC 1983, is in practice an interplay between the two processes. The holistic risk assessment framework developed by Harvey and co-workers and the risk assessment framework proposed by the Health Council of The Netherlands are for instance examples of this interplay $(34,35)$.

Effective communication between risk managers and risk assessors become more important during the development of risk assessment and is added as a separate element in the holistic risk assessment framework (34). The proposed framework is broader than the NAS/NRC framework. The output of the holistic assessment is a range of risk options for risk managers. The consequence is that risk assessors and managers already cooperage in an early phase of the process.

In 1995, the Health Council of The Netherlands has proposed a framework of the relationship between health and ecological risk assessment and risk management as shown in Figure 1.5. The framework is more in line with the ecological risk assessment framework of the U.S. EPA and includes the following subjects; problem formulation, risk analysis and risk characterization $(35,36)$. In the view of this committee, the relationship between risk assessment and risk management is dynamic. They recommend a consultation between the risk assessor and the risk manager during the first step of the process, with subsequent communication of the results of the assessment.

Recently, two reports have been published in the field of risk assessment and risk management to inform better decision making in the face of scientific uncertainty (37,38). The NAS/NRC committee published in 1996 a report entitled Understanding Risk: Informing Decisions in a Democratic Society. The committee beliefs that to increase the likelihood of sound and acceptable decisions, risk characterization as the final step in the risk assessment process has to be improved. They belief that risk characterization is more than the current practice of translating or summarizing the results of an assessment into non-technicall language. It is a decision-driven activity and is the outcome of an analytic-deliberative process that involves stakeholders at the beginning of the risk assessment process $(37,39)$. 


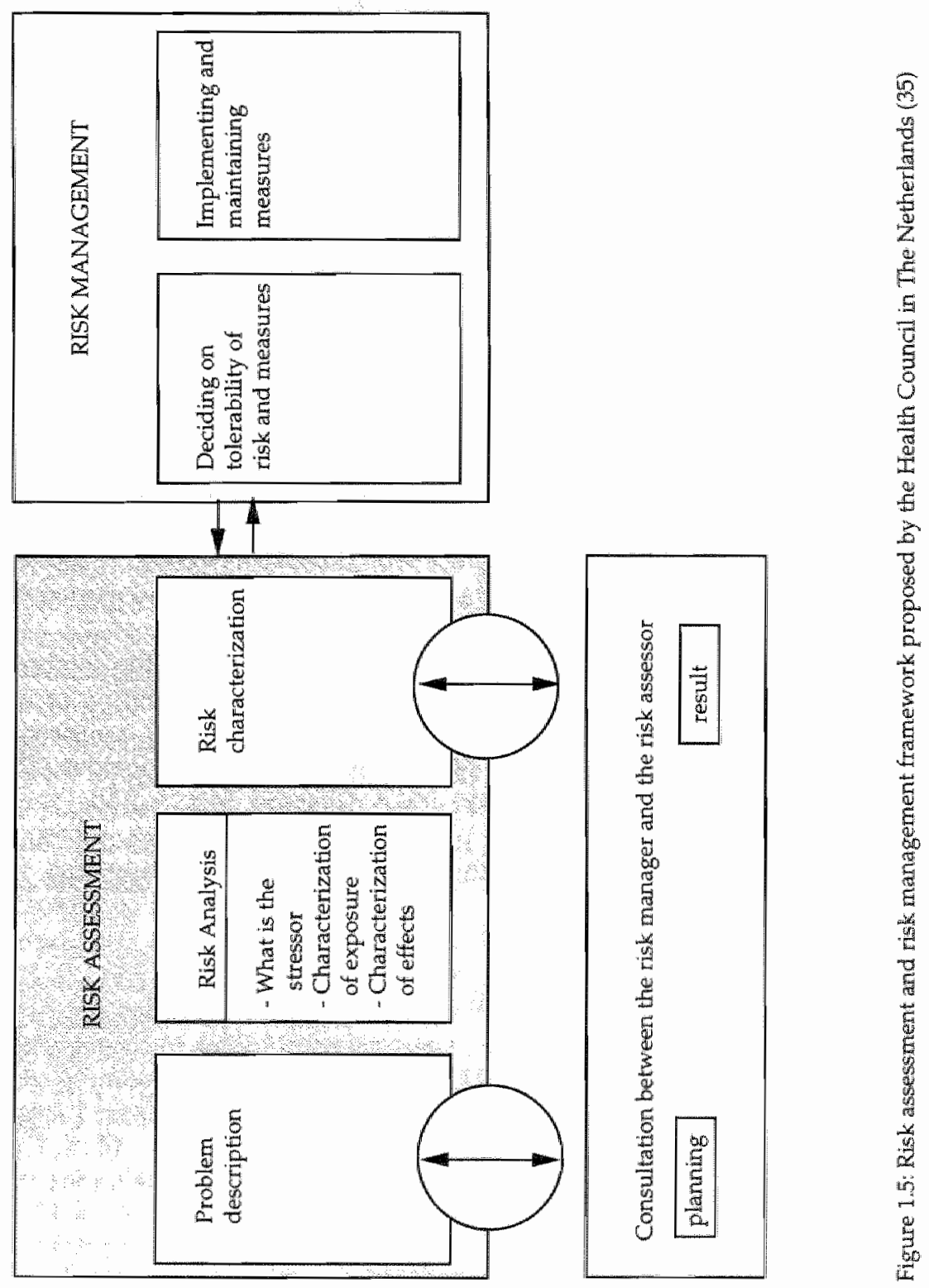


The second report entitled Risk Assessment and Risk Management in Regulatory Decision-making published by the U.S. Congress Commission on Risk Assessment and Risk Management in 1997, postulated a new framework for environmental health risk management (38). Risk assessment is one of the six stages of the risk management framework. The framework begins by putting an environmental problem into a broad public health or ecosystem health context. In addition, the risks are estimated and options are defined for addressing the risks. Subsequently, decisions are made and actions are taken to implement and evaluate the results of the action. An important aspect of the framework is the central role of stakeholder collaboration. The commission beliefs that stakeholder involvement informs decision making.

Hazard and risk assessment are important themes in the regulation of chemicals. National authorities as well as international organisations use hazard and risk assessment for their regulation of substances (for instance governments of The Netherlands, the U.S., and the United Kingdom; European Centre for Ecotoxicology and Toxicology of Chemicals (ECETOX), International Programme on Chemical Safety (IPCS, joint activity of the WHO), Organization of Economic Co-operation and Development (OECD)) (40-43). There is a tendency for an agreement between the different methods and concepts used $(16,43,44)$.

For instance in The Netherlands, a uniform system for the evaluation of substances (USES) has been developed which should achieve a rapid, preliminary and intermediate evaluation of organic substances, comprising new substances, existing substances, plant protection products and biocides (45). For a quantification of the hazards and risks for ecosystems (e.g. aquatic, terrestrial, micro-organism in sewage treatment plants, and top predators) and for human populations (e.g. consumers indirectly exposed via the environment), the Predicted Environmental Concentration (PEC)/ predicted Nomeffect Concentration (PNEC) or hazard quotients approach has been used (45). This approach can be compared with the original risk assessment framework. The PEC is a part of exposure assessment and the effect assessment (PNEC) includes dose-response assessment and hazard identification. The hazard quotient indicates the probability of a substance to cause adverse effects, which can be compared to risk characterization. The PEC/NEC approach has been used for hazard assessment of substances by other national and international authorities (43). The basic principle of a hazard assessment is the chemical of concern, whereas the basic principle for a risk assessment is a specific case (46).

\subsubsection{Risk Management}

The NAS/NRC committee in their report of 1983 has defined risk management as "the process of weighing policy alternatives and selecting the most appro- 
priate regulatory action, integrating the results of risk assessment with engineering data and with social, economic and political concerns to reach a decision" (21). The committee has recommended a separation of risk assessment and risk management. They assume as described previously that decision makers may influence the research outcomes. The committee notes that policy choices and scientific judgements (e.g. uniform guidelines) have to be made to carry out risk assessments, but the committee distinguish those judgements and choices from the social and economic policy issues that are part the risk management process. They have used the phrase 'risk assessment policy" or scientific policy for these policy choices and scientific judgements. Science policy is between facts (science) and values (policy) $(17,19,21$ ).

As discussed previousily, there is some discussion on the conceptual separation between risk assessment and risk management (14-16,20,22,35,47). Risk assessment is generally seen as an objective and scientific process, whereas values are elements which influence the management process $(16,17)$. However, some authors critisize the objectivity of risk assessment and argue that social justice and public policy are important aspects which influence the risk assessment $(48,49)$. It is recognized by some authors that these two processes are related and complementary. The type of management decision frequently affects the type and details of the risk assessment $(14,16,20,35)$.

Determination of the acceptability of risks, a selection of the most costeffective method to prevent or reduce adverse effects from environmental exposure, an evaluation of the success of risk mitigation efforts (monitoring), regulatory requirements, remediation of environmental pollution and risk communication all are important goals of the management process $(35,36,47)$. A variety of options can be taken to achieve these goals, broadly classified as regulatory, economic, advisory or technological (50). In this process, the results of a risk assessment are used to decide whether risks are unacceptable and if so, what do about it. Although quantitative risk estimates are an important aspect, it is only one element in formulating regulatory decisions. Decision makers must also consider other important factors such as political, social, economical and technical factors, before they decide whether actions are needed to protect human health $(5,21)$. The following section describes the risk assessment and management process in environmental policy in The Netherlands.

\subsubsection{Risk Assessment/management in environmental policy in The Netherlands}

The Ministry of Housing, Physical Planning and Environment has formulated the risk approach as a policy in the Indicative Environmental. Policy Program 1986-1990, and it has been extended in the National Environmental Policy Plan 1990-1994 (18,51). The Netherlands government has implemented sustainable 
development as a concept of long term environmental policy to protect humans, animals, plants, ecosystems and goods. As appendix of the National Environmental Policy Plan, the Premises of Risk Management in 1989 have moved human health considerations with respect to environmental policy into the centre of interest. Health and ecological risk assessments have been important topics of this appendix (18). Environmental policy has been formulated along two lines of approaches: the source-directed approach and the effect-directed approach $(18,51)$. To prevent environmental pollution is the basic principle of the source-directed approach. The basic principle of the effectdirected approach is that the likelihood of undesirable effects for humans, animals, plants, ecosystems and goods has to be negligible (18).

In The Netherlands, risk assessment is one of the tools for effect-oriented environmental management. On the basis of the results of the risk assessment process risk managers will have to make a decision whether the estimated risk is unacceptable, taking further into account political, social, economic and engineering facts. Policymakers decide which risk limits are acceptable or tolerable.

According to Premises for Risk Management in 1989, two different risks limits are defined: the maximum permissible risk (MPR), and the negligible risk (NR) which has generally been defined as $1 \%$ of the MPR taking into account factors such as multi-media exposure, toxicity of mixtures, uncertainties in the estimates and a sufficient margin between the two risk limits. Risks above the upper limit (e.g. maximum permissible risk) are considered unacceptable and legal action is in principle mandatory. Risks below the lower limit are considered negligible and no further reduction of the risk is required. Within the grey zone (e.g. the zone between the upper and lower risk levels), risk reduction is required according on the ALARA (e.g. as low as reasonable achievable) principle by using the best practicable means (18).

This risk management approach claims to represent a method for dealing with risks caused by exposure of people and ecosystems to ionizing radiation, major accidents and to hazardous substances. For these risks categories, three risk measures have been defined; the individual and group risk for man, and the collective risk for ecosystems. Furthermore, a distinction has been made between substances with and without threshold (in their mechanism of toxicological action). The negligible individual risk level for hazardous substances (without threshold e.g. genotoxic carcinogen) and to ionizing radiation corresponds to a lifetime cancer risk of $10^{-6}$ meaning a probability of $10^{-6}$ to die as a consequence of cancer of any type, resulting from lifetime exposure to the carcinogenic agent of concern. At the political level, it has been agreed that the lifetime cancer risk of $10^{-6}$ is in accordance with an annual probability to die of $10^{-8}$, taking a hypothetical lifetime of 100 years into consideration (52). The 
maximum permissible individual risk level for an exposure to a hazardous substance (genotoxic carcinogen) and to ionizing radiation has been defined as an annual probability to die of 10-6.

For hazardous substances with a threshold (e.g. non-genotoxic carcinogens), the maximum permissible risk level corresponds to the no-adverse effect level, divided by a margin of safety, generally a factor of 100 (e.g. ADI). This negligible risk level corresponds to $1 \%$ of the MPR. The group risk has been defined as the annual probability of $10^{-5}$ of death of a group of ten or more persons within a short period of time due to an accident (MPR). The negligible risk corresponds to an annual probability of $10^{-7}$. The group risk has been included into the risk pollicy for taking into account social disruptions (18). The collective risk for ecosystems has been set at $95 \%$ of the species protection level (maximum permissible concentration). The negligible risk level corresponds to $1 \%$ of the MPC.

In the last years, this two level quantitative risk assessment system has been changed under influence of the public debate (52-55). Much attention has been given to the maximum permissible risk level as the upper risk limit. For the three policy areas (e.g. hazardous substances, ionizing radiation and major accidents), risks above the MPR level are regarded as unacceptable, except for some situations involving major accidents. Below the MPR level, risk reduction is necessary according to the ALARA principle. The negligible risk level appears to have two different meanings. First, it corresponds to the lower limit of ALARA (e.g. major accidents and ionizing radiation), secondly it has a normative character as target value (e.g. hazardous substances). Furthermore, there is some discussion on the range between the maximum permissible risk level and the negligible risk level (e.g. $1 \%$ of MPR) $(52,53)$.

Limits for the environmental quality in relation to public health as formulated in the National Environmental Policy Plan 1990-1994, are generally expressed as the maximum permissible (upper) and negligible (lower) risk limits. The aim of the Plan is that by the year 2000 the maximum permissible risk levels for hazardous substances should not be exceeded anymore $(52,56)$. The two level quantitative risk assessment system is the framework to set environmental quality standards and health based standards $(18,57)$.

\subsection{Uncertainties}

An important issue in risk characterization as part of the risk assessment framework is a description and discussion of uncertainties (21). According to CAPRA, uncertainty can be described as "the lack of knowledge as to what the 
truth is whether qualitative or quantitative" (31). Different sources of uncertainty play a role in many risk assessments. They mostly refer to the limitation of the scientific understanding to interpret the available data and to the lack of available and appropriate information and data $(5,8,14,16,19,21,24)$. Because of the lack of data, risk assessments have to be based on defaults and expert judgement (15).

Variability (e.g. heterogeneity) among individuals in a population due to for instance, age, breathing rate, body weight and vegetable intake also contributes to the uncertainties in risk assessment. Usually, variability refers to type A uncertainty and the 'true uncertainty' as described above refers to type B uncertainty (58-60). The NAS/NRC committee in 1994 has recommended that risk estimates should be expressed as ranges or distributions and that as part of the risk characterization step both qualitative and quantitative sources of uncertainty have to be addressed (31). The CRARM committee in 1997 stresses the qualitative description of uncertainty for routine risk assessments which is more understandable and effective for the risk manager and the public (38).

The usual approach for quantification of uncertainty in environmental health risk assessment is the Monte-Carlo approach $(15,61,62)$. Many human health risk assessments have used a deterministic approach (e.g. single point estimate) for the quantification of risks. The purpose of the Monte-Carlo analysis is to estimate probability distributions for human health risks in a particular situation. Nowadays, the Monte-Carlo approach has been applied in many environmental health risk assessments especially for the quantification of uncertainty in exposure assessment $(3,4,24,27,28,30,40,47,58,65-68)$. However, also this approach contains a degree of uncertainty; for instance, to model transfer processes correctly is still difficult because of the lack of scientific understanding $(38,63,64)$.

\subsubsection{Defaults}

In order to deal with uncertainty (e.g. resulting from the lack of knowledge), scientific judgements have to be made. The NAS/NRC committee in 1983 has introduced inference guidelines for risk assessment, which have been described as 'an explicit statement of a predetermined choice among the options that arise in inferring human risk from data that are not fully adequate or not drawn directly from human experiences" (21). These inferences can be seen as default assumptions (21). Default assumptions are generic assumptions to fill in data gaps and are also used as a policy option for dealing with disagreement in models and theories $(15,19,69)$. Major advantages of the guidelines are the uniformity and the predictability of risk assessments, which make it difficult to integrate new science to replace default options. Oversimplifications, and using mostly conservative assumptions are regarded as major disadvantages of the use of guidelines for risk assessment $(19,21,31,70,71)$. Instead of a quantification 
of uncertainty, conservatism has been introduced in risk assessment in order to deal overall with uncertainty. Conservative default values have been developed which prevent risk underestimation $(8,19,32,69)$. The major criticism on health risk assessments refers to the use of these conservative default assumptions (11). Some argue that the choice for conservatism is a policy judgement and not a choice by the risk assessor $(8,69)$. Using conservative assumptions in many stages of the risk assessment process certainly implies an overestimation of risks but it is frequently done in regulatory decision making. However, Finkel has indicated that the use of conservatism in risk assessment may both under- and overestimate the risks $(70,71)$. A problem appears to be that the degree of conservatism differs from one risk assessment to the other, and furthermore, it is not always clear on what scientific or policy judgements the defaults are based $(8,24)$.

The CAPRA committee justifies the use of conservative default assumptions in screening risk assessments, and indicates that explicit guidelines have to be designed for choosing default assumptions and that furthermore, a procedure has to be established that permits departure from defaults (31). Finkel advocates the use of scientifically plausible conservatism in choosing and altering default assumptions. He argued that the use of plausible conservatism allows risk management decisions to be made under conditions of uncertainty and variability (31).

\subsection{Research and research requires}

From the NAS/NRC committee perspective in 1983, scientific research provides the factual basis for risk assessment and should reflect the latest scientific understanding. Research forms the basis for the four steps of the risk assessment framework (see Figure 1.2) (74). Health risk assessment research is related to many disciplines, e.g. biology, chemistry, epidemiology, genetics $s_{r}$ pharmacology, pathology, physics, toxicology, and statistics. Although research was a part of the framework, at that time much attention has been given to the conceptual difference between risk assessment and risk management (32).

The role of scientific research in risk assessment and risk management decisions has been evaluated by Sexton and co-workers $(5,17,19)$. They have postulated that feedback loops exist between scientific research, risk assessment and risk management. Scientific data and understandings are important inputs for risk assessment and management, and therefore indirectly also for management decisions, while the output of the risk assessment and management process may generate additional research.

McClellan and North in their paper as appendix to the CAPRA report describe the maximum use of scientific information in risk assessment (32). They sub- 


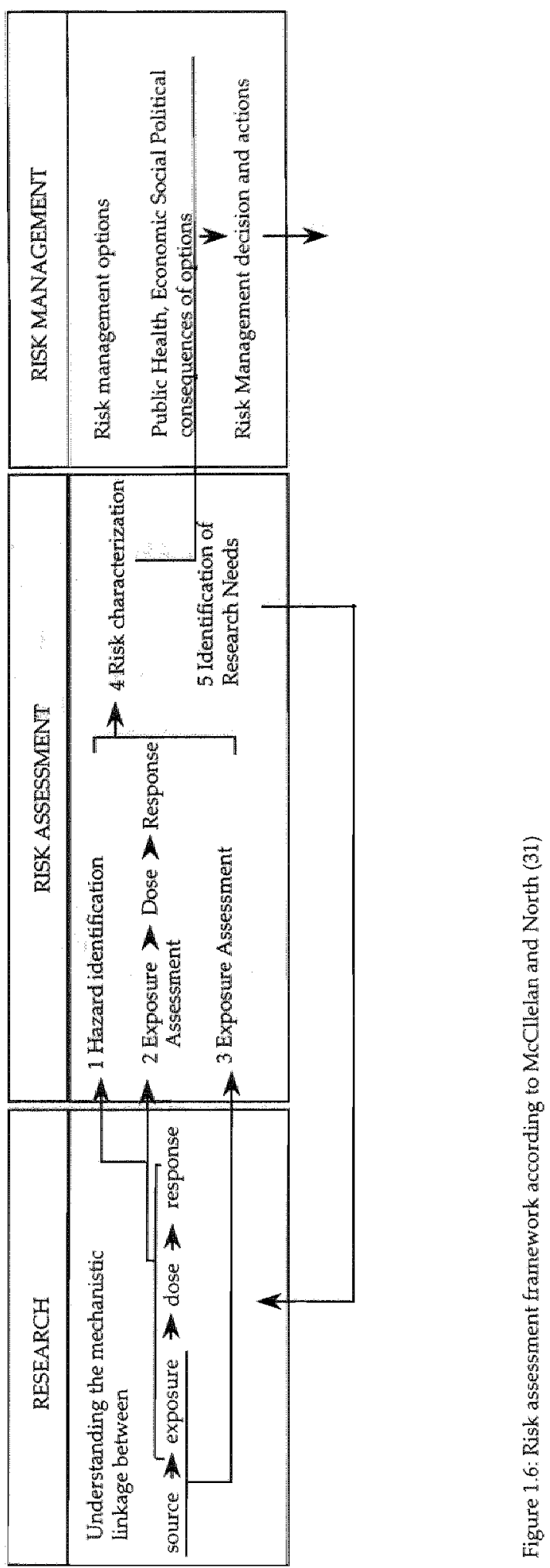


scribe the iterative approach of risk assessment and observe a feedback loop between risk assessment and research (Figure 1.6). The outpul of risk assessment is a risk characterization and furthermore, a description of research requirements (e.g. uncertainties and unknowns), which upon met properly will reduce uncertainty in future risks. According to McClellan the effectiveness of the feedback loop appears to depend on a risk assessment system responsive to new science $(70,71)$.

An evaluation of the health risk assessment research has been performed by the U.S. Office of Technology Assessment (OTA) in 1993. The committee has stated that scientific research needed for providing health risk assessments, does not exactly correspond to the four components of the traditional NAS/NRC risk assessment framework. They have classified research needs into three categories: methodological research, basic research and chemical-specific data development. From the OTA point of view, methodological research is general. It provides information on the method of risk assessment. A better understanding of the extrapolation from high to low doses or a quantification of the uncertainties are examples of methodological research. Basic research improves the underlying scientific knowledge of the risk assessment process, for instance, investigations of disease mechanism associated with exposure to an environmental agent. The OTA also beliefs that collection of chemical-specific data on exposure to an environmental agent is an important research category for improving health risk assessments (20). They have concluded that health risk assessment research is necessary and that mainly methodological research has to be improved.

\subsubsection{Exposure Assessment}

There are different methods to improve exposure assessments $(5,13,19,65)$. The research needs can be categorized according to sources of uncertainty. In general, improvements are linked to the different parts of the environmental heallth chain. For a better understanding of the exposure assessment process, research is required to improve exposure scenario models; related to the interrelationship between exposure factors, to the assumption of the exposure factors, to the modeling of the indirect exposure pathways (such as transfer processes and bioavailability) and to the development of distributions of exposure. Furthermore, a main issue is to develop integrated human exposure models, which include all sources, environmental media and routes of exposure. It is a combination of time-activity data and monitoring in different micro-environments $(5,13,19,65,74)$.

Another important aspect to be improved in exposure assessments, is pharmacokinetic modeling. It is relevant to both exposure and dose-response assessment. A better estimation of the received dose can indirectly be related to the adverse health effect and furthermore, the influences of different exposure 
scenarios on the impact on the calculations of the received dose can be evaluated $(19,65)$. Improvement of PBPK modeling and integrated human exposure models are indicated by Sexton al. as improvements of mechanistically based mathematical models (19). Additionally to the requirements for a better understanding of exposure assessment, more data have to be generated, on lifestyle and human activity patterns as input to exposure models, in order to be able to identify high risk groups, to identify environmental equity and also to validate exposure models (74). In particular, actual exposure measurements have to be extended to monitor total human exposure (65).

\subsubsection{Dose-Response Assessment}

The major uncertainties in dose-response assessment deal with extrapolation issues, from high to low dose and from animals to humans. As described in section 1.5.1, mechanistically based mathematical models have to be improved, to get a better understanding of the source-to-effect continuum, whereas doseresponse assessment concentrates on the later portion of the continuum i.e. relationship between exposure, internal dose and adverse effect. An example is the improvement of PBPK-models and PBPD-models. The latest model refers to pharmacodynamic processes from target dose to the induced disease $(5,19,74-76)$. Examples of mechanistic research refer to the mode of action of a toxicant, new models for carcinogenesis and receptor binding models $(5,19,75,77-80)$.

Incorporation of the available data into the risk assessment process is an important issue, especially in non-cancer risk assessment, in order to replace the standard default uncertanty factors (e.g. 10) (81,82).

Improvements of mechanistic research and effective use of available data can replace default assumptions and therefore, enhance the credibility of cancer and non-cancer risk assessment (80). These models may provide a more biological interpretation, and a more solid foundation for extrapolation beyond the circumstances under which the primary data were obtained.

For instance, the EPA is improving the guidelines for carcinogen risk assessment which have been described in a review draft entitled "Draft Revision to Guidelines for Carcinogen Risk Assessment". Major improvements imply the use of all available cancer data, including mechanistic data $(69,79,83-85)$. The EPA will only use default values to complete major data gaps $(69,84,85)$. Furthermore, a two-step dose-response assessment has been recommended (79). A revision of the carcinogenic risk assessment of methylene chloride is an example of the use of biological information for quantification of the risks instead of using the LMS model as the default assumption (86).

Most of the alternative methods and approaches are preliminary, and to depart from default assumptions by incorporating biological information and chemical specific data to estimate risk therefore is a difficult issue. Clewell for- 
mulates two criteria to refrain from default assumptions/approaches (86). First, the default approach is not appropriate for the chemical of concern. However, the limitation of the default approach is not a criterion if the alternative approach has the same limitations. Secondly, the alternative approach has to reach an acceptable level of confidence. Clewell furthermore, states that in order to be able to improve risk assessment by incorporating biological information to replace default assumptions, interactions between scientific researchers and risk assessment scientists are mandatory (see also paragraph 1.5$)(86,87)$.

\subsection{Aim and outline of the thesis}

The risk assessment process and the environmental health chain analysis can assist to estimate and evaluate human health risks in relation to exposure of environmental hazards. As described in the preceding paragraphs, risk assessment has to deal with a high degree of uncertainty. Default assumptions cannot be avoided in both exposure assessment and dose-response assessment. Within this respect, relevant examples are the use of exposure scenarios for estimating human exposure to environmental hazards, and the linearity of the dose-response curve at low doses in cancer risk assessment.

The aim of this thesis is to evaluate the health risks of various environmental pollutants in the context of several specific case studies, focusing on current default assumptions in exposure assessment and dose-response assessment.

Part one (chapter 2-5) of this thesis deals with exposure assessment. The case studies in this part refer to various environmental pollutants which are present in the respective environmental media air, food, soil and water. The case studies are structured along the source-to-effect continuum. For identifying health risks, in these studies the total estimated exposure to the environmental pollutant, is compared to the existing health-based standard (e.g. TDI), which corresponds to the MPR in the Dutch Environmental Policy Plan. In chapter 2 the possible health risks in relation to the emission of dioxins and PCBs by three planned waste incinerators in The Netherlands have been evaluated. The health risk assessment has been based on a worst-case exposure scenario, in order to prevent underestimating of the possible health risks. The second case study (chapter 3) evaluates the health risks for anglers of consuming PCB contaminated fish from brooks in the south-west part of The Netherlands. Anglers can be considered as a subpopulation that might be at higher exposure risk because of the amount and/or frequency of fish consumption. In order to improve exposure assessment chemical analysis of $\mathrm{PCB}$-congeners, mercury and insecticides in eel have been performed. The third case study concerns the river Meuse. In The Netherlands and also in Belgium, the river banks and the 
winterbeds of this river are commonly used for agriculture practice. The banks are regularly inundated, and therefore enriched for instance by heavy metals which are present as a result of mining and related activities in the past.

The possible health risks for riverbank inhabitants after the flooding of the river Meuse during the winter of 1993-1994 have been evaluated (chapter 4). As a screening method, a multiple exposure model implying many assumptions and maximum use of default values, has been used for estimating exposure in relation to the river bank pollution. To improve the exposure assessment especially with regard to soil-plant transfer, we thave studied the uptake of heavy metals in three different crop groups in 6 experimental gardens.

Many artificial lakes have been created along the river Meuse, due to excavation of minerals as sand and gravel. Some of these lakes are used for recreation purposes. In chapter 5 health risks in relation to recreational activities have been evaluated in two lakes, one connected and the other disconnected with the river Meuse. In this study, also a multiple exposure model has been used for estimating exposure. Actual measurements in water and suspended material have been carried out to replace some default assumptions.

The second part (chapter 6-9) of this thesis deals with dose-response assessment, in particular cancer risk assessment in relation to indoor radon exposure. It is well known from epidemiological studies of uranium and other underground miners that radon exposure causes lung cancer. However, the lung cancer risk for the general population exposed to much lower radon concentrations, is uncertain. Furthermore, because of some contrasting epidemiological findings, it is not clear whether radon exposure imposes an extrapulmonary cancer risk. The presented. studies are designed to validate the default assumption of the linearity of the dose-response curve at low dose. By applying epidemiological techniques, it is difficult to estimate cancer risks in relation to indoor radon exposure, because of the relatively low indoor radon exposure levels and the high background of lung cancer in the generall population. Therefore, multiple genetic biomarkers which may be indicative for oncogenesis at the biological rather than at the pathological level, have been analyzed in relation to indoor radon exposure in order to obtain more insight into the shape of the doseresponse curve. In order to describe human exposure accurately, indoor radon measurements have been performed in the Dutch-Belgian border region (chapter 6). This study furthermore, evaluates the usefulness of soil measurements for predicting indoor radon exposure. Chapter 7 describes a feasibility study on the use of genetic biomarkers (e.g. sister chromatid exchanges, hprtmutations, micronuclei and chromosome aberrations in peripheral lymphocytes) in relation to domestic radon exposure. A small group of 11 people living in the south of The Netherlands or in the east of Belgium has participated in this study. The larger-scale follow-up study on the relationship 
between indoor radon exposure and genetic damage has been described in chapter 8 and 9 .

Finally, in chapter 10, the results of these case studies will be summarized and the implications for environmental health risk assessment will be discussed.

\section{References}

1. Sampson, E.J; Needham, L.L.; Pirkle, J.L.; Hannon, W.H.; Miller, D.T.; Patterson, D.G.; Bernert, J.T.; Ashley, D.L.; Hill, R.H.; Gunter, E.W.; Pascal, D.C.; Spierto, F.W.; Rich, M.J. Technical and Scientific Development in Exposure marker Methodology. Clinical Chemistry 40, no 7: 1376-1384; 1994.

2. Environmental Protection Agency. Guidelines for exposure assessment notice 1992, Federal register 57, no 104: 5-29-92; United States government printing office Washington DC 20402; 1992.

3. McKone, T.E.; Bogen, K.T. Predicting the uncertainties in risk assessment. Environ. Sci. Technol. 25, no 10: 1674-1681; 1991.

4. McKone, T.E.; Bogen, K.T. Uncertainties in health risk assessment: An integrated case study based on tetrachloroethylene in California groundwater. Regulatory Toxicology and Pharmacology 15: 86-103; 1992.

5. Sexton, K.; Olden, K.; Johnson, B.L. Environmental justice the central role of research in establishing a credible scientific foundation for informed decision making. Toxicology and Industrial Health 9, no 5: 685-727; 1993.

6. Ott, W.R. Total human exposure: an emerging science focuses on humans as receptors of environmental pollution. Environ. Sci. Tech. 19, no 10; 1985.

7. Lioy, P.J. Assessing total human exposure to contaminants. Environ. Sci. Technol. 24, no. 7: 938-945; 1990 .

8. Covello, V.T.; Merkhofer, M.W. Risk assessment methods. Approaches for assessing health and environmental risks. Plenum Press, New York; 1993.

9. Sexton, K.; Selevan, S.; Wagener, D.K.; Lybarger, J.A. Estimating human exposures to environmental pollutants: availability and utility of existing databases. Archives of Environmental Health 47, no 6: 398-407; 1992.

10. Sexton, K.; Callahan, M.A.; Bryan, E.F. Estimating exposure and dose to characterize health risks the role of human tissue monitoring in exposure assessment. Environmental Health Perspectives 103, supp 3: 13-30; 1995.

11. Gillen, $M$. Exposure Assessment: an underrated element of the risk assessment paradigm. AIHA Journal 57: 799-802; 1996.

12. Sexton, K. Human exposure assessment and public health. Prog. Clin. Biol. Res. $455-466 ; 1991$.

13. Graham, J.; Walker, K.D.; Berry, M.; Bryan, E.F.; Callahan, M.A; Fan, A.; Finley, B; Lynch, J.; McKone, T.; Ozkaynak, H.; Sexton, K. Role of exposure databases in risk assessment. Archives of Environmental Health november/december 47, no 6: 408420; 1992 . 
14. Patton, D.E. The ABCs of Risk Assessment. EPA Journal, jan/feb/mar/ 10-15; 1993.

15. Graham, J.D. Historical perspective on risk assessment in the federal government. Toxicology 102: 29-52; 1995.

16. Leewwen wan, C.J. Hermens, J. Risk assessment of chemicals an introduction. chapter 1. General introduction. Kluwer academic publishers, Dordrecht, The Netherlands; 1995.

17. Sexton, K. Science and policy in regulatory decision making: Getting the facts right about hazardous air pollutants. Environmental Health Perspectives 103, supp 6 : 213-222; 1995 .

18. Premises of Risk Management, 1989. Annex to the Dutch National Enwironmental Policy Plan 1990-1994. Second Chamber of the States General, session 1988-1989, 21137, no 5; The Hague, The Netherlands (in Dutch).

19. Sexton, K, Reiter, L.W.; Zenick, H. Research to strengthen the scientific basis for health risk assessment a survey of the context and rationale for mechanistically based methods and models. Toxicology 102: 3-20; 1995.

20. Ziegler, ]. Health risk assessment research: The OTA report. Environmental Health Perspectives 101, no 5: 402-406; 1993.

21. Committee on the Institutional Means for Assessment of Risks to Public Health. Commission on Life Sciences. National Research Council. Risk Assessment in the federal government: Managing the process. National Academy Press, Washington, D.C.: 1983.

22. Ozonotf, D. Conceptions and misconceptions about human health impact analysis. Environ. Impact Assess. Rev. 14: 499-515; 1994.

23. Barnthouse, L.W. Issues in ecological risk assessment: The CRAM Perspective. Risk Analysis 14 , no $3: 251-256 ; 1994$.

24. Withmyre, G.K.; Driver, J.H.; Ginevan, M.E.; Rardiff, R.G.; Baker, S.R. Human exposure assessment 1 : understanding the uncertainties. Toxicology and Industrial Health 8, no 5: 297-320; 1992.

25. Hawkins, N.C.; Jayjock, M.A.; Lynch, J. A rationale and framework for establishing the quality of human exposure assessment. Am. Ind. Hyg. Assoc. J, 53, no. 1: 34-41; 1992.

26. Sexton, K.; Callahan, M.A.; Bryan, E.F.; Saint, C.G.; Wood, W.P. Informed decisions about protecting and promoting public health rationale for a national human exposure assessment survey. Journal of Exposure Analysis and Environmental Epideniology 5, no 3: 233-256; 1995.

27. Morgan, MG.; Henrion, M.; Morris, S.C.; Amaral, D.A.L. Uncertainty in risk assessment; a case study inwolving sulfur transport and health effects. Environ. Sci.Tech. 19, no $8: 662-667,1985$.

28. Funley, B; Paustenbach, D. The benefits of probabilistic exposure assessment: Three case studies involving contaminated air, water and soil. Risk Analysis 14, no 1: 53$73 ; 1994$.

29. McKone, T.E.; Daniels, J1. Estimating human exposure through multiple pathway from air water and soil. Regulatory Toxicology and Pharmacology 13: 36-61; 1991.

30. Hawkins, N.C. Conservatism in maximally exposed individual MEI predictive exposure assessments: A. First cut-analysis. Regulatory Toxicology and Pharmacology 14: 107-117; 1991 . 
31. National Academy of Sciences/National Research Council (NAS/NRC) Science and and Judgement in risk assessment. National Academy Press Washington, DC: 1994.

32. McClellan, R.O. An annotate review of the NAS/NRC report: science and judgement in risk assessment. CITT Activities: 14, no. 4: 1994.

33. Keenan, R.E.; Finley, B.L.; Price, P.S. Exposure assessment: then now, quantum leaps in the future. Risk Analysis 14, no $3: 225-230 ; 1994$.

34. Harvey, T.; Mahaffey, K.R.; Velazquez, S.; Dourson, M. Holistic risk assessment: an emerging process for environmental decisions. Regulatory Toxicology and Pharmacology 21: 110-117; 1995.

35. Health council of The Netherlands: Committee on risk measures and risk assessment. Not alll risks are equal. The Hague. The health council of the Netherlands. no 06; 1995.

36. Health council of The Netherlands: Committee on risk measures and risk assessment. Risk is more than just a number. The Hague, The health council of The Netherlands. no 03; 1996.

37. National Academy of Sciences/National Research Council (NAS/NRC) Understanding risk: informing decisions in a democratic society. Stern, P.C., Fineberg, H.V. (eds). National Academy Press Washington, DC; 1996.

38. Commission on Risk Assessment and Risk Management (CRARM). Risk assessment and risk management in regulatory decision-making. U.S. Congress, Washington, DC; 1997.

39. Ohanian, E.V.; Moore, I.A.; Fowle III, J.R.; Omenn, G.S.; Lewis, S.C.; Gray G.M.; North, D.W. Risk characterization: a bridge to informed decision making. Fundamental and Applied Toxicology 39: 81-88; 1997.

40. Si Duk, L. Risk assessment and risk management of noncriteria pollutants. Toxicology and Industrial Health 6 , no 5: 245-255; 1990.

41. Vermeire, T.G.; Zandt van der, P.T.J.; Roelfzema, H.; Leeuwen van, C.J. Uniform system for the evaluation of substances I principles and structure. Chemosphere 29 , no $1: 23-38 ; 1994$.

42. ECETOX, Environmental Exposure Assessment, technical report no 61: Brussels, Belgium; 1994.

43. ECETOX, Environmental Hazard Assessment of substances, technical report no 51 : Brussels, Belgium; 1993.

44. Mullin, C.S. Harmonization of approaches to the assessment of risk from exposure to chemicals. Risk newsletter, The Society for Risk Analysis, fourth quarter; 1995.

45. Uniform system for the evaluation of substances (USES) version 1.0. National Institute of Public Health and Environmental Protection (RIVM), Ministry of Housing, Spatial Planning and the Environment (VROM), Ministry of Welfare, Health and Cultural Affairs (WVC). The Hague, Ministry of Housing, Spatiall Planning and the Environment. Distribution No 11144/150; 1994.

46. Hart, J.W.; Jensen, N.J. Integrated risk assessment or integrated risk management? Regulatory Toxicology and Pharmacology 15: 32-40; 1992.

47. Burke, T; Anderson, H.; Beach, N.; Colome, S.; Drew, R.; Firestone, M; Hauchman, F.S.; Miller, T.O.; Wagener, D.K.; Zeise, L.; Tran, N. Role of exposure databases in risk management. Archives of Environmental Health november/december 47 , no 6: 421-429; 1992.

48. Jasanoff, S. Bridging the two cultures of risk analysis. Risk Analysis 13, 2: 123-129; 1993. 
49. Somers, E Perspectives on risk management. Risk Analysis 15, 6: 677-684; 1995.

50. Krewski, D.; Oxman, A.; Torrance, G.W. A decision oriented framework for evaluating environmental risk management strategies: A case study of lead in gasoline. In: The risk assessment of environmental and human health hazards. A textbook of case studies. eds. Paustenbach, D. A Willey interscience publication, New York; 1989.

51. Indicative Environmental. Policy Program 1986-1990. Second Chamber of the States Ceneral, session 1985-1986, 19204, no 1-2; The Hague. The Netherlands (in Dutch).

52. Risk management in environmental policy. Second Chamber of the States General, session 1993-1994, 22666, no 4; The Hague, The Netherlands (in Dutch).

53. Risk management in environmental policy. Second Chamber of the States General, session 1992-1993, 22666, no 2, The Hague, The Netherlands (in Dutch).

54. Risk maragement in environmental policy. Second Chamber of the States General, session 1992-1993, 22666, no 1; The Hague, The Netherlands (in Dutch).

55. Ionizing radiation; Occupational and environmental guidelines. Second Chamber of the States General, session 1993-1994, 21483 no 16; The Hague, The Netherlands (in Dutch).

56. Krijgsheld, K.R. Decision making based on health impact assessment: strategies and experiences in The Netherlands. Environ. Impact. Assess. Rev. 14: 425-438; 1994.

57. Concern for Tomorrow. A national environmental survey 1985-2010. eds. Langeweg, F. National Institute of Public Health and Environmental Protection (RIVM), Bilthoven, The Netherlands; 1989.

58. McKone, T.E. Uncertainty and variability in human exposure to soil contaminants though home-grown food: A Monte Carlo assessment. Risk Analysis 14, no 4: 449463; 1994 .

59. Hoffman, F.O.; Hammonds J.S. Propagation of uncertainty in risk assessments: the need to distinguish between uncertainty due to lack of knowledge and uncertainty due to variability. Risk Analysis 14, no. 4: 707-712; 1994.

60. Bogen, K.T.; Spear, R.C. Integrating uncertainty and interindividual variability in environmental risk assessment. Risk Analysis 7, no 4: 427-436; 1987.

61. Moore, D.R.J.: Elliott, B.I. Should uncertainty be quantified in human and ecological risk assessments used for decision-making? Hum. Ecol. Risk. Assess. 2, no 1: 11-24; 1996.

62. Hamby, D.M. A review of techniques for parameter sensitivity analysis of environmental models. Environmental Moritoring and Assessment 32: 135-154; 1994.

63. Burmaster, D.E.; Willson, J.C. Risk assessment for chemicals in the environment. The encyciopedia of Biostatistics. in press.

64. Stanek III, E.J. Estimating exposure distributions: A caution for Monte Carlo risk assessment. Human and Ecological Risk Assessment 2, no 4: 874-891; 1996.

65. Whitmyre, G.K.; Driver, J.H.; Ginevan, M.E.; Tardiff, R.G.; Baker, S.R. Human exposure assessment 1I: Quantifying and reducing the uncertainties. Toxicology and Industrial Health, 8, no 5: 321-342; 1992.

66. Thompson, K.M.; Burmaster, D.E.; Crouch, A.C. Monte Carlo techniques for quantitative uncertainty analysis in public health risk assessments. Risk Analysis, 12 , no $1: 53-61 ; 1992$.

67. Finley, B.L.; Scott, P.; Paustenbach, J. Evalluating the adequacy of maximum contaminant levels as health-protective cleanup goals: An analysis based on MonteCarlo techniques. Regulatory Toxicology and Pharmacology $18: 438-455 ; 1993$. 
68. Stern, A.H. Monte Carlo analysis of the U.S. EPA model of human exposure to cadmium in sewage sludge through consumption of garden crops. Joumal of Exposure Analysis and Environmental Epidemiology 3, no 4: 449-469; 1993.

69. Barnard, R.C. Risk assessment: the default conservatism controversy. Regulatory Toxicology and Pharmacology $21: 431-438 ; 1995$.

70. McClellan, R.O. Risk assessment and biological mechanisms: lessons leamed, future opportunities. Toxicology 102: 239-258; 1995.

71. McClellan, R.O. CIT Testimony on updating OSHA permissible exposure limits for air contaminants. Critical issues in developing permissible exposure limits for air contaminants. CIT Activities 16, no 2: 8-10; 1996.

72. Finkel, A.M. Risk assessment research: only the beginning. Risk Analysis 14, 6:907$911 ; 1994$.

73. Finkel, A.M. Myths, chicanery, and blundering on the risk assessment front. AIHA Journal 57: 793-798; 1996.

74. Gregory, A.R. Uncertainty in health risk assessments. Regulatory Toxicology and Pharmacology 11: 191-200; 1990.

75. Goddard, M.I.; Krewski, D. The future of mechanistic research in risk assessment: Where are we going and can we get there from here? Toxicology 102:53-70; 1995.

76. Jarabek, A.M. The application of dosimetry models to identify key processes and parameters for default dose-response assessment approaches. Toxicology Letters 79: 171-184; 1995.

77. Clayson, D.B.; Iverson, F. Cancer risk assessment at the crossroads: The need to turn to a biological approach. Regulatory Toxicology and Pharmacology 24: 45-59; 1996.

78. Daston, G.P. Advances in understanding mechanisms of toxicity and implications for risk assessment. Reproductive Toxicology 11, no 2/3: 389-396; 1997.

79. Page, N.P.; Singh, D.V.; Farland, W.; Goodman, J.I.; Conolly, R.B.; Andersen, M.E.; Clewell, H.J.; Frederick, C.B.; Yamasaki, H.; Lucier, G. Implementation of EPA revised cancer assessment guidelines: Incorporation of mechanistic and pharmacokinetic data. Toxicology 37: 16-36; 1997.

80. Lovell, D.P.; Thomas, G. Quantitative risk assessment and the limitations of the linearized multistage model. Human \& Experimental Toxicology 15: 87-104; 1996.

81. Dourson. M.L. Uncertainty factors in noncancer risk assessment. Regulatory Toxicology and Pharmacology 24: 107; 1996.

82. Dourson, ML.; Felter, S.P; Robinson, D. Evolution of sciencebased uncertainty factors in noncancer risk assessment. Regulatory Toxicology and Pharmacology 24: $108-120 ; 1996$.

83. Sielken, R.L.: Bretzlaff, R.S.; Stevenson, D.E. Challenges to default assumptions stimulate comprehensive realism as a new tier in quantitative cancer risk assessment. Regulatory Toxicology and Pharmacology 21: 270-280; 1995 .

84. Butterworth, B.E. CIIT Risk assessments for nongenotoxic carcinogens. CIIT Activities, 16 , no 2 : $11-12 ; 1996$.

85. Goldman, L.R. Risk assessment as a major tool for EPA policy decisions. Risk newsletter, The Society for Risk Analysis, second quarter; 1995.

86. Harvey, J.; Clewell, I.I.I. Incorporating biologicall information in quantitative risk assessment: an example with methylene chloride. Toxicology 102: 83-94; 1995.

87. McClellan, R. Reducing uncertainty in risk assessment by using specific knowledge to replace default options. Drug Metabolism Reviews 28 (1\&2): 149-179; 1996. 

PART I:

EXPOSURE ASSESSMENT 
The case of dioxins and PCBs 


\title{
Chapter 2
}

\section{Waste incineration and health risks: the dioxin case revisited}

\author{
H.J. Albering, J.C.S. Kleinjans \\ Department of Health Risk Analysis and Toxicology, University of Maastricht, \\ Maastricht, The Netherlands
}

Based on: Milieu, 2: 58-64(1994)

\begin{abstract}
Incineration of municipal waste by waste incinerators (WIs) is regarded with considerable concern because of the emission of hazardous substances possibly implying adverse health risks for inhabitants of the surrounding regions. Specifically dioxins and polychlorinated biphenyls (PCBs) draw major attention within this context. Newly to be constructed WIs have to submit to emission standards as imposed by the recent Waste Incineration Act; this should decrease the emission of these compounds into the general environment sufficiently over the decades to come to reduce related health risks to acceptable levels. The aim of the present study is to assess adverse health risks for surrounding populations in relation with the emission of dioxins and PCBs by a future WI which will be designed to meet the air quality requirements set by the Waste Incineration Act. For this purpose, emission levels of dioxins and PCBs as estimated in recent environmental impact assessment (EIA) reports for three planned WIs in The Netherlands, have been evaluated. The calculated daily intake of these substances added to the estimated background levels has been compared with the established health standard, the so-called Tolerable Daily Intake (TDI) as recommended by the World Health Organization and implemented by the Dutch government. It is concluded that at certain emission scenarios for PCBs as described in the respective ElA reports, at maximum exposure level the intake of these compounds by surrounding populations may exceed TDI levels, therefore imposing an unacceptable health risk. However ${ }$ it is acknowledged that estimates on particulatly PCB emission by WIs suffer from major uncertainty possibly implying overestimation of related health risks. It is furthermore concluded that the Waste Incineration Act does not regulate emission levels of PCBs.
\end{abstract}




\section{Introduction}

Health risks for inhabitants of the surroundings of waste incinerators (WIs) are intensely discussed. This is clearly noticeable at public hearings during the procedure of environmental impact assessment for newly proposed WIs. Concern about adverse health risks is dictated by the fact that during the incineration of municipal waste, various potentially toxic compounds like polychlorinated dibenzo-p-dioxins (PCDDs), dibenzofurans (PCDFs) and polychlorinated biphenyls (PCBs) are released into the environment (1). Besides, existing WIs in The Netherlands are to a considerable extent responsible for the total emission of these compounds into the air, for instance up to $80 \%$ in the case of PCDDs and PCDFs $(2,3)$. It is conceivable that exposure to these compounds is increased for inhabitants of the surroundings of a WI compared to the Dutch average, due to direct exposure through inhalation, and indirect exposure through intake of locally produced food like dairy products (1).

The insight in the health risks of these compounds is increasing. Recently, several Dutch studies have observed subclinical effects by pregnant women and young mothers and children at relatively low levels of exposure to PCBs, PCDFs and PCDDs. Although the reported effects fell within clinical reference values, it has been shown that pre- and/or postnatal exposure to these compounds are related to reduced neurological, psychomotoric and immunological scores in neonates, as well as to changes in thyroid hormone status in mother and child (4-9).

The chemical emissions of WIs should be decreased in the future as a consequence of the implementation of the Incineration Directive of 1989 and of the Waste Incineration Act of 1993. For instance, it is estimated that in the year 2000 the total PCDD/PCDF emission onto air will have decreased with $90 \%$ as compared to 1985 (10). Nowadays, in The Netherlands the WIs must meet the legal emission standard of $0.1 \mathrm{ng}$ toxic equivalent (TEQ) $/ \mathrm{m}^{3}$. This standard is for the combined emission of PCDDs and PCDFs. The emission of PCBs is however, not regulated by the Waste Incineration Act.

In the present study, no notice is taken of the question to what extent these emission standards are technologically feasible, nor alternatives for waste incineration will be discussed. The aim of this study is to assess adverse health risks for the surrounding community in relation to the emission of PCDDs, PCDFs and PCBs by a newly proposed WI which meet the legal emission standard set by the Waste Incineration Act. 


\section{Exposure assessment}

Apparently, the potential human exposure in relation to a newly to be constructed WI cannot be determined by means of measurements, but has to be estimated. This means that, additional human exposure due to the emissions of a newly to build WI has to be estimated by modeling and should be added to the known or estimated human background exposure (11). The resulting total human exposure is compared to established health based guidelines, that have been designed in the scope of the environmental policy to prevent or limit the risk of adverse health effects (12). If the total daily exposure is less than the health based guideline it can be concluded that building of a WI will not pose an unacceptable health hazard for the surrounding community. If it is concluded that there is a possibility of exceeding this guideline, then further analyses are indicated.

For the above mentioned compounds, e.g. the PCDDs, the PCDFs and certain PCBs, a health based guideline is available (13). To set an exposure guideline for the total of 75 PCDDs and 135 PCDFs (the so-called dioxincongeners) the dose is expressed as toxic equivalents (TEQ) by relating the toxicity of 17 dioxin congeners which are hazardous to human health, to the most toxic of them, 2,3,7,8-TCDD, via toxicity equivalence factors (TEF). In the process of revaluation of the dioxin guideline it has been decided by the World Health Organization that on the base of comparable structure and action mechanism some PCBs are to be suspected of dioxin-like activity and therefore these compounds have also been assigned a TEF-value (13). This combined guideline can be used to evaluate the health risks of the emission of dioxin-like compounds and PCBs from a WI.

The basic assumption at setting this guideline is the fact that these compounds do not have direct carcinogenic properties. Most epidemiological data for dioxin-like compounds seem to confirm this (14-16), although recently indications have been found for an elevated incidence of some forms of cancer in the cohort of persons that in 1976 at Seveso was exposed to high levels of dioxin due to an industrial accident. There is a growing consensus that the dioxin-like compounds generate their toxic effect by binding to a receptor as a first step. This implies that below a certain critical dose, the so-called threshold value, no toxic effect is observed. By dividing this threshold value by a safety factor it is possible to determine a dose, the so-called tolerable daily intake (TDI), which may be taken in throughout the entire lifetime without causing adverse health effects. The current TDI for dioxin-like compounds as used by the Dutch government is $10 \mathrm{pg}$ TEQ $/ \mathrm{kg}$ body weight.

In order to determine potential human exposure due to the emission from a new activity an exposure model has been used, which estimates the concentration in the environmental compartments (e.g. air, food, soil and 
water) and estimates total dally intake via direct and indirect exposure routes (11).

In the present study, potential human TEQ exposure is calculated for an individual residing at the location where due to the emission of the WI, the increase of dioxin-like compounds and PCBs in the respective environmental compartments is maximal and who is also situated outdoors for 365 days per year as well as solely consumes locally grown and produced crops, meat and dairy products, which obviously represents a worst-case situation.

Human exposure can occur via inhalation of ambient air, assuming an average breathing rate of $7.6 \mathrm{~m}^{3}$ per day for a child and $20 \mathrm{~m}^{3}$ per day for an adult (19), and can furthermore occur by ingestion. Firstly, PCDDs, PCDFs and PCBs, after being released from a WI, will deposit onto soil. The subsequent uptake through the root system of vegetables will occur with difficulty, due to the relatively low solubility of organochloric compounds in the soil liquid phase; the contribution to the additional exposure on the inhabitants of the surroundings of the incinerator via this route however can be calculated (19). Consumption by man and animal due to direct deposition on vegettables leaves is more substantial, however this route is difficult to describe quantitatively. In the present study, a risk assessment in relation to an existing WI is used to calculate this pathway, taking into account the relatively lower emissions of the newly to build incinerators. Moreover, a daily milk consumption of $400 \mathrm{ml}$ by an adult and $500 \mathrm{ml}$ by a child $(20,21)$, as well as a meat fat consumption of $10 \mathrm{~g}$ by an adult (23) and $5 \mathrm{~g}$ by a child are assumed. The possible intake by infants via breast feeding is not taken into consideration because of the impossibility to model this in itself important route adequately at the present state of knowledge.

Another important exposure route especially for children, is the direct ingestion of soil particles on which the mentioned compounds have been deposited after emission. A soil ingestion rate for children of $200 \mathrm{mg} / \mathrm{day}$ is assumed (19). A possible TEQ exposure by the ingestion of water is not taken into account. Exposure via the dermal route is thought to be of lithe relevance.

To determine the additional human exposure in relation to the emission of a newly to build WI, resulting ambient air concentrations have been estimated within the scope of recent environmental impact assessments for three new incinerators (22-24). However, these new WIs differ from each other with respect to the capacity and the associated emission concentrations (Table 2.1. and 2.2).

In general, two emission scenarios are used in the respective environmental impact assessments. The expected average emission scenario represents that emission level that is certainly achievable by using the best technological means. Furthermore, a worst case scenario is applied, which represents the emission concentration at the level set by the Waste Incineration Act (23). The difference in emission levels between both scenarios for the three WIs in 
question is a factor of 2 with respect to the amount of dioxin related TEQ. This difference is a factor of 10 for PCBs at the Moerdijk and ZON WIs (AVI Moerdijk and AVI-ZON); no maximum emission scenario for PCBs is given for the Wijster WI (GAVI Wijster).

Table 2.1: Maximum predicted air and deposition concentrations due to the emission of dioxinTEQ for the three planned WIs (the expected scenario)

\begin{tabular}{lllll} 
W I & $\begin{array}{l}\text { Capacity } \\
(\text { tons } / \mathrm{yr})\end{array}$ & $\begin{array}{l}\text { emission concentration } \\
(\text { year average }) \\
\left(\mathrm{mg} / \mathrm{m}^{3}\right)\end{array}$ & $\begin{array}{l}\text { air concentration } \\
(\text { year average })(1) \\
\left(\mathrm{ng} / \mathrm{m}^{3}\right)\end{array}$ & $\begin{array}{l}\text { soil deposition } \\
(2) \\
(\mathrm{g} / \mathrm{ha} . \mathrm{yr})\end{array}$ \\
\hline & & & & \\
Gavi-Wijster & 378.000 & $5^{*} 10^{-8}$ & $8.5^{*} 10^{*-8}$ & $1.5^{*} 10^{-7}$ \\
Avi-Moerdijk & 600.000 & $5^{*} 10^{-8}$ & $1.0^{*} 10^{-7}$ & $1.7^{*} 10^{-7}$ \\
Avi-Zon & 600.000 & $5^{*} 10^{-8}$ & $9.6^{*} 10^{-8}$ & $1.6^{*} 10^{-7}$ \\
\hline
\end{tabular}

(1) The National Model (WI-Wijster and WI-Zon) and the National Long Term Frequency Distribution Model (LTFD-model-version Plume Plus) (WI-Moerdijk) are used for the prediction of the concentrations into the air

(2) Deposition may be distinguished into dry and wet deposition. In the Table, the total deposition (dry and wet) values are listed. Dry and wet deposition calculations for the Gavi-Wijster and Avi-Moerdijk originate from the respective Environmental Impact Assessments (EIAs). ElA Avi-Zon does not contain deposition calculations. In the later case, a linear relation is assumed between air concentration and deposition in order to calculate wet and dry deposition, using the deposition factors for the Avi-Moerdijk.

As shown in Table 2.1 and 2.2, the air and soil concentrations due to the emissions of PCDDs, PCDFs and PCBs appear to be extremely low.

Per incinerator, the addutional TEQ-exposure for inhabitants of the surroundings is estimated at the location of maximal deposition (Table 2.3). Based on incidental measurements of exhaust fumes of an existing incinerator (25), it has been estimated that the three coplanar PCBs with the higher TEF value account for $10 \%$ of the total PCB emission. The nine mono-ortho PCB congeners with the lower TEF value would account for $3 \%$ of the total PCB concentration. 
Table 2.2. Maxmum predicted air and deposition concentrations due to the emission of PCB$\mathrm{TLQ}$ for the three planned WHs (the expected scenario)

\begin{tabular}{|c|c|c|c|c|c|c|}
\hline \multirow[t]{2}{*}{ WI } & Capacity & $\begin{array}{l}\text { emission } \\
\text { conoen. } \\
\text { fyr averat }\end{array}$ & $\begin{array}{l}\text { ait concen. } \\
\text { (yr average })(1) \\
\text { (e) }\end{array}$ & $\begin{array}{l}\text { air concen. } \\
\text { (yr average) } \\
\text { PCB-TEQ (2) }\end{array}$ & $\begin{array}{l}\text { deposition } \\
\text { (3) }\end{array}$ & $\begin{array}{l}\text { deposition } \\
\text { PCB-TEQ (2) }\end{array}$ \\
\hline & (toms/yr) & $\left(\mathrm{mg} / \mathrm{m}^{3}\right)$ & $\left(\mathrm{ng} / \mathrm{m}^{3}\right)$ & $\left(\mathrm{ng} / \mathrm{m}^{3}\right)$ & $(\mathrm{g} / \mathrm{ha} \cdot \mathrm{y} / \mathrm{r})$ & (g/ha.yr) \\
\hline Gawi-Wijster & 378.000 & $7 * 10^{-3}$ & 0.012 & $4.6^{4} 10^{-5}$ & 0.012 & $7.6^{*} 10^{-5}$ \\
\hline Avi-Moerdijk & 600.000 & $8^{*}+10^{-5}$ & $1.6^{3} 10^{-4}$ & $6.1 * 10^{-7}$ & $2.8 * 10^{-4}$ & $1.11 * 10^{-6}$ \\
\hline Awi-Zon & 600.000 & $5^{4} \cdot 10^{-6}$ & $1.2 * 10^{-5}$ & $4.6^{* 1} 10^{-8}$ & $2.2^{*} 10^{-5}$ & $8.3^{*} 10^{-8}$ \\
\hline
\end{tabular}

(1) The National Model (Gavi-Wijster and Avi-Zon) and the National Long Term Frequency Distribution Model (LTFD-model-version Plume Plus) (Avi-Moerdijk) are used for the prediction of the concentrations into the air

(2) Assuming $10 \%$ coplanar PCB congeners and 3\% mono-ortho PCB congeners (PCB-TEQ)

(3) Deposition may be distinguished into dry and wet deposition. In the Table, total deposition (dry and wet) values are listed. Dry and wet deposition calculations for the Gavi-Wijster and Avi-Moerdijk originate from the respective Environmental Impact Assessments (ElAs). EIA Avi-Zon does not contain deposition calculations. In the later case, a linear relation is assumed between air concentration and deposition in order to calculate wet and dry deposition, using the deposition factors for the Avi-Moerdijk.

Table 2.3 shows that the additional TEQ exposure in relation to the release of PCDDs and PCDFs at waste incineration is estimated not to vary substantially for adults and children living on the location of maximal deposition when comparing the three newly to build incinerators.

For persons aged $20-70$ (body weight of $60 \mathrm{~kg}$ ) the background exposure, or the actual median daily intake, for these compounds expressed as TEQ, is $60 \mathrm{pg}$ $T E Q /$ day; for children of $14 \mathrm{~kg}$ it is $35 \mathrm{pg}$ TEQ/day (26). In combination with the prevailing background exposure, the additional exposure by PCDD/PCDFs in relation to the expected emissions of the newly to be build WIs appears not to exceed the TDI of $10 \mathrm{pg} \mathrm{TEQ} / \mathrm{kg}$ bw for both children and adults.

The variation in additional exposure to PCB-related TEQ in both adults and children is considerable, which is the consequence of formerly mentioned differences in PCB emission levels between the incinerators. The average background exposure to planar PCBs expressed as TEQ, is $60 \mathrm{pg} /$ day for an adult and $35 \mathrm{pg} /$ day for a child with a body weight of $14 \mathrm{~kg}$ (26). Based on the expected emission of PCBs from the WI Wijster, it is estimated that the additional TEQ exposure for adults and children appears to exceed the TDI at the site of maximal deposition, even without taking the background exposure to PCBs and 
the total exposure to dioxins and furans into account. The TDI is not exceeded for the other two incinerators. However, the worst case approach concerning the emission by the WL Moerdijk results in an estimated total daily TEQ exposure which appears to exceed the TDI for children.

Table 2.3: Additional TEQ exposure (pg/day) due to the emission of dioxin-TEQs en PCB$T E Q$ s at waste incineration by the different incinerators (the expected scenario).

\begin{tabular}{|c|c|c|c|c|c|c|}
\hline \multirow[t]{2}{*}{ Uptake route } & \multicolumn{2}{|c|}{ Gavi-Wijster } & \multicolumn{2}{|c|}{ Avi-Moerdijk } & \multicolumn{2}{|c|}{ Avi-Zon } \\
\hline & adult & child & addult. & child & adult: & child \\
\hline \multicolumn{7}{|l|}{ dioxin-TEQ } \\
\hline inhalation & $1.7 * 10^{-3}$ & $6.5^{*} 10^{-4}$ & $2 * 10^{-3}$ & $7.6 * 10^{-4}$ & $1.9^{4} 10^{-3}$ & $7.3^{*} 10^{-4}$ \\
\hline $\begin{array}{l}\text { soil ingestion } \\
\text { food: }\end{array}$ & & $1.9 * 10^{-4}$ & & $2.110^{-4}$ & & $2 * 10^{-4}$ \\
\hline - vegetables & 0.59 & 0.31 & 0.66 & 0.35 & 0.62 & 0.33 \\
\hline - meat/dairy & 1.42 & 1.31 & 1.61 & 1.48 & 1.51 & 1.39 \\
\hline Totall dioxin-TEQ & 2.01 & 1.62 & 2.27 & 1.83 & 2.13 & 1.72 \\
\hline PCB -TEQ & & 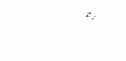 & & & & \\
\hline inhalation & 0.91 & 0.35 & 0.01 & 0.005 & $9.1 * 10^{-4}$ & $3.5^{*} 10^{-4}$ \\
\hline soil ingestion & & 0.1 & & 0.001 & & $1.0^{*} 10^{-4}$ \\
\hline food: & & & & & & \\
\hline - vegetables & 297.35 & 157.20 & 4.29 & 2.27 & 0.32 & 0.17 \\
\hline - meat/dairy & 720,22 & 663.15 & 10.39 & 9.57 & 0.78 & 0.76 \\
\hline Total PCB-TEQ & 1018.48 & 820.80 & 14.69 & 11.85 & 1.11 & 0.93 \\
\hline
\end{tabular}

Assumptions exposure model:

- The calculation method used in the FIA for the WI Moerdijk, is applied to determine the soil concentration (17) milk fat percentage of $4 \%$ (14)

ratio of the concentration in meat fal to concentration in milk fat is 1.25 (17) the log octanol-water partition coefficient of $2,3,7,8-\mathrm{TCDD}$ is $6.42(24)$

\section{Discussion}

Estimates of health risks in relation to exposure to environmental pollution involve large uncertainties which in fact may only be reduced by means of 
measurements. For instance, it is assumed that dioxin-like compounds and PCBs introduced into the environment by incineration, reach the surrounding inhabitants completely and unmodified and are taken up by them; in other words, the biological availability of these compounds is $100 \%$. However, actually these compounds will notably differ from each other with respect to their biological availability.

In the present risk assessment the total human exposure in relation to the emission of dioxin-like compounds has been compared to the current tolerable daily intake of $10 \mathrm{pg} \mathrm{TEQ/kg} \mathrm{body} \mathrm{weight.} \mathrm{Recently,} \mathrm{the} \mathrm{Health} \mathrm{Council} \mathrm{has}$ recommended a $T D I$ of $1 \mathrm{pg} T E Q / \mathrm{kg}$ bw based on animal studies with monkeys (27). Daily exposure to about $100 \mathrm{pg} 2,3,7,8-\mathrm{TCDD} / \mathrm{kg}$ bw caused endometriosis in. female Rhesus monkeys; and changes in cognitive development in infants were observed. This dose of $100 \mathrm{pg} 2,3,7,8-\mathrm{TCDD} / \mathrm{kg}$ bw per day is considered by the Health Council to be the lowest exposure level at which there are notable effects; the so-called lowest observed adverse effect level (LOAEL). Subsequently, a safety factor of 100 is applied to determine the above recommended level, taking into account a factor of 10 for differences in sensitivity between humans (intraspecies variation), a factor of 5 for the interspecies variation (between monkey and man) and a factor of 2 for extrapolation of a LOAEL to a no observed effect level (NOEL) (27). This guideline of the Health Council is lower than the current TDI of $10 \mathrm{pg} / \mathrm{kg}$ body weight per day recommended by the WHO by a factor of 10 .

The additional exposure caused by TEQ emission of dioxin-like compounds by newly to build WIs, appears to exceed this recommended guideline of $1 \mathrm{pg}$ TEQ/kg bw per day. Furthermore, human background exposure to these compounds already exceeds this guideline, which implies that an additional exposure, as caused by the expected emissions of WIs, is not desirable. As the Health Council indicates, health effects are not to be excluded with reasonable certainty at the present median background exposure (27).

The guideline of the Health Council has not been implemented by the Dutch government, on account of the impossibility to reject the present guideline without taking additional measures like prohibition of fat containing dairy and meat products, and of breast feeding. Governmental policy is aimed at minimizing exposure risks with respect to dioxin-like compounds, emphasizing on the already started national and international environmental policy to reduce TEQ emission. Therefore, Dutch authorities maintain the WHO guideline of $10 \mathrm{pg}$ TEQ/ $\mathrm{kg}$ body weight per day. In comparison to this WHO guideline, the TEQ emission by the WI Wijster (Gavi-Wijster) is expected to lead to unacceptable human exposure of the surrounding inhabitants.

However, the largest uncertainty at the calculation of the TEQ exposure in the surrounding inhabitants of a WI is found in the assumption of the emission of PCBs. The Waste Incineration Act sets the limit of emission of PCDDs and PCDFs to $0.1 \mathrm{ng} \mathrm{TEQ} / \mathrm{m}^{3}$, furthermore, many measurements of 
emissions and forthcoming air concentrations of dioxin-like compounds have been already performed at existing WIs (3). However, PCB emissions are estimated to be a certain fraction of the amount of PCBs that could generally be present in municipal waste (assumption $45 \mathrm{mg} / \mathrm{ton}$ ) (17). It is unclear whether the emission of PCBs from a WI is the result of incomplete incineration and purification, or the result of de novo synthesis taking place in the incinerator. Results of $\mathrm{PCB}$ emission measurements in exhaust gas of a WI are scarce. After monitoring the emissions of dioxins by waste incinerators, the National Institute of Public Health and Environmental Protection has recently investigated the emissions of PCBs. Indicator congeners have been analyzed in exhaust gas as well as PCB congeners with a dioxin-like effect (the so-called PCBTEQ congeners) (29). The emission of PCBs via exhaust gas is larger than the emissions by fly ash, slug and washing water, the levels appearing to be negligible in relation to dioxin emission (expressed as TEQ) (30). The contribution of PCB-TEQ emission to the total TEQ emission in exhaust gas of the examined WIs ( 6 in total) varied from $1.8 \%$ to $10.3 \%$ (29). The percentage expressed in mass fraction turns out to be $6-28 \%$. The contribution to total PCB emission varies from $6 \%$ to $55 \%$. No relation between emission of indicator congeners and the emission of PCB-TEQ was observed. Presumably, the PCB emission process runs via de novo synthesis as well as via incomplete incineration and purification of the PCBs present in municipal waste (29).

Analyses in experimental set-ups under controlled conditions seem to confirm that the emission of coplanar related TEQ accounts for not more than $10 \%$ of the total TEQ emission (31,32). This means that the emission of PCBs by WIs, as estimated from PCBs content in municipal waste, implies a considerable overestimation. As a consequence, the above calculated additional TEQ exposure for surrounding inhabitants will also be overestimated.

\section{Conclusions}

Once more it needs to be emphasized that the estimated exposure of inhabitants of the surroundings of a future WI is the result of an mathematical approach with no solid base on empirical observations. On the other hand, an environmental impact assessment needs to determine possible environmental effects in relation to a new activity in a conscientious and scientifically wellfounded way. It is therefore justified that public opinion seriously takes notice of the data incorporated in such a report as well as the conclusions about health risks based on those data. If emissions and forthcoming air concentrations as quoted in the ElAs are used to assess human exposure, it may be concluded that upon applying certain emission scenarios for PCBs with dioxin-like toxicity, there is a risk of exceeding the present exposure standards for surrounding inhabitants. This should be a matter of concern to decision makers. At the same 
time, it may be argued that especially the uncertainties about PCB emissions by incinerators are very large and that the first analytical results permit the preliminary conclusion that these emission scenarios may be overestimated. Apart from technological feasibility, an important part of these uncertainties may be eliminated by regulating that the legal emission standard of $0.1 \mathrm{ng}$ $\mathrm{TEQ} / \mathrm{m}^{3}$, as set by the Waste Incineration Act 1993, involves the combined emission of PCDDs, PCDFs and PCBs with TEF values.

\section{References}

1. Theelen, R.M.C.; Heijden, C.A. van der; Sangster, B. Dioxins, environment and health. Ned Tijdschr Geneeskd 134: 627-631; 1990 (in Dutch).

2. Coordination Committee for Measurements of Radioactivity and Xenobiotic compounds. Dioxins in environment and food in The Netherlands. Bilthoven, 1991 (in Dutch).

3. Slob, W.; Troost, L.M.; Krijgsman, M.; Koning, I de.; Sein, A.A. Incineration of municipal waste in The Netherlands. Emissions occurring at incineration. Dispersion and risks of dioxins. RIVM/TNO/VROM, 1992 (in Dutch).

4. Pluim, H.J.; Koppe, J.G.; Olie, K.; Slike, J.W. van der; Vulsma, T.; Tijn, D van.; Vijlder, J.J. de. Effects of dioxins on thyroid function in newborn babies. The Lancet 339: 1303; 1992.

5. Huisman, M.; Koopman-Esseboom, C.; Fidler, V.; Hadders-Algra, M.; van der Paauw, C.G.; Tuinstra, L.G.M.Th.; Weisglas-Kuperus, N.; Sauer, P.J.J; Touwen, B.C.L.; Boersma, E.R. Perinatal exposure to polychlorinated biphenyls and dioxins and its effect on neonatal neurological development. Early Human Development 41 : $111-127 ; 1995$.

6. Sauer, P.J.J.; Huisman, M.; Koopman-Esseboom, C.; Morse, D.C.; Smits-van Prooije, A.E.; van de Berg, K.J.; Tuinstra, L.G.M.Th.; van der Paauw, C.G.; Boersma, E.R.; Weisglas-Kuperus, N.; Lammers, J.H.C.M.; Kulig, B.M.; Brouwer, A. Effects of Polychlorinated Biphenyls (PCBs) and Dioxins on growth and development. Human and Experimental Toxicology 13: 900-906; 1994.

7. Koopman-Esseboom, C.; Morse, D.C.; Weisglas-Kuperus, N.; Lutkeschipholt, I.J.; van der Paauw, C.G.; Tuinstra, L.G.M.T.; Brouwer, A.; Sauer, P.J.J. Effects of dioxin and polychlorinated biphenyls on thyroid hormone status of pregnant women and their infants. Pediatric Research 36, no 4: 468-473; 1994.

8. Koopman-Esseboom, C.; Weisglas-Kuperus, $\mathrm{N}_{\text {.; }}$ de Ridder, M.A.J.; van der Paauw, C.G.; Tuinstra, L.G.M.Th.; Sauer, P.J.J. Effects of PCB/Dioxin exposure and feeding type on the infant's mental and psychomotor development Pediatrics 97(5): 700$706 ; 1996$. 
9. Weisglas-Kuperus, N.; Sas, T.C.J.; Koopman-Esseboom. C; van der Zwan, C.W.; de Ridder, A.J.; Beishuizen, A.; Hooijkaas, H.; Sauer, P.J.J. Immunological effects of background prenatal and postnatal exposure to dioxins and polychlorinated biphenyls in Dutch infants. Pediatric Research sept 38(3): 404-410; 1995.

10. National Institute for Public Health and the Environment. National Environmental Outlook 1993-2015. Bilthoven, 1993.

11. Department of Housing, Spatial Planning and Environment. Environmental Impact Assessment, part X Health. 's Gravenhage 1989 (in Dutch)

12. Premises of Risk Management, 1989. Annex to the Dutch National Environmental Policy Plan 1990-1994. Second Chamber of the States General, session 1988-1989. 21137, no 5; The Hague, The Netherlands (in Dutch).

13. Theelen, R.M.C; Knaap, A.G.A.C.; Sangster, B. Dioxin; a standard recommended by the World Health Organization. Ned Tijdschr Geneeskd 135: 875-877; 1991 (in Dutch).

14. Fingerhut, M.A.; Halperin, W.E.; Marlow, D.A.;Piacitelli, L.A.; Honchar, P.A.; Sweeney, M.H.; Greite, A.L.; Dill, P.A.; Steenland, K.; Suruda, A.J. Cancer mortality in workers exposed to 2,3,7,8-tetrachlorodibenzo-p-dioxin. New Engl J Med 324: 212-218; 1991 .

15. Bailar, J.C. How dangerous is dioxin? New Engl J Med 324: 260-262; 1991.

16. Triebing, G. Is dioxin carcinogenic ? The Lancet 338: 1592; 1991.

17. Bertazzi. P.A.; Pesatori, A.C.; Consonni, D.; Tironi, A, Landi, M.T.; Zocchetti, C. Cancer incidence in a population accidentally exposed to $2,3,7,8$-tetrachlorodibenzo-para-dioxin. Epidemiology 4: 398-406; 1993.

18. Roberts, L. Dioxin risks revisited. Science 251: 624-626; 1991.

19. Linders, J.B.H.J. Human risk assessment on exposure to compounds Basic Primciples and Assumptions. RIVM report no. 725201003. Bilthoven, 1990 (in Dutch).

20. Theelen, R.M.C. Humane exposure to dioxins and furans and contribution of waste incinerators to this exposure by deposition of fly ash. RIVM report no. 738473009. Bilthoven, 1989 (in Dutch).

21. VCP. What do The Netherlands eat ? Results of the Food Consumption Survey. Department of Agriculture and Department of Public Health and Culture. s Gravenhage, 1988 (in Dutch).

22. Haskoning, VAM, IIsselmij. Environmental Impact Assessment for the integrated waste incinerator GAVI Wijster VAM/IJsselmij project. Nijmegen, 1989 (in Dutch).

23. Haskoning. Environmental Impact Assessment for the new-to-build waste incinerator at Moerdijk. Nijmegen, 1992 (in Dutch).

24. Grontmij/Haskoning. Environmental Impact Assessment Waste Incineration ZuidOost Nederland. Province of Limburg/Province of North-Brabant. De Bilt, 1993 (in Dutch).

25. Sakai, S.; Hiraoka, M.; Takeda, N.; Shiozaki, K. Coplanar PCBs and PCDDs/PCDFs in municipal waste incineration. Dioxin 9: 215-218; 1992.

26. Liem, A.K.D; Theelen, R.M.C.; Slob. W.; Wijnen, J.H. van. Dioxins en planar PCBs in food. Contents in food products and intake by the Dutch population. RIVM report no. 730501034 . Bilthoven, 1991 (in Dutch).

27. Health Council of The Netherlands. Dioxins. Polychlorinated dilsenzo-p-dioxins, dibenzofurans and dioxin-like polychlorobifenyls. Rijswijk 1996-10. 
28. Air pollution aspects of waste incinerators for municipal and industrial waste. Second Chamber of the States General, session 1996-1997, 18319, no 64: The Hague, The Netherlands (in Dutch).

29. Bremmer, H.; Booij, H. PCB Emissions in telation to dioxin emissions. RVM report no. 601014005 , Bilthoven 1995 (in Dutch).

30. Mathijsen, A.J.C.M.; Beek van de, A.I.M.; Kootstra, P.R.; Sein, A.A. Dioxins and PCBs in solid residues of waste incinerators. RVM report no. 770501004, Bilthowen 1993 (in Dutch).

31. Făngmark, I, Marklund, S.; Rappe, C.; Strömberg, B.; Berge, N. Use of a synthetic refuse in a pilot combustion system for optimizing dioxin emission, part II. Chemosphere 23: 1233-1243; 1992.

32. Bavel van, B,; Fángmark, I.; Marklund, S.; Söderström, G.; Ljung, K.; Rappe, C. Quantitative analysis of organic trace compounds by isotope dilution: formation of non-ortho PCBs 77, 126, 169 during incineration. Dioxin 8: 225-228; 1992. 


\title{
Chapter 3
}

\section{Health risk by consuming contaminated fish from brooks in the South- west part of The Netherlands}

\author{
H.J. Albering, H.W.A. Jans ${ }^{1}$, J.C.S. Kleinjans ${ }^{2}$, H.F.L. Hendriks
}

Municipal Health Services, Bergen op Zoom; ${ }^{1}$ Municipal Health Services, Breda; The Netherlands ${ }^{2}$ Department of Health Risk Analysis and Toxicology, University of Limburg, Maastricht, The Netherlands

Translated from: T.Soc. Gezondheidsz. 71, 4:1-4 (1993)

\begin{abstract}
The sediment of two Dutch brooks (Roosendaalse Vliet and the Watermolenbeek) appeared contaminated by various heavy metals, insecticides and polychlorinated biphenyls.

In order to evaluate the potential health risk of the contamination for anglers consuming fish from these brooks, three eel samples (each consisting of 25 specimen) were taken for analysis of PCB congeners, mercury, and insecticides. The concentrations of mercury, $\mathrm{PCBs}$ and insecticides in the eel samples appeared very low compared with eel from contaminated Dutch rivers. For a health risk assessment of a combined intake of PCBs, toxicity equivalence factors (TEF) were applied, as proposed by a national scientific forum. Taking into account the background exposure to 2,3,7,8-TCDD equivalents (TEQ) and related compounds, it is estimated that the current tolerable daily intake (TDI) of $10 \mathrm{pg} 2,3,7,8$ $\mathrm{TCDD} / \mathrm{kg}$ body weight (WHO 1990) is not exceeded by consumption of up to 406 eels per year. This assessment is mainly based on measured concentrations of three PCB mono-ortho congeners (IUPAC-no. 105, 118 and 156) in the eel samples. Anglers who are used to eat fish from the Roosendaalse Vliet and the Watermolenbeek, appear to consume 10 eels per week on average during the months May till October and are therefore not at risk of exceeding the TDI of 2,3,7,8-TCDD.
\end{abstract}

\section{Introduction}

In 1989, on planning a new marima in the municipality of Roosendal it appeared that the nawigable depth was insufficient in a part of the Roosendaalse Vliet due to a thick layer of sediment. Further investigations revealed that this sediment, originating from both the Roosendaalse Vliet and the Watermolen- 
beek, was heavily polluted, to such a degree that it exceeded the B-reference value for a number of heavy metals. The level that were found for compounds like polychlorinated biphenyls (PCBs) and (organochlorine) pesticides were between the $A$ - and $B$-reference values (1-3). The mentioned waters are frequently used for recreational fishing. Recreational anglers therefore, asked the Municipal Health Services (MHS) Bergen op Zoom whether the fish caught in these Roosendaal waters were safe for consumption by themselves or others. Recreational anglers may be at higher exposure risk since they consume more and/or frequently fish they catch themselves, and consequently may be more exposed to fish contaminants than the general population (4).

In the present limited study, performed in 1990 at the MHS Bergen op Zoom in collaboration with the University of Limburg, the possible health risk in relation to frequent consumption of fish from these waters has been evaluated. Eel was used as indicator organism. Next to pike and trout, eel is the inland freshwater fish which is most frequently taken home for consumption (4). Polychlorinated biphenyls, organochlorine pesticides and mercury were analyzed. In view of the apparently low levels of organochlorine pesticides and mercury, the present paper will focus on the possible health risk in relation to contamination of eel by PCBs.

\section{Toxicity Equivalence Factors (TEF)}

An assessment of the possible adverse health effects of PCBs is feasible by means of TEFs, initially set up for polychlorinated dibenzo-p-dioxins (PCDDs) and polychlorinated dibenzo-p-furans (PCDFs) (5). The toxicity of these compounds is compared with the most toxic 2,3,7,8-tetrachlorodibenzo-p-dioxin (TCDD). Subsequently, the exposure is weighted by toxicity equivallence factors and summed to 2,3,7,8-TCDD equivalents (TEQ) and compared with the standard for $2,3,7,8$-TCDD. This is possible as the biological effects of toxic PCDD/Fs are qualitatively equal.

Considering the comparability of the toxicological action mechanism of some flat PCBs, the so-called coplanar and mono-ortho PCB congeners, to 2,3,7,8-TCDD, TEF values for these congeners have also been proposed (6). Up until today, it is the only possible way to assess the toxicity of mixtures of dioxin-like PCBs. In the present study only 3 mono-ortho PCB congeners (IUPAC-no. 105, 118 and 156) have been analyzed in fish and expressed as $2,3 \times 7,8$-TCDD equivalents and compared to the guideline for $2,3,7,8$-TCDD of 10 $\mathrm{Pg} / \mathrm{kg}$ body weight per day (7). In addition, it is assumed that the examined fish do not contain more than the average background levels of PCDD/PCDFs. 


\section{Methods}

$27 \mathrm{PCB}$ congeners have been analyzed in eel to evaluate the possible health risk of consumption of eel from the polluted brooks - the Roosendaalse Vliet and the Watermolenbeek. In general, eel may be used as indicator organism for the determination of the exposure to PCBs because of its lifestyle and its relatively high level of body fat, into which PCBs accumulate. Elimination of these compounds hardly occurs. In fact, the PCB levels found in eel are an integration of the polluting, conditions to which the eel has been exposed throughout its life. Where as attention should be paid to the fat content, forage and migratory behaviour, sex and growth rate of the eel (8).

The fish were caught in one single month, e.g. in May 1991 to exclude fluctuations due to migratory behaviour of the eel as much as possible. Fluctuations as a result of differences in behaviour and growth rate of individual fishes were minimized by sampling $22-25$ specimen belonging to a specific length class $(25-35 \mathrm{~cm})(8)$. The eels were caught by means of electrofishing (9). Three samples of 22 - 25 specimen were taken, two from the Roosendaalse Vliet and one from the Watermolenbeek.

Chemical analyses were performed by the National Institute for Fisheries Research (RIVO) at IJmuiden. Per sampling site, a pooled sample was prepared by taking an equal amount of fillet from each eel and by subsequent homogenization. The homogenates were stored at $-20^{\circ} \mathrm{C}$ in glass jars until analysis. Determination of the concentration of PCBs was carried out by capillary gas chromatography with electron capture detection (CG-ECD). The detection limit for the separate congeners was $0.1 \mu \mathrm{g} / \mathrm{kg}$ fresh product (10).

\section{Results}

A summary of the general data on fish from both freshwater brooks is presented in Table 3.1. Table 3.2 shows the concentrations of the individual PCB congeners in eel samples from the Roosendaalse Vliet and the Watermolenbeek as compared to eel from two other inlland freshwaters: the lake Oostvaardersplassen and Haringvliet (8). The concentrations of the individual PCB congeners in eels from the two Brabant waters are relatively low and appear not to differ from eels caught in lake Oostvaardersplassen. The determined levels are clearly lower than those in eels caught in the Haringvliet. 
Table 3.1. Sample data of als caught in the Roozendaalse Viet and the Watermolembeek

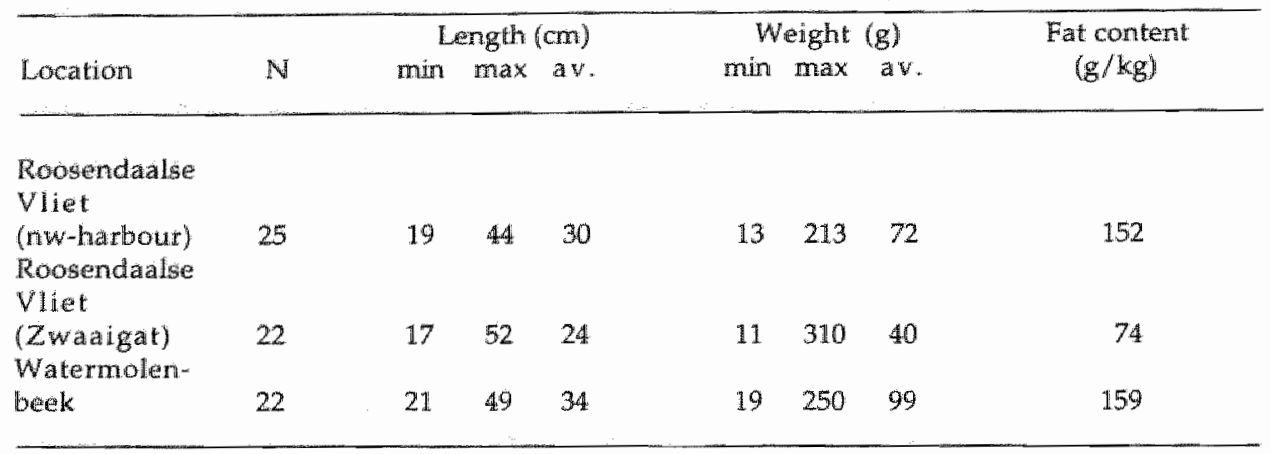

\section{Risk assessment}

A risk assessment was performed despite the fact that the PCB concentrations found in eels from the Roosendaalse Vliet and the Watemolenbeek were lower than those from other fishing locations in The Netherlands, for instance from the Haringuliet.

In the present risk assessment only the data from 3 measured mono-ortho coplanar PCBs (IUPAC-no. 105, 118, 156) in eels from the Roosendaalse Vliet and the Watermolenbeek could be used, since TEF values have been proposed for only these PCBs congeners. There still is a possibility that other nonanalyzed coplanar and mono-ortho PCB congeners may be present in the examined eels.

The TEF values for the 3 measured PCBs, e.g. IUPAC-no 105, 118 en 156, are 104, $5^{*} 10^{-5}$ and $5^{*} 10^{-4}$ respectivelly $(6)$.

Table 3.3 shows the results of these 3 PCB congeners in eel weighted by toxic equivalence factors.

Table 3.3: Conversion of $\mathrm{PCB}$ contents of 3 mono-ortho $\mathrm{PCB}$ congeners in eel from the Roosendaalse Vliet and the Watermolenbeek to $\mathrm{Pg}$ TEQ per g total product

\begin{tabular}{lccc}
\hline $\begin{array}{l}\text { Congener } \\
\text { IUPAC-no. }\end{array}$ & $\begin{array}{c}\text { Average concentration in the caught eel } \\
\text { of the 3 sampling locations }(\mu \mathrm{g} / \mathrm{kg} \text { product) }\end{array}$ & $\begin{array}{l}\text { TEF-2,3,78- } \\
\text { TCDD }\end{array}$ & $\begin{array}{l}\text { Pg TEQ/ } \\
\text { g product }\end{array}$ \\
\hline 105 & 4.3 & $10^{-4}$ & 0.43 \\
118 & 9 & $5 \times 10^{-5}$ & 0.45 \\
156 & 2.6 & $5 \times 10^{-4}$ & 1.3 \\
Total & & & $\overline{2.18}$ \\
\hline
\end{tabular}




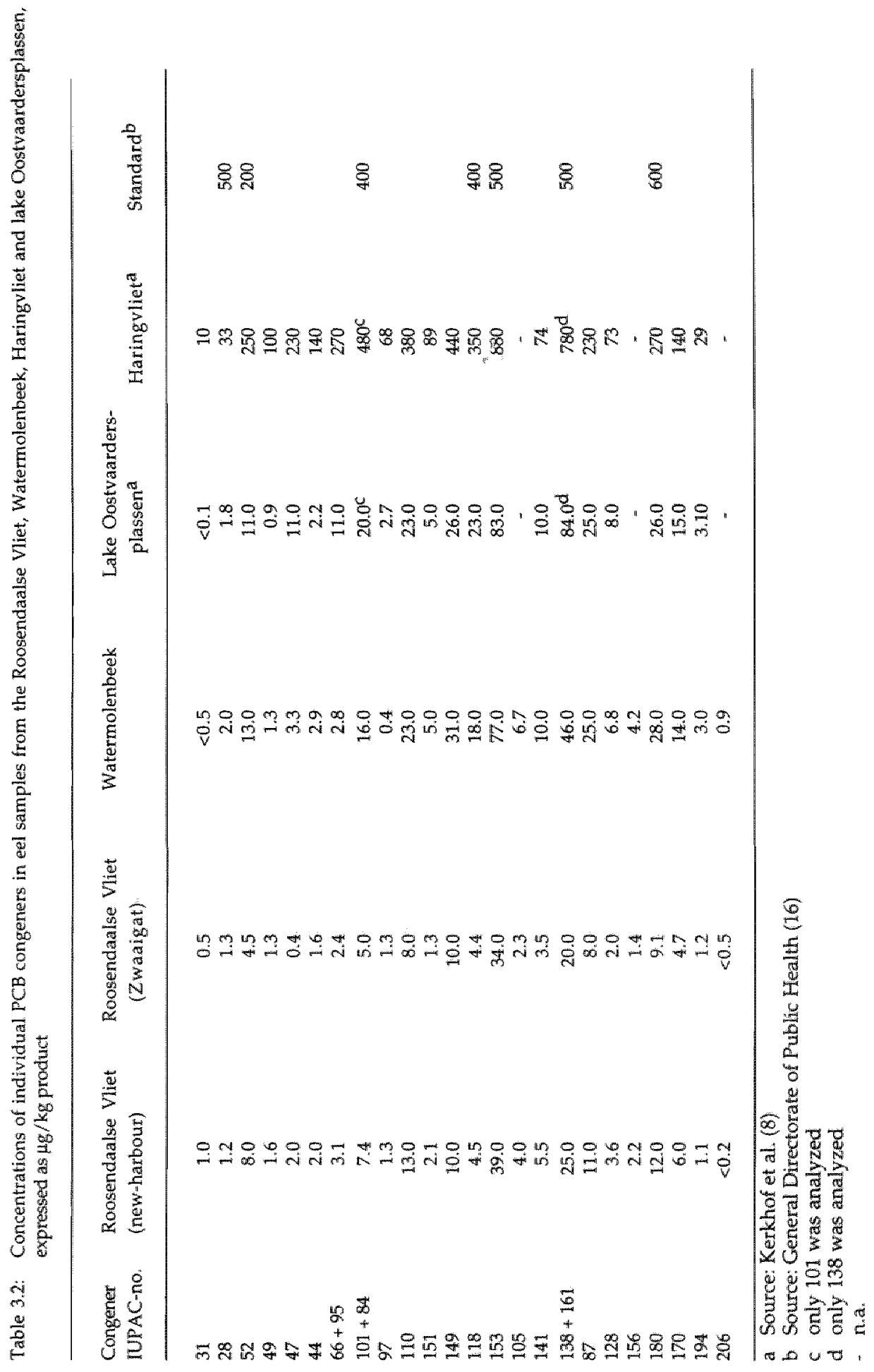


The total TEQ levels of the investigated eel, expressed as 2,3,7,8-TCDD TEQ, can be calculated by adding up the contribution by coplanar and mono-ortho PCBs and that by PCDDs and PCDFs. An average concentration of $4.72 \mathrm{pg} T E Q / \mathrm{g}$ product was determined in a recent study by Van der Valk et al. (11) in which eel from the Dutch large rivers and their catchment areas were analyzed for PCDDs and PCDFs. Assuming similar rates of occurrence of polychlorinated dibenzo-p-dioxins and polychlorinated dibenzo-p-furans in eel from the Roosendaalse Viet and the Watermolenbeek, the total TEQ level of the investigated eel from these waters appears $6.9 \mathrm{pg} T E Q / \mathrm{g}$ product at the lowest. This might increase when the other coplanar and mono-ortho PCBs also would have been analyzed.

It is possible to estimate the consumption rate of eels while still complying the tolerable daily intake (TDI) of $10 \mathrm{pg} 2,3,7,8-\mathrm{TCDD} / \mathrm{kg}$ body weight per day (12), using these calculated and partly hypothetical TEQ levels of eel (6.9 pg TEQ/g product).

The actual median daily intake is $1 \mathrm{pg}$ TEQ per $\mathrm{kg}$ bodly weight for persons aged 20-70 years (13). This means background exposure of $60 \mathrm{pg}$ TEQ per day for an adult of $60 \mathrm{~kg}$. Giving this background exposure level it is estimated that $78 \mathrm{~g}$ of eel, containing $6.9 \mathrm{pg}$ TEQ/g product, can be consumed per day without exceeding the TDI. This implies that at a consumption rate of 406 eels per year (average weight of $70 \mathrm{~g}$ per eel) the TEQ exposure equals the tolerable daily intake of $10 \mathrm{pg} 2,3,7,8-\mathrm{TCDD} / \mathrm{kg}$ body weight.

Recreational anglers fishing in the Roosendaalse Vliet and the Watermolenbeek appear to consume 1.0 eels per week on average (average weight of $70 \mathrm{~g}$ per eel) during the months of May to October. The additional daily TEQ exposure due to consumption of contaminated eel is $284 \mathrm{pg}$ on average on a yearly basis. Added to the background daily exposure of $60 \mathrm{pg}$ on average, the total TEQ exposure of recreational anglers fishing in the Roosendaalse Vliet and the Watermolenbeek appears to be $344 \mathrm{pg}$ per day. The tolerable daily intake of $10 \mathrm{pg} 2,3,7,8-\mathrm{TCDD} / \mathrm{kg}$ body weight is not exceeded at the mentioned fish consumption rate by recreational anglers.

\section{Conclusion}

Evaluation of the possible health risk in relation to eel consumption from contaminated brooks in Brabant, has been performed by converting the concentration of 3 mono-ortho PCB congeners in the eel into 2,3,7,8-TCDD equivalents (TEQ) and by comparison to the Dutch guideline of 10 pg $2,3,7,8$ $\mathrm{TCDD} / \mathrm{kg}$ body weight per day.

The risk assessment has been performed using a limited amount of data from 3 pooled eel samples from two waters in West Brabant. Only 3 mono-ortho PCB congeners have been analyzed. The contribution of non-measured PCB 
congeners to the total sum of TEQ has not been taken into consideration. In addition, the exposure to the analyzed PCBs with a non-dioxin like action mechanism has also not been taken into account. Furthermore, there are uncertainties about the fish consumption rate of recreational anglers fishing in the Roosendaalse Vliet and the Watermolenbeek. In spite of the limited reliability of TEF derivations, health risk assessment by means of the TEF method is a pragmatic approach, which has been previously used at a waste incinerator in relation to the possible health risk of consumption of dairy products from cattle grazing in the direct surroundings of this waste incinerator $(14,15)$. In that way, the available data allow an overall view on the possible health risk in relation to consumption of contaminated eel from these brooks in West Brabant.

Based on the actual contamination of eel with PCBs and on the presently available knowledge it may be concluded that no health risk is expected as a consequence of the consumption of eel by recreational anglers.

It is recommended to extend the present investigation of chemical exposure of fish in large rivers to smaller inland freshwaters and to apply the risk assessment method described in this paper.

\section{References}

1. Oranjewoud BV. Report on the inventory investigation of sediment from the Watermolenbeek at Roosendaal. Oosterhout. Project no. 78-40432; 1989 (in Dutch).

2. Oranjewoud BV. Report on the quality investigation of sediment from the Roosendaalse Vliet between Kadeplein and Borchwerf/Vermeerlaan. Oosterhout. Project no. 78-36063; 1989 (in Dutch).

3. Oranjewoud BV. Report on the sediment investigation Halsegat/Schipbeek at Roosendaal. Oosterhout. Project no. 78-36064; 1989 (in Dutch).

4. Potting, S.M.C. Consumption of fish by recreational anglers. Inspectorate for Health Care; Rijswijk, The Netherlands 1989 (in Dutch).

5. Zorge, J.A.; Wijnen van, J.H.; Theelen, R.M.C.; Olie, K.; Berg van, M. Assessment of the toxicity of mixtures of halogenated dibenzo-p-dioxins and dibenzofurans by use of toxicity equivalency factors (TEQ). Chemosphere 19: 1881-95; 1989.

6. Theelen, R.M.C. Preliminary results of the project group TEQ (II). Bilthoven: RIVM; 1990 (in Dutch).

7. Theelen, R.M.C.; Knaap, A.G.A.C.; Sangster, B. Dioxin: a standard recommended by the World Health Organization. Ned. Tijdschr. Geneesk. 135: 875-7; 1991 (in Dutch) 
8. Kerkhoff, $\mathrm{M}_{\text {; }}$ Boer de, J; Vries de, A,; Otte, P; Warnaar, D.; Masereeuw, P. PCB contamination in red eel; trends in chlorobiphenyl levels.(1977-1985). IJmuiden: RIVO. Rapport MO 86-01; 1986 (in Dutch).

9. OVB. Electrofishing in our inland freshwaters. OVB-info magazine. March 1990 (in Dutchi.

1.0. Boer de ${ }_{*}$. Chlorobiphenyls in bound and non-bound lipids of fishes; comparison of different extraction methods. Chemosphere 17: 1803-10; 1988.

11. Valk van der, Fi, Pieters, H.; Wegman, R.C.C. Bioaccumulation in yellow eel (Anguilla anguilla) and perch (Perca fluviatilis) from the Dutch branches of the Rhine-Mercury, organochlorine compounds and polycyclic aromatic hydrocarbons. IJmuiden: RIVO. Rapport MO 89-205; 1989.

12. WHO/EURO. Consult on Tolerable Daily Intake from food of PCDDs and PCDFs. Copenhagen: WHO Regional Office of Europe. Summary Report UER/ICP/PCS $\mathrm{m030}(\mathrm{S}) ; 1990$.

13. Liem, A.K.D.; Theelen, R.M.C.; Slob, W; Wijnen van, J.H. Dioxins and planar PCBs in food; levels in food products and intake by the Dutch population. Bilthoven: RIVM. Report no. 730501034; 1991 (in Dutch).

14. Liem, A.K.D.; Olie, K.; Jong de, A.P.J.M.; Theelen, R.M.C.; Marsman, J.A.; Boer den, A.C.; e.a. Dioxins and dibenzofurans in cow milk from dairies in the Rijnmond area and other locations in The Netherlands. Bilthoven: RIVM. Report no. 748762001; 1989 (in Dutch).

15. Jong de, A.P.M.J.; Liem, A.K.D.; Boer den, A.C.; Marsman, J.A.; Hartog den, R.S.; Groenemeijer, G.S; e.a. Follow up of the investigation on dioxins in cow milk from dairies at Vlaardingen (Lickbaert area). Bilthoven: RIVM. Report no. 748704027; 1989 (in Dutch).

16. General Directorate of Public Health. Regulations on PCB standards (Commodities Act). Staatscourant 239; 1984 (in Dutch).

\section{Appendix}

In the present study, a health risk assessment has been performed in relation to PCB levels measured in 3 pooled samples of eel from two brooks in West Brabant. This study was initiated by a question coming from a recreational anglers club inquiring whether the fish caught in these waters was suitable for consumption, considering the contamination of the sediment.

Another risk assessment approach may be based on the exposure model as described in chapter 5 , which also aims to quantify human exposure in relation to contaminated sediment. Considering the present use of the Roosendaalse Vhet and the Watermolenbeek, consumption of contaminated fish appears to be the major exposure route. The other routes (ingestion and dermal contact with surface water and sediment) are not taken into account. 
The model calculates the levels in fish from the concentrations of pollutants in surface water by means of contaminant-specific bioconcentration factors. The concentration in surface water is calculated from the concentration in sediment by using partition coefficients. Next to $\mathrm{PCB}$ congeners, a number of insecticides and mercury were analyzed in the pooled eel samples from above mentioned waters. It is not possible to make a direct comparison between the measured levels in the eel samples and the calculated levels (by using the model) for PCB congeners and insecticides, since at the time of the sediment analyses, the individual compounds were not analyzed. Only the EOX-level (level of extractable organic halogen compounds) in the sediment was determined. For mercury, however a direct comparison between the measured and the calculated level in fish is possible.

Total mercury levels in the analyzed eel samples from the three locations Roosendaalse Vliet (new harbour, Zwaaigat) and the Watermolenbeek were $0.067,0.059$ en $0.063 \mathrm{mg} / \mathrm{kg}$ respectively, expressed on wet weight basis (Table 3.4). The exposure model used to calculate the concentrations in fish on basis of the contaminated sediment, appears to underestimate the mercury concentration by a factor of 7.5 to 22 . Subsequently, the exposure may be quantified by taken the fish consumption rate into account.

Table 3.4: Total mercury levels in fish expressed in $\mathrm{mg} / \mathrm{kg}$ wet weight

\begin{tabular}{|c|c|c|}
\hline Location & $\begin{array}{c}\text { location specific } \\
\text { measured }\end{array}$ & $\begin{array}{c}\text { standard model } \\
\text { calculated }\end{array}$ \\
\hline $\begin{array}{l}\text { Roosendaalse Vliet } \\
-\quad \text { (new harbour) } \\
-\quad \text { (Zwaaigat) } \\
\text { Watermolenbeek }\end{array}$ & $\begin{array}{l}0.067 \\
0.059 \\
0.063\end{array}$ & $\begin{array}{l}0.003 \\
0.008 \\
0.008\end{array}$ \\
\hline
\end{tabular}

In the general discussion, a comparison will be made between the use of this exposure model and the performing of exposure risk assessments on the basis of location specific measurements. 

The case of the river Meuse 



\title{
Chapter 4
}

\section{Evaluating environmental health risks after the flooding of the river Meuse during the winter of 1993-1994}

\author{
H.J. Albering, S.M. van Leusen, E.J.C. Moonen, J.A. Hoogewerff 1 , J.C.S. \\ Kleinjans
}

\begin{abstract}
Department of Health Risk Analysis and Toxicology, University of Limburg, PO Box 616, $6200 \mathrm{MD}$ Maastricht, The Netherlands. 1 Geotechíucal Institute, DeFPZ Arsenal, Vienna, Austria
\end{abstract}

Based on: Bodem, 2: 77.79; 1995

\begin{abstract}
At the end of December 1993 and also at the end of January 1995, the river Meuse, one of the major rivers in Europe, has flooded and river banks were inundated. We investigated the possible health risks in relation to the river bank pollution resulting from the flooding of the river Meuse at the end of 1993. Soil and deposit samples and corresponding arable and fodder crops were collected and analyzed for heavy metals. Although the soils of the floodplain of the river Meuse appeared severely polluted mainly by $\mathrm{Cd}$ and $\mathrm{Zn}$, the heavy metal concentrations in the crops grown on these soils were within background ranges. Incidentally, the legal standard for $\mathrm{Cd}$ as endorsed by the Commodities Act, was exceeded in wheat crops.

The main exposure pathways for the general population are through the consumption of food crops cultured on the river banks and through the direct ingestion of contaminated soils. For estimating potential human exposure in relation to soll pollution, a multiple pathway exposure model was used. For estimating the actual risk, metal contents of vegetables grown in 6 experimental gardens, were determined. From this study, it can be concluded that there is a potential health risk for the river bank inhabitants as a consequence of $\mathrm{Pb}$ and $\mathrm{Cd}$ contaminations of the floodplain soils of the river Meuse which are frequently inundated (averaged flooding frequency ance every two years).
\end{abstract}

\section{Introduction}

The river Meuse is located in western Europe, originates in France, flows through Belgium and has its entrance into the North Sea in The Netherlands. The river Meuse is a rain river, which implies that the river reacts very fastly to rainfall in its catchment area. At Borgharen (Figure 4.1) near the Dutch-Belgian border the annually averaged flow rate is around $250 \mathrm{~m}^{3} / \mathrm{s}$ (1). However, this 
flow rate can range from $25 \mathrm{~m}^{3} / \mathrm{s}$ during summertime periods of drought, to $2000 \mathrm{~m}^{3} / \mathrm{s}$ or more during ongoing precipitation (2). High peak flows repetitively cause floodings of the river Meuse, predominantly in wintertime. The southern part of The Netherlands is particularly vulnerable to precipitation upstream in the Meuse basin in the Belgian Ardennes and northern France. This is manly due to the geomorphological composition of the river system which is characterized by a steep narrow valley in the Belgian Ardennes with only a few storage possibilities for suddenly rising water levels of the river (2). A discharge of $1500 \mathrm{~m}^{3} / \mathrm{s}$ (at Borgharen) occurs on average once every two year and may result in flooding of the river Meuse at a few locations in the southern part of the Dutch Province of Limburg. At $2000 \mathrm{~m}^{3} / \mathrm{s}$ some villages in this area become inundated. For the first time since 1926, extremely large scalle inundation of the river Meuse has occurred in December 1993 and January $1995(2,3)$. The river flooded its banks at several sites in The Netherlands, as in Belgium and northern France (2). For instance, 21.000 ha was inundated during the flood of December 1993 in the Province of Limburg (10\% of the total province) in The Netherlands (4). In time, this frequent flooding of the river in the riparian countries implies a more or less serious contamination by river pollutants of the soil in these areas. Important chemical contaminants of the water phase, and also of the sediment, are heavy metals including $\mathrm{Zn}, \mathrm{Pb}$ and $\mathrm{Cd}$, as well as multiple organic compounds such as pesticides and polycyclic hydrocarbons (PAH) which is due to the historical and actual industrial and agricultural processes in the catchment area $(1,5)$. A study performed in The Netherlands after the flooding of the river Meuse in 1984, has indicated that the flood deposits are highly contaminated by heavy metals (5). Various reports published in The Netherlands and Belgium after the previous floodings of the river. Meuse in 1980 and 1984, have evaluated heavy metal levels in flood deposits and topsoil, and have shown that also the soils of the floodplain are enriched by heavy metals.

In The Netherlands, as well as France and Belgium, the soils of the floodplain are commonly used for agriculture practice $(6,7)$. In general, the total surface of arable land is increasing with decreasing inundation frequency of the river banks while the forelands which are regularly inundated e.g. once every two years, are mainly used as pasture land (6). Crops grown on the floodplain of the river banks of the Meuse, may be consumed by man and/or by livestock. Incidental studies conducted in Belgium and The Netherlands, have shown that high levels of $\mathrm{Cd}$ and/or $\mathrm{Pb}$ may be present in vegetables (strawberries, lettuce, spinach, endive and kale), arable crops (barley and wheat) and fodder crops (ensiled grass and hay produced from flooded grass) grown on the floodplain of the river Meuse, although the major part of the samples taken from vegetables and arable and fodder crops grown on the river banks, shows heavy metal levels within background range (6). 
The objective of this study was to evaluate heavy metal exposure risks for inhabitants of the river banks in relation to the flooding of the river Meuse during the winter of 1993-1994. The heavy metal contents (e.g. As, Cd, Cu, Pb and $\mathrm{Zn}$ ) of the topsoil and flood deposits and the corresponding food and feed crops were evaluated. A general multiple pathway exposure model (HESP) was used to estimate potential human exposure in relation to soil contamination of the floodplain of the river Meuse (8). This model relates the soil concentration of a pollutant to various environmental media and predicts the concentration of a pollutant in vegetation, beef and diary products. Within this respect, it is of relevance that uncertainties in modeling the food-chain are dominated by uncertainty of transfer factors, for instance from soil to plant $(9,10)$. The uptake of heavy metals by plants appears to be influenced by different factors, specific for both soil and plant, such as; $\mathrm{pH}$, temperature, cation exchange capacity of the soil, the presence of other heavy metals in the soil, chemical speciation, the age of the plant, plant species etc. (11-15). To assess these uncertainties, in the present study the metal uptake by three different crop groups e.g. legumes (beans), leafy vegetables (lettuce) and root vegetables (potatoes), was investigated in 6 experimental gardens located on the floodplain of the river Meuse, and exposure risks as a consequence of the consumption of locally grown vegetables were calculated.

\section{Methods}

Study area

The study area (see Figure 4.1) is lacated in the Province of Limburg in the southern part of The Netherlands. Two villages are located in this area. The lowest parts of the two villages are predisposed to inundation as they are nearly non-protected from the river, and built close to the river bank at the site where the steep slope of the river changes into a more moderate slope (2). In general, the soils of the floodplain of the river Meuse in this area are used for vegetable gardens as well as for pasture and arable farming. The range of flooding frequencies in these areas is from once every two years to once every three thousand years.

Sampling

Immediately after the flooding in January 1994 soil samples were colllected from 15 agricultural fields (at least two samples per field), to a total of 48 soil samples. Each soil sample was composed of 5 pooled subsamples taken at a depth of 0-20 $\mathrm{cm}$ of the topsoill layer at $1 \mathrm{~m}^{2}$. Additionally, samples from the fllood deposits and the underlying subsoils were collected from 5 fields. The thickness of the flood deposits varied from $5-10 \mathrm{~cm}$. From these fields, crops e.g. silage maize (Zea Mays), potatoes (Solanum tuberosum L), English ryegrass (Lolium 


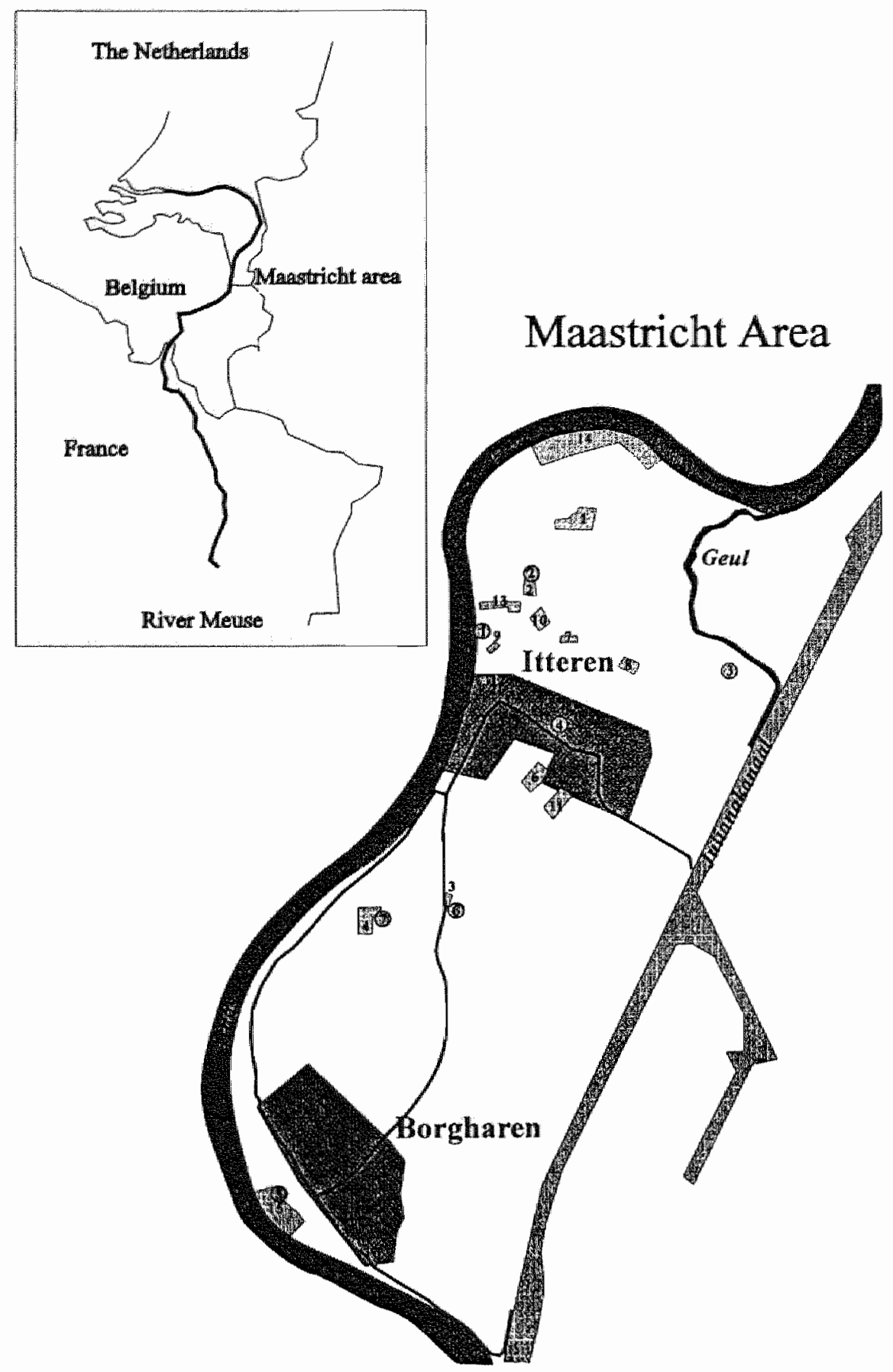

Figure 4.1: Map of the river Meuse and the area under study.

Oexperimental gardens $\square$ arable and pasture fields 
perenne) and wheat (Triticum aestivnm $L$ ) were sampled just prior to harvest in late July, August and September 1994.

Furthermore, we established 6 experimental gardens on the floodplains of the river Meuse in March 1994. Before planting, soil samples were collected as described above. The soil was turned over to a depth of $25 \mathrm{~cm}$ and a solid commercial fertilizer ( $\mathrm{N}-27 \%$ ) was used in an application rate of $4 \mathrm{~kg} / \mathrm{ha}$. Potatoes (Solanum tuberosum), lettuce (Lactuca sation acephala) and beans (Phaseolus oulgaris) were sown in these gardens in April and May 1994. Weeding, watering and loosening of the soil was done manually as needed. A net was spread over the garden to protect the crops against birds and rabbits. Additionally, metaldehyde $(6.4 \%)$ was applied following label recommendations once during the season of growth to prevent slugs. The crops were harvested late June or early July (lettuce), and during late July and early August (potatoes and beans).

In addition, from one cow from the study area, the liver and kidney were sampled at slaughter, and sliced and stored at $-20{ }^{\circ} \mathrm{C}$ until analysis.

\section{Chemical Analysis}

Soil and deposits

Soil and flood deposit samples were dried at $105{ }^{\circ} \mathrm{C}$, sieved $(2 \mathrm{~mm})$ and subsequently grounded in an agate mortar and stored until analysis. For metal analysis, $0.5 \mathrm{~g}$ of the grounded samples were digested with aqua regia for $2 \mathrm{~h}$ followed by filtration. After evaporation to a moist residue of $1 \mathrm{ml}$, the residue was dissolved in $100 \mathrm{ml}$ of $0.1 \% \mathrm{HNO}_{3}$. As, $\mathrm{Cd}, \mathrm{Cu}$ and $\mathrm{Pb}$ concentrations were measured by graphite-furnace Atomic Absorption Spectrometry with Zeeman background corrections, and concentrations of $\mathrm{Zn}$ by flame Atomic Absorption Spectrometry. All glass and plastic labware was previously washed in diluted nitric acid and deionized water to prevent contamination.

Soil parameters ( $\mathrm{pH}-\mathrm{KCl}$, organic matter and clay fraction) were determined according to Dutch NEN instructions. In short, the $\mathrm{pH}$ was estimated potentiometrically after equilibration with $\mathrm{KCl}$ and organic matter was determined by loss-on ignition at $550^{\circ} \mathrm{C}$ for $2 \mathrm{~h}$. The clay fraction (particulate fraction $<2 \mu \mathrm{m}$ ) was determined by treatment with $\mathrm{H}_{2} \mathrm{O}_{2}$ and $\mathrm{HCl}$, followed by sieving over a $38 \mu \mathrm{m}$ sieve. Upon settling, the clay fraction was subsequently separated. For both the agricultural and experimental fields the $\mathrm{pH}$ and organic fraction of the soil were determined. The clay content of the soil was only determined in the experimental gardens.

\section{Crops}

All portions of lettuce, beans and potatoes produced during the entire growing season in the experimental gardens were cumulatively harvested. Crops were thoroughly washed with demineralized water to remove surface dust and soil. 
A subsample was taken prior for the washing procedure, to determine the dry weight. In addition, the beans were topped and the potatoes were peeled with a stainless steel peeler and sliced. The edible material was bulked, dried at $70^{\circ} \mathrm{C}$ and grounded in an agate mortar. To prevent slime formation the lettuce samples were previously dried at $35^{\circ} \mathrm{C}$.

Agricultural crop samples were randomly collected from the fields. To determine dry weight also a subsample from the agricultural crops was taken. Ryegrass samples were taken with ceramic scissors up to $5 \mathrm{~cm}$ above the topsoil, sliced and dried at $70^{\circ} \mathrm{C}$ and grounded in a stainless steel mill. From the wheat plants only the ears were collected. The grains were separated, dried at $70^{\circ} \mathrm{C}$ and grounded. The total silage maize plant was collected. Plants were air-dried, bulked and grounded. To the agricultural potatoes the same procedure was applied as described for the potatoes grown in the experimental gardens.

Each sample $(0.5 \mathrm{~g})$ was treated with $20 \mathrm{~m} \|$ of a $1: 1$ mixture of concentrated $\mathrm{HNO}_{3}$ and $\mathrm{mQ}$ water and boiled for $30 \mathrm{~min}$. After filtration, the filtrate was evaporated to a moist residue $(2-3 \mathrm{ml})$ and subsequently diluted in $50 \mathrm{ml}$ of $0.1 \% \mathrm{HNO}_{3} . \mathrm{Cd}, \mathrm{Cu}, \mathrm{Pb}$ and $\mathrm{Zn}$ concentrations were measured by $\mathrm{AAS}$ as indicated above.

\section{Animal tissue}

The liver and kidney samples were sliced, bulked and dried at $110^{\circ} \mathrm{C}$ and subsequently grounded in an agate mortar. $0.5 \mathrm{~g}$ of tissue was treated with $\mathrm{HNO}_{3}(7 \mathrm{~N})$ and boiled for $1 \mathrm{~h}$. After filtration followed by evaporation the residue was dissolved in $50 \mathrm{ml}$ of $0.1 \% \mathrm{HNO}_{3}$. The heavy metal concentrations were measured by AAS as described above.

\section{Soil guideline values in The Netherlands}

At present, The Dutch government uses two guideline values e.g. intervention and target value, to assess the degree of pollution in the soil and to decide on remediation strategies (16). The target value refers to an acceptable or natural concentration in the soil. The intervention value indicates an unacceptable risk to man or environment due to soil contamination and is based on human toxicological and ecotoxicological data. The values are standardized for the clay fraction $(25 \%)$ and organic matter fraction of the soil (10\%). Exceedance of the intervention value implies a potential risk, taking all possible exposure pathways into account. Subsequently, an actual risk analysis (taking into account only the relevant exposure pathways) has to be performed in order to determine the priority for clean up. In the present study, heavy metal levels of soil and sediment samples were compared to these target and intervention values, normalized for the organic fraction (average $8.5 \%$ ) and clay fraction (average $2 \%$ ) of the floodplain soills. 


\section{Commodities Act}

The heavy metal concentrations in the vegetables, arable crops and animal tissue were compared to the legal standards according to the Commodities Act in The Netherlands (17). In addition, a comparison was made with generally observed concentrations in vegetables and animal tissue in The Netherlands and furthermore, with baseline values of heavy metals in crops grown in uncontaminated areas $(18,19)$. Commodities Act standards are based on generally observed concentrations in the edible part of the crops and animal tissue, as well as on established acceptable daily intake standards. For $\mathrm{Cu}$ and $\mathrm{Zn}$, no standards for crops and animal tissue have been set. The concentrations of heavy metals in fodder crops were compared to the prescribed limits according to the Commodity Board on animai feed in The Netherlands (20).

\section{Exposure assessment}

For quantification of potential human exposure in relation to the contamination by heavy metals of the banks after the flooding of the river Meuse, a multiple pathway exposure model (entitled HESP; Human Exposure to Soil Pollutants) was used (8). This model describes all relevant exposure pathways and transfer processes in relation to the physic-chemical characteristics of the soil. The model uses a general equation to estimate exposure to contaminants:

\section{$\operatorname{Exp}=\quad$ C X IR $\times E F \times F I \times A F$ \\ $B W$}

$C=$ concentration of the contaminant in different media
$I R=$ ingestion rate
$E F=$ exposure frequency
$E D=$ exposure duration
$F I=$ fraction contaminated
$A F=$ absorption factor
$B W=$ body weight

Relevant exposure pathways in relation to the agricultural function of the floodplain of the river Meuse were the ingestion of soil, the ingestion of crops grown on the contaminated floodplains and ingestion of meat and dairy products from cattle, pigs and poultry fed with feed crops grown on the contaminated floodplains. By modeling these pathways it was assumed that adults and children spend $24 \mathrm{~h} / \mathrm{d}$, every day of the year, on the contaminated site. Moreover, the fraction of time that adults and children spend outdoor on the site was respectively 0.32 and 0.12 on annual average. Furthermore, it was assumed that $10 \%$ of the ingested vegetables, meat and dairy products was coming from the contaminated site. The ingestion rates of soil and dust by 
adults respectively children were estimated to be 295 respectively $150 \mathrm{mg} /$ day (8).

However, in view of the uncertainties regarding plant-soil transfer, the indirect exposure pathway of home-grown consumed vegetables was quantified by using the results of the heavy metal analyses in the crops grown in the experimental gardens on the soils of the floodplain, so that more specific data could be applied as input parameters to the HESP model. It was assumed that the crops cultivated in the experimental gardens represent the range of crops generally grown in vegetable gardens. Subsequently, the heavy metall uptake by potatoes, beans and lettuce was assumed to represent the metal uptake in all root vegetables, legumes and leafy vegetables. Further in contrast to HESP conditions, it was assumed that $100 \%$ of the consumed vegetables are homegrown. The indirect exposure pathway was determined by multiplying the daily consumption rate of home grown vegetables with the contamination of the heavy metals in the corresponding crops. The daily consumption rate of homegrown vegetables was derived from a study performed by home-gardeners in The Netherlands (21). The daily consumption rate for potatoes, leafy vegetables, root vegetables, legumes, kale and other vegetables was respectively $158 \mathrm{~g}, 80 \mathrm{~g}$ $41 \mathrm{~g}, 37 \mathrm{~g}, 29 \mathrm{~g}$ and $68 \mathrm{~g}$ for adults, and for children respectively $75 \mathrm{~g}, 25 \mathrm{~g}, 16 \mathrm{~g}, 19$ $\mathrm{g}, 9 \mathrm{~g}$ and $21 \mathrm{~g}$. The heavy metal concentration in kale and other vegetables were assumed to equal the heavy metal concentration in leafy vegetables. To estimate actual human exposure the ingestion of soill was also taken into account. The ingestion rate of soil was assumed to be 50 respectively $150 \mathrm{mg} / \mathrm{day}$ for adults respectively children (8). The soil ingestion rate for adults was less than $295 \mathrm{mg} /$ day as used for the potential human exposure assessment because the fraction of time that adults spend outdoor on the site was assumed to be 0.05 on annual average instead of 0.32 (8). Furthermore, it is questionable whether in the study area, the locally produced dairy and meat products are actually consumed by inhabitants. Therefore, this pathway was excluded.

Additionally to exposure in relation to soil contamination, man is exposed to background levels of the same pollutants. Therefore, total exposure levels (additional plus background) were calculated for both children and adults, and compared to the established tolerable daily intake values (TDI). The TDI refers to the dose of a substance that can be taken in daily without identifiable risk at lifelong exposture. Additionally, the hazard quotient was calculated, which refers to the ratio of the calculated lifetime daily exposure divided by the reference dose (TDI). Daily exposure $(\mathrm{mg} / \mathrm{kg} . \mathrm{d}$ ) averaged over lifetime (e.g. 70 years), was calculated by 6 * daily exposure child $(\mathrm{mg} / \mathrm{kg} \cdot \mathrm{d})+64$ * daily exposure adult (mg/kg.d) $/ 70$. If the hazard quotient is below 1 no health risk may occur. For $\mathrm{Pb}$, different TDIs have been established for adults and children, because children appear to be more sensitive to $\mathrm{Pb}$ than adults (23). The TDIs for heavy metals were taken from Veerkamp et al (8). 


\section{Statistical analysis}

Spearman rank correlation coefficient analysis was used to explore the relationship between the heavy metal content in soil and soil characteristics, such as pH, organic matter and clay fraction. Furthermore, this analysis was used to correlate mutual data. Statistical differences between the heavy metal content in soils of the floodplain of the river Meuse with different flooding frequencies were evaluated by means of the Mann-Whitney U-test. Furthermore, the Mann-Whitney $U$-test was used to evaluate the heavy metal uptake by the different plant species. For all statistical analyses, a $p<0.05$ was considered significant.

\section{Results}

\section{Soil and flood deposits}

Heavy metal analysis in deposits and underlying soil taken from 5 arable fields, showed that the $\mathrm{Cd}, \mathrm{Zn}$ and $\mathrm{Pb}$ lewels in the deposits were remarkably higher than in the underlying soil. Mean ( $t$ sd) concentrations of $\mathrm{Cd}, \mathrm{Pb}$ and $\mathrm{Zn}$ in the deposits of the floodplain were respectively $6.74 \pm 0.3,207 \pm 56$ and $864 \pm 64$ $\mathrm{mg} / \mathrm{kg} \mathrm{dm}$. Concentrations of the elements in soil samples collected at the arable fields, are presented in Figure 4.2.

In soils from the most frequently flooded areas the highest heavy metal concentrations were observed. The high standard deviation of the mean illustrates the heterogeneity of the heavy metal concentrations in the soil. For instance, the heavy metal concentrations in soils with a flooding frequency on average of once every 2 years, varied from 11.1 to $17.7 \mathrm{mg} / \mathrm{kg} \mathrm{dw}$ for $\mathrm{As}$, from 5.6 to $14.0 \mathrm{mg} / \mathrm{kg} \mathrm{dw}$ for $\mathrm{Cd}$, from 62 to $116 \mathrm{mg} / \mathrm{kg} \mathrm{dw}$ for $\mathrm{Cu}$, from 157 to 326 $\mathrm{mg} / \mathrm{kg} \mathrm{dw}$ for $\mathrm{Pb}$ and from 705 to $1239 \mathrm{mg} / \mathrm{kg} \mathrm{dw}$ for $\mathrm{Zn}$. Soils of the floodplain which are inundated on average once every 50 years, were significantly less contaminated by heavy metals (except As) in reference to solls which are flooded at higher frequency (Mann Whitney $U$-test, p<0.05). Moreover, in soils inundated on average once every 10 years, the cadmium levels were significantly lower in comparison to the soils which are inundated on average once every 2 years.

Comparison of the results with the soil quality guidelines as set by the Dutch government, indicated that the intervention value for $\mathrm{Zn}$ was exceeded in $80 \%$ of the soil samples. Incidentally, the intervention value for $\mathrm{Cd}$ and $\mathrm{Cu}$ was exceeded (Figure 4.2).

Spearman rank correlation coefficient analysis demonstrated a significant correlation between the organic matter fraction of the soil and the heavy metal content in the soil (except As). Subsequently, the pH of the soil significantly correlated with heavy metal content; the heavy metal levels were significantly interrelated $(p<0.05)$. 


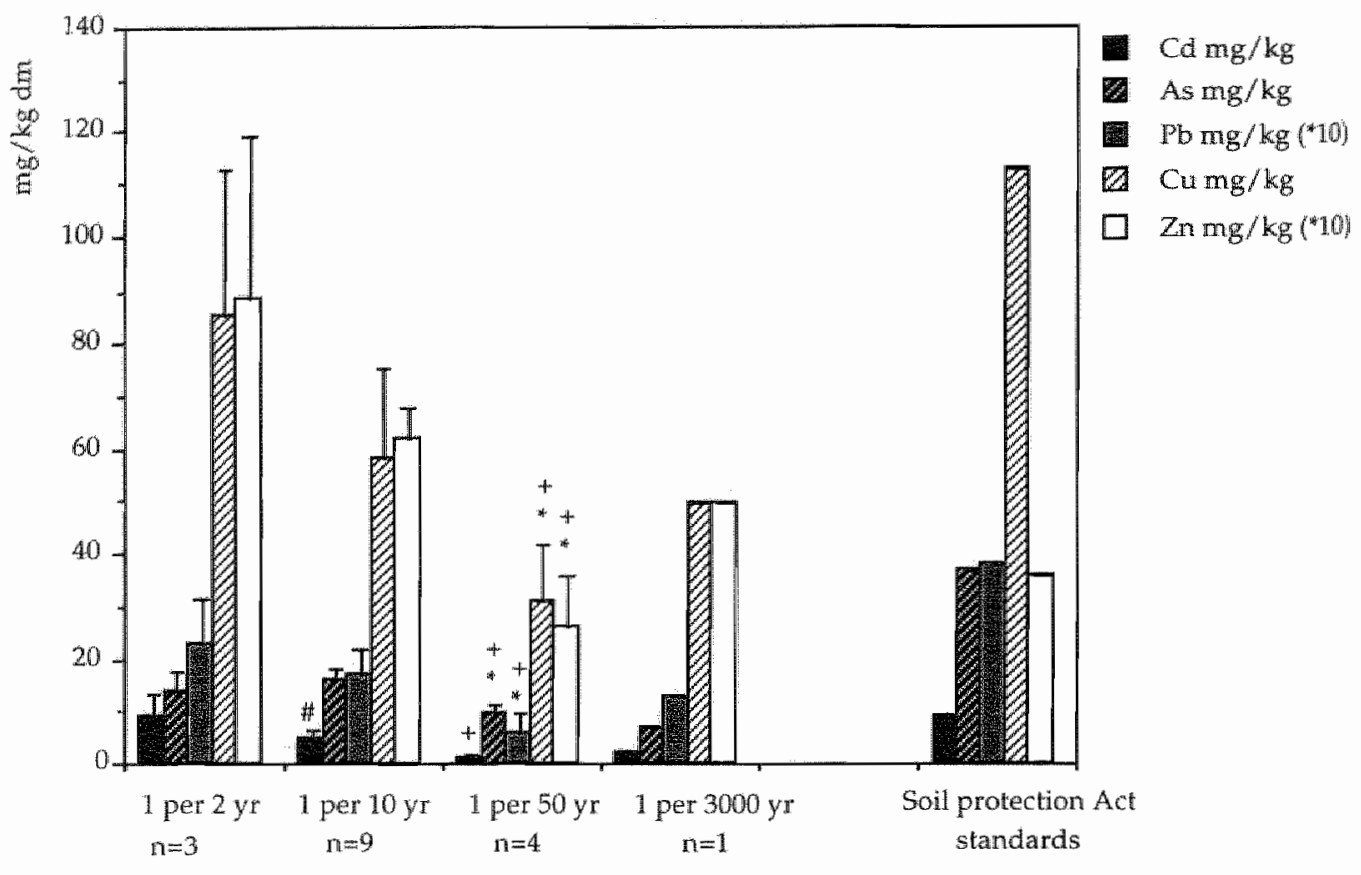

Flooding, rrequency

Figure 4.2: Mean ( $t \mathrm{sd}$ ) concentrations of some heavy metals $(\mathrm{mg} / \mathrm{kg}$ d w) in soil samples from the floodplain of the river Meuse, The Netherlands in relation to the flooding frequency and the Soil protection Act standards. The mean ( $\mathrm{LSd}$ ) concentrations of $\mathrm{Pb}$ and $\mathrm{Zn}$ have to be multiplied by 10 . The statistical significance of differences have been evaluated by the Manu-Whitney U-test.

to significantly different from flooding frequency of 1 per 10 yr $(p<0.05)$.

* significantly different from flooding frequency of 1 per 2 yr $(p<0.05)$.

significantly different from flooding frequency of 1 per 2 yu $(p<0.05)$.

$n=$ number of fields

\section{Crops and animal lissue}

The mean (tsd) concentrations of heavy metals in arable and fodder crops cultivated on the agricultural fields are listed in Table 4.1, as compared to the guideline value according to the Commodities Act and to the Commodity Board on animal feed in The Netherlands. Only in two wheat samples the permissible level for $C d(0.15 \mathrm{mg} / \mathrm{kg}$ fresh weight) was exceeded, despite the fact that these plants were cultivated on soils with a relatively low cadmium content ( 1.1 and $4.4 \mathrm{mg} / \mathrm{kg} \mathrm{dm}$ ). The heavy metal content observed in the other arable and fodder crops, were within normal background levels (Table 4.2). 


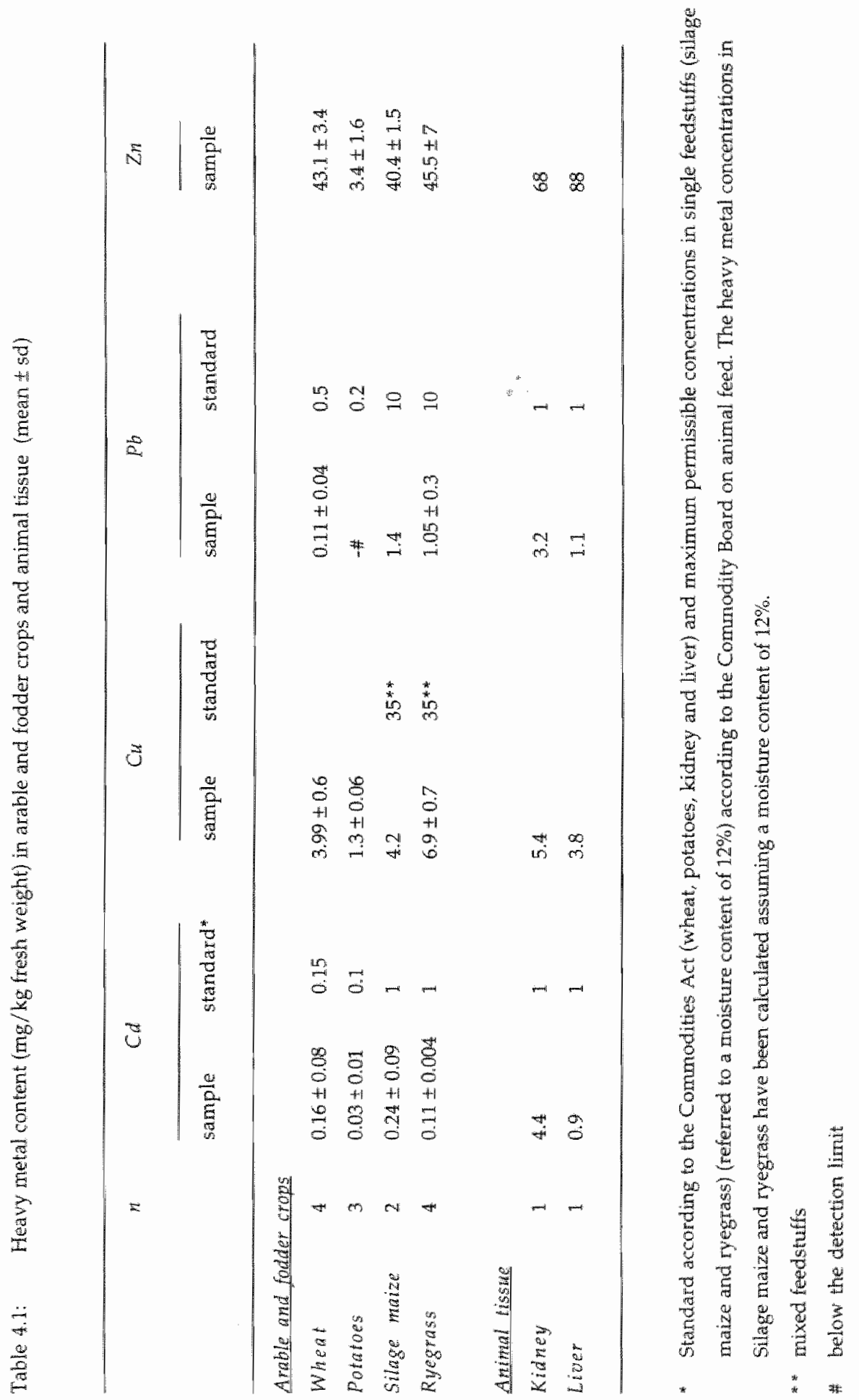


Table 4.2: Background walues for heavy metals in vegetables, arable and fodder crops and animal tissue in The Netherlands ( $\mathrm{mg} / \mathrm{kg}$ fresh weight) (18)

\begin{tabular}{|c|c|c|c|c|}
\hline & $\mathrm{Cd}$ & $\mathrm{Cl}$ & $\mathrm{Pb}$ & $Z n$ \\
\hline \multicolumn{5}{|l|}{ Vegelaties } \\
\hline Lettuce & $0.01-0.19$ & $0.23 \cdot 1.6$ & $0.01-0.03$ & $1.2-4.3$ \\
\hline Potatoes & $0.01-0.09$ & $0.3-2.9$ & $0.01-0.08^{*}$ & 1.9 .11 \\
\hline Beans & 䊁 & $0.3-0.8$ & - & $1.9-10$ \\
\hline \multicolumn{5}{|l|}{ Arable Crops } \\
\hline Whet & $0.01-0.26$ & $1.4-4.5$ & $0.02-0.69$ & $19-41$ \\
\hline Potatoes & $0.01-0.09$ & $0.3-2.9$ & $0.01-0.08^{\mathrm{nt}}$ & $1.9-11$ \\
\hline \multicolumn{5}{|l|}{ Eodder crops } \\
\hline Silage Maize & $0.14-6.8^{*}$ & - & $1.0-4.1^{*}$ & $\infty$ \\
\hline Ryegrass & $0.03-0.84 *$ & " & $0.7-9.1^{*}$ & - \\
\hline \multicolumn{5}{|l|}{ Animal Tissue } \\
\hline Kidney & $0.15-1.4$ & $2.1-6.2$ & $0.04-0.5$ & $11-56$ \\
\hline Liver & $0.04-0.16$ & - & $0.02-0.32$ & - \\
\hline
\end{tabular}

* Wiersma et al (19)

\# no information

Heavy metal levels of vegetable crops cultivated in the experimental gardens, are shown in Table 4.3. No detectable concentrations of $\mathrm{Pb}$ were found in beans and potatoes. In addition, the $\mathrm{Cd}$ level in beans was below the detection limit. The heavy metal concentrations in these crops were also within normal background ranges except for the $\mathrm{Pb}$ and $\mathrm{Zn}$ levels in lettuce, in which samples relatively high levels were observed. Moreover, in one garden located in an area with a flooding frequency of once every two years, the cadmium concentration in lettuce and potatoes exceeded the Commodity Act standard 0.1 $\mathrm{mg} / \mathrm{kg}$ fresh weight). Mann-Whitney $U$ test analysis showed a significant difference between the $\mathrm{Cu}$ content of potatoes and the $\mathrm{Cu}$ content of beans and lettuce. A significantly higher concentration of $\mathrm{Cd}$ was observed in lettuce in comparison to the $\mathrm{Cd}$ content in potatoes. In addition, the $\mathrm{Zn}$ content in lettuce significantly differed from the $\mathrm{Zn}$ content of potatoes and beans (MannWhitney- $U$ test, $\mathrm{p}<0.05)$. 
Table 4.3: Heavy metal content of the vegetables harvested in the experimental gardens on the floodplain of the river Meuse $(\mathrm{mg} / \mathrm{kg}$ fresh weight)

\begin{tabular}{|c|c|c|c|c|c|}
\hline & child & mean & sd & range & $\begin{array}{l}\text { number of samples } \\
\text { exceeding the standard } \\
\text { value }\end{array}$ \\
\hline \multirow[t]{3}{*}{$\mathrm{Ca}$} & lettuce & 0.10 & 0.06 & $0.03-0.21$ & 1 \\
\hline & potatoes & 0.06 & 0.04 & $0.02-0.12$ & 1 \\
\hline & beans & 曲 & - & - & 0 \\
\hline \multirow[t]{3}{*}{$\mathrm{Cu}$} & lettuce & 0.70 & 0.34 & $0.3-1.1$ & \\
\hline & potatoes & 1.45 & 0.11 & $1.36-1.65$ & \\
\hline & beans & 0.71 & 0.36 & $0.3-1.38$ & \\
\hline \multirow[t]{3}{*}{$P b$} & lettuce & 0.10 & 0.03 & $0.04-0.13$ & 0 \\
\hline & potatoes & - & - & - & 0 \\
\hline & beans & - & - & " & 0 \\
\hline \multirow[t]{3}{*}{$Z n$} & lettuce & 6.87 & 1.41 & $5.4-9.1$ & \\
\hline & potatoes & 3.70 & 1.28 & $1.8-6.1$ & \\
\hline & beans & 5.03 & 0.92 & $4.3-6.3$ & \\
\hline
\end{tabular}

\# below the detection limit; the detection limit for $\mathrm{Cd}$ and $\mathrm{Pb}$ in beans is respectively 0.003 and $0.03 \mathrm{mg} / \mathrm{kg}$ fresh weight and for $\mathrm{Pb}$ in potatoes respectively $0.065 \mathrm{mg} / \mathrm{kg}$ fresh weight

From only one cow pastured in the area under study the kidney and liver was analyzed. The results are listed in Table 4.1. The Commodities Act standard was exceeded for $\mathrm{Pb}$ and $\mathrm{Cd}$ in the kidney and also for the $\mathrm{Pb}$ content of the liver. The $\mathrm{Cu}$ content of the animal tissues was within background values, whereas the $\mathrm{Zn}$ content was relatively high compared to background values.

\section{Exposure Assessment}

Human exposure to heavy metals presented in the soil of the floodplain of the river Meuse might occur directly through the ingestion of soll or indirectly through consumption of food of locally grown vegetables and locally produced dairy products and meat products from locally raised farm animals. 
Table 4.4: Calculated heavy metal doses (mg/kg.d) for adults and children, exposed to contaminants in the floodplain soil with an inundation frequency of once every two years.

\begin{tabular}{|c|c|c|c|c|}
\hline & Pathway & Adult & & Child \\
\hline \multirow[t]{6}{*}{$c d$} & $\begin{array}{l}\text { Ingestion of soil } \\
\text { Ingestion of vegetables }\end{array}$ & $0.10 E-5$ & & $0.14 \mathbb{E}-3$ \\
\hline & root vegetables & $0.34 \mathrm{E}-3$ & & $0.72 \mathrm{E} \cdot 3$ \\
\hline & lleafy vegetables* & $0.53 \mathrm{E}-3$ & & $0.77 \mathrm{E}-3$ \\
\hline & legumes & $0.16 \mathrm{E}-7$ & & $0.38 \mathrm{E}-5$ \\
\hline & Tofal* & $0.11 E-2$ & & $0.18 E-2$ \\
\hline & Hozard index & & 1.2 & \\
\hline \multirow[t]{6}{*}{$\mathrm{Cu}$} & $\begin{array}{l}\text { Ingestion of soil } \\
\text { Ingestion of vegetables }\end{array}$ & $0.85 \mathrm{E}-4$ & & $0.12 \mathrm{E}-2$ \\
\hline & root vegetables & $0.44 \mathrm{E}-2$ & & $0.94 \mathbb{E}-2$ \\
\hline & leafy vegetables & $0.24 \mathrm{E}-2$ & & $0.34 \mathrm{E}-2$ \\
\hline & legumes & $0.35 \mathrm{E}-3$ & & $0.85 E-3$ \\
\hline & Total & $0.26 E-1$ & & $0.34 E-1$ \\
\hline & Hazard index & & 0.19 & \\
\hline \multirow[t]{7}{*}{$P b$} & Ingestion of soill & $0.24 \mathrm{E}-3$ & & $0.33 \mathrm{E}-2$ \\
\hline & Ingestion of vegetables. & & & \\
\hline & root vegetables** & $0.18 \mathrm{E}-3$ & & $0.39 E-3$ \\
\hline & leafy vegetables & $0.33 E-3$ & & $0.48 \mathrm{E}-3$ \\
\hline & legumes & $0.16 \mathrm{E}-6$ & & $0.38 \mathrm{E}-4$ \\
\hline & Tolal & $0.10 E-2$ & & $0.44 E-2$ \\
\hline & Hazard index & 0.14 & & 1.2 \\
\hline \multirow[t]{7}{*}{$Z_{n}$} & Ingestion of soll & $0.85 \mathrm{E}-3$ & & $0.12 \mathrm{E}-1$ \\
\hline & Ingestion of vegetables & & & \\
\hline & root vegetables & 0.011 & & 0.024 \\
\hline & leafy vegetables & 0.022 & & 0.033 \\
\hline & legumes & 0.002 & & 0.005 \\
\hline & Toral & 0.22 & & 0.25 \\
\hline & Hazard index & & 0.22 & \\
\hline
\end{tabular}

* including kale and other vegetables

* * for values below the detection limit, the detection limit has been used

* * including background exposure 
The area under study is predominantly an agricultural area. Taken into account background exposure, the TDI for $\mathrm{Pb}$ and $\mathrm{Cd}$ appeared to be exceeded by children at all sample locations. For adults the TDI was exceeded at $65 \%$ of the locations and resulted in a hazard quotient for $\mathrm{Cd}$ varying from 1.4 to 5.5 . Only at one location, the TDI for As and $\mathrm{Zn}$ was exceeded by children; however, the hazard quotient was below 1 . The ingestion of locally produced dairy products and meat products from locally raised farm animals appeared to be the primary source of potential human exposure and accounted for more than $80 \%$ (adults) or $90 \%$ (children) of total human exposure. Table 4.4 summarizes the results of the actual exposure assessment for adults and children exposed to contaminants in the floodplain soil which has a flooding frequency on average of once every two years. Only one experimental garden (no." 1) was located in this area.

The heavy metal concentrations in vegetables cultivated in the other experimental gardens (no, 2-6), were relatively low and the results of the exposure assessment indicate that there was no potential human health risk (data not shown). TDI exceedance for $\mathrm{Cd}$ and $\mathrm{Pb}$ was indicated only for soils with a flooding frequency on average once every two years fexperimental garden 1). The most important exposure pathway for $\mathrm{Cd}$ appeared to be the ingestion of domestically grown vegetables. Specifically for children, a health risk of $\mathrm{Pb}$ was indicated, the main exposure pathway being the direct ingestion of soil.

\section{Discussion}

\section{Soil and flood deposits}

In the area under study, the heavy metal concentrations in the soil of the floodplain of the river Meuse significantly increased with increasing flooding frequency of the river. The area was frequently inundated in the past decades. The results show an enrichment of the floodplain soil by heavy metals predominantly by $\mathrm{Cd}$ and $\mathrm{Zn}$. In general ${ }_{i}$ low levels of $\mathrm{As}$ and $\mathrm{Cu}$ were found in these soils, the concentration of As being comparable to background concentrations in Dutch agricultural clay soils (6). The high standard deviation of the mean (Figure 4.2) illustrates the heterogeneity of the heavy metal concentrations in the soil which is probably related to differences in sedimentation, mineralogy and particle size characteristics as well as nonfluvial supply of heavy metals (6). The measured values were well in agreement with reported literature values $(4,6)$. In comparison to Dutch soil quality guideline values the intervention value for $\mathrm{Zn}$ appeared frequently exceeded.

After our 1994 study, in January 1995 again widespread inundation of the river Meuse occurred. Large parts of The Netherlands, as well as parts of 
Belgitum and northern France became inundated (2). The flood had a longer duration than the flood of December 1993. Settled sediments along the Dutch part of the river after the flooding of the river Meuse in January 1995 were on average of better or equal quality as compared with the situation in 1986, 1988 and 1993 (23). The heavy metal concentrations in settled sediment collected in the area under study were in accordance with the values reported in our study after the flooding of the river during the winter of 1993-1994 (23). Wolterbeek et al (24) have found higher metal concentrations in settled sediment in comparison to the topsoil after the flooding of the river in 1995. However, the higher concentrations in settled sediment did not result in a distinct increase in the metal content of the topsoil.

Heavy metal concentrations in surface water and suspended matter of the river Meuse have decreased during the last decades; however, the chemical quality of the sediment and soils of the floodplain has changed only to a minor degree (1). This means that the quality of the flood deposits of the river Meuse did not change profoundly during the past decades.

Soil characteristics such as $\mathrm{pH}$, organic matter fraction and clay fraction were considered in this study. In general, the $\mathrm{pH}$ of the soil and organic matter of the soil decreased with the decrease of flooding frequency of the calciferous sediments of the river (7). However in this study, no relationship was observed between the soil level of heavy metals and the clay fraction $(<2 \mu \mathrm{m})$ of $(7)$. Relatively low clay fractions were measured in this study (range from 1-3.1\%). This might be due to the high flow velocities in the study area, during the flood. of the river in December 1993. The transport capacity of water at high discharges is large, and erosion of the riverbed and the streambank may result in a large supply of coarse material $(5,6)$. A decrease of flow velocities results in sedimentation of more finer material (23). The topsoil samples collected in this study, immediately after the withdrawal of the flood, might consist of coarse material (e.g. low clay fraction). A positive correlation was demonstrated between the inundation frequency of the river Meuse and the clay fraction in the soil $\left(R_{s}=0.83, p<0.05\right)$. This implies that regularly inundated soils have a lower clay fraction in the soil.

\section{Crops and animal tissue}

Various studies have been conducted to evaluate the heavy metal uptake by plants in relation to soil pollution and to atmospheric deposition on the surface of soils $(6,11,13,15,25-27)$. Variable results are reported. Larsen et al (28) have found elevated concentrations of $\mathrm{Cr}$ and $\mathrm{As}$ in soils and plants around a wood preservation factory in Denmark. Around a $\mathrm{Cd}$ processing factory in Germany very high $C d$ levels have been found in soils and in the banks of the Grumbach brook, which resulted in very high $\mathrm{Cd}$ levels in lettuce, onion and parsley which exceeded the limit values (25). In contrast, Ward and Savage (11) have observed no high values of trace metals in crops located near a motorway in 
London, despite the fact that the $\mathrm{Pb}$ content of the surface soil was significantly increased. In general, the heavy metal concentrations in crops grown on the enriched floodplain soils of the river Meuse are within the range of concentrations found in crops grown on uncontaminated soils, but incidentally high $\mathrm{Cd}$ and $\mathrm{Pb}$ values in crops are observed (7).

Uptake of heavy metals from the soil by plant species is influenced by the physical-chemical characteristics of the soil and the plant species, and can be changed by different environmental and human factors (11-15). For instance, a low $\mathrm{pH}$ of the soil appears to increase the bioavailability of metals and enhances the uptake by plants $(10,28)$. The area under study can be characterized as an agricultural area. In this study, most heavy metal concentrations in various arable and fodder crops grown in the area, were within background values. In general, the relative high $\mathrm{pH}$ of the floodplain soil $(6.9 \pm 0.6)$ reduces the availability of the metals for plant uptake (6). However, relatively high levels of $\mathrm{Cd}$ in wheat were observed in relation to the relatively low $\mathrm{Cd}$ levels in arable soils. An earlier study in 1988 on heavy metals in arable crops grown on the floodplain of the river Meuse has shown similar results and indicated that the $\mathrm{Cd}$ level in wheat may exceed the permissible level of $0.15 \mathrm{mg} / \mathrm{kg}$ fresh weight if the $\mathrm{pH}$ of the corresponding floodplain soil is respectively 7 or lower and the $\mathrm{Cd}$ content of the soil is $1 \mathrm{mg} \mathrm{Cd} / \mathrm{kg} \mathrm{dm}$ or higher (6). In this study, 2 samples of wheat exceeded the permissible levels. The Cd level in the soil was respectively $1.1 \mathrm{mg} / \mathrm{kg}$ and $4.4 \mathrm{mg} / \mathrm{kg} \mathrm{dm}$ and the $\mathrm{pH}$ of the soil was respectively 5.5 and 7.3 .

Our results confirm that the relative uptake of heavy metals differs between vegetables crops (13). In the experimental gardens the highest concentrations of $\mathrm{Cd}, \mathrm{Pb}$ and $\mathrm{Zn}$ were found in lettuce, whereas for $\mathrm{Cu}$ the highest concentrations were observed in potatoes. Lettuce and potatoes cultivated on a soil with an inundation frequency of on average once every two years, exceeded Commodities Act standards. In the other experimental gardens the heavy metal contents of the vegetables were within background values (18). In a few cases a significant correlation was observed between the metal uptake by the plant and the metal content in the soil. The $\mathrm{Cd}$ levels in lettuce and potatoes and the $\mathrm{Zn}$ levels in lettuce were significantly correlated to the $\mathrm{Cd}$ and $\mathrm{Zn}$ levels in the soil (Spearman rank correlation coefficient, $\mathrm{p}<0.05$ ). However, due to the limited number of experimental gardens no relation could be assessed between the metal levels in vegetables and different soil factors such as pH, organic matter and clay fraction.

The bioconcentration factor (BCF) is widely used in modeling human exposure in relation to ingestion of vegetables via the soil-plant-human pathway $(9,10,29,30)$. The BCF is defined by the equilibrium concentration of the pollutant in plant tissue (dry weight) divided by the equilibrium concentration of the pollutant in the soil on a dry weight basis. As expected, the highest $B C F$ values were observed for lettuce. The $\mathrm{BCF}$ values ranged from 0.28 to 0.98 for $\mathrm{Cd}$, from 0.14 to 0.54 for $\mathrm{Cu}$, from 0.001 to 0.016 for $\mathrm{Pb}$ and from 0.14 to 0.26 for 
$\mathrm{Zn}$. Moreover, the highest $\mathrm{BCF}$ value for potatoes and beans was found for $\mathrm{Cu}$. The mean $\mathrm{BCF}$ of $\mathrm{Cu}$ was respectively $0.14 \pm 0.065$ and $0.116 \pm 0.06$ for potatoes and beans.

Incidentally, the heavy metal content of tissue samples from cows living in the Meuse valley has been evaluated. Since the flooding of the river in 1980 high $\mathrm{As}, \mathrm{Cd}$ and $\mathrm{Pb}$ levels have been reported in fodder crops. However, the $\mathrm{Cd}$, $\mathrm{Pb}$ and $\mathrm{As}$ content in kidney and liver appeared not elevated. In the present study, in one cow the heavy metal content was analyzed. The results showed a higher $\mathrm{Cd}$ and $\mathrm{Pb}$ concentration in the kidney than in the liver, which has also been reported by others $(31,32)$. The $\mathrm{Cd}$ and $\mathrm{Pb}$ concentration in the kidney and the $\mathrm{Pb}$ concentration in the liver exceeded the permissible level according to the Commodities Act.

\section{Exposure assessment}

The results of the exposure risk assessment showed that the $\mathrm{Pb}$ and $\mathrm{Cd}$ contaminations of the floodplain soil of the river Meuse presented a health hazard if the exposure was calculated by the HESP model taking the exposure pathways in relation to the agricultural function of the floodplain soils into account. The total human exposure was dominated by the ingestion of locally raised meat and dairy products. However, with respect to our study area, it is questionable whether locally produced dairy and meat products were locally distributed.

In using food-chain exposure models, one has to be aware of the uncertainties which are inherent to the model parameters $(9,10,29,30)$. McKone and Ryan (10) have performed an uncertainty analysis of a food-chain model in relation to As and TCDD exposure, and have found that the overall uncertainty in exposure is due to the uncertainty in biotransfer factors which limits the precision of food-chain exposure prediction to a $90 \%$ confidence range of roughly two orders of magnitude. By contrast, validation of the EPA food-chain model based on background concentrations in air, water and soil by Travis and Blayblock (30) has indicated that the predicted total human exposure to contaminants in the food-chain is within a factor of two of the measured exposure in market basket studies. However, the distribution of exposure in the population (variability) has not been assessed. McKone (9) indicates that both uncertainty and variability have to be taken into account to estimate the overall variance in the prediction of exposure. For instance, biotransfer factors (from soil-to-plant) can be seen as uncertain, whereas the daily vegetable intake is characterized by variability, which also may have an important influence on the variance of total exposure (29).

The concentration in the plant depends on two processes: uptake through the roots with subsequent internal transport, and deposition of dust on the leaves and subsequent uptake (8). BCF factors are used to estimate the uptake 
through the root and the subsequent internal transport. In this study, the uncertainty in soil-plant transfer factors was reduced by measuring the heavy metal content ratios in root and leafy vegetables. The default BCF values for $\mathrm{Cd}$ (BCF-leafy vegetables) and $\mathrm{Cu}$ (BCF-root vegetables) used in the HESP model, were within the range of the calculated BCF on basis of the heavy metal content in the vegetables (dry weight) cultivated in the experimental. gardens. For the other heavy metals, the calculated BCFs for leafy vegetables as well as root vegetables were remarkably lower. An exception was $\mathrm{Cu}$ (leafy vegetables) for which the calculated BCF values were higher. Ratios of the predicted (on basis of the default BCF value) versus measured heavy metal content in leafy vegetables were respectively $3.5 ; 1.2 ; 6.6$ and 4.2 for $\mathrm{Cd}, \mathrm{Cu}, \mathrm{Pb}$ and $\mathrm{Zn}$. The ratio for root vegetables was $2.7 ; 0.8$ and 3.5 for respectively $\mathrm{Cd}, \mathrm{Cu}$ and $\mathrm{Zn}$. This implies that by using the HESP model, human exposure through the ingestion of vegetables was overestimated by $70 \%$ for respectively $\mathrm{Cd}, \mathrm{Pb}$ and $\mathrm{Zn}$ and underestimated by $27 \%$ for $\mathrm{Cu}$.

An assessment of human exposure risks based on actually measured contaminant concentrations in locally grown vegetables, and on the direct ingestion of soil indicated a possible health hazard for $\mathrm{Cd}$ and $\mathrm{Pb}$ (only for children) for soils which become inundated on average once every two years. The calculation suggested that under certain circumstances consumption of home grown vegetables might be a major contribution to total $\mathrm{Cd}$ exposure. The calculations were based on average crop consumption rates of the home gardeners population in The Netherlands (21). In the experimental gardens, lettuce, potatoes and beans were grown as representative crops cultivated in domestic gardens. $93 \%, 67 \%$ and $98 \%$ of the home-gardeners in The Netherlands grow respectively lettuce, potatoes and beans. No insight in the variability of the consumption rate of domestically grown vegetables in the area under study was available. The exposure calculation was based on the worstcase assumption that all vegetables consumed were home-grown and that the consumption of any group was fixed in relation to the other groups. However, the actual consumption of home-grown leafy vegetables, potatoes and legumes appears to be on average respectively $57 \%, 12 \%$ and $22 \%$ for the home-gardeners population in The Netherlands (21). Taken into account these percentages, the calculated $\mathrm{Cd}$ exposure in relation to soil contamination of the floodplain with an inundation frequency of once every two years appeared to be decreased and resulted in an hazard quotient of 0.24 .

Muller et al (25) have investigated the relationship between high $\mathrm{Cd}$ levels in soil and plants and the Cd levels in hair, blood and urine of people living in a contaminated area in Germany. The values are within normal range, suggesting that exposure through the consumption of home grown vegetables may be excluded. By contrast, Staessen et al (33) have found that $2-4 \%$ of the variance in long term body burden of $\mathrm{Cd}$ is due to the consumption of vegetables grown in domestic gardens on sandy acidic soils, implying that the 
ingestion of locally grown vegetables is an important source for human $\mathrm{Cd}$ exposure.

In summary, although the soils of the floodplain of the river Meuse appeared to be enriched with heavy metals, the heavy metal content in crops grown on these soils were within normal background values. Incidentally, high $\mathrm{Cd}$ values were observed in wheat, lettuce and potatoes. The human health risk associated with the heavy metal contamination of the soil and indirectly of the food-chain, seemed very low. The most important exposure risks were associated with $\mathrm{Cd}$ and $\mathrm{Pb}$ levels in soils which have a flooding frequency of once every two years. In the case of $\mathrm{Pb}$ the most important pathway was the ingestion of soil. However, for $\mathrm{Cd}$ the ingestion of locally grown vegetables was the predominant pathway.

In general, the applied exposure model can serve as an assessment tool, to identify the critical exposure pathways in situations of soil pollution. However, the results of this study suggest that current exposure assessment models are likely to both over- and underestimate exposure through the ingestion of vegetables to a considerable degree. Therefore, location-specific data are necessary to calculate actual human exposure through the ingestion of vegetables.

\section{References}

1. Ploco SS. Using modular planning and modular modeling towards sound water quality management of the river Meuse. European water pollution control 5:6: 41-50; 1995.

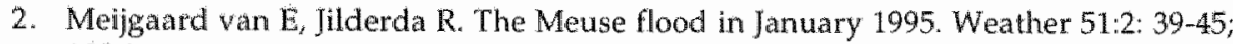
1996.

3. Ven van de G. The Netherlands and its rivers. Tijdschrift voor Economische en Sociale Geografie 87:4: 364-370; 1996.

4. Delft Hydraulics. Survey after the flooding disaster of the river Meuse. Delft: The Netherlands, 1994 (in Dutch).

5. Leenaers $\mathrm{H}$, Schouten Cl. Rang MC. Variability of the metal content of flood deposits. Environ Geol Watter Sci 11:1: 95 106; 1988 .

6. Institute for soil fertility. Research group heavy metals in river bank soils of the Meuse and tributaries. Heavy metal concentrations in river bank soils and corresponding crops in the Meuse, Geul and Roer basin in the Province of Limburg. Haren: The Netherlands; 1987-1988 (in Dutch).

7. Micha JC, Borlee MC. Recent historical changes on the Belgian Meuse. In: Historical change of large alluvial rivers: Western Europe, (Petts GE, Moeller H, Rouse AL. eds) John Wiley: 269-293; 1989. 
8. Veerkamp W. Berge ten W. Human exposure to soil pollutants (HESP). Shell Internationale Petroleum Maatschappij b.v. The Hague: The Netherlands; 1994.

9. McKone TE. Uncertainty and variability in human exposure to soil contaminants through home-grown food: A Monte Carlo Assessment. Risk Analysis 14:4: 449$463 ; 1994$.

10. McKone TE, Ryan PB. Human exposures to chemicals through food-chains: An uncertainty analysis. Environ Sci Technol 23: 1154-1163; 1989.

11. Ward NI, Savage JM. Metal dispersion and transportational activities using food crops as biomonitors. The science of the total environment 146/147:309-319; 1994 .

12. Haghiri F. Plant uptake of cadmium as influenced by cation exchange capacity, organic matter, zinc and soil temperature. J Environ Quality $3: 2: 180-183 ; 1974$.

13. Haghiri F. Cadmium uptake by plants. J Environ Quality 2:1: 93-96; 1973.

14. Abdel-Sabour MF, Mortvedt IJ, Kelsoe II. Cadmium-zinc interactions in plants and extractable cadmium and zinc fractions in soil. Soil Science $145: 6: 424-431 ; 1988$.

15. Voutsa D, Grimanis A, Samara $\mathbb{C}$. Trace lements in vegetables grown in an industrial area in relation to soil and air particulate matter. Environmental Pollution 94: $3: 325-335 ; 1996$.

16. Berg, van den $\mathbb{R}$, Denneman CAI, Roels IM. Risk assessment of contaminated soil: Proposals for adjusted, toxicologically based Dutch soil clean-up criteria. In: Contaminated soil 93. (Arendt F, Annokkée Gl, Bosman R, Brink van den WJ. eds) Amsterdam, The Netherlands: 349-364; 1993.

17. Commodities Act; Regulation of heavy metals. Rijswijk: The Netherlands; 1985.

18. Staarink T. Hakkenbrak P. Book of contaminants. Commodity inspection department. Rijswijk: The Netherlands; 1991 (in Dutch).

19. Wiersma D, Goor wan BI, Veen van der NG. Cadmium, Lead, Mercury and Arsenic Concentrations in crops and corresponding soils in The Netherlands. J Agric Food Chem 34:1067-1074; 1986.

20. Animal feed act. Product board animal feed. The Hague: The Netherlands, 1988.

21. Hulsh of PIM. Vegetable consumption rate by home-gardeners. Inspectorate for health care. Rijswijk: The Netherlands; 1988 (in Dutch).

22. Bowers TS, Beck B., Karam HS. Assessing the relationship between enwironmental lead concentrations and adult blood lead levels. Risk Analysis 14:2: 183-189; 1994.

23. Hoogewerf MR, Hout wan HRA. Sampling of the flood deposits of the river Meuse 1995. Public Works and Water Management Directorate Limburg. CSO, Burnik: The Netherlands; 1995 (in Dutch).

24. Wolterbeek HTh, Verburg TG, Meerten van "ThG. On the 1995 Hooding of the rivers Meuse, Rhine and Waal in The Netherlands: metal concentrations in deposited river sediments. Geoderma 71:143-156; 1996.

25. Müller $M$, Anke M. Distribution of cadmium in the food-chain (soil-plant-human) of a cadmium exposed area and the health risks of the general population. The science of the total enviromment $156: 252-258 ; 1994$.

26. Davies BE. Plant-avallable lead and other metals in British garden soils. The science of the total environment 9:243-262;1978.

27. Larsen EH, Moseholm L. Nielsen M. Atmospheric deposition of trace elements around point sources and human health risk assessment. II: Uptake of arsenic and chromium by vegetables grown near a wood preservation factory. The science of the total environment 126: 263-275; 1992. 
28. Garcia WJ, Blessin CW, Inglett GE, Kwolek W, Carlisle JN, Hughes LN, Meister IF. Metal accumulation and crop yield for a variety of edible crops grown in diverse soil media amended with sewage sludge. Environmental Science and Technology 15:7: 793-804; 1981.

29. Stern AH. Monte Carlo analysis of the U.S. EPA model of human exposure to cadmium in sewage sludge through consumption of garden crops. Journal of Exposure Analysis and Environmental Epidemiology. 3:4: 449-469; 1993.

30. Travis CC, Blaylock BP. Validation of a terrestrial food-chain model. Journal of exposure analysis and environmental epidemiology $2: 2: 221-239 ; 1992$.

31. Ven van de WSM, Gebend J, Driel van W, Goejy de IJM, Tjioe PS, Holzhowwer C, Verweij JHP. Trace elements in cows grazing on the forelands of the river Rhine and Issel. Land bouwkundig Tijdschrift 89: 262-269; 1977.

32. Vreman $K$, Veen van der $\mathbb{N G}$, Molen van der El, Ruig de WG. Transfer of cadmium, lead mercury and arsenic from feed into milk and various tissues of dairy cows: chemical and pathological data. Netherlands Journal of Agricultural Science 34: 129$144 ; 1986$.

33. Staessen JA, Vyncke G, Lauwerijs RR, Roels HA, Celis HG, Claeys F, Dondeyne F, Fagard RH, Ide G, Lijnen PJ, Rondia D, Sartor F, Thijs LB, Amery AK. Transfer of cadmium from a sandy acidic soil to man: a poptilation study. Environmental Research 58: 24-34; 1992. 


\title{
Chapter 5
}

\section{Human health risk assessment in relation to environmental pollution in two artificial freshwater lakes in The Netherlands}

\author{
H.J. Albering, J-P. Rila, E.J.C. Moonen, J.A. Hoogewerff ${ }^{1}$ and J.C.S. Kleinjans
}

Department of Fealth Risk Analysis and Toxicology, Maastricht University, Maastricht, The Netherlands. ${ }^{1}$ Geotechnical Institute, OeFPZ Arsenal, Vienna, Austria

Subnitted for publication

\begin{abstract}
A human health risk assessment has been performed in relation to recreational activities on two artificial freshwater lakes along the river Meuse in The Netherlands. Although the discharges of contaminants into the river Meuse have been reduced in the last decades, which is reflected in decreasing concentrations of pollutants in surface water and suspended matter, the levels in sediments are more persistent. Sediments of the two freshwater lakes appear highly polluted and may pose a health risk in relation to recreational activities. To quantify health risks for carcinogenic (e.g. PAHs) as well as noncarcinogenic (e.g. heavy metals) compounds, an exposure assessment model has been used. First, a standard scenario has been applied which solely uses data on sediment contamination as input parameter. After modeling this standard scenario, the highest intake is associated with the consumption of contaminated fish, and results in a health risk for $\mathrm{Pb}$ and $\mathrm{Zn}$ (hazard index exceeds 1). For the other heavy metals and for $B($ a $) P$, the total averaged exposure levels are below levels of concern. Secondly, input data for a more location specific callculation procedure have been provided via analyses of samples from sediment, surface water and suspended matter. When these data (concentrations in surface water) were taken into account, the risk due to consumption of contaminated fish decreased by more than two orders of magnitude and appeared to be negligible. In both scenarios, many assumptions have to be made which contribute to a major degree to the uncertainty of this risk assessment. However, this health risk evaluation is useful as a screening methodology for assessing the urgency of sediment remediation actions.
\end{abstract}

\section{Introduction}

The river Meuse is located in the north-western part of Europe and flows through three countries. It arises in France, proceeds through Belgium and has its entrance into the North Sea in The Netherlands. The river Meuse is a pluvial river, characterized by low base flows in summer and relatively high peak flows in winter. 
The river responds very fastly to rainfall in its catchment area. High peak flows may result in flooding of the river, which is mainly due to the geomorphological composition of the river system. The river Meuse has many important functions, e.g. drinking water supply, water supply for industry and agriculture, shipping, power generation, recreation and sustaining the ecological value $(1,2)$. Furthermore, by excavation of minerals, e.g., gravel and sand, artificial freshwater lakes have been created allong the river. These lakes are mainly situated in The Netherlands; some are in open connection with the river, others are disconnected.

The river Meuse basin is contaminated by different pollutants, both of organic and inorganic nature. The most problematic are heavy metals, some organic micropollutants in relation with suspended matter, (PCBs, PAHs and pesticides), nitrogen and phosphorus compounds, fluorides, cyanides and chlorides $(1,3,4)$. Only a small amount originates from natural processes like weathering and erosion (5). For many metals and also for PAHs, emissions from antropogenic sources exceed natural sources by far (5-8). Communal waste water and discharges by industry are major antropogenic sources but probably most important is diffuse pollution, resulting from atmospheric deposition, shipping, river bank protection, road traffic and agriculture.

In general, monitoring data on the river Meuse generated by the Association of Rhine and Meuse water supply companies, indicate an improvement of the water quality over the last decades, in particular over the period 1974-1982/1983 (9). However, concentrations of various compounds still exceed Dutch and EC Guidelines for drinking water quality, and the Dutch Guideline for general environmental water quality. In river water, compounds like PAHs, PCBs, pesticides and heavy metals, are primarily adsorbed to suspended matter and consequently, to the sediments. The concentrations of these compounds in suspended matter have also decreased over the last decades, although these still do not comply with the Dutch guidelines yet (1). By contrast, the chemical quality of the sediments has changed only to a minor extent.

The water quality of the river Meuse may influence the environmental quality of the artificial lakes along the river Meuse. Generally, in lake sediments, the suspended matter/sediment is stored as a result of a significant decrease in velocity at the point of inflow into the lake, and furthermore, by the large water storage capacity relative to the inflow rate. The fine-grained suspended matter/sediment deposits in the deeper water region (5). Furthermore, as a result of high flow rates in the river, and consequently of the floodings, sediments may accumulate in the lakes. In 1989, various connected as well as disconnected lakes have been investigated. Of the 15 lakes investigated, in 8 lakes the sediments were highly contaminated by heavy metals (e.g. Ni, Cd, $\mathrm{Zn}, \mathrm{Cu}$ and $\mathrm{As}$ ) and organic micro-pollutants (e.g. PCBs and PAHs) (10). Additionally, the EC Guideline for bathing water quality $(76 / 160 / \mathrm{EEC})$ was 
frequently exceeded in these artificial lakes. These guidelines are based on

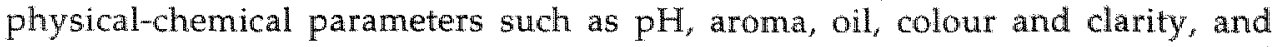
bacteriological parameters such as thermotolerant coliforms and faecal streptococci. Mainly, standards for clarity and $\mathrm{pH}$ were exceeded.

The artificial lakes along the river Meuse are increasingly used for recreational purposes. Within this respect, the pollution levels of these lakes may pose a risk to human health. During recreational activities, human exposure may occur via three different pathways: ingestion, inhalation and dermal contact. Dermal contact includes direct contact of the skin with contaminated sediments, with riverbank soils, or with water. Ingestion occurs through contaminated sediment, surface water during swimming and via consumption of fish (11). Inhalation of contaminants volatilized from surface water and sediment, may also occur. However, this pathway is of minor importance in relation to recreational activities $(12,13)$. In general, only a few studies, predominantly conducted in the area of the U.S. Great Lakes, have been performed to estimate human health risks in relation to recreational activities on freshwater lakes (12-17). Various studies have estimated health risks in relation to fish consumption from different lakes $(12,18-21)$. Recreational or subsistence anglers may be at higher risk since they probably consume more fish and consequently fish contaminants, than the general population (12). Next to ingestion of fish, the dermal route represents an important exposure pathway, in particular for organic compounds like DDT and most of the PAHs $(11,13,22)$.

This report describes a human health risk assessment as a function of recreational activities in relation to environmental pollution (e.g. by the heavy metals $\mathrm{As}, \mathrm{Cd}, \mathrm{Cu}, \mathrm{Pb}$ and $\mathrm{Zn}$, and 16 EPA-listed PAHs) of two artificial freshwater lakes, one connected to the river Meuse and the other nowadays disconnected from the river. Input data for the risk assessment model were derived from measurements of samples of sediments, surface water and suspended matter. An existing exposure assessment model, SEDISOIL, has been used to calculate human health risk (11). This model incorporates all relevant exposure pathways and is based on an exposure model to quantify health risk in relation to contaminated soils; it is currently used by the Dutch government as a guidance model to determine the urgency of remediation of sediment pollution. Two different model scenarios have been used to estimate the risks in relation to recreational activities; the standard scenario which is based on sediment concentrations of relevant pollutants, and a location-specific scenario which incorporates actual measurements performed in the present study in suspended matter and surface water to replace some default assumptions. In addition, the measured concentrations of contaminants in sediment in both lakes are compared to the previous study performed in 1989, and the differences between the lakes in relation to the connection of the river Meuse are discussed. 


\section{Methods}

\section{Study area}

The location of the study area is shown in Figure 5.1. The artificial freshwater lake Eijsden actually is a branch of the river Meuse. The Dilkensplas is an artificial freshwater lake which is nowadays disconnected from the river. By the mid 1960 s at the beginning of the enclosure works the lake has been in an open connection to the river, in view of various transport activities of the excavated materials. Since 1974/1975, no further enclosure works have been performed, but the lake was still connected to the river via a channel. By the mid 1980 s the lake was disconnected from the river Meuse. At present, during high flow rates and consequently by the flooding of the river, polluted river sediment may still enter the lake. The maximum depth of the lake Dilkensplas is $14 \mathrm{~m}$ and the surface area is 14.8 ha. The surface area of lake Eijsden is about 156 ha. The mean depth of this lake is $6 \mathrm{~m}$, with a maximum of $8 \mathrm{~m}$. The lake exists for ca 20 years, and unti] 1995 , enclosure works have been executed in a small part of the lake (23). Various recreational activities take place at both lakes. At the lake Eijsden, various beaches and swimming areas exist, and the lake is used by boaters and windsurfers and by recreational anglers. Yacht clubs and campingsites are located around the lake. Swimming, windsurfing and fishing are the recreational activities occurring at the lake Dilkensplas where also a campingsite is located. In summex time, 2000 to 5000 people visit the lake Eijsden and about 500 people visit the lake Dilkensplas. Furthermore, both lakes are eutrophic and have an ecological function (23).

\section{Sampling}

Sediment samples (top $10 \mathrm{~cm}$ ) were collected in the spring of 1995 at the beach zone and from a boat at deeper parts of the lakes by a Van Veen grab. At each sample location, within $1 \mathrm{~m}^{2}$ three subsamples were taken and homogenized. A total of 27 sediment samples was collected from the freshwater lake Eijsden and 16 samples from lake Dilkensplas. The homogenized samples were stored in clean polyethylene jars (2 L). Upon arriving at the laboratory, the sediment samples were separated into subsamples for the respective pretreatment procedures.

The surface water samples were taken at the same location as the sediment samples. Polyethylene bottles $(100 \mathrm{ml})$ were previously cleaned with diluted nitric acid $(5 \%)$ and before sampling, the jars were rinsed with surface water. Water samples were acidified to $\mathrm{pH}<2$ with concentrated nitric acid and centrifuged for $15 \mathrm{~min}$. at $2500 \mathrm{rpm}$. The samples were stored at $4{ }^{\circ} \mathrm{C}$ for further analysis. 


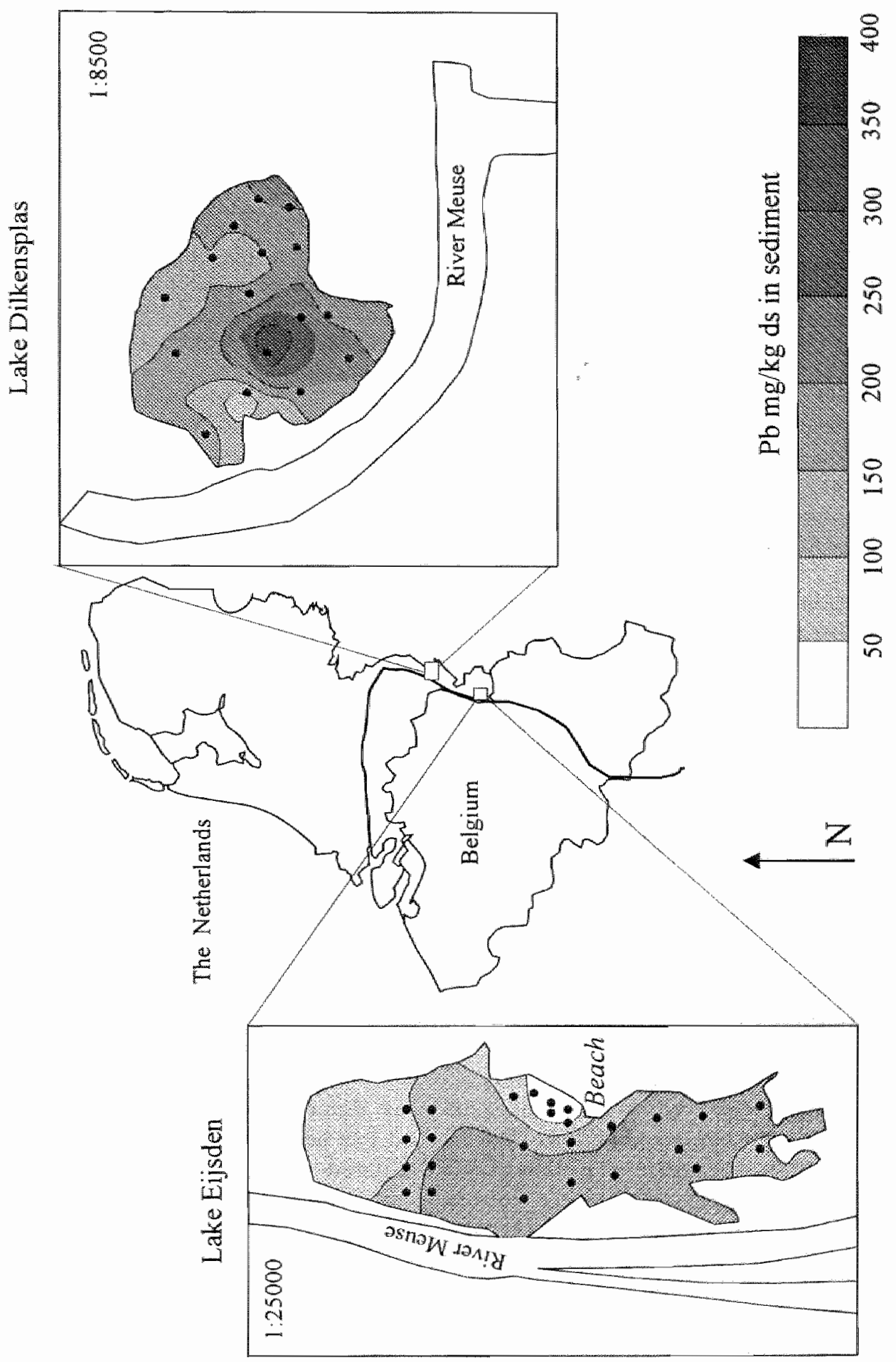

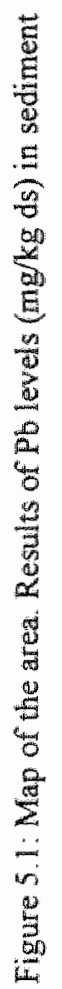


Collection of suspended matter was only performed at the beach zone of the freshwater lakes. Suspended matter was sampled using polyethylene buckets. 5 $L$ of surface water were collected. The suspended matter precipitated and the water layer was filtered. In order to concentrate the amount of suspended matter, this procedure was repeated. In total, $50 \mathrm{~L}$ of surface water were sampled (10 buckets per site).

The concentrated samples were stored in clean polyethylene jars $(2 \mathrm{~L})$. Samples were centriluged for $15 \mathrm{~min}$. at $3000 \mathrm{rpm}$. The supernatant was removed after which the residue was evaporated under nitrogen.

\section{Chemical Analysis}

Heavy metals

The sediment samples were dried at $105^{\circ} \mathrm{C}$, sieved $(2 \mathrm{~mm})$ and subsequently grounded in an agate mortar. From each dried sample collected at two different zones at lake Eijsden (beach zone and total lake) and lake Dilkensplas, $30 \mathrm{~g}$ of dried sediment were taken, bulked and successively passed through different sieves. The sediment and suspended matter samples $(0.5 \mathrm{~g})$ were boiled under reflux for $2.5 \mathrm{~h}$ in Aqua Regia and then filltrated. The $\mathrm{Cd}-, \mathrm{Cu}$ - and $\mathrm{Pb}-$ concentrations in sediment, suspended matter and water were measured by graphite furnace atomic absorption spectrometry with Zeeman background correction, the $\mathrm{Zn}$ concentration being determined by flame atomic absorption spectometry. Determination of the arsenic content in water samples was performed by atomic absorption spectrometry applying the hydride generation technique. The As-content of sediments and suspended matter was also determined by graphite furnace atomic absorption spectrometry with Zeeman background correction.

The detection limit of heavy metals in sediment/suspended matter was 0.18 $\mathrm{mg} / \mathrm{kg} \mathrm{dw}$ for $\mathrm{As}, 0.02 \mathrm{mg} / \mathrm{kg} \mathrm{dw}$ for $\mathrm{Cd}, 0.36 \mathrm{mg} / \mathrm{kg}$ dw for $\mathrm{Cu}, 0.48 \mathrm{mg} / \mathrm{kg}$ $\mathrm{d} w$ for $\mathrm{Pb}$ and $7.8 \mathrm{mg} / \mathrm{kg} \mathrm{dw}$ for $\mathrm{Zn}$. The detection limits in water were estimated to be $0.9 \mu \mathrm{g} / \mathrm{l}, 0.1 \mu \mathrm{g} / \mathrm{l}, 1.8 \mu \mathrm{g} / 1,2.4 \mu \mathrm{g} / 1$ and $3.9 \mu \mathrm{g} / 1$ for respectively $\mathrm{As}, \mathrm{Cd}, \mathrm{Cu}, \mathrm{Pb}$ and $\mathrm{Zn}$.

To prevent contamination, all used glass and plastic labware was previously washed in diluted nitric acid and deionized water.

\section{Polycyclic aromatic hydrocarbons (PAHs)}

The PAH concentration of the sediments was determined by a method described by Schilderman et al. (24). The method has been partly modified to quantify PAFts in sediments. The 16 EPA-listed PAHs (naphthalene, acenaphthylene, acenaphthene, fluorene, phenanthrene, anthracene, fluoranthene, pyrene, benzo(a)anthracene, chrysene, benzo(b)fluoranthene, benzo(k)fluoranthene, benzo(a)pyrene, benzo $(g, h, i)$ pyrene, dibenzo $(a, h)$ anthracene and indeno $(1,2,3-c, d)$ pyrene) were measured except for 
acenaphthylene which cannot be measured by fluorescence detection. Briefly, after filtration of the water layer, the wet sediment $(10 \mathrm{~g})$ was mixed with a suitable amount of anhydrous $\mathrm{Na}_{2} \mathrm{SO}_{4}$ and extracted with petroleum ether (40$60^{\circ} \mathrm{C}, 120 \mathrm{ml}$ ) in a soxhlet apparatus for $4 \mathrm{~h}$. The extract was concentrated under reduced pressure on a rotary evaporator at $45^{\circ} \mathrm{C}$ to $\mathrm{ca} 50 \mathrm{ml}$ after which petrolleum ether was added to a total of $100 \mathrm{ml}$. From this extract, $0.5 \mathrm{ml}$ was dissolved in $1 \mathrm{ml}$ acetonitrile and concentrated under nitrogen until the upper polyethylene layer was evaporated, and analyzed by high performance liquid chromatography with fluorescence detection. The PAH concentration was quantified by comparison with selected standards. The detection limit of the individual PAHs in sediment was $8 \mu \mathrm{g} / \mathrm{kg} \mathrm{dw}$.

Soil characteristics

All sediment samples were analyzed for organic matter as loss on ignition by $550^{\circ} \mathrm{C}$ for $4 \mathrm{~h}$. The clay content of the sediment (particulate fraction $<2 \mu \mathrm{m}$ ) was determined in 7 samples at both artificial lakes. The samples were treated with $\mathrm{H}_{2} \mathrm{O}_{2}$ and $\mathrm{HCl}$, and subsequently sieved over a $38 \mu \mathrm{m}$ sieve, after which the fraction $(<2 \mu \mathrm{m})$ was separated by settling technique.

\section{Risk assessment}

For quantification of exposure in relation to sediment contamination by heavy metals and PAHs, a multiple pathway exposure model (SEDISOIL) was used (11). The model has been developed by the National Institute of Public Health and Environmental Protection in Bilthoven, and includes six exposure routes: the ingestion of sediment, surface water including suspended matter, dermal contact via surface water and sediment, and fish consumption. The following equations are incorporated into the model to calculate total exposure: 
Lngestion of contaminated sediment ( $\mathrm{mg} / \mathrm{kg}$.day)

Eq: 1

$=\operatorname{CS} \times M \times E F \times A F$

$B W$

Ingestion of surface water ( $\mathrm{mg} / \mathrm{kg}$.day)

$\mathrm{Eq}: 2$

$=$ CW $\times \mathbb{R} \times E E \times A E$

$B W$

Ingestion of suspended material ( $\mathrm{mg} / \mathrm{kg}$.day)

Eq: 3

$=\mathrm{CM} \times \mathrm{CMW} \times \mathrm{IR} \times \mathrm{EF} \times \mathrm{AF}$

$B W$

Dermal contact with contaminated sediment (mg/ $\mathrm{kg}$.dlay)

Eq: 4

$=\quad C S \times S A \times A D \times A S \times M \times E D \times E F \times A F$

$B W$

Dermal contact with contaminated surface water $(\mathrm{mg} / \mathrm{kg}$ day)

Eq: 5

$=\quad C W \times S A \times A S \times E F \times A E \times E D$

$B W$

Ingestion of fish ( $\mathrm{mg} / \mathrm{kg}$ day)

Eq: 6

$=$ CFXIR $\times$ FIXAF

$\mathrm{BW}$

in which:

$\mathrm{CS}=$ concentration of the contaminant in sediment ( $\mathrm{mg} / \mathrm{kg} \mathrm{dw}$ )

$\mathrm{CM}=$ concentration of the contaminant in suspended matter $(\mathrm{mg} / \mathrm{kg} \mathrm{dw}$ )

CMW $=$ suspended matter content of surface water $(\mathrm{kg} / \mathrm{l})$

$\mathrm{CW}=$ concentration of the contaminant in surface water $(\mathrm{mg} / \mathrm{l})$

$C F=$ concentration of the contaminant in fish $(\mathrm{mg} / \mathrm{kg} \mathrm{fw})$

IR = ingestion rate of surface water (I/exposure day); ingestion rate of sediment

(mg/kg dw);

ingestion rate of fish $(\mathrm{kg} \mathrm{fw} /$ day)

$\mathrm{SA}=$ dermal surface area exposed to the contaminant $\left(\mathrm{m}^{2}\right)$

$A D=$ dermal adherence rate for sediment $\left(\mathrm{mg} / \mathrm{cm}^{2}\right)$

AS = dermal absorption rate $(1 / h)$

$\mathrm{ASW}=$ dermal absorption tate from water $\left[\left(\mathrm{mg}^{2} / \mathrm{m}^{2}\right) /(\mathrm{mg} / 1) / \mathrm{h}\right]$

$M$ matrix factor (unitless)

$\mathrm{EF}=$ exposure frequency (days/year)

$\mathrm{BD}=$ exposure duration $(\mathrm{h} / \mathrm{d})$

FI = fraction contaminated (unitless)

AF = absorption factor (unitless)

$\mathrm{BW}=$ body weight $(\mathrm{kg})$

The default parameters which have been used in the health risk assessment, are presented in Table 5.1.

The standard scenario as described above is in current use by the Dutch government; it uses data on sediment pollution as input. The concentrations of contaminants in surface water and suspended matter are derived from these sediment concentrations by application of known equilibrium partitioning 
coefficients ( $\mathrm{K}$ d values). For heavy metals, the concentration ratio between suspended matter and sediment is 1.5 and for organic compounds 2.0 (11). For the location specific scenario developed in the present study, data on heavy metal concentrations (mean values) from surface water and suspended matter (only lake Eijsden) were directly used to calculate total average exposure.

In general, amounts on sampled suspended matter were insufficient for measuring reliably its PAHs contents, which implies that for PAH exposure assessment, solely the standard scenario could be applied. For both scenarios, exposure via individual pathways as well as total exposure have been calculated for both children and adults.

Table 5.1: $\quad$ Parameters used in SEDISOIL (11)

\begin{tabular}{|c|c|c|}
\hline Parameter & Child & Adult \\
\hline \multicolumn{3}{|l|}{ Eq 1: sediment ingestion } \\
\hline Ingestion rate (IR) (kg dw/exposure day) & $10^{-3}$ & $0.35 * 10^{-3}$ \\
\hline Absorption factor (AF) (unitless) & 1 & 1 \\
\hline Exposure frequency (days/year) & 30 & 30 \\
\hline body weight (BW) (kg) & 15 & 70 \\
\hline \multicolumn{3}{|c|}{$\mathrm{Eq} 2$ : ingestion of surface water $+\mathrm{Eq} 3$ ingestion of suspended material } \\
\hline Ingestion rate (IR) (1/exposure day) & $0^{*} 10^{-3}$ & $50^{*} 10^{-3}$ \\
\hline \multicolumn{3}{|l|}{ Eq 4: Dermal contact with sediment } \\
\hline Dermal surface area exposed to the contaminant (SA) $\left(\mathrm{m}^{2}\right)$ & 0.17 & 0.28 \\
\hline Dermal adherence rate for sediment $(\mathrm{AD})\left(\mathrm{mg} / \mathrm{cm}^{2}\right)$ & 0.51 & 3.75 \\
\hline dermal absorption rate (AS) $(1 / h)$ & 0.01 & 0.005 \\
\hline matrixeffect (M) (unitless) & 0.15 & 0.15 \\
\hline exposure duration $(\mathrm{ED})(\mathrm{h} / \mathrm{d})$ & 8 & 8 \\
\hline \multicolumn{3}{|l|}{ Eq 5: Dermal contact with surface water } \\
\hline Dermal surface area exposed to the contaminant $(\mathrm{SA})\left(\mathrm{m}^{2}\right)$ & 0.95 & 1.80 \\
\hline exposure duration (ED) $(\mathrm{h} / \mathrm{d})$ & 2 & 1 \\
\hline \multicolumn{3}{|l|}{ Eq 6: Ingestion of fish } \\
\hline Ingestion rate of fish (IR) ( $\mathrm{kg}$ fw/day) & 0.015 & 0.055 \\
\hline fraction contaminated ( $\mathrm{FI}$ ) (unitless) & 0.5 & 0.5 \\
\hline
\end{tabular}

Calculated total heavy metal exposure levels were compared with the tolerable daily intake (TDI). The tolerable daily intake refers to the reference dose of a substance that can be taken in daily without identifiable risk at lifetime exposure. Additionally, the hazard index has been calculated, which refers to the ratio of the calculated lifetime daily exposure divided by the reference dose (TDI) (15). Daily exposure ( $\mathrm{mg} / \mathrm{kg} \cdot \mathrm{d}$ ) averaged over lifetime (e.g. 
70 years), has been calculated by $6 *$ daily exposure child $(\mathrm{mg} / \mathrm{kg} . \mathrm{d})+64 *$ daily exposure adult $(\mathrm{mg} / \mathrm{kg}$. d) $/ 70$. If the hazard index is below 1 no health risk may occur. For $\mathrm{Pb}$, a distinction has been made between the TDI for adults and children, because children are more sensitive to $\mathrm{Pb}$ than adults. The TDIs for heavy metals have been derived from Bocking et al (11).

For quantification of health risks in relation to PAH exposure, the TEF (toxic equivalency factor) approach has been used $(25,26)$. The TEF approach has been designed to estimate the toxicity of complex mixtures for risk assessment purposes $(25,27)$. PAH compounds have been separated into two sub-classes; carcinogens and non-carcinogens. Benzo(a)pyrene is assumed to be one of the most potent carcinogenic PAH compounds. The cancer potencies of the various $\mathrm{PAH}$ compounds are compared with the cancer potency of $\mathrm{B}(\mathrm{a}) \mathrm{P}$ after which a scaling factor has been established. By this method, the evaluation of PAH mixtures can be expressed as $\mathrm{B}(a) \mathrm{P}$ equivalents. Nisbet and Lagoy (25) propose for the 16 EPA-listed PAHs the following TEF factors: dibenzo( $a, h)$ anthracene 5 ; benzo(a)pyrene - 1 ; benzo( $a$ ) anthracene - 0.1 ; benzo $(b)$ fluoranthene -0.1 ; benzo $(k)$ fluoranthene - 0.1 ; indeno $(1,2,3-c, d)$ pyrene - 0.1 ; anthracene - 0.01 ; benzo$(g, h, i)$ perylene - 0.01 ; chrysene - 0.01 ; acenaphthene - 0.001; acenaphthylene 0.001 ; fluoranthene -0.001 ; fluorene - 0.001; naphthalene - 0.001; phenanthrene 0.001 ; pyrene -0.001 . The $\mathrm{B}(a) \mathrm{P}$ equivalent concentration is the sum of the weighted potency factor of each compound in the mixture multiplied by the concentration of the compound in the mixture. The carcinogenic risks associated with exposure to $\mathrm{B}(\mathrm{a}) \mathrm{P}$ equivalents averaged over a lifetime (e.g. 70 years), are calculated and compared to the Dutch maximum permissible individual risk level (MPR), which corresponds to an annual probability to die as a consequence of cancer of $10^{-6}$.

\section{Statistical analysis}

The Spearman rank correlation coefficient was used to determine relationships between heavy metal and PAH contents in sediment, and bottom soil characteristics, and additionally, to correlate mutual data. A $p<0.05$ was considered statistically significant.

Statistical differences between the lakes with respect to bottom soil characteristics, heavy metal content in respectively sediment and surface water, and PAH concentration in sediments were analyzed by the Mann-Whitney $U$ test. Again, $p<0.05$ was considered statistically significant. For statistical purposes, all values below the detection limit have been replaced by half the detection limit. 


\section{Results}

\section{Chemical analysis}

Figure 5.2 presents $\mathrm{As}_{p} \mathrm{Cd}, \mathrm{Cu}, \mathrm{Pb}$ and $\mathrm{Zn}$ contents as well as the sum of the 16 EPA-listed PAHs in sediment samples collected at the two freshwater lakes. Results from the beach zone and the total lake with respect to lake Eijsden have been subdivided. The heavy metal and PAH concentrations vary between sampling sites, but in general, comparable levels are observed in sediment samples taken from the total lake Eijsden and lake Dilkensplas.

In each lake, considerable variations in sediment heavy metal and PAH contents exist. The sum of the EPA-listed PAHs in the lake Eijsden (total) and lake Dilkensplas vary from respectively 2.6 to $29.9 \mathrm{mg} / \mathrm{kg} \mathrm{dw}$ and 0.89 to 25.5 $\mathrm{mg} / \mathrm{kg} \mathrm{dw}$. In lake Eijsden (total) the sediment values range from 14 to 22 $\mathrm{mg} / \mathrm{kg} \mathrm{dw}$ for $\mathrm{As}$, from 2 to $10 \mathrm{mg} / \mathrm{kg} \mathrm{dw}$ for $\mathrm{Cd}$, from 29 to $115 \mathrm{mg} / \mathrm{kg} \mathrm{dw}$ for $\mathrm{Cu}, 39$ to $191 \mathrm{mg} / \mathrm{kg} \mathrm{dw}$ for $\mathrm{Pb}$ and 149 to $970 \mathrm{mg} / \mathrm{kg}$ dw for $\mathrm{Zn}$. In lake Dilkensplas, the concentrations of heavy metals range from 11 to $47 \mathrm{mg} / \mathrm{kg} \mathrm{dw}$ for As, from 1 to $20 \mathrm{mg} / \mathrm{kg}$ dw for Cd, from 15 to $237 \mathrm{mg} / \mathrm{kg}$ dw for Cu, from 48 to $430 \mathrm{mg} / \mathrm{kg}$ dw for $\mathrm{Pb}$ and from 188 to $2080 \mathrm{mg} / \mathrm{kg} \mathrm{dw}$ for $\mathrm{Zn}$. The highest heavy metal concentrations have been measured in sediment samples, located in the centre of lake Dilkensplas, and are approximately 2 to 4 times above the mean levels in the lake. As an example, in Figure 5.1 the $\mathrm{Pb}$ variation between sampling sites is shown.

At the beach zone of lake Eijsden, the heavy metal content and the sum of EPAlisted PAHs in sediment are remarkably low (Figure 5.2). Mann-Whitney $U$-test analysis shows a significant difference between sediment PAH and heavy metal content (except for As) at the beach zone of lake Eijsden and the total lake Eijsden. Differences in PAH and heavy metal concentrations in sediment between the total lake Eijsden and lake Dilkensplas are minimal, only $\mathrm{Cd}$ and Cu concentrations are significantly lower in lake Dilkensplas.

The individual PAH levels (except for fluorene) in sediment at the beach zone of lake Eijsden are significantly lower in comparison to the sediment levels in the total lake Eijsden (Mann Whitmey $U$-test, $p<0.05$ ). The profile of the individual PAHs in sediment of lake Dilkensplas is similar to that of lake Eijsden (total). Relatively high concentrations of 2 -ring PAHs are observed. The mean levels of the individual PAHs in sediment from lake Dilkensplas are higher compared to the sediments in lake Eijsden. Only sediment levels of fluorene, phenanthrene, benzo( $a)$-anthracene, dibenzo( $a$, $h$ )anthracene and chrysene are statistically different between the lakes. 


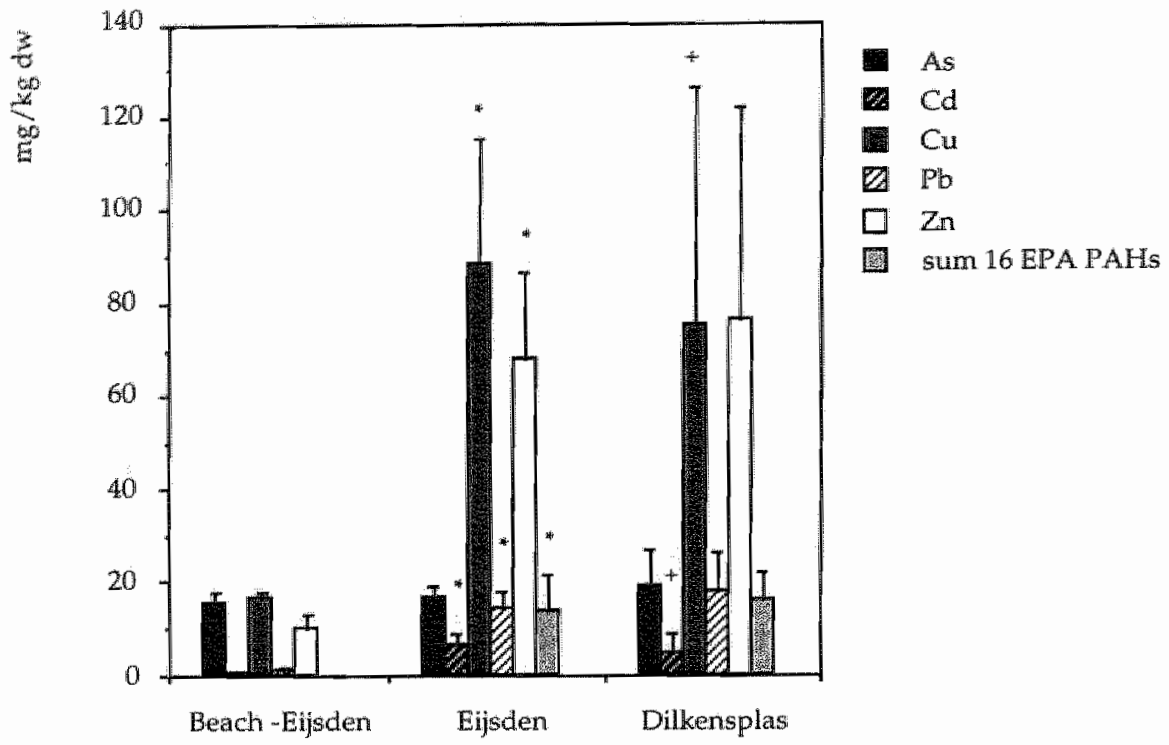

Figure 5.2: Mean ( $t$ sd) concentrations of some heawy metals and sum of EPA-listed PAHs (mg/ $\mathrm{kg} \mathrm{dw}$ ) in sediment samples from the artificial lakes Eijsdlen and Dilkensplas, The Netherlands. The mean (tsd) concentrations of $\mathrm{Pb}$ and $\mathrm{Zn}$ have to be multiplied by 10 . The statistical significance of differences are evaluated by the Mann-Whitney $U$ - test.

* significantly diffenent from beach zone $(p<0.001)$

$+\quad$ significantly different from lake Eijsden $(p<0.05)$

The levels of heavy metals in surface water are shown in Figure 5.3. No detectable concentrations of As have been found in the water samples. Furthermore, in some water samples the $\mathrm{Pb}$ and $\mathrm{Zn}$ concentrations are below the detection limit. In surface water samples taken at the beach zone of lake Eijsden, the highest levels have been found. The Marn-Whitney $U$-test demonstrates a significant difference between the $\mathrm{Cd}, \mathrm{Cu}, \mathrm{Pb}$ and $\mathrm{Zn}$ levels in lake Eijsden (total) and the surface water levels at the beach zone $(p<0.05)$.

Additionally, $\mathrm{Cu}, \mathrm{Pb}$ and $\mathrm{Zn}$ levels in surface water from lake Dilkensplas differ significantly from the surface water concentrations in lake Eijsden (total) ( $p<0.05$ ). No significant correlation has been observed between the heavy metal contents in sediment and surface water in either lake. 


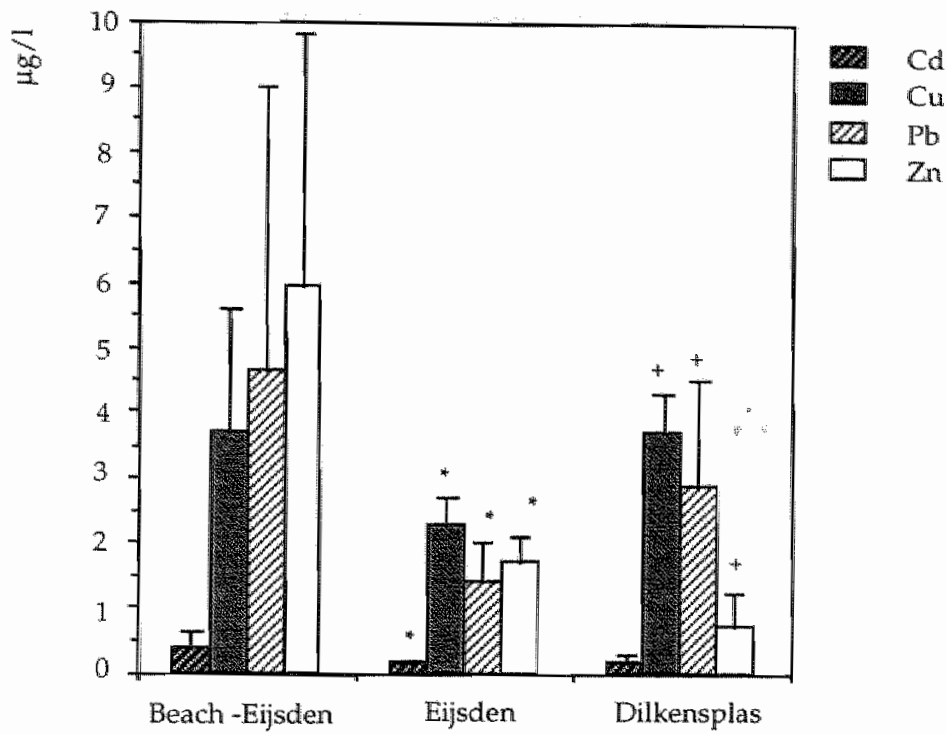

Figure 5.3: Mean (Isd) concentrations of some heavy metals ( $\mathrm{gg} / \mathrm{l}$ ) in surface water samples from the artificial lakes Eijsden and Dilkensplas, The Netherlands. The mean (Isd) concentrations of $\mathrm{Zn}$ has to be multiplied by 10 . The statistical significance of differences are evaluated by the Mann-Whimey $U$ - test

* significantly different from beach zone $(p<0.001)$

$+\quad$ significantly different from lake Eijsden $(p<0,05)$

The heavy metal contents in suspended matter have only been determined at lake Eijsden. Two samples were taken and the mean concentrations are respectively $18 \pm 2,6 \pm 1,65 \pm 5,130 \pm 7,806 \pm 31 \mathrm{mg} / \mathrm{kg} \mathrm{dw}$ for $\mathrm{As}, \mathrm{Cd}, \mathrm{Cu}, \mathrm{Pb}$ and $\mathrm{Zn}$. Due to the limited sample yield it was not possible to analyze EPA-listed PAHs and soil characteristics such as organic matter and clay fraction in the suspended material. Furthermore, the amounts of suspended matter collected at lake Dilkensplas, are not sufficient for analysis. The total amount of suspended matter is $33 \mathrm{mg} / 1$ in lake Eijsden and $20 \mathrm{mg} / 1$ in lake Dilkensplas.

The Dutch intervention-value for zinc is exceeded in more than $80 \%$ of the sediment samples from both lakes. The sediment levels of other heavy metals exceed the intervention-value incidentally. The intervention-value indicates an unacceptable risk to man or environment due to soil or sediment contamination. The value is normalized for the clay $(25 \%)$ and organic matter 
$(10 \%)$ content of the soil/sediment. In most surface water samples collected at the beach zone of lake Eijsden, the Dutch short term quality standard for $\mathrm{Cd}, \mathrm{Cu}$ and $\mathrm{Zn}$ is exceeded. For the total lake the concentrations of heavy metals in surface water meet the long term quality standard (e.g. $\mathrm{Cu}$ and $\mathrm{Pb}$ ) and are below the short term quality standard for $\mathrm{Zn}$ and $\mathrm{Cd}$. The concentrations of $\mathrm{Cu}$ and $\mathrm{Cd}$ (in $30 \%$ of the samples) in surface water from lake Dilkensplas exceed the short term qualiky standard. The $\mathrm{Pb}$ and $\mathrm{Zn}$ concentrations in lake Dilkensplas meet the long term quality standard. The short and long term quality standards represent the general environmental water quality. The long term quality standard refers to an acceptable or natural concentration, and the short term standard directs to an acceptable risk level.

For lake Dilkensplas, a significant correlation has been observed between the organic matter and clay fraction in sediment and the heavy metal content $(p<0.05)$. Furthermore, sediment heavy metal levels correlate significantly to each other. No significant correlation has been found between sediment levels of EPA-listed PAHs and the organic matter and clay fraction in sediment. Additionally, for lake Eijsden (total) the data show a significant correlation between heavy metal content in sediment and organic matter (except for As). The heavy metal levels in sediment furthermore correlate to each other (except for $\mathrm{As} / \mathrm{Cu}, \mathrm{As} / \mathrm{Pb}$ and $\mathrm{As} / \mathrm{Zn}$ ). Moreover, the sum of EPA-listed PAHs in sediment significantly correlate to the organic matter fraction in sediment. For the beach zone of lake Eijsden, no appreciable correlations have been found.

\section{Risk assessment}

The $\mathrm{B}(a) \mathrm{P}$ equivalent concentrations (mean $\pm \mathrm{sd}$ ) in sediments from the different lakes (lake Eijsden (total), beach zone of lake Eijsden and lake Dilkensplas) are respectively $3.0 \pm 1.7 \mathrm{mg} / \mathrm{kg} \mathrm{dw}, 0.01 \pm 0.03 \mathrm{mg} / \mathrm{kg} \mathrm{dw}$ and 3.5 $\pm 1.3 \mathrm{mg} / \mathrm{kg} \mathrm{dw}$. Spearman rank correlation coefficient analysis demonstrates a significant correlation between the sum of EPA-listed PAHs and the $B(a) P$ equivalent concentration in sediments of lake Dilkensplas $\left(p<0.01 ; R_{S}=0.82\right)$, and in sediments of lake Eijsden (total) ( $p<0.0001 ; R_{S}=0.90$ ). For the beach zone of lake Eijsden, no significant correlation has been observed. Table 5.2 and 5.3 summarize the results of the health risk assessment for adults and children exposed to contaminants in the freshwater lakes.

The heavy metal and $\mathrm{B}(a) \mathrm{P}$ equivalent concentrations in sediment at the beach zone for lake Eijsden are relatively low and the results of the risk assessment calculations applying the standard scenario model, indicate that there is no potential human health risk (data not shown). 
Table 5.2: Carcinogenic risk and average total exposure levels ( $\mathrm{kg} / \mathrm{kg} . \mathrm{d}$ ) for benzo(a)pyrene equivalents

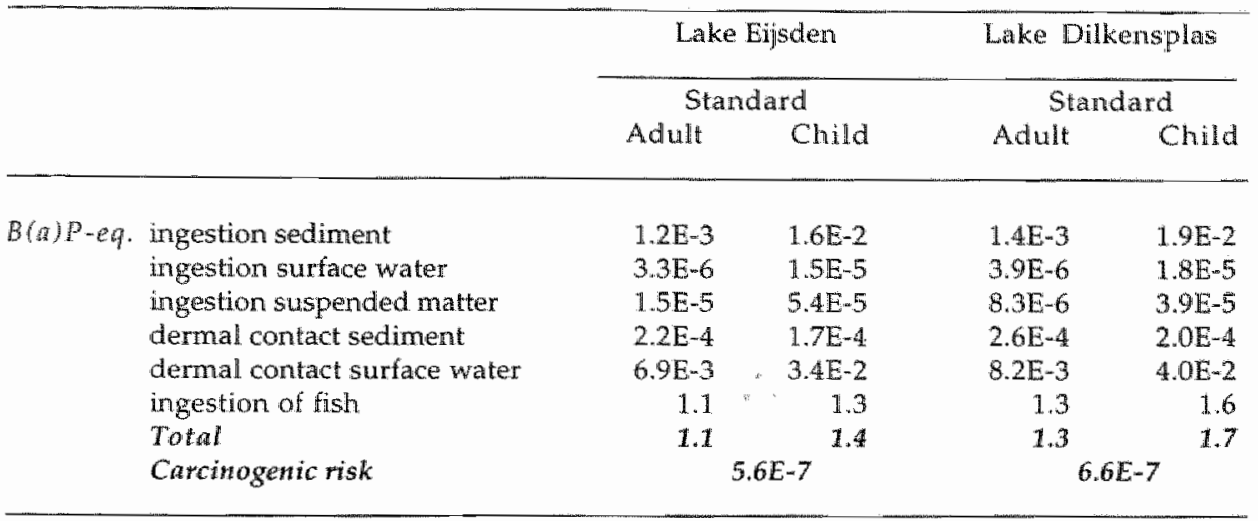

After modeling the standard scenario for both lakes, the calculated average exposure levels for $\mathrm{Zn}$ and $\mathrm{Pb}$ as present in both lakes exceed the tolerable daily intake (TDD), which implies that chronic health effects may occur. The calculated average carcinogenic risk for $\mathrm{B}(a) \mathrm{P}$ equivalents as present in both lakes are below the maximally tolerated level of exposure to genotoxic carcinogens. For both lakes, modelling the location specific scenario indicates that the calculated total average exposure levels for $\mathrm{As}, \mathrm{Cd}, \mathrm{Cu}, \mathrm{Pb}$ and $\mathrm{Zn}$ are below the levels of concern for human health (the hazard indices are far below 1). Therefore, no significant health risk seems to exist in relation to recreational activities on freshwater lakes.

For both lakes the ingestion of fish by adults and the ingestion of sediment by children comprise the majority of exposure to heavy metals. Dermal exposure to surface water appears an important exposure route for $\mathrm{B}(a) \mathrm{P}$ if ingestion of fish is not included into the risk assessment.

The calculated averaged total exposure levels to heavy metals are much higher when applying the standard scenario than for the location specific scenario. The difference in exposure levels between the two scenarios is mainly due to the ingestion of fish and the ingestion of surface water while swimming. 


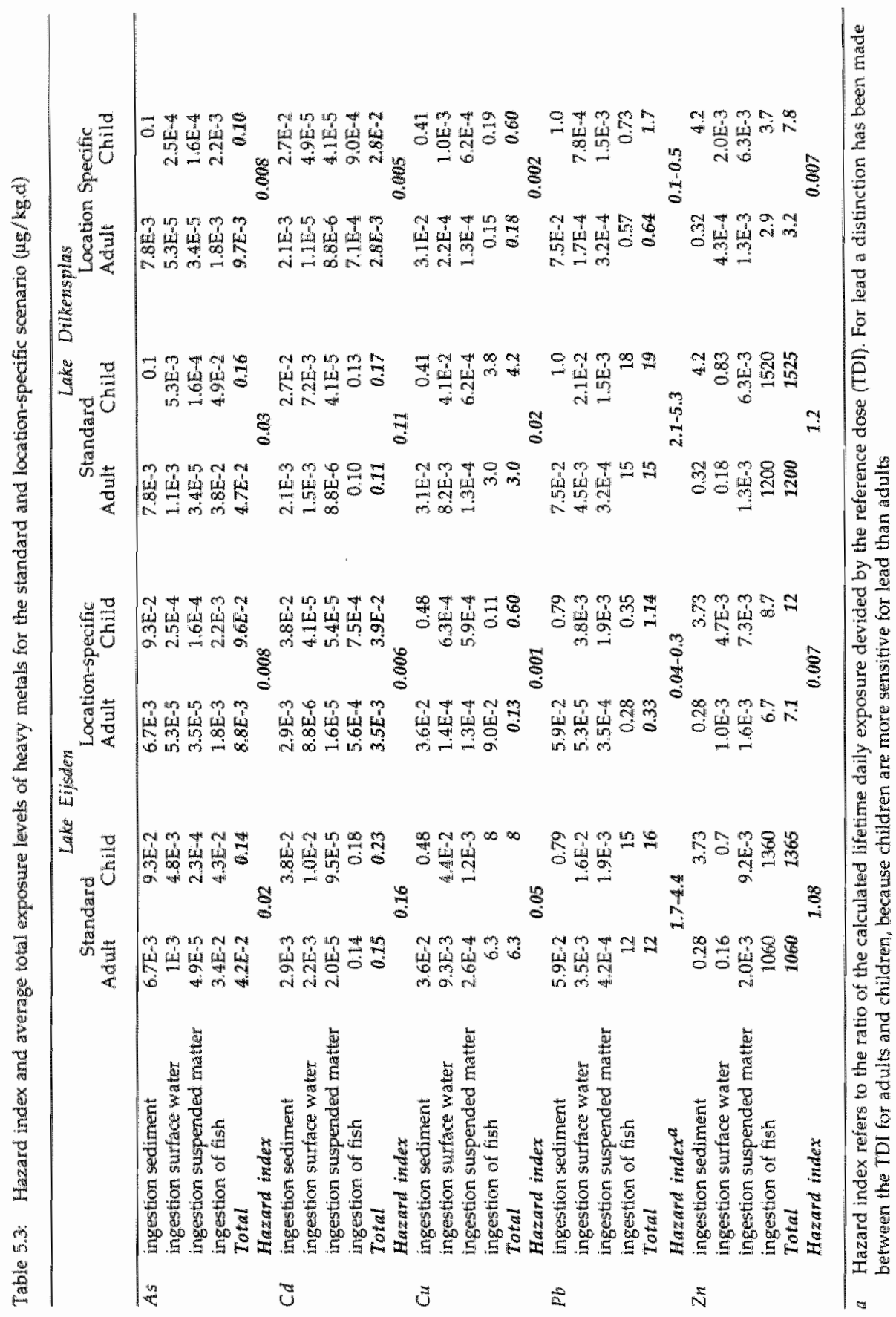




\section{Discussion}

\section{Environmental monitoring}

Heavy metals and PAH levels determined in sediment in the two artificial freshwater lakes in this study, are not significantly different from those determined 7 years previously in the same lakes (10). An exception is $\mathrm{Cd}$. The mean levels in sediment in both lakes have decreased by $15 \%$ for lake Eijsden and $50 \%$ for lake Dilkensplas as compared to 1989 . However, at that time only one sample has been taken from lake Dilkensplas and two samples (beach zone and deeper part) from lake Eijsden. Although the chemical quality of the surface water, including suspended matter, of the river Meuse has improved over the last decades, the quality of the lake sediments for both lakes in general has changed only to a minor extent during the previous years.

The quality of the river Meuse may influence the quality of the freshwater lakes along the river. Although lake Dilkensplas is nowadays disconnected from the river, sediment/sludge may accumulate into the lake as a result of flooding of the river. Lake Eijsden is connected to the river and therefore, directly effected by the river. Since 1989, two flooding disasters have occurred along the Belgium and Dutch part of the river at the end of December 1993 and at the end of January 1995, and sedimentation of polluted suspended matter and sediments have occurred. However, comparable results have been found in sediment samples taken from both lakes. This suggests that a direct or indirect connection to the river Meuse appears less important for the pollution of both freshwater lakes; sediment contamination presumably reflects historical pollution.

The concentrations of heavy metals (except for As) and PAHs in sediment are significantly lower at the beach zone of lake Eijsden as compared to the total lake. After the flooding of the river Meuse in January 1995 the sludge has been removed and new sand has been pumped onto the beach zone of lake Eijsden. The more sandy sediment and low organic matter content $(2 \%)$ contribute also to the lower heavy metal and PAH concentrations in the sediment at the beach zone (28). The As levels represent background levels for both sites in the lake (beach and total).

When comparing lake sediment concentrations, heavy metals significantly correlate with each other. Diffuse sources (for instance atmospheric deposition, industrial discharges, road traffic) may contribute to the heavy metal load in both lakes; furthermore, post-depostional remobilization may occur (5). To identify the main source, geochemical and palaeolimnological studies have to be performed (5). In addition, heavy metals correlate significantly with organic matter and clay fraction (only lake Dilkensplas) of the sediments, which indicates that heavy metals may be adsorbed by Fe-hydroxides, Fe/Mn oxides or carbonates (29). Surfaces of these particles are negatively charged and interaction 
may occur with the positively charged heavy metals. Additionally, other factors may influence sorption and desorption processes related to the properties of sediment (e.g. grain size, $\mathrm{pH}$, temperature, water content, cation exchange capacity and salt concentration) to the properties of water (e.g. pH) and the properties of the chemical itself (chemical speciation and water solubility) $(30,31)$. The adsorption to these compounds influences the potential availability to biota $(5,31)$. Because heavy metals tend to adsorb to clay and organic matter in sediment, the Dutch environmental standards for sediment and soil are normalized for the clay content $(25 \%)$ and organic matter content $(10 \%)$. Results from this study indicate that in both lakes, the intervention-value for $\mathrm{Zn}$ (environmental standards) normalized to organic matter and clay fraction is exceeded in more than $80 \%$ of the sediment samples. Other heavy metals incidentally exceed these environmental standards.

PAHs are primarily adsorbed on organic matter (30) and a significant correlation has been observed between the organic matter content of the sediments and the sum of EPA-listed PAHs for lake Eijsden (total). However, for lake Dilkensplas no significant correlation has been found.

No correlation has been observed between the heavy metal concentration in sediment and the surface water concentration for both lakes. We have measured the totall concentration (dissolved and particulate forms) of heavy metals in surface water. In river systems $\mathrm{As}, \mathrm{Cd}, \mathrm{Cu}$ and $\mathrm{Zn}$ appear to occur for $10-50 \%$ as the dissolved fraction and $\mathrm{Pb}$ appears for $1-10 \%$ dissolved $(5,31)$. The monitoring network at the river Meuse managed by the Association of Rhine and Meuse water supply, determines total concentration of heavy metals in surface water (9), During the same sampling period, higher surface water concentrations of $\mathrm{Pb}$ and $\mathrm{Zn}$ (total concentration) have been observed in the river Meuse at the monitoring station Eijsden in comparison to the total $\mathrm{Pb}$ and $\mathrm{Zn}$ concentrations measured in the surface water in lake Eijsden. However, concentrations of heavy metals in the river are reflecting more temporal trends influences by discharges and water transport (flow rates) (5).

Concentrations of heavy metals in surface water at the beach zone of lake Eijsden are significantly higher in comparison to concentrations in the lake itself. This is probably due to the sampling strategy at the beach zone of lake Eijsden. These samples have been taken while standing in the water (depth 1 $\mathrm{m}$ ), and it is assumable that the surface sediments have been grubbed out, and therefore relatively more suspended material has been sampled. Because at the laboratory the water samples were directly acidified without filtration, consequently higher heavy metal concentrations in the surface water at the beach zone of lake Eijsden have been found. 


\section{Risk assessment}

There are only a few reports on possible health risks in relation to recreational activity on freshwater lakes or estuaries, in particular in an estuary in the Tidewater region of Virginia, US and from areas of the five Great Lakes Areas, US/Canada (12-17). These studies identify ingestion of contaminated fish as an important exposure pathway in relation to exposure to PCBs, PAHs and heavy metals in sediments. In these studies, PCB exposure accounted for the excess cancer risk, which was mainly due to the consumption of crab (Tidewater region) and carp (Great Lakes) $(13,14)$. The non-carcinogenic risks are of minor importance, except for subsistence anglers in the area of the Great Lakes whereas exposure to heptachlor epoxide (16), dieldrin (17), methyl mercury and copper contaminations $(15,16)$ exceeds the health based standards.

The results of this health risk assessment indicate that sediment contamination by $\mathrm{Pb}$ and $\mathrm{Zn}$ in both lakes presents a health hazard, if the risks are calcullated on the basis of the standard exposure model. However, by modeling location specific data including data of actually measured contaminant concentrations in surface water and suspended matter, the health hazards are insignificant. Furthermore, the additional exposure through recreational activities on both freshwater lakes appeared to be much lower than background values; an exception is $\mathrm{Pb}$, for which the additional exposure levels contribute for approximately 100\% (adults) and 300\% (children) to background exposure levels. Background exposures to respectively $\mathrm{As}, \mathrm{Cd}, \mathrm{Cu}, \mathrm{Pb}$ and $\mathrm{Zn}$, have been estimated to be approximately $0.18,0.26,21,0.46$ and $190 \mu \mathrm{g} / \mathrm{kg}$. day (32).

Various assumptions applied in this risk assessment, contribute to uncertainty about the estimated risks (e.g. exposure frequency and durations, ingestion rate of sediments and contaminated fish, the concentration in surface water and suspended matter, the fish content and absorption factors) $(12,13)$. For example, it is assumed that exposure levels, exposure duration and exposure frequency do not change in a lifetime, and that human activities remain the same. It is apparent that the probability of this is extremely small. To illustrate this, people spend only a fraction of their lifetime in any one location (33). By using these conservative assumptions the health risks are overestimated.

In the present study, measured concentrations of heavy metals in surface water are remarkably lower than the predicted concentrations. Ratios of measured versus predicted concentrations in surface water for lake Eijsden are respectively $4.210^{-3}, 0.014,0.024$ and $6.210^{-3}$ for the heavy metals $\mathrm{Cd}, \mathrm{Cu}, \mathrm{Pb}$ and $\mathrm{Zn}$. For lake Dilkensplas, the ratios are in the same range. The standard scenario model overestimates heavy metal concentrations in surface water by more than two orders of magnitude. However, the relative contribution of surface water ingestion during swimming to the total average exposure levels for heavy 
metals is small. The total average exposure is dominated by the ingestion of fish (adults) or the ingestion of sediment (children).

However, the contaminant concentration in fish is expressed by the contaminants bioconcentration factor $(\mathrm{BCF})$ and the contaminants concentration in surface water. By modeling the standard scenario, the concentrations of heavy metals in surface water are overestimated by more than two orders of magnitude, and therefore, the concentrations in fish are also overestimated by more than two orders of magnitude, which has a renarkable influence on total average exposure levels in relation to sediment pollution for heavy metals.

Besides, different physical, chemical and physiological parameters influence the BCF. Examples are the age of the fish, the fish species, the chemical speciation, the dietary habits of the fish and the physical and chemical properties of sediments $(5,12,34-36)$. Concentrations in fish estimated by means of a mean $B C F$ value, are therefore of limited accuracy (11). Additionally, no information on the amount and frequency of fish caught at both lakes and consumed by recreational anglers, is directly available. For freshwater recreational anglers on lakes and ponds, Finley et al. recommended as default values for risk assessment a fish consumption rate of $1.7 \mathrm{~g} /$ day as median value and $15 \mathrm{~g} /$ day as 95 th percentile (37). To estimate human health risks for recreational anglers and their famillies with regard to consumption of contaminated fish from the Great Lakes, a fish ingestion rate of $54 \mathrm{~g} /$ day has been assumed, from which $25 \%$ is selfcaught (15-17). This assumption is in agreement with the 95th percentile of the exposure distribution recommended by Finley et al (37). In the standard scenario applied in this study, the default fish ingestion rate is respectively 55 and $15 \mathrm{~g} /$ day for adults and children, considering $50 \%$ of the fish consumption selfcaught (11). This assumption (25 g/day; adults) is at the extreme of the exposure distribution, and therefore represents a conservative assumption. Furthermore, the concentrations in fish are based on uncooked fish and on whole fish instead of edible part of the fish, which also represent conservative assumptions (14). In general, for both scenarios exposure through ingestion of contaminated fish is highly overestimated by using conservative assumptions. Additionally, for the standard scenario, modeling the concentration of heavy metals in surface water causes an overestimation of the health risks by more than two orders of magnitude.

The ingestion of sediment has been considered an important exposure route in the location-specific risk assessment. However, no specific data on the sediment ingestion rate by children and adults are available which can be used for risk assessment purposes. Therefore, sediment ingestion rates are based on soil ingestion rates in relation to contaminated sites (11). In the standard exposure 
model, a sediment ingestion rate of $\mathbb{1} \mathrm{g} /$ day for children has been used as a default value.

The other exposure routes are of minor importance in relation to total exposure levels for heavy metals. For instance, the ingestion of suspended matter while swimming, contributes for less than $1 \%$ to the total average exposure levels. The concentration of heavy metals in suspended matter has also been modeled on the basis of partition coefficients. Equilibrium has been assumed between surface water and suspended matter (11). The ratio predicted versus measured concentration in suspended matter for lake Eijsden are respectively $0.71,0.57,0.49,0.60$ and 0.79 for the heavy metals $\mathrm{As}, \mathrm{Cd}, \mathrm{Cu}, \mathrm{Pb}$ and $\mathrm{Zn}$. The predicted values are slightly higher but have no influence on the total average exposure levels.

To estimate human risks in relation to contaminated PAH sediments, the IEF approach has been used. By this approach the sum of EPA-listed PAHs in sediments are expressed as $\mathrm{B}(a) \mathrm{P}$ equivalents to calculate the carcinogenic risk associated with exposure to a mixture of PAH compounds (25). The ingestion of fish is the predominant exposure route due to sediment contamination with $\mathrm{B}(a) \mathrm{P}$. Exposure to lower molecular weight PAHs in sediments is directed by the dermal exposure of surface water while swimming and ingestion of contaminated fish, for higher molecular PAHs (log Kow range from 5 - 6.2) by the ingestion of contaminated fish and for the very high molecular PAHs (log Kow $>6.2$ ) by dermal exposure to sediments and ingestion of fish (11). The very high molecular PAHs $(\log \mathrm{Kow}>6.2)$ predominantly dibenzo $(a, h)$ anthracene, contribute for more than $75 \%$ to the total $\mathrm{B}(a) \mathrm{P}$ equivalents in sediments. This indicates that the exposure levels of $\mathrm{B}(a) \mathrm{P}$ for the pathways ingestion of contaminated fish and dermal exposure while swimming are overestimated, because the very high molecular PAHs are less soluble in water, which is reflected by lower surface water concentrations and lower concentrations in fish.

In summary, the application of the standard exposure scenario which as has been currently used by the Dutch government, leads to the conclusion that sediment contamination by $\mathrm{Pb}$ and $\mathrm{Zn}$ cause a health risk in relation to recreational activities on both lakes, which is mainly due to the ingestion of fish. However, upon inclusion of location-specific data, in particular the concentrations in surface water, into the risk assessment model exposure risk estimate are reduced by more than two orders of magnitude. It is therefore recommended to use location-specific data, if exposure through ingestion of contaminated fish is a relevant exposure pathway. Furthermore, calculated risks for both scenarios do not represent actual risks, due to the incorporation of conservative assumptions. In general, exposure risk assessment of the present type can be used for screening purposes to identify important exposure pathways and to determine the urgency of sediment remediation actions. 


\section{References}

1. Ploco SS. Using modular planning and modular modeling towards sound water quality management of the river Meuse. European Water Pollution Control 5 (6): 4150: 1995 .

2. Ketelaars HAM, Volz J, Jülich WFB. Biological and exotoxicological monitoring of the rivers Rhine and Meuse by the drinking water industry. Wat. Sci. Tech. 29 (3): 249-251; 1994.

3. Vreedenburgh EGH, Waals IMJ Recent developments in Drinking-Water Supply from the International Rivers Rhine and Meuse in The Netherlands. Aqua 4: 197204; 1987.

4. Klink F. An alternative approach to achieve a clean river Meuse. Wat. Sci. Tech. 29 (3): $121-123 ; 1994$.

5. Foster IDL, Charlesworth SM. Heavy metals in the hydrological cycle: trends and explanation. Hydrological Processes 10: 227-261; 1996.

6. Christensen ER, Irwan AL, Razak A, Rachdawong P, Karls JF. Sources of polycyclic aromatic hydrocarbons in sediments of the Kinnickinnic River, Wisconsin. J Great Lakes Res 23 (1): 61-73; 1997.

7. Gümgüm B, Unlü E, Tez, Z, Gülsün Z. Heavy metal pollution in water, sediment and fish from the Tigris river in Turkey. Chemosphere 29:1: 111-116; 1994.

8. Sanders M. Distribution of polycyclic aromatic hydrocarbons in Oyster (Crassostrea Virginica) and surface sediment from two estuaries in South Carolina. Arch Environ Contam Toxicol 28: 397-405; 1995.

9. RIWA. The river Meuse Annual report 1993. Amsterdam, The Netherlands: Association of Rhine and Meuse Water Supply Companies; 1995 (in Dutch).

10. Province of Limburg. Complementary research of sediments. Maastricht, The Netherlands: Province of Limburg; 1989 (in Dutch).

11. Bockting GIM, Koolenbrander JGM, Swartjes FA. SEDISOIL. Estimation of human exposure to sediments. Rpt no 715810011. Bilthoven, The Netherlands: National Institute of Public Health and the Environment; 1996 (in Dutch).

12. Crane JL. Carcinogenic Human Health Risks Associated with Consuming Contaminated Fish from Five Great Lakes Areas of Concern. I Great Lakes Res 22 (3): 653$668 ; 1996$.

13. Adams MR, Hanna CA, Mayernik JA, Mendez Jr WM. Probabilistic Health Risk Assessment for Exposures to Estuary Sediments and Biota Contaminated with Polychlorinated Biphenyls, Polychlorinated Terphenyls and other Toxic Substances. Risk Analysis 14 (4): 577-594; 1994.

14. U.S. Great Lakes National Program Office. Risk assessment and modeling overview document. EPA 905-R93-007. Chicago:U.S. Environmental Protection Agency; 1993.

15. Crane JL. Baseline human health risk assessment: Ashtabula River, Ohio, Area of Concern. EPA 905-R92-007. Athens:U.S. Environmental Protection Agency; 1992.

16. Crane JL. Baseline human health risk assessment: Saginaw River, Michigan Area of Concern. EPA 905-R92-008. Athens:U.S. Environmental Protection Agency; 1992.

17. Crane JL. Baseline human health risk assessment: Buffalo River, New York, Area of Concern. EPA 905-R93-008. Athens:U.S. Environmental Protection Agency; 1993.

18. Hicks HE. The great lakes: a historical overview. Toxicology and Industrial Health $12(2 / 3): 303-313 ; 1996$. 
19. Tremblay NW, Gilman AP. Human Health, the Great Lakes, and Environmental Pollution: a 1994 Perspective. Environ Health Perspect 103 (suppl 9): 3-5; 1995.

20. Vena JE, Buck GM, Kostyniak P, Mendola P, Fitzgerald E, Sever L, Freudenheim J, Greizerstein H, Zielezny M, McReynolds J, Olson J. The New York angler cohort study: exposure characterization and reproductive and developmental health. Toxicology and Industrial Health $12(3 / 4): 327-334 ; 1996$.

21. Pellettieri MB, Hallenbeck WH, Brenniman GR ${ }_{*}$ Cailas M $_{*}$ Clark M. PCB intake from sport fishing along the Northem Dlinois shore of lake Michigan. Bull Enviton Contam Toxicol 57: 766-770; 1996.

22. Moody RP, Chu I. Dermal exposure to environmental contaminants in the Great Lakes. Environ Health Perspect 103 (suppl 9): 103-112; 1995.

23. RIZA. Report of the project ecological rehabilitation of the river Meuse. The ecology of gravel pits adjacent to the rive Meuse in The Netherlands. An overview of studies conducted. Rpt no 28. Lelystad, The Netherlands: The Institute of Water Management and Waste Water "Treatment; 1995.

24. Schilderman PAEL, Hoogewerff JA, van Schooten FI, Maas LM, Moonen EIC, Os van $\mathbb{B J H}$, Wijnen van JH, Kleinjans JCS. Possible relevance of pigeons as an indicator species for monitoring air pollution. Environmental Health Perspectives 105 (3): 322-330; 1997.

25. Nisbet ICT, LaGoy PK. Toxic equivalency factors (TEFs) for polycyclic aromatic hydrocarbons (PAHs). Regulatory Toxicology and Pharmacology 16: 290-300; 1992.

26. Kleinjans JCS, Moonen EJC, Dallinga JW, Albering HJ, Boogaard van den AJM, Schooten van FJ. Polycyclic aromatic hydrocarbons in whiskies. The Lancet 348: $1731 ; 1996$.

27. Birnbaum LS, DeVito MJ. Use of toxic equivalency factors for risk assessment for dioxins and related compounds. Toxicology 105: 391-401; 1995.

28. Absil MCP, Scheppingen van $Y$. Concentrations of selected heavy metals in benthic diatoms and sediment in the Westerschelde Estuary. Bull Environ Contam Toxicol 56: 1008-1015; 1996.

29. Stone $M$, Droppo, IG. Distribution of lead, copper and zinc in size-fractionated river bed sediment in two agricultural catchments of southern Ontario, Canada. Environmental Pollution 93 (3): 353-362; 1996.

30. Paustenbach DJ. A survey of health risk assessment. In The risk assessment of environmental and human health hazards: A textbook of case studies. (Paustenbach DJ, ed). New York:Wiley; 1989.

31. Sálomons W, Mook WG. Biogeochemical processes affecting metal concentrations in lake sediments (IIsselmeer, The Netherlands). The science of the total Environment 16: $217-229 ; 1980$.

32. CCRX. Results of measurements of the radioactive contaminations in The Netherlands. Rijswijk, The Netherlands: Coordinating Committee of the Monitoring of Radioactive and Xenobiotic Substances; 1991.

33. Paustenbach DJ, Jernigan JD, Bass R, Kalmes R, Scott, P. A proposed approach to regulating contaminated soil: Identify safe concentrations for seven of the most frequently encountered exposure scenarios. Regulatory Toxicology and Pharmacology 16:21-56;1992.

34. Allen-Gil SM, Gubala CP, Landers DH, Lasora K. Heavy metal accumulation in sediment and freshwater fish in U.S. Arctic Lakes. Environmental Toxicology and Chemistry 16 (4): 733-741; 1997. 
35. Linde AR, Arribas P, Sanchez-Galan S, Garcia-Vazquez E Eel (anguilla anguilla) and brown trout (Salmo trutta) target species to assess the biological impact of trace metal pollution in freshwater ecosystems. Arch Enwiron Contam Toxicol 31: $297-302 ; 1996$.

36. Brannon IM, Price CB, Reilly Ir FJ, Pennington JC, McFarland VA. Effects of sediment organic carbon on distribution of radiolabeled fluroanthene and PCBs among sediment interstitial water and biota. Bull Environ Contam Toxicol. 51: 873$880 ; 1993$.

37. Finley B, Proctor D, Scott P, Harrington N, Paustenbach D, Price P. Recommended distributions for exposure factors frequently used in Health Risk Assessment. Risk Analysis 14 (4): 533-552; 1994. 
PART II:

DOSE-RESPONSE ASSESSMENT 

The case of Radon 



\title{
Chapter 6
}

\section{Survey of $222 \mathrm{Rn}$ concentrations in dwellings and soils in the Dutch Belgian border region}

\author{
H.J Albering, J.A. Hoogewerff, J.C.S. Kleinjans
}

Department of Health Risk Analysis and Toxicology, University of Limburg, PO Box 616, $6200 \mathrm{MD}$ Maastricht, The Netherlands.

Published in: Health Physics, 70, 1: 64-69 (1996)

\begin{abstract}
${ }^{222} \mathrm{Rn}$ levels in dwellings and soil gas have been investigated in the Eijsden-Vise region, located at the Dutch-Belgian border, in order to analyze the relationship between domestic radon levels and soil gas radon levels, in view of the fact that the local geology varies substantially from uranium-rich to uranium-poor rocks and soils. During February 1992, charcoal detectors were exposed for $24 \mathrm{~h}$ in $116 \mathrm{dwel}$ lings in the township of Visé, a radon prone area in Belgium. As expected, the results show a large regional variation, with an averaged indoor air radon level of $116 \mathrm{~Bq} \mathrm{~m}$. In the nearby township of Eijsden, The Netherlands, an area with a

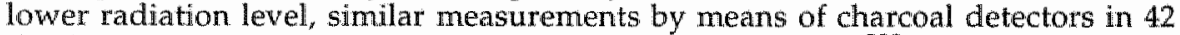
dwellings during March 1993, resulted in an averaged indoor ${ }^{222} \mathrm{Rn}$ concentration of $46 \mathrm{~Bq} \mathrm{~m}{ }^{-3}$. Furthermore, in the same region time-integrated radon measurements were performed in 15 dwellings on different floors. These results indicate that a gradient in indoor air radon concentration exists from basement to upper floor level. In addition, a significant positive correlation has been found between radon gas levels of soils surrounding 26 houses and indoor air radon levels. The variation in indoor ait radon levels is in the region under study mainly due to the variation of the radon levels in the soil. A soil gas radon survey is suitable for prescreening of the radon potential of an area taking into account the spatial heterogeneity of the local geology.
\end{abstract}

\section{Introduction}

The major health risk in relation with residential radon exposure is thought to be lung cancer. This is based on extrapolations from various epidemiological studies consistently indicating an increased pulmonary cancer risk among uranium and other underground miners (1-3). However, several case-control and ecological studies on the relation between domestic radon exposure and lung cancer have shown conflicting results (4-6). In consequence of this, the 
lung cancer risk of radon exposure for the generall population is not actually known.

In The Netherlands and Belgium, domestic radon exposure is the most important source of environmental irradiation received by the general population. A nationwide study carried out in The Netherlands has established an annual averaged indoor concentration of $29 \mathrm{~Bq} \mathrm{~m}^{-3}$ (range 8-118 Bq $\mathrm{m}^{-3}$ ) (7). Relatively high indoor air radon concentrations have been measured in several areas, e.g. the southern part of the province of Limburg (median annual radon concentration is $43 \mathrm{~Bq} \mathrm{~m} \mathrm{~m}^{-3}(7)$. In Belgium, a similar study determined the mean annual domestic radon concentration to be $53 \mathrm{~Bq} \mathrm{~m}^{-3}$ (8). However, in individual houses in the township of Visé, lacated at the border with the province of Limburg in The Netherlands, indoor levels of $3500 \mathrm{~Bq} \mathrm{~m} \mathrm{~m}^{-3}$ have been measured (9).

$238 \mathrm{U}$ and $226 \mathrm{Ra}$ distributions in soils and rocks are the major sources of radon, the emission of radon from building materials representing a relatively small contribution to indoor radon exposure. The concentrations of ${ }^{226} \mathrm{Ra}$ in soils and rocks may vary over several orders of magnitude. The emanation of radon from the soil depends not only on the ${ }^{238} \mathrm{U}$ and $226 \mathrm{Ra}$ concentrations but also on the nature of the host mineralogy, the porosity, the soil moisture content, and the permeability of the host rock and soil (10-12).

It can therefore be expected that soil gas radon levels are a useful indicator of the radon potential of an area. Furthermore, the local geology of the subsoil has also been used as an indicator to predict the radon potential of an area (13,14).

The Eijsden-Visé region is a small area $\left(55 \mathrm{~km}^{2}\right)$ characterized by extreme differences in the geology of the subsoil. Therefore, this region has been selected for studying the usefulness of soil measurements for identifying the radon potential of this small area in relation to the local geology.

As part of a larger study on the relationship between indoor radon exposure and genetic damage in radon exposed inhabitants, alpha-track and charcoal detector measurements were made in this Eijsden-Vise region. The details of the cytogenetic study have been reported elsewhere (15). This paper describes the data of ${ }^{222} \mathrm{Rn}$-levels in dwellings and soils in the township of Vise in the eastern part of Belgium, and in the neighbour township of Eijsden in the southern part of The Netherlands, and presents observations on the radon distribution within the dwellings. 


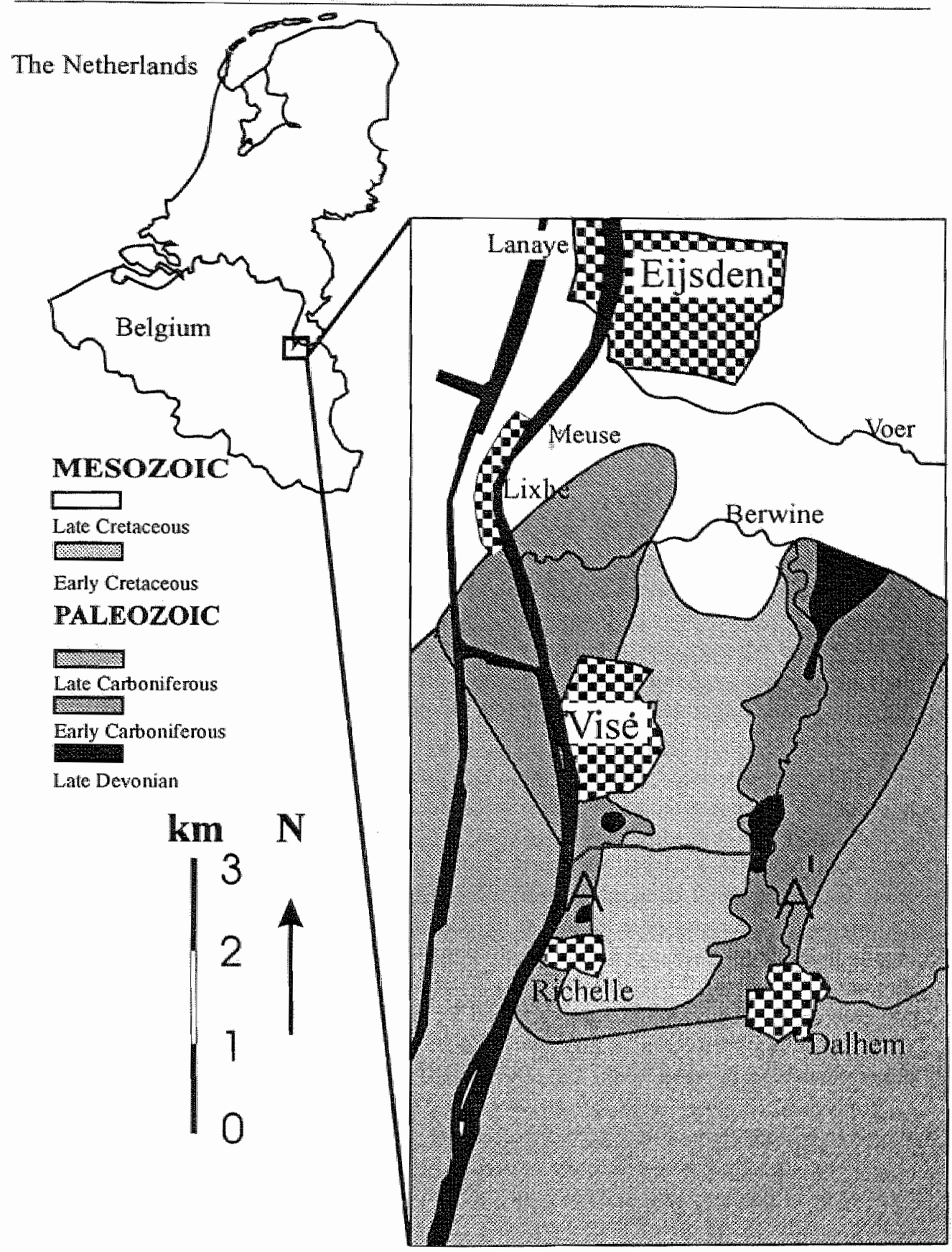

Figure 6.1: Map of The Netherlands and Belgium. A simplified geological map of the EijsdenVise area is shown in the amplification. The traverse $\mathrm{A}-\mathrm{A}$ " corresponds to a soll gas radon profile. 


\section{Lacal Area}

In the region under study (Fig. 6.1) a Paleozoic sequence consisting of limestones containing ${ }^{23.8} \mathrm{U}$-phosphate mineralization and black shales is the most likely origin of the high radon flux.

The origin of the uranium-phosphate mineralization is still prone to discussion (16). It may occur as a primary in situ uranium-phosphate mineralization (with $238 \mathrm{U}$ content up to $700 \mathrm{ppm}$ in the minerals) or as a second stage mineralization caused by fluid exchange because the limestones containing the minerals are overlain by Namurian black shales containing up to $80 \mathrm{ppm}{ }^{238} \mathrm{U}^{1}$. The zones of high uranium-phosphate levels appear to consist of elongated pockets ranging in size from a few centimeters to several meters, and the current hypothesis is that they are randomly distributed through the host limestones.

The complete Paleozoic sequence outcropping in the Visé region, constitutes an anticline dipping in a NNE direction, reaching a depth of approximatelly 50 meters underneath the township of Eijsden (17). At Eijsden, the Paleozoic is covered with sub-horizontal Upper Creataceous limestones and coated by a thin veneer of Pleistocene loess. At the deepest parts of the riverbed of the river Meuse, sediments are lying directly on the Paleozoic sequence. Because of this geological structure, the radon exhalation rate of the soil in the Eijsden area is expected to be relatively low as compared to the Visé area.

\section{Methods}

Domestic air and soil radon levels in the Eijsden-Vise region were measured from February 1992 through March 1994. Indoor air radon measurements were performed by means of a charcoal canister during $1 \mathrm{~d}$, or by a time-integrated alpha-track detector for $3 \mathrm{mo}$, both provided and analyzed by the Nuclear Research Centre in Mol, Belgium. Soil gas ${ }^{222} \mathrm{Rn}$ levels were measured using a soil gas extraction method as described by Ball et al. (11). Using a gauge auger with a diameter of $3 \mathrm{~cm}$, a hole was made at $1 \mathrm{~m}$ depth near the dwelling. Soil gas radon was pumped into the $\mathrm{ZnS}$ scintillation counter ${ }^{2}$ and three sequential 1 -min counts were recorded to determine the activity of radon taken into account a correction for ingrowth of decay products. By pumping gas from the soil into the ZnS scintillation counter no suspended decay products were carried into the counter, because the pore spaces were small (11). Furthermore a small cotton wool filter was used on the inlet tube against contamination by soil particles of the counter. An efficiency of $33 \%$ was assumed according to the manufacturer"s description. Measurements were repeated three times. Standard

1 Personal communication, Hoogewertf, J.A., Department of Health Risk Analysis and Toxicology, University of Limburg

2 RD-200, EDA, Scintrex, 222 Snidercrott Road Concond, Ontaria, Canada 
error of the mean was generally $22 \%$. Fresh counting cells with no background were used in order to prevent cross contamination of the cells.

A first study on indoor air radon levels has been performed in February 1992 in the township of Visé (17.000 inhabitants) in Belgium in order to identify possible sites with elevated radon concentrations in the dwellings. The selection was not based on random sampling. Preselection was founded on geological considerations, e.g., paleozoic rocks with uranium phosphate mineralizations of the soil. Four hundred and twenty addresses of houses situated in this area were obtained from the local authorities. From the total response of 218, complete measurements were obtained for 116 addresses. Indoor air radon levels were initially determined during $24 \mathrm{~h}$ by means of a charcoal canister. The number of houses investigated is limited but not small in relation to the size of the community. In the successive follow up study during the period of June to September 1992, an alpha track detector was placed in the living room of 24 dwellings.

On the basis of the previously described geological situation at the township of Eijsden (11.000 inhabitants) it was expected that the indoor air radon concentrations in dwellings in this area would be elevated in comparison with the mean indoor air radon level in The Netherlands but relatively low as compared to the Visé area. Initially, radon air levels were determined using a charcoal detector in a pilot survey in 42 dwellings in March 1993. Subsequently, alpha track detectors were placed for three months (April till June 1993) in 15 dwellings, on different floors: cellar/crawl space, ground floor and 1st floor.

Radon gas levels in different soils derived from bedrock in relation to domestic radon were assessed in March 1994 for 11 dwellings in the township of Eijsden and 15 dwellings in the township of Visé, by means of the previously described soil gas extraction method.

Correlation and linear regression analysis were used to evaluate the relationship between the radon soil gas levels and the domestic radon levels, and also for the interrelationship between the radon air concentrations on the different floors.

\section{Results and discussions}

The results of the first 116 measurements of the domestic radon concentrations in the township of Vise, the radon prone area, are presented in a simplified geological bedrock map in Fig. 6.2; areas indicated by heavy lines contain the indoor air radon levels above $200 \mathrm{~Bq} \mathrm{~m}^{-3}$.

Only a small proportion of the radon levels measured in these dwellings, exceeds $400 \mathrm{~Bq} \mathrm{~m}{ }^{-3}$. The arithmetic and the geometric means and standard deviations as well as the minimum and maximum values obtained in this survey are listed in Table 6.1. The distribution of the radon concentrations appears to be 
lognormal. The occurrence of anomalies indicated by the charcoal detector measurements in the dwellings, relates reasonably well with the geological lithology in the area as can be observed in Fig. 6.2. The major anomalies occur along the western alignment of $238 \mathrm{U}$-phosphate outcrops.

Table 6.1: Summary of the results of indoor ${ }^{222} \mathrm{Rn}$ surveys in the Dutch Belgium border region. Indoor tadon concentrations are expressed $\mathrm{as} \mathrm{Bq} \mathrm{m}^{-3}$

\begin{tabular}{|c|c|c|c|c|c|c|c|}
\hline & \multirow{2}{*}{$\begin{array}{l}\text { Number of } \\
\text { houses }\end{array}$} & \multicolumn{2}{|c|}{ Arithmetic } & \multicolumn{2}{|c|}{ Geometric } & \multicolumn{2}{|c|}{ Range } \\
\hline & & Mean & SD & Mean & $5 \mathrm{SD}$ & Min & $\operatorname{Max}$ \\
\hline \multicolumn{8}{|l|}{$\begin{array}{l}\text { Radon prone area: } \\
\text { township of Visé }\end{array}$} \\
\hline Pilot study & 116 & 116 & 221 & 68 & 3.4 & 15 & 1,625 \\
\hline Follow up & 24 & 306 & 654 & 149 & 3.7 & 50 & 3,300 \\
\hline \multicolumn{8}{|l|}{$\begin{array}{l}\text { Low background arrea: } \\
\text { township of Eijsden }\end{array}$} \\
\hline Pilot study & 42 & 46 & 30 & 40 & 1.8 & 15 & 170 \\
\hline \multicolumn{8}{|l|}{ Follow up: } \\
\hline cellar/crawl space & 1.5 & 253 & 229 & 177 & 2.2 & 75 & 910 \\
\hline ground floor & 15 & 73 & 23 & 70 & 1.4 & 45 & 135 \\
\hline first floor & 15 & 82 & 79 & 63 & 2.2 & 30 & 290 \\
\hline
\end{tabular}

Statistical analysis (ANOVA) shows significant differences $(\mathrm{p}<0.1)$ between the indoor radon levels in dwellings on lower carboniferous rocks and indoor radon levels in dwellings on upper carboniferous rocks. The mean indoor radon concentration are respectively 201 en $93 \mathrm{~Bq} \mathrm{~m} \mathrm{~m}^{-3}$ for lower and upper carboniferous rocks. The eastern alignment is less well pronounced but this might be biased by the low density of sample points. The anomaly Northwest of Visé, near the township of Lixhe, is not simply explained by occurrence of the mineralizations. It seems more likely that uranium transport is taking place from local groundwaters, in which we have measured high uranium concentrations $^{3}$. The follow up study among 24 dwellings indicates a geometric mean and standard deviation of 149 and $3.7 \mathrm{~Bq} \mathrm{~m}^{-3}$ respectively.

3 Personal communication, Hoogewerf, $J$, A, Department of Heahth Risk Analysis and Toxicology, Lniversity of Limburg 


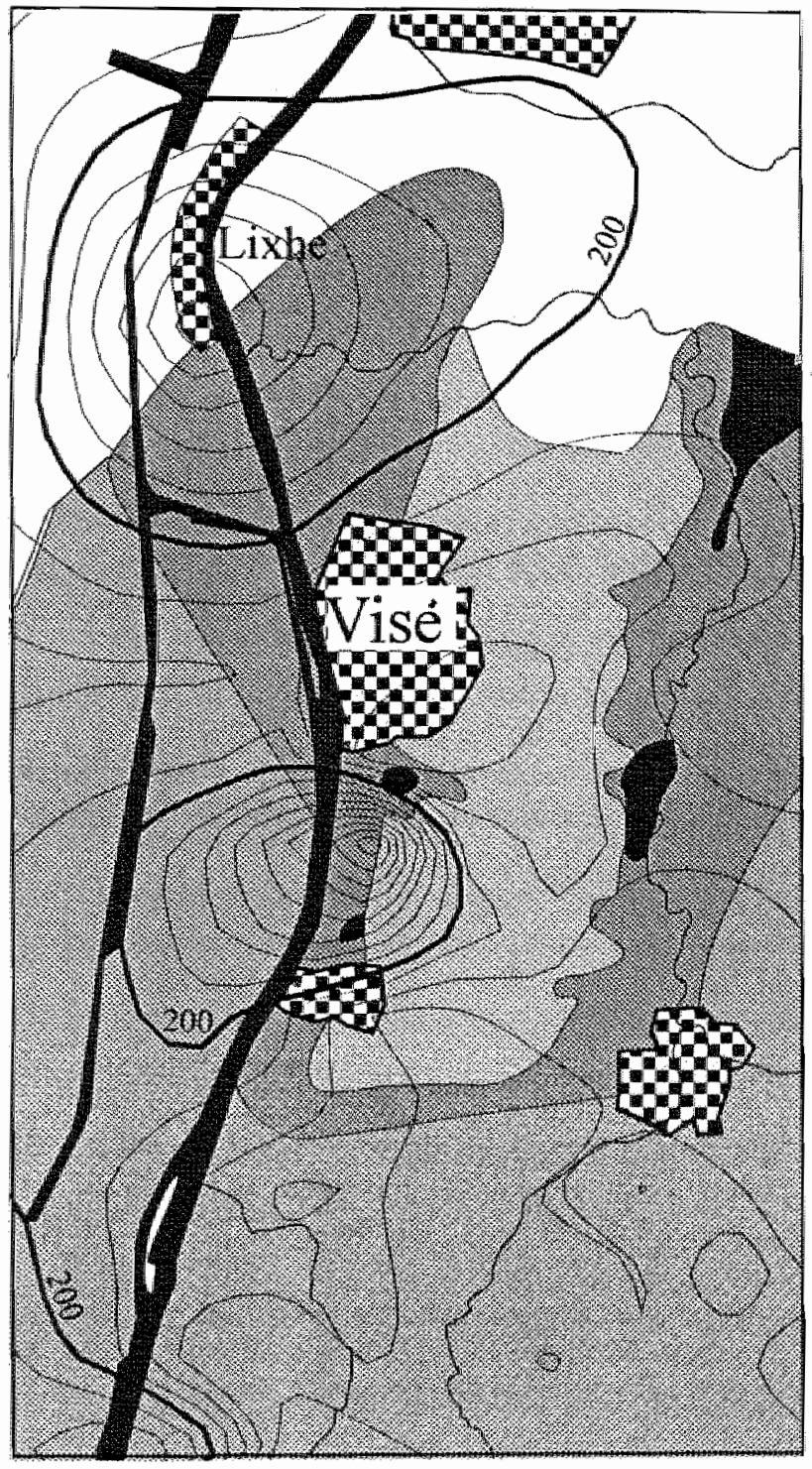

\section{MESOZOIC}
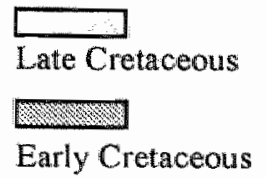

\section{PALEOZOIC}

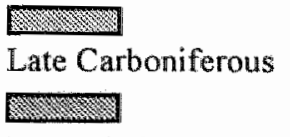

\section{Early Carboniferous}

Late Devonian

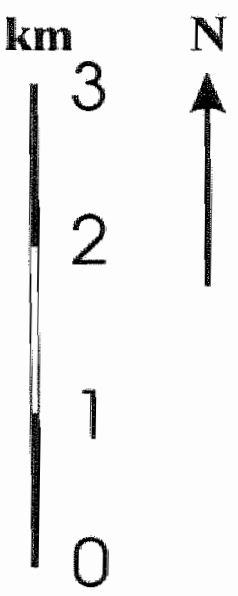

Figure 6.2: Results of the radon levels in dwellings from 116 measurements with a chancoal detector on the ground floor plotted on a geological map; contours increasing by $50 \mathrm{~Bq}$ $\mathrm{m}^{-3}$ are given. Areas indicated by heavy solid lines contain the indoor air radion levels above $200 \mathrm{~Bq} \mathrm{~m}$ 
In the township of Eijsden, an area with lower background radiation, a domestic radon level survey of 42 dwellings during March 1993 gives arithmetic and geometric means of 46 and $40 \mathrm{~Bq} \mathrm{~m}^{-3}$ respectively, and these are relatively high as compared to the average indoor air radon level of $29 \mathrm{~Bq} \mathrm{~m}^{-3}$ in The Netherlands (7) (Table 6.1).

The highest value observed in a particular house was $170 \mathrm{~Bq} \mathrm{~m}^{-3}$. Although the domestic radon levels in the township of Eijsden are relatively high as compared to the average in The Netherlands, they are rather low in comparison with the Visé region.

There are two possible explanations for these relatively high domestic radon levels in the township of Eijsden. It may be that the loess has an higher than average radium concentration but it is also possible that some of the radon is coming from the strongly radon producing Paleozoic layers at $50 \mathrm{~m}$ depth.

The follow up study among $15 \mathrm{~d}$ wellings indicated that the arithmetic mean of radon levels in cellar/crawl space is higher than the average radon concentration on the ground floor or the first floor (Table 6.1). In two particular houses, on the first floor high indoor radon levells $\left(>200 \mathrm{~Bq} \mathrm{~m}^{-3}\right)$ were observed which were emitted by the building material used.

The relationship between the indoor air radon concentrations in the living room vs the levels in the cellar/crawl space is shown $(R=0.55, p<0.05)$ in Fig. 6.3. Similar results on the cellar/living room relationship of radon have been reported by others (18-20). No significant correlation between the ${ }^{222} \mathrm{Rn}$ levels in the bedrooms and the living rooms has been found.

In order to evaluate the usefulness of soil measurements for predicting the eventual indoor air radon levels in a very small area 26 , radon measurements in soils from different geological units were performed. The concentrations of ${ }^{222} \mathrm{Rn}$ levels in soil gas vary over several orders of magnitude (range $0.7-107$ $\mathrm{kBq} \mathrm{m} \mathrm{m}^{-3}$ ). The arithmetic and geometric mean values for the radon levels in soil gas are 10.000 and $3.200 \mathrm{~Bq} \mathrm{~m}$ m $^{-3}$ respectively, with the geometric standard deviation being $3.8 \mathrm{Bg} \mathrm{m}{ }^{-3}$. For the different geological units, the arithmetic and geometric mean of the soil gas radon levels are 16.000 and $5000 \mathrm{~Bq} \mathrm{~m}^{-3}$ (GSD of $3.5 \mathrm{~Bq} \mathrm{~m} \mathrm{~m}^{-3}$ ) for the radon prone area, and 2.100 and $1.800 \mathrm{~Bq} \mathrm{~m}^{-3}$ (GSD of $1.6 \mathrm{~Bq}$ $\mathrm{m}^{-3}$ ) for the area with lower background.

For the whole data set, after logarithmic transformation the soil gas radon levels significantly correlate with the ground floor air radon concentrations measured with an alpha track detector $(R=0.63 \mathrm{p}<0.005)$ (Fig. 6.4).

This confirms the hypothesis that the variation in domestic radon concentrations in this area is mainly due to the variation of the radon levels in the soil. The major source for indoor air radon is the exhalation of radon from the soil. However, it should be noted that the analyses of domestic radon 


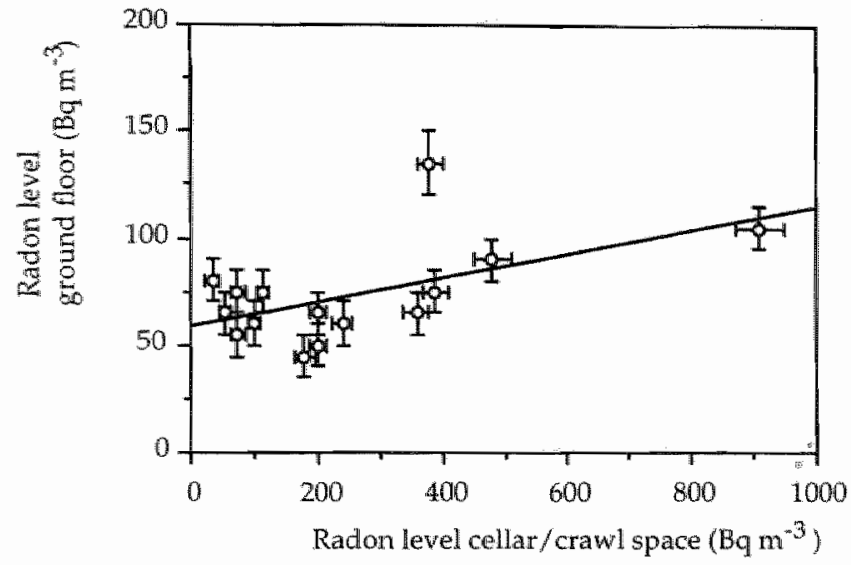

Figure 6.3: The relationship between radon levels of the ground floor (living room) vs. the cellar/crawl space for the dwellings in the township of Eijsden (error bars indicate $1 \mathrm{SD})$.

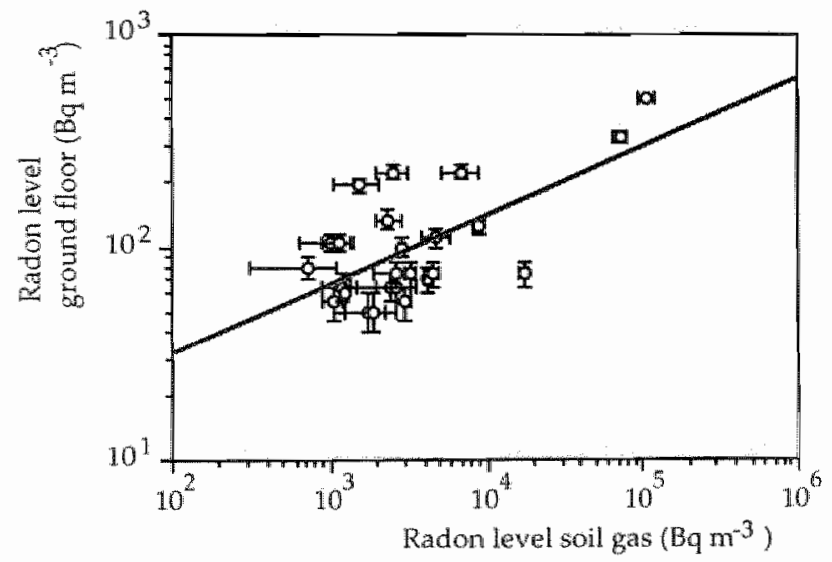

Figure 6.4: The relationship between radon levels in soil gas and radon levels on the groundflow in the area under study (error bars: radon levels on the ground floor; 1 . SD for the radon lewels in soil gas; standard error of the meany. 
levels for each township were carried out at different times. After subdividing the data obtained in the two different geological units, no correlation between soil gas radon levels and domestic radon levels for the $11 \mathrm{dwellings}$ in the township of Eijsden can be observed. However, after logarithmic transformation a significant positive correlation is found between the radon air concentrations on the ground floor and the soil gas levels in the radon prone area ( 15 houses, $\mathrm{R}=0.65, \mathrm{p}<0.01$ ).

In the present study, the area with highest radon levels in the soil is situated in the radon prone region on limestones containing $238 \mathrm{U}$-phosphate mineralizations and black shales. This demonstrates that the composition of the bedrock and overlying soil is an important factor with respect to the eventual radon concentration in dwellings. The results of this study are in agreement with the study by Akerblom et al. (10), who have studied the effects of soil gas radon on indoor $222 \mathrm{Rn}$-concentrations in 105 houses in Sweden. In this study, the indoor air radon concentrations varied from 20 to $20.000 \mathrm{~Bq} \mathrm{~m}^{-3}$ and the soil gas radon levels varied from $5.000 \mathrm{~Bq} \mathrm{~m}^{-3}$ in sandy soils to 700.000 $\mathrm{Bq} \mathrm{m}^{-3}$ in alum shale-rich soils; radon levels in soil gas varied considerably between the different geological areas and also within the same geological area. Also in the Reading Prong area, United States, a positive correlation between the indoor air radon and the soil gas radon concentrations was found for 18 dwellings ( $R=0.77, p<0.01$ ) (13). Nason and Cohen (21) however, found no correlation between the $222 \mathrm{Rn}$ levels in soil gas (average $8.500 \mathrm{~Bq} \mathrm{~m} \mathrm{~m}^{-3}$ ) and radon levels in indoor air (average $529 \mathrm{~Bq} \mathrm{~m}^{-3}$ ) for 11 houses in Pittsburgh in the United States, due to the fact that the uranium content of the soil was too low for a useful prediction of indoor radon concentration by measuring the radon levels of the soil. This is in agreement with our results on the soil radon levels in relation to domestic radon concentrations in the township of Eijsden. The variation of the radon levels in the soil was too high to predict the minor differences in indoor radon levels for this specific low background area.

To test the spatial heterogeneity of the radon flux from the soil, the radon soil gas levels of one profile covering a part of the radon prone area have been measured in August 1993 by means of the ZnS scintillometer. (The profile is described in Fig. 6.5a and indicated as A-A' in Fig. 6.1). A small section of the profile was measured every $20 \mathrm{~m}$ in March 1994 (Fig. 6.5b). It appeared that within the same geological area large variations exist in the radon flux from the soil at relatively small distances. This can be explained by the field observation that the specific uranium-rich mineralization occurs in bands with a thickness of only several decimeters, or even centimeters. Furthermore, the orientation of these bands together with emanation and permeability features, as well as the moisture content of the soil may effect the radon flux. 


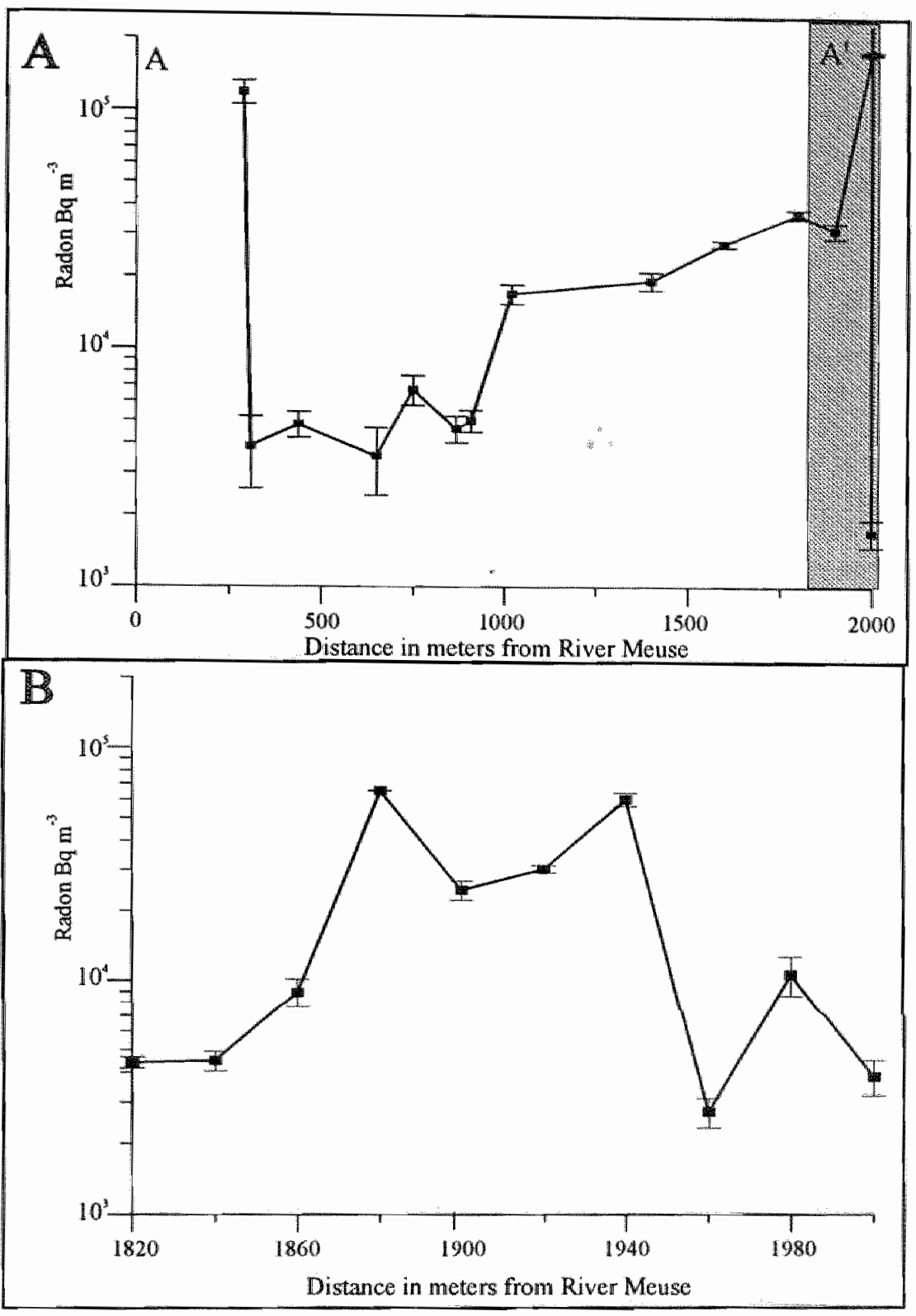

Figure 6.5: Spatial distribution of radion in soil gas (error bars indicate the standard error of the mean). Gray band is amplified area in Figure 6.5b.

Figure $6.5 \mathrm{a}:{ }^{222} \mathrm{Rn}$ profile measurements with on average $150 \mathrm{~m}$ interval:

Figure 6.5b: A small section of this profile has been amplified and measured every $20 \mathrm{~m}$. 


\section{Conclusions}

In summary, in the Eijsden-Visé area located at the Dutch-Belgian border, the radon concentrations in the soil and domestic environment vary widely. On average, the domestic radon levels decrease with increasing house floors. In cellars or crawl space, the radon levels are more than a factor of two higher than radon air levels on the ground floor (living room). Soil gas radon levels surrounding $26 \mathrm{dwellings} \mathrm{in} \mathrm{this} \mathrm{area} \mathrm{have} \mathrm{been} \mathrm{measured.} \mathrm{The} \mathrm{soil} \mathrm{gas} \mathrm{levels}$ correlate with indoor levels. A measurement of soil gas radon is suitable as an indicator for ${ }^{222} \mathrm{Rn}$ in houses. The method is not appropriate to predict minor differences in indoor air radon concentrations. From our study, it can be concluded that the spatial density of soil gas sampling should agree with the spatial heterogeneity of the local geology. In the radon prone area, only measurements with a very high sample density will be able to give a reliable indication for eventual indoor radon levels. In an area with no high background only a representative amount of samples on each geological unit has to be taken in order to estimate possible future risks.

Acknowledgement:

We thank dr. H. Vanmarcke, Nuclear Research Centre, Mol, Belgium, for determining the radon concentrations in the dwellings.

\section{References}

1. Samet, J.M.; Pathak, D.R.; Morgan, M.V.; Key, C.R.; Valdivia, A.A.; Lubin, J.H. Lung cancer mortality and exposure to radon progeny in a cohort of New Mexico underground uranium miners. Health Physics 61: 745-752; 1991.

2. Kusiak, R.A.; Ritchie, A.C.; Muller, J.; Springer, J. Mortality from lung cancer in Ontario uranium miners. British Journal of Industrial Medicine 50:920-928; 1993.

3. Scevc, J.; Tomasek, L.; Kunz, E.; Placek, V.; Chmelewsky, D.; Barclay, D.; Kellerer, A.M. A survey of the Czechoslovak follow-up of lung cancer mortality in uranium miners. Health Physics 64: 355-369, 1993.

4. Blot, W.J.; Xu, Z.Y.; Boice, J.D.; Zhao, D.Z.; Stone, B.J.; Sun, J.: Jing, L. B.; Fraumeri, J.F. Indoor radon and lung cancer in China. Joumal of the National Cancer Institute 82: $1025-1030 ; 1990$.

5. Cohen, B.L. Relationship between exposure to radon and various types of cancer. Health Physics 65:529-531: 1993. 
6. Pershagen, G.; Akerblom, G.; Axelson, O.; Clavensjö, B.; Damber, L; Desai, G.; Enflo, A.; Lagarde, F.; Mellander, H.; Swartengren, M.; Swedjemark, G. Residential radon exposure and lung cancer in Sweder. The New England Journal of Medicine 330: $159-164 ; 1994$.

7. Put, L.W.; Veldhuizen, A.; de Meijer, R.J.; Radon concentrations in The Netherlands. SAWORA program. Ministry of Housing. Physical Planning and Environment, the Hague; 14; 1986 (in Dutch).

8. Vanmarcke, H.; Poffijn, A.; Raes, F.; Eggermont, G.; Uyttenhove, J.; Berkvens, P.; van Dingenen, $R_{* ;}$ Bourgoignie, $R$; Jacobs, $R$. Radon in het leefmilieu. Annales de I'Association belge de Radioprotection 13:33-56; 1988 (in Dutch).

9. Hallez, S., Flémall, J.M. Carographie communale des concentrations de radon a l'interieur des habitants. Bruxelles: Institut d'Hygiene et d'Epidemiologie; 1990.

10. Akerblom, G.; Andersson, P.; Clavensjö, B. Soil gas radon- a source for indoor radon daughters. Radiation Protection Dosimetry 7 , no 1-4:49-54; 1984.

11. Ball, T.K.; Cameron, D.G.; Colman, T.B. Roberts, P.D. Behaviour of radon in the geological environment: a review. Quarterly Journal of Engineering Geology 24:169. $182 ; 1991$.

12. Grasty, R.L. Summer outdoor radon variations in Canada and their relation to soil moisture. Health Physics 66: 185-193; 1994.

13. Reimer, G.M.; Gundersen, L.C.S. A direct correlation among indoor Rn, soil gas Rn and geology in the Reading Prong near Boyertown, Pennsylvania. Health Physics 57: $155-160 ; 1989$.

14. Crameri, R; Brunner, H.H.; Buchli, R.; Wernli, C.; Burkart, W. Indoor Rn levels in different geological areas in Switzerland. Health Physics 57: 29-38; 1989.

15. Albering, H.J., Engelen, J.J.M., Hageman, G.J. Koulischer, L. Vanmarcke, H., Kleinjans, J.C.S. Genetic biomarkers indicative for DNA damage in relation to indoor radon exposure. Annales de l'Association belge de Radioprotection 19, no 1-2: 15$26 ; 1994$.

16. Herbosch, A., De Witte, S.M., Preat, A. Recherches sur les Indices de Minéra-lisation Uranifères dans la Region de Visé. Bruxelles: Service Geologique de Belgique, Proffesional Paper no. 162; 1979.

17. Geological State Service. Geological map of the southern part of the province of Limburg; Government printing office, The Hague; 1984.

18. Gesell, T.F. Background atmospheric ${ }^{222}$ Rn concentrations outdoors and indoors: a review. Health Physics 45: 289-302; 1983.

19. Borak, T.B.; Woodruff, B.; Toohey, R.E. A survey of winter, summer and anmual average ${ }^{222} \mathrm{Rn}$ concentrations in family dwellings. Health Physics 57: 465-470; 1989.

20. Mose, D.G.; Mushrush, G.W.; Chrosniak, C.E. A 2-year study of seasonal indoor radon variations in Northern Virginia. Journal of Toxicology and Environmental Health $33: 115-130 ; 1991$.

21. Nason, R.; Cohen, B.L. Correlation between ${ }^{226 R a}$ in soil, ${ }^{222} \mathrm{Rn}$ in soil gas, and ${ }^{222} \mathrm{Rn}$ inside adjacent houses. Health Physics $52: 73-77 ; 1987$. 


\title{
Chapter 7
}

\section{Indoor radon exposure and cytogenetic damage}

\author{
H.J. Albering, G.J. Hageman, J.C.S. Kleinjans, J.J.M. Engelen 1, L. Koulischer ${ }^{2}$ \\ C. Herens ${ }^{2}$
}

Department of Health Risk Analysis and Toxicology, ${ }^{1}$ Department of Genetics, University of Limburg, PO-Box 616, 6200 MD Maastricht, The Netherlands, ${ }^{2}$ Centre for Human Genetics, University of Liège, Sart Tïlman, Liège, Belgium

Published in: The Lancet, 340, 8821: 739 (1992)

$\mathrm{Sir}_{r}$ - Radon contributes to pulmonary carcinogenesis in uranium miners and is an important lung cancer risk in the general population. Correlation studies indicate an additional role for indoor radon exposure in the development of extrapulmonary cancers, suggesting that carcinogenic effects may not be restricted to lung epithelium $(1,2)$. Studies in populations living and or working in areas with increased background radiation have shown higher frequencies of peripheral lymphocyte chromosome aberrations, or hypoxanthine guanine phosphoribosyl transferase-locus (hprt) mutations $(3,4)$. Genetic effects in peripheral lymphocytes of radon-exposed individuals may also indicate extra pulmonary distribution of genotoxic particles.

Our pillot study was designed to test the feasibility of multiple genetic marker analysis (sister chromatid exchanges, hprt mutations, micronuclei and chromosome aberrations in peripheral lymphocytes from subjects in the Netherlands and Belgium exposed to indoor radon concentrations in their dwellings (16-713 $\left.\mathrm{Bq} \mathrm{m}^{-3}\right)$. The table summarises indoor radon exposure and cytogenetic indices in the 11 participants. With or without correction for confounding factors such as passive smoking and age, there was no relation between the level of exposure and occurrence of micronuclei, chromosome aberrations and sister chromatid exchanges in peripheral lymphocytes of exposed individuals, as assessed by standard procedures $(7,8)$. For hprt mutations, we detected 6thioguanine-resistant lymphocytes with 5-bromodeoxyuridine labelling and immunochemical staining. These mutations were inversely related to the level of exposure by linear regression $(R=-0.632, p<0.05)$. After adjustment for age and peripheral lymphocyte proliferation rate by multiple regression, the relation between individual hprt mutation and indoor radon exposure was no 
longer significant. After exclusion of one outlier $\left(230 \times 10^{-6}\right)$ in the hprt assay, and combined with adjustment for age and lymphocyte labelling index, the relation between hprt mutations and indoor radon exposure was again significant $(\mathbb{R}=0.910, p<0.05)$.

Sister chromatid exchanges (SCE) hprt mutations (MF), micronuclei (MN) and chromosome aberrations (CA) in peripheral $T$ lymphocytes of 11 subjects exposed to indoor radon

\begin{tabular}{|c|c|c|c|c|c|}
\hline \multirow[b]{2}{*}{$\begin{array}{l}\text { Subject } \\
\text { (age/sex) }\end{array}$} & \multirow{2}{*}{$\begin{array}{l}\text { Radon } \\
\text { exposure } \\
\left(\mathrm{Bq} / \mathrm{m}^{3}\right)\end{array}$} & \multicolumn{4}{|c|}{ Cytogenetic biomarkers } \\
\hline & & $\begin{array}{l}\text { SCE per } \\
\text { cell }\end{array}$ & MF $\left(10^{-6}\right)$ & $\begin{array}{l}\text { MN per } \\
2000 \text { cells }\end{array}$ & $\begin{array}{l}\text { CAper } 100 \\
\text { metaphases }\end{array}$ \\
\hline 1. $(64 / \mathrm{F})$ & 16 & 6.35 & 9.9 & 54 & 4 \\
\hline 2. $(49 / \mathrm{M})$ & 29 & 6.16 & 8.8 & 38 & 2 \\
\hline 3. $(42 / \mathrm{M})$ & 30 & 7.73 & 230.0 & 26 & 1 \\
\hline 4. $\quad(56 / F)$ & 39 & 7.19 & 4.9 & 37 & 2 \\
\hline 5. $(58 / F)$ & 52 & 6.49 & 18.8 & 43 & 1 \\
\hline 6. $(45 / F)$ & 64 & 6.70 & 13.8 & 62 & 3 \\
\hline 7. $(32 / \mathrm{M})$ & 80 & 5.97 & 5.1 & 22 & 1 \\
\hline 8. $(20 / \mathrm{M})$ & 90 & 5.68 & 1.5 & 16 & 4 \\
\hline 9. $(50 / \mathrm{M})$ & 250 & 7.36 & 6.4 & 39 & 2 \\
\hline 10. $(47 / \mathrm{F})$ & 400 & 6.83 & 1.8 & 64 & 1 \\
\hline 11. $(33 / \mathrm{M})$ & 713 & 5.30 & 0.8 & 22 & 3 \\
\hline
\end{tabular}

Indoor radon concentrations were initially measured for at least 3 months by an $\alpha$ track detector in 1987-90 (5,6). Radon concentration is shown as reassessed in 1991 by charcoal canister for 24 $h$; correlation between these measurements was significant $(R=0.88, p<0.05)$. SCE frequencies significantly correlated with exposure to indoor cigarette smoke $(\mathbb{R}=0.597, p=0.05)$ and frequency of $M N$ was positively related to age $(R=0.688, p<0.05)$. MF showed significant positive correlation with age after exclusion of highest mutant frequency value $(R=0.667$, $\mathrm{p}<0.05 \mathrm{y}$

However, the small sample size should be noted. Our data diverge from the results reported by Bridges et al. (4). Applying the cloning efficiency method for hprt-mutation analysis, these investigators found a positive association between the hprt-mutations in human peripheral lymphocytes and domestic radon concentration. In their study, the significant association disappeared after correction for age and cloning efficiency and after exclusion of the highest reading. Our results confirm the necessity to evaluate thoroughly possible confounding effects of age and smoking when studying the relation between indoor radon exposure and genetic damage.

Further research at this genetic marker level should be directed at a more reliable establishment of exposure-effect relations. Exposure should be defined as the internal lung radon dose, calculated from accurate measurements of in- 
door radon air concentrations and occupancy of the house and by use of lung dosimetry models. Eventually, this multiple biomarker approach may be an aid in the evaluation of current risk assessment models, which postulate a linear relation between indoor air radon exposure and cancer.

We thank C. Puts, environmental officer, township of Visé, Belgium and Dr. L.W. Put, Nuclear Acceleration Institute, University of Groningen, The Netherlands, for their assistance in contacting the participants to this study.

\section{References}

1. Henshaw, D.L.; Eatough, J.P.; Richardson, R.B. Radlon as a causative factor in induction of myeloid leukaemia and other cancers. Lancet 335: 1008-12; 1990.

2. Richardson R.B.; Eatough, I.P.; Henshaw, D.L. Dose to red bone marrow from natural radon and thoron exposure. Br. J. Radiol. 64: 608-24; 1991.

3. Pohl-Rüling, J. Chromosome aberrations in man in areas with elevated natural radioactivity. XV Berzulius Symposium: 103-11; 1988.

4. Bridges, B.A.; Cole, J.; Arlett, C.F., et al. Possible association between mutant frequency in peripheral lymphocytes and domestic radon concentrations. Lancet 337: 1187-89; 1991.

5. Put, L.W. Radon concentrations in twenty dwellings. Groningen: Nuclear Acceleration Institute, R04 March; 1989.

6. Hallez, S.; Flemal, J.M. Cargraphie communale des concentrations de radon a l'interieur des habitations. Bruxelles: Institut d'Hygiene et d'Epidemiologie; 1990.

7. Dean, B.J. Danford, N. Assays for detection of chemically induced chromosome damage in cultured mammalian cells. In: Venitt S., Parry J.M. eds. Mutagenicity testing. Oxford: IRL Press, 187-232; 1984.

8. Fenech, M.; Morley A. Measurements of micronuclei in lymphocytes. Mutation Res. 147: 29-37; 1985. 


\title{
Chapter 8
}

\section{Genetic biomarkers indicative for DNA damage in relation to indoor radon exposure}

\author{
H.J. Albering, J.J.M. Engelen ${ }^{1}$, G.J. Hageman, L. Koulischer ${ }^{2}$, H. Vanmarcke ${ }^{3}$, \\ J.C.S. Kleinjans
}

Department of Health Risk Analysis and Toxicology, ${ }^{1}$ Department of Genetics, PO Box 616, 6200 MD Maastricht, ${ }^{2}$ Centre of Human Genetics, University of Liège, 4000 Sart Tilman Liège, ${ }^{3}$ Nuclear Research Centre, $2400 \mathrm{Mol}$, Belgium

Based on: Annales de I'Association Belge de Radioprotection, $19, \overline{12}$; 15-26 (1994)

\begin{abstract}
The cancer risk assessment in humans exposed to radon was evaluated using four cytogenetic biomarkers indicative for genetic damage. These genetic markers were analyzed in peripheral lymphocytes from 24 subjects living in the township of Visé in Belgium. Indoor radon concentrations in their dwellings ranged from 50 to 3300 $\mathrm{Bq} / \mathrm{m}^{3}$. Occurrence of lymphocyte sister chromatid exchanges, chromosome aberrations and micronuclei frequency in peripheral lymphocytes did not correlate with indoor air radon concentrations, indicating that peripheral lymphocyte DNA is not adversely affected as a consequence of indoor air radon concentration.
\end{abstract}

\section{Introduction}

In The Netherlands and Belgium, radon and radon daughters considerably contribute to the background of environmental irradiation received by man. The average annual effective dose equivalent for man due to radon has been estimated to be $1.2 \mathrm{mSv}$ a year and contributes at this exposure level for about $50 \%$ to the total exposure of all sources of ionizing radiation. Several epidemiological studies of uranium and other underground miners have shown a relationship between radon exposure and lung cancer (1-4). In addition, it is suggested that next to cigarette smoking radon exposure is an important risk for lung cancer for the general population (5-7). Several case-control studies have shown no increase in risk of lung cancer associated with domestic radon exposure $(8,9)$. However, it is difficult to investigate the relationship between low levels of environmental exposure to radon and cancer mortality. Actual observations in humans as well as large sample sizes are needed. Furthermore, 
accurate measurements of radon levels in dwellings are necessary (10).

The estimated number of radon related deaths in The Netherlands corresponds to about 900 fatal lung cancers per year based on extrapolations from epidemiological studies of miners exposed to radon (11).

This indicates that indoor radon exposure might also be a causal factor in lung carcinogenesis among the general population but the factual risk of the general population to low dose radon exposure remains unclear.

Furthermore, several extrapulmonary cancers have also been associated with radon exposure. These include leukaemia, melanoma, kidney and prostate cancer (12-14). However, these data are sparse and the geographical association are weak and very reliable.

Over the last decade, several markers of DNA damage have been developed by application of genetic techniques which may be indicative for the oncogenesis of cancer at the biological rather than at the pathological levels.

Higher frequencies of chromosome aberrations in peripheral lymphocytes have been detected in people exposed to a low level of radiation from natural sources (15), also an increase of chromosome aberrations has been found in uranium miners (16). Furthermore, Bridges and co-workers have shown a possible dose-response relationship between indoor air radon levels ranging from $30-700 \mathrm{~Bq} / \mathrm{m}^{3}$, and the hypoxanthine guanine phosphoribosyl transferase (hprt) mutation frequency in DNA of peripheral lymphocytes of non-smoking subjects (17). Because of the growing concern of the carcinogenic effect of low doses of alpha particles derived from radon in homes, we find it worthwhile to analyze cytogenetic biomarkers, indicative for DNA-damage, in a population exposed to domestic radon.

A pilot study has shown that analysis of peripheral lymphocytes sister chromatid exchanges, micronuclei frequency, hypoxanthine guanine phosphoribosyl transferase (hprt) mutation frequency and chromosome aberrations in relation to domestic radon exposure in dwellings in The Netherlands and Belgium can readily be performed (18).

In view of the rather large inter individual variations in cytogenetic biomarker responses, we speculate that a larger sample size is necessary before reliable conclusions can be drawn in relation with exposure to domestic radon.

The present follow up study has therefore been designed to study peripheral lymphocyte DNA damage in a larger population exposed to domestic radon. 


\section{Methods}

\section{Selection of participants}

An initial study on indoor air radon levels has been performed in the township of Vise in Belgium in order to achieve a reliable selection of participants at relatively high exposure levels. The selection of the individual dwellings was based on the knowledge of geological structure, e.g. carboniferous rocks with high levels of uranium phosphate mineralizations of the soil.

From the local authorities, 420 addresses were obtained. A questionnaire in which data of biological interest (age, smoking habits, medicine, alcohol and coffee consumption, occupational exposure, vaccination and chemotherapy and also the period living in the particular houses) were requested, was used for final selection of the participants. From the total response of 218,125 dwellings were selected for indoor radon measurements.

The indoor radon concentrations (living room) were determined by means of a charcoal canister during one day in February 1992.

After proper selection, a final number of 24 individuals entered the study, possible confounding factors as age and gender as well as period living in the particular house being homogeneously distributed among this population. Two subjects were current smokers, 15 were non-smokers and 9 were former smokers. All subjects donate $10 \mathrm{ml}$ of venous blood in heparinized tubes for lymphocyte genome analyses.

The indoor radon concentration was once again determined for at least three months by means of an alpha track detector (June to September 1992). For both radon measurements, the concentrations were determined by the Nuclear Research Centre in Mol, Belgium.

All slides were coded to microscope analysis for the three cytogenetic endpoints. The SCE-incidence and chromosome aberrations in peripheral lymphocytes have been analyzed according to the standard protocol by Dean and Danford (19). SCE frequencies were determined by means of the analysis of 40 metaphases with a minimum of 40 chromosomes. The numbers of SCE's were normalized over 46 chromosomes and averaged as number of SCE per cell per individual.

Chromosome aberrations were scored in 100 metaphases containing 46 chromosomes and also averaged as number of CA per cell per individual.

Micronuclei were scored by means of the cytokinesis block method (20). For each subject, 2000 cytokinesis blocked (CB) cells were analyzed for presence of micronuclei ( 1000 cells from each of two replicate cultures). The results are expressed as the average number of MN per $1.000 \mathrm{CB}$ cells. 


\section{Statistical edaluation}

Linear and multiple regression analysis were used to evaluate the reliability between the various effect parameters.

\section{Results and discussions}

\section{Domestic radon concentrations}

In the Visé region located at the Belgian border, domestic radon concentrations tend to be relatively high. Figure 8.1 shows the distribution of the indoor air radon concentrations in 116 dwellings in the township of Visé.

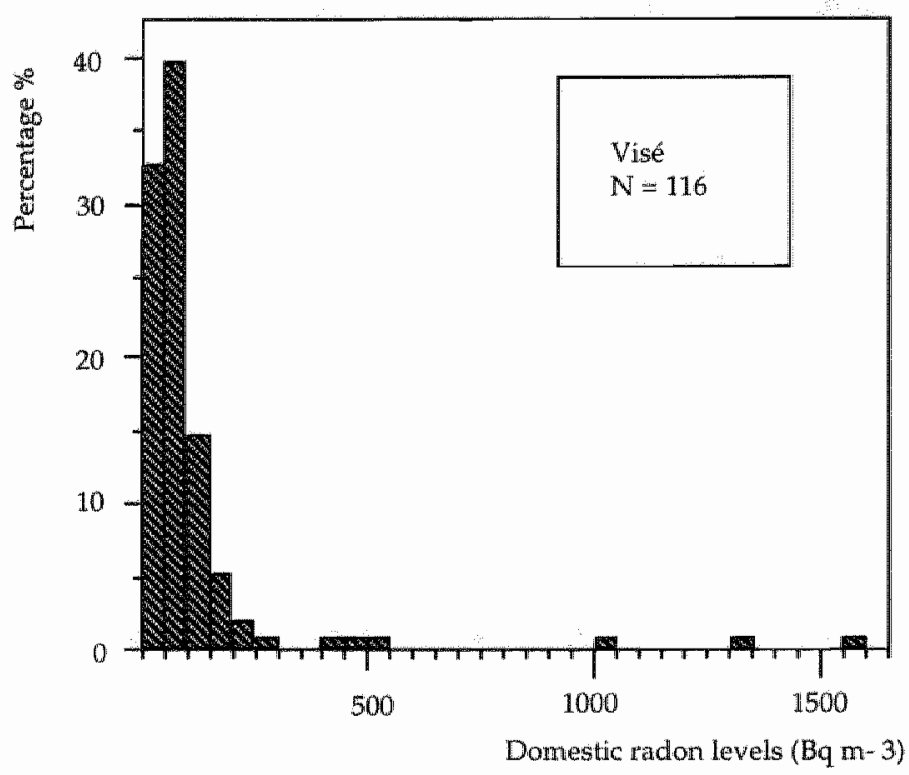

Figure 8.2, Histogram of the concentrations of radon in the living room of dwellings in the township of Visé

The radon measurements have been determined by a charcoal detector for one day in February 1992 and are log normally distributed. This distribution is in agreement with many other published data on domestic radon exposure (21-23). The arithmetic and geometric mean are respectively 116 and $68 \mathrm{~Bq} / \mathrm{m}^{3}$. The highest value measured by this method in an individual house was 1625 $\mathrm{Bq} / \mathrm{m}^{3}$. Only a small proportion of the radon concentrations measured in the dwellings in the township of Visé, is above $400 \mathrm{~Bq} / \mathrm{m}^{3}$. Due to this indoor 
radon concentration range it appeared feasible to construct an exposure gradient from high to low levels of indoor radon exposure for the follow up study. 24 subjects living in the township of Visé have participated in the follow up study. The domestic radon concentrations were once again determined in these 24 dwellings by means of a time integrated alpha track detector for three months. Indoor radon measurements by means of short-term charcoal detectors versus time integrated alpha track detectors in these selected dwellings correlate significantly $(r=0.56, p<0.05)$. We like to stress that in our view, long term radon concentration measurements applying time integrated alpha-track methodology, still are necessary for a reliable selection of subjects exposed to relatively high indoor radon levels $\left(>300 \mathrm{~Bq} / \mathrm{m}^{3}\right)$. However, short term tests may be used for screening in order to determine if additional tests are needed. Time integrated measurements are furthermore required for accurate dose calculations (24).

\section{Biomarker analyses}

Table 8.1 summarizes the indoor radon exposure and the cytogenetic endpoints, chromosome aberrations, sister chromatid exchange frequency and micronuclei frequency in peripheral lymphocytes of 24 subjects exposed to indoor radon in the township of Visé.

The first results of this follow up study on genetic biomarkers indicative for DNA damage and indoor radon exposure show that there is no relation between domestic radon exposure and the occurrence of sister chromatid exchanges, chromosome aberrations and micronuclei frequency in peripheral lymphocytes of the exposed subjects. No interaction between known confounders as subjects age, smoking habits, alcohol and coffee consumptions, use of medicine and occupational exposure and the induction of micronuclei and chromosome aberrations in peripheral lymphocytes appear to occur. However, a significant positive correlation is found between cigarette smoking and the $S C E$-frequency in peripheral lymphocytes of the exposed population ( $R=0.498$, $p<0.05)$.

The hypothesized adverse health effect of radon in the general population has not been directly demonstrated in this study. In the study of Pohl-Ruting the chromosome aberrations in peripheral lymphocytes of people exposed to natural radioactivity, appear to follow a non linear dose-response relationship. The doses have been accumulated over a 6 month period and range from 0.6-12 mGy (15). However in the present study, no relation is found between chromosome aberrations in peripheral lymphocytes and indoor radon exposure (range $50-3300 \mathrm{~Bq} / \mathrm{m}^{3}$ ) in people living in the township of Visé. In view of these rather low radon doses, chromosome aberration frequencies are expectantly relatively low. 
Table 8.1: Sister chromatid exchange frequency (SCE/cell), chromosome aberrations (CA/cell) and micronuclei frequency $(\mathrm{MN} / 1000 \mathrm{CB}$ cells) in peripheral lymphocytes of the Vise population exposed to indoor radon

Cytogenetic biomarkers

\begin{tabular}{|c|c|c|c|c|}
\hline $\begin{array}{l}\text { Subject } \\
\text { (age/sex) }\end{array}$ & $\begin{array}{l}\text { Radon exposure level } \\
\left(\mathrm{Bq} / \mathrm{m}^{3}\right)\end{array}$ & $\begin{array}{l}\text { SCE/cell } \\
\text { (it sd) }\end{array}$ & $\mathrm{CA} /$ cell & $\begin{array}{l}\mathrm{MN} / 1000 \mathrm{CB} \text { cell } \\
( \pm s d)\end{array}$ \\
\hline 1. $(39 / \mathrm{M})$ & 50 & $6.16( \pm 2.59)$ & 0.00 & $18( \pm 2.5)$ \\
\hline 2. $(39 / \mathrm{F})$ & 55 & $6.04( \pm 2.61)$ & 0.00 & $15( \pm 1.5)$ \\
\hline 3. $(41 / / \mathbb{F})$ & 55 & $686( \pm 2.49)$ & 0.02 & $24( \pm 6.0)$ \\
\hline 4. $(45 / \mathrm{M})$ & 55 & $6.73( \pm 2.55)$ & 0.00 & $16( \pm 0.5)$ \\
\hline 5. $(55 / \mathbb{F})$ & 65 & $8.77( \pm 4.06)$ & 0.01 & $16( \pm 3.5)$ \\
\hline 6. $(21 / F)$ & 70 & $6.21( \pm 2.98)$ & 0.00 & $6( \pm 0.5)$ \\
\hline 7. $(32 / /)$ & 70 & $6.53( \pm 2.89)$ & 0.02 & $22(4.0)$ \\
\hline 8. $(46 / F)$ & 70 & $8.00( \pm 3.51)$ & 0.00 & $18( \pm 1.5)$ \\
\hline 9. $(48 / M)$ & 75 & - & 0.00 & $11( \pm 3.0)$ \\
\hline 10. $(28 / M)$ & 85 & $6.79( \pm 2.16)$ & 0.01 & - \\
\hline $11 .(41 / \mathrm{F})$ & 100 & $6.60( \pm 3.13)$ & 0.02 & $18( \pm 0.5)$ \\
\hline 12. $(45 / M)$ & 105 & $6.05( \pm 2.26)$ & 0.00 & $16( \pm 3.0)$ \\
\hline $13 \cdot(28 / M)$ & 110 & $5.75( \pm 2.20)$ & 0.03 & $13( \pm 2.5)$ \\
\hline 14. $(47 / \mathbb{E})$ & 125 & $7.43( \pm 3.19)$ & 0.00 & $14( \pm 1.0)$ \\
\hline 15. $(42 / M)$ & 195 & $6.67( \pm 2.59)$ & 0.00 & $14( \pm 5.5)$ \\
\hline $16 .(33 / \mathrm{F})$ & 225 & $6.71( \pm 3.42)$ & 0.00 & $1.5( \pm 2.5)$ \\
\hline 17. $(47 / M)$ & 225 & $8.43( \pm 3.02)$ & 0.02 & $24( \pm 0.5)$ \\
\hline 18. $(37 / \mathrm{F})$ & 240 & $6.81( \pm 2.21)$ & 0.01 & $27( \pm 0.5)$ \\
\hline 19. $(28 / \mathbb{F})$ & 265 & $5.48( \pm 2.04)$ & 0.01 & $29( \pm 1.5)$ \\
\hline 20. $(20 / F)$ & 330 & $7.5 \mathbb{A}( \pm 2.56)$ & 0.02 & $10( \pm 0.5)$ \\
\hline 21. $(40 / M)$ & 480 & $6.58( \pm 2.09)$ & 0.03 & $20( \pm 0.5)$ \\
\hline $22 .(48 / M)$ & 500 & $6.28( \pm 3.14)$ & 0.01 & $25( \pm 0.5)$ \\
\hline 23. $(52 / M)$ & 510 & $6.60( \pm 2.77)$ & 0.00 & $10( \pm 1.5)$ \\
\hline $24 .(26 / M)$ & 3300 & $6.56( \pm 2.84)$ & 0.01 & $12( \pm 0.5)$ \\
\hline
\end{tabular}

Many metaphases have to be scored for the presence of chromosome aberrations, for obtaining significant differences between the different dose groups. Pohl-Rulling thave pooled the results from test persons receiving similar doses, thereby scoring more than 500 metaphases (15). Conclusions on the linearity of the dose response relationship between individual chromosome aberrations in peripheral lymphocytes and radon exposure are therefore not possible.

A positive significant correlation between peripheral lymphocyte hprt mutation frequency and domestic radon exposure in Somerset, UK, has been found by Bridges et al. (1.7). In the beginning of next year we will have obtained our hprt mutation frequency results and we will be able to elaborate on this topic. 


\section{Conclusions}

In summary, in the previous feasibility study (18) as well as the presented follow up study no increases have been found in the frequency of micronuclei, sister chromatid exchanges and chromosome aberrations in peripheral lymphocytes of the exposed population to domestic radon, indicating no increased risk of DNA damage in this tissue at these particular exposure levels.

Conclusions on the linearity of the dose response curve between DNAdamage and radon exposure and the implications for current risk assessment models are for this moment premature.

Acknowledgement

We thank C. Puts, environmentall officer, township of Vise, Belgium for the opportunity of providing the 420 addresses in the township of Visé

\section{References}

1. Zhen, XX.; Lubin, J.H.; Yao, L.J.; Fen, X.L.; Sheng, L.Q.; Zhang, Y.W.; Blot, W.J. A cohort study in southern China of Tin Miners exposed to radon and radon decay products. Health Physics woll 64, no. 2: 121-131; 1993.

2. Sevc, I.; Tomasek, L; Kunz, E.; Placek, V.; Chemelevsky, D.; Barclay D.; Kellerer, A.M. A survey of the Czechoslowak follow-up of lung cancer mortality in uranium miners. Health Physics vol. 64, no. 4: 355-369; 1993.

3. Kusiak, R.A.; Ritchie, A.C.; Springer, J.; Muller, J. Mortality from stomach cancer in Ontorio Miners. British Journal of Industrial Medicine vol. 50: 920-928; 1993.

4. Samet, I.M.; Pathak, D.R.; Morgan, M.V.; Key, C.R.; Validivia, A.A.; Lubin, J.H. Lung cancer mortality and exposure to radon progeny in cohort of New Mexico underground miners. Health Physics vol. 61, no. 6: 745-752; 1991.

5. Biberman, R.; Lusky, A.; Schlesinger, T; Margaloit M.; Neeman, E.; Modan, B. Increased risk for small cell lung cancer following residential exposure to low-dose radon: A pilot study. Archives of Environmental Health vol. 28, no. 4: 209-212; 1993.

6. Svensson, C.: Pershagen, G.; Klominek, J. Lung cancer in women and type of dwelling in relation to radon exposure. Cancer Reseatch vol. $49: 1861-1865 ; 1989$.

7. Schoenberg, J.B.; Klotz, J.B.; Wilcox, H.B.; Nicholls, G.P.; Gil-del-Real, M.T.; Stemhagen, A.; Mason, T.J. Case control study of residential radon and lung cancer among New-Jersey women. Cancer Research vol. 50, no. 15:6520-6524; 1990.

8. Blot, W. .: Xu, Z.X; Boice, J.D. Ir.; Zhao, D. H.; Stone, B.J.; Sun, J.; Jing, L. B.; Faumeni, J.F.Jr. Indoor radon and lung cancer in China. Journal of the National Cancer Institute vol. 82, no. 12: 1025-1030; 1990. 
9. Lees, R.E.M.; Steele, R.; Roberts, J.H. A case-control study of lung cancer relative to domestic radon exposure. International Joumal of Epidemiology vol. 16, no. 1: 7-12; 1987.

10. Lubin. Health Physics vol. 65 , no. 5: 529-531; 1993.

11. Vaas, L.H. Criteriadocument Radon, RIVM report no. 710401014; Bilthoven, 1991 (in Dutch).

12. Henshaw, D.L., Eatough, I.P.; Richardson, R.D. Radon as a causative factor in induction of myeloid Jeukaemia and other cancers. The Lancet vol 335: 1008-1012; 1990.

13. Lucie, N.P. Radon exposure and leukaemia. The Lancet vol 2 (8654): 99-100; 1989

14. Viel, J.Padon exposure and leukaemia in adulthood. International Journal of Epidemiology vol 22, no. 4: 627-631; 1993.

15. Pohl-Rüling, J. Chromosome aberrations in man in areas with elevated natural radioactivity. Berzelius Symposium XV, 103-111; 1988.

16. Brandom, W.F.; Saccomanno, G.; Archer, V.E.; Archer, P.G.; Bloom, A.D. Chromosome aberrations a biological dose response indicator of radiation exposure in uranium miners. Radiation Research. 76: 159-171; 1978.

17. Bridges, B.A.; Cole, J.; Arlett, C.F.; Green, M.H.; Waugh, A.P.; Beare, D.; Henshaw, D.L.; Last, R.D. Possible association between mutant frequency in peripheral lymphocytes and domestic radon concentrations. The Lancet. 337: 1187-1189; 1991

18. Albering, H.J.; Hageman, G.J.; Koulischer, L.; Engelen, J.J.M.; Herens, C.; Kleinjams J.C.S. Assessment of cytogenetic damage in human populations in relation to indoor exposure to radon. A feasibility study. The Lancet vol. 340:8821; 739; 1992.

19. Dean, B.J. Danford, N. In: Venit, S. Parry, J.M. eds. Mutagenicity testing. Oxford. IRL Press 1984.

20. Fenech, M.; Morley, A.A. Measurement of micronuclei in lymphocytes. Mutation Research 147: 29-37; 1985.

21. Lubin, J.H.; Boice, J.D. Jr. Estimating Rn-induced lungcancer in the United States. Health Physics vol 57, no 3: 417-427; 1989.

22. Put, L.W.; de Meijer, R.J.; Hogeweg, B. Survey of radon concentrations in Dutch dwellings. The science of the total environment 45: 441-448; 1985 .

23. Schmier, H.; Wicke, A. Results from a survey of indoor radon exposure in the Federal Republic of Germany. The science of the total environment 45: 307-310; 1985.

24. Quindos, L.S.; Fernandez, P.L.; Soto, J. Short vs long term indoor radon measurements. Health Physics vol 61, no 4: 539-542; 1991. 


\title{
Chapter 9
}

\section{Indoor Radon exposure an extrapulmonary genetic risk?}

\author{
H.J. Albering, J.J. Engelen ${ }^{1}$, L. Koulischer ${ }^{2}$, 1.J. Welle, \\ and J.C.S Kleinjans.
}

\begin{abstract}
Department of Health Risk Analysis and Toxicology, ${ }^{1}$ Department of Genetics, University of Limburg POBox $^{6} 16,6200 \mathrm{MD}$ Maastricht, The Netherlands, ${ }^{2}$ Centre for Human Genetics, University of Liège, Sart Tilman, Liège, Belgium.
\end{abstract}

Published in: The Lancet, 344, 8924; 750-751 (1994)

Sir. - The possibility of adverse health risks in relation to indoor exposure to radon, a radioactive gas infiltrating into dwellings from underlying uranium containing soils, is continuously debated. Radon is known to represent a major cause of lung cancer in uranium miners. Additionally, a recent case-control study has shown an increased incidence of lung cancer at domestic radon concentrations of $140 \mathrm{~Bq} \mathrm{~m} \mathrm{~m}^{-3}$ and higher (1). Furthermore, indoor radon is suggested to cause cancer at extra-pulmonary sites (2). Monitoring of genetic damage in blood lymphocytes is frequently used to assess effects of exposure to environmental carcinogens; thus, indoor radon-exposed humans have been analyzed for peripheral lymphocyte hprt mutations, with conflicting results $(3,4)$.

As a follow up to our pilot study, we aimed to re-evaluate the relationship between domestic radon exposure and DNA damage in a larger population (4). Therefore, chromosome aberrations, sister chromatid exchanges, micronuclei and hprt mutations in peripheral. lymphocytes have been determined by standard procedures (4) in individuals newly selected from the township of Visé, Belgium. The occurrence of uranium mineralizations containing paleozoic rocks at soil surface was the criteria to select 116 houses for prescreening of indoor air radon concentrations. Only in $26 \%$ of the dwellings, radon levels appeared above $100 \mathrm{~Bq} \mathrm{~m}$; 24 inhabitants of these houses were incorporated into this study. The indoor radon concentrations ranged from 50 to $3300 \mathrm{~Bq} \mathrm{~m} \mathrm{~m}^{-3}$. One subject with an extremely high domestic radon exposure of $3300 \mathrm{~Bq} \mathrm{~m}$. and one subject who had to undergo chemotherapy, have subsequently been excluded.

The results of this study are consistent with our previous observations. No association exists between domestic radon levels and lymphocyte chromosome aberrations, sister chromatid exchanges and micronuclei frequencies. After cal- 


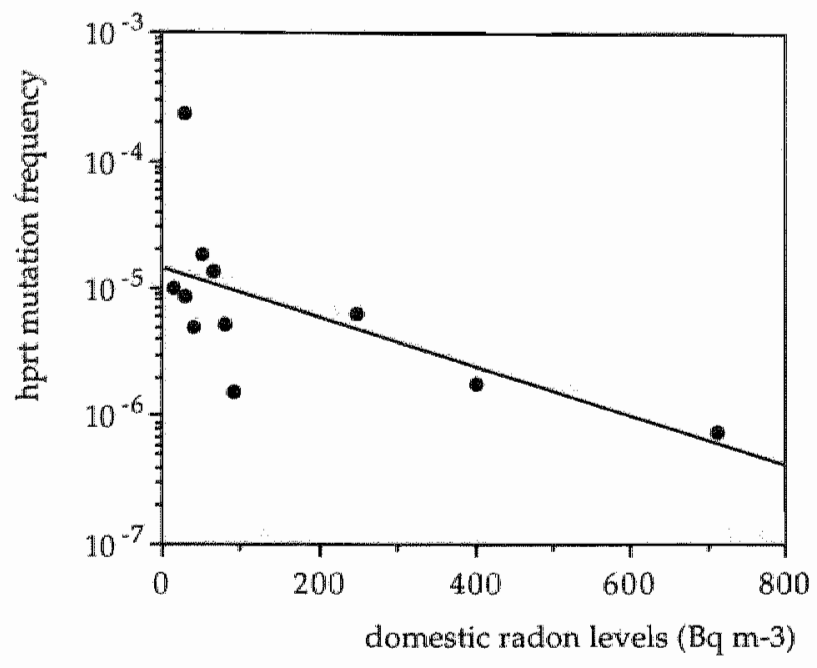

Figure 9.1a: Relationship between domestic radon concentrations and hprt mutation frequencies in peripheral lymphocytes of exposed individuals.

Pilot study (4). The domestic radon exposure have been measured by means of a charcoal canister during one day in 199\%. $(\mathrm{R}=-0.632, \mathrm{p}<0.05)$.

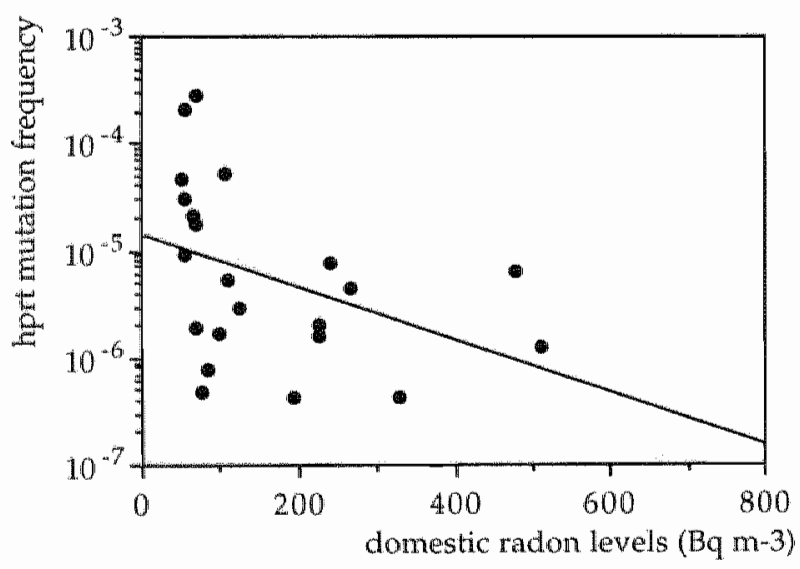

Figure 9.1b: Relationship between domestic radon concentrations and hprt mutation frequencies in peripheral lymphocytes of exposed individuals.

Follow up study. The domestic radon exposure have been analyzed by means of an time integrated alpha track detector during three months in 1992 ( $R=$ $-0.402, p=0.06$ ) 
culation of the annual effective dose of alpha radiation, using the 1993 International Commission on Radiological Protection conversion conventions with an equilibrium factor of 0.4 for radon/radon decay product ratios, and an occupancy factor of the house of $80 \%$, or alternatively of $60 \%$ for subjects with an occupation outdoors, also no association was found between the annually cumulating dose, varying from 0.9 to $12.6 \mathrm{mSv}$, and lymphocyte genetic damage.

Remarkably, although new participants were selected for our second study, we again observed a negative association between (logarithmic transformed) lymphocytic hprt mutation frequency and the exposure to indoor radon (Figure 9.1). We suggest that exposure to rather low levels of radioactive radon induces a repair capacity for hprt mutations as has been described in vitro, which at gradually increasing radon exposure reduces the effectiveness of other mutagenic factors (5). Only sister chromatid exchange frequencies appeared to be significantly correlated with subject's age $(R=0.474, p<0.05)$ as well as with cigarette smoking $(\mathrm{R}=0.496, \mathrm{p}<0.05)$.

We conclude that no peripheral genetic risk at these levels of indoor radon exposure exists. This is confirmed by a recent study among uranium miners which also reported no indication for extrapulmonary cancer risks (6).

We thank dr. H. Vanmarcke, Nuclear Research Centre, Mol, Belgium, for determining the radon concentrations in the dwellings. 


\section{References}

1. Pershagen, G.; Akerblom, G.; Axelson, O.; Clavensjo, B.; Damber, L.; Desai, G.; et al. Residential radon exposure and lung cancer in Sweden. N Engl J Med 330: 15964; 1994.

2. Henshaw, D.L. Eatough, J.P.; Richardson, R.B. Radon as a causative factor in induction of myeloid leukaemia and other cancers. Lancet 335: 1008-12; 1990.

3. Bridges, B.A.; Cole, J.; Arlett, C.F.; Green, M.H.L.; Waugh, A.P.W.; Beare, D.; et al. Possible association between mutant frequency in peripheral lymphocytes and domestic radon concentrations. Lancet 337: 1187-89; 1991.

4 Albering. H.J "Hageman, G.J.; Kleinjans, J.C.S., Engelen, J.J.M.; Koulischer, L.; Herens, C. Indoor radon exposure and cytogenetic damage. Lancet 340: 739; 1992.

5. Kelsey, K.T.; Memisoglu, A.; Frenkel, D.; Liber, H.L. Human lymphocytes exposed to low doses of X-rays are less susceptible to radiation-induced mutagenesis. Mutation Res 263: 197-201; 1991.

6. Tomásek Li; Darby, S.C.; Swerdlow, A.J.; Placek, V.; Kunz, E. Radon exposure and cancers other than lung cancer among uranium miners in West Bohemia. Lancet 341 : 919-23; 1993. 


\section{Chapter 10}

\section{Summary and General Discussion}

In this thesis, the health risks of different environmental hazards such as heavy metals, PCBs/dioxin and indoor radon have been evaluated in several case studies. The process of risk assessment is a formal tool that can be applied to assess the potential adverse health effects in relation to environmental hazards. It is embedded in "Premises of Risk Management" of the Dutch National Environmental Policy Plan in 1989 (1). The process has been established in 1983 in general terms by the U.S. National Academy of Science/National Research Council. This committee defines risk assessment as 'estimating the magnitude, likelihood and uncertainties of environmentally induced health effects'. The process generally exists of four steps: hazard identification, exposure assessment, dose-response assessment and risk characterization (2).

The results of a risk assessment together with social, economic and political aspects are integrated into the risk management process, to formulate decisions aimed to protect public health.

As part of the risk characterization step, the uncertainties in the successive steps of the assessment process have to be described. These uncertainties are most commonly directed to the limited scientific knowledge to interpret the available data and furthermore, to the lack of available data (3-6). In order to deal with uncertainty in health risk assessments default assumptions have to be applied. Default assumptions are generic assumptions based on general knowledge, to fill in data gaps, and are furthermore used as a policy option for dealing with disagreements in models and theories (7). The use of default assumptions in risk assessment is matter of debate (4,6-10). Some authors comment that these assumptions are conservative and that it is not always clear on what judgements they are based; others argue that default assumptions enhance the uniformity of risk assessments. The National Academy of Science and the National Research Council stated in their follow-up report in 1994 (11) that the merits and effects of risk assessments will be enhanced by generating more data and by relying on fewer default assumptions, although default assumptions are justified as screening tools. In order to be able to rely on fewer default assumptions, the research underlying the risk assessment process has to be improved and results have to be effectively incorporated into the risk assessment process $(3,6,12-15)$. Risk assessment, research and risk management are interrelated, and a feedback loop is postulated between risk management, risk assessment and research $(3,11)$. 
In addition to the risk assessment process, the environmental health chain can be used to evaluate the potential health risks of environmental hazards. The environmental health chain is characterized by a continuum of events: from the emission from a source into the environment to the final adverse health effects (3).

The chapters in this thesis have been structured along the environmental health chain as illustrated in Figure 10.1. Exposure assessment as part One of this thesis, concentrates on the first part of the chain: from emission from a source into the environment to environmentall concentration to human exposure to internal dose, while dose-response assessment (part Two) concentrates on the last part of the chain: from human exposure to internal dose and to the ultimate adverse health effects (3).

In general, there are three different approaches to estimate exposure to an environmental agent: the direct, the reconstructive and the predictive approach $(10,16,17)$. The predictive approach has been used in part One of this thesis by applying different scenario models. This method is predominantly used in environmental health studies (17-23) and has been developed as a default method, to be used if measurements are unavailable (6). Additionally, to the use of scenario models, location-specific measurements have been performed to replace some default assumptions and to provide more realistic estimates of exposure. Subsequently, the estimated exposure added to background exposure levels, has been compared to existing health-based standards (e.g. TDI) to determine whether there is any potential health impact. The first two case studies in this thesis address PCB and dioxin exposure.

Chapter 2 describes a human health risk assessment in relation to dioxin/PCB emission concerning three newly proposed waste incinerators in The Netherlands. The incineration of solid waste is regarded to represent the main source of dioxin exposure for the general population $(24,25)$. Before a waste incinerator can be installed it is generally required that a health risk assessment is performed as part of the environmental impact assessment (ELA) procedure. The only way to estimate exposure that might arise from future actions, is by using the predictive approach (5). The current exposure model has been designed by using worst-case assumptions to estimate additional exposure to the $\mathrm{PCB} /$ dioxin emission (expressed as toxic equivalents) at the maximally exposed location as estimated in the EIAs. From the risk management point of view, it is acceptable to use a worst-case scenario in order to protect public health.

Although numerous uncertainties are inherent to this exposure model, the major uncertainty in this risk assessment appears to be the PCB-TEQ emission from a WI. In monitoring the emission from WIs, only the dioxins (expressed as TEQ) have been taken in consideration (26). Newly to be constructed WIs 

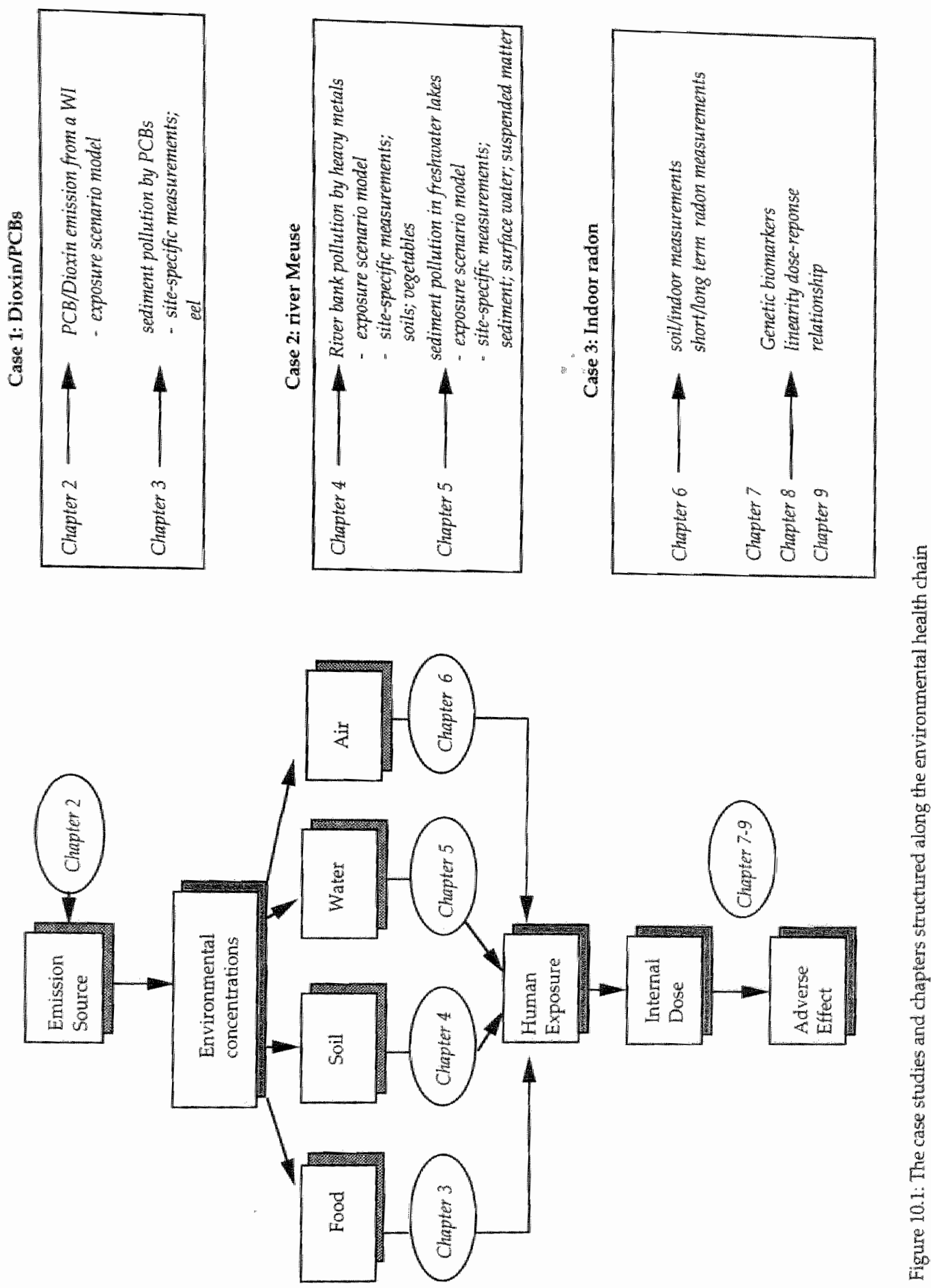
have to meet with emission standards by the Waste Incinerator Act from 1993. The dioxin-TEQ emission standard has been set on $0.1 \mathrm{ng} \mathrm{TEQ} / \mathrm{m}^{3}$. However, the emission of PCBs by a WI is not regulated. Quantitative information about the PCBs and in particular the PCB-TEQ emission is not available. The emission of PCBs as estimated in the EIAs is based on the amount of PCBs in the waste taken different extraction efficiencies into consideration. In calculating the health risk for the different PCB-TEQ emission scenarios, we have assumed that the contribution of the coplanar PCBs to the total PCB emission is a fixed percentage (10\%). The calculated total (additional and background) exposure to dioxin-TEQ and PCB-TEQ has been compared to the health based standard (TDI) of $10 \mathrm{pg}$ TEQ $/ \mathrm{kg}$ bw per day as recommended by the WHO. For a few PCB-TEQ emission scenarios the TDI will be exceeded. However, a study performed in The Netherlands recently, indicated that the PCB-TEQ emission accounted for only a few percents of the total dioxin-TEQ emission (26). This suggests that the calculated PCB-TEQ emission in our study overpredicts reality and as a consequence also the to be expected exposure risks are overestimated. From this study, it is concluded that the major uncertainty in exposure risk assessment for a population surrounding a $W I_{x}$ refers to $P C B$ emission. To regulate the PCBTEQ emission by a WI, it is recommended that the dioxin-TEQ emission standard of $0.1 \mathrm{ng} \mathrm{TEQ} / \mathrm{m}^{3}$ matches the TEQ emission of both dioxins and PCBs.

The second case study with respect to $\mathrm{PCB}$ and dioxin exposure describes the health risks in relation to consumption of contaminated fish (chapter 3). The sediments of brooks in the south-west part in The Netherlands are polluted by various heavy metals, insecticides and PCBs. Public health officials were concerned about the hazards associated with the consumption of contaminated fish caught at these brooks by recreational anglers. Recreational anglers fishing in these brooks, tended to consume more fish and consequently fish contaminants, than the general population and therefore appeared to be at higher exposure risk. Location-specific measurements of PCBs, insecticides and mercury in three eelsamples (each consisting of 25 specimen) were performed. The contaminant concentrations in the eel samples appeared to be low in comparison to eel samples from Dutch rivers. Only for the PCBs (as toxic equivalents) the potential human health risk associated with consumption of contaminated eel has been evaluated. Recreational anglers in this area appear to consume 10 eels per week on average during the months May till October. This study demonstrates the huge impact of data on fish consumption rates on the final outcome of the exposure assessment. Considering background exposure to TEQ, the dailly intake for anglers in this area appears to be $344 \mathrm{pg}$ TEQ, which is below the current TDI of $10 \mathrm{pg} T E Q / \mathrm{kg}$ bw. Eel consumption by recreational anglers in this area therefore does not impose a possible health risk. 
In chapter 5 exposure to river sediment derived contaminants has been evaluated. The sediments of two freshwater lakes along the river Meuse are highly polluted by heavy metals and PAHs. The lakes have been created by excavation of minerals, and are nowadays used for recreational activities such as swimming, surfing and fishing. A standard exposure scenario model has been applied to estimate exposure with respect to these recreational activities. The concentrations of the contaminants in sediments are the source for the model, that furthermore predicts the environmental concentration at the point of human exposure. For instance, the model calculates the contaminant concentration in fish. By incorporating location-specific measurements of the contaminant concentration in surface water and suspended matter, the exposure assessments have been refined and the uncertainties reduced. A possible health risk as a consequence of exposure to $\mathrm{Zn}$ and $\mathrm{Pb}$ is indicated in relation to the recreational activities on both lakes. The consumption of contaminated fish is the dominant exposure pathway for the heavy metals (e.g. $\mathrm{As}, \mathrm{Cd}, \mathrm{Cu}, \mathrm{Pb}$ and $\mathrm{Zn}$ ) and $\mathrm{PAH}$ (as $\mathrm{B}(\mathrm{a}) \mathrm{P}$ equivalents). Taken location-specific measurements into account, the risks of consumption of contaminated fish are reduced by more than two orders of magnitude implying that the health-based standards are not exceeded.

As previously described exposure through the ingestion of contaminated fish is also the only relevant exposure pathway in relation to sediment pollution of the two brooks located in the south-west part of The Netherlands (Chapter 3). Upon application of the same exposure scenario model, it is indicated that the location-specific levels of contaminants in eel, e.g. heavy metals, specifically $\mathrm{Hg}$, are actually higher than calculated. The total mercury content which exists almost entirely of methylmercury, has been analyzed in the fillet of the fish (27). A comparison between predicted vs measured concentrations in fish is not possible for the other compounds (e.g. PCBs and insecticides) because of the lack of appropriate data of the sediments. This underestimation of eel mercury content by the exposure assessment model can be due to several causes. Accumulation of contaminants in fish can occur via different processes; by diffusion across the gill or through components of the foodchain $(27,28)$. Physiochemical properties of the contaminant and the habitat and physiological properties of the organism comprise the most important factors (29). Accumulation of mercury in eel predominantly occurs by accumulation through the foodchain (30). The concentration in fish has been predicted by a general contaminant-specific bioconcentration factor, which expresses contaminant partitioning between fish and surface water. The BCF (mean value) represents the potential for accumulation of a compound (29). Several physical, chemical and biological parameters may contribute to the variation in $B C F$, such as fish species, age of the fish, dietary habits of the fish and chemical properties of the sediment $(30,31)$. Moreover, the BCF for mercury is based on total mercury concentration in fish and surface water. The 
speciation of mercury (inorganic, organic and methylmercury) is not taken into consideration (30). In addition, methylmercury can be formed from inorganic mercury in fish, which also contributes to the uncertainty of the general $\mathrm{BCF}$ (30). Concentrations in fish estimated by means of a general BCF value are therefore of limited accuracy (32).

This comparison between results from studies described in chapters 3 and 5 , clearly demonstrates the impact of intercompartimental transfer data on the final results of the exposure assessment, e.g. in relation to indirect exposure.

Due to the uncertainty of the $B C F$ it is recommended to use location-specific measurements of fish, specifically bottom feeding fish, to estimate the possible health risk in relation to the consumption of locally caught fish. In addition, information on local fish consumption rates and patterns is necessary to estimate the exposure correctly.

Next to the recreational function of the river, the banks of the river Meuse in The Netherlands and also in France and in a part of Belgium are commonly used for agriculture practice (e.g. pasture, arable farming and vegetable gardens). The frequent flooding of the river in these countries, however causes a more or less serious contamination of the soils in these areas. The agricultural function of the river is threatened by deposition of sludge and pollutants on the river banks. We have investigated the possible health risks in relation to the Dutch river bank pollution in the Borgharen-Itteren area after the flooding of the river during the winter of 1993-1994 (chapter 4). It was found that the river banks soils, and crops grown on these soils as well as cattle pasture may be burdened to a considerable degree by heavy metals.

After modeling the exposure scenario for agricultural situations, the highest intake appears associated with the consumption of meat and dairy products and results in a health risk for the general population in relation to $\mathrm{Cd}$ and $\mathrm{Pb}$ contamination of the river banks in the whole area under study. Incidentally, the health based standards for As and $\mathrm{Zn}$ are exceeded by children. However, it is assumed that $10 \%$ of the consumed meat and dairy products comes from the contaminated area, which is a conservative assumption and therefore, is not included in the realistic estimate of exposure based on location-specific measurements. These measurements were performed for quantification of the indirect exposure pathway (consumption of home grown vegetables) in view of the uncertainties regarding soil-plant transfer. The heavy metal concentrations in plants are modeled by contaminant-specific bioconcentration factors. In view of the large uncertainties on intercompartimental transfer parameters, as has been discussed previously, leafy vegetables (e.g. lettuce), legumes (e.g. beans) and root vegetables (e.g potatoes) have been grown in 6 experimental gardens in the area. The heavy metal levels in the crops appear within normal background levels, except for one garden located in an area with 
a flooding frequency of once every two years, where the cadmium concentration in lettuce and potatoes exceeded the maximum permissible concentration according to the Commodities Act. From this study it can be concluded that the measured mean contaminant-specific bioconcentration factor for the different plants appeared to be lower than the default value, except for $\mathrm{Cu}$ for which the measured mean values were higher. This implies that human exposure through the ingestion of vegetables has been overestimated by $70 \%$ for respectively $\mathrm{Cd}, \mathrm{Pb}$ and $\mathrm{Zn}$ and underestimated by $27 \%$ for $\mathrm{Cu}$. This demonstrates as in chapter 3 and 5 the influence of the transfer data on the final results of the exposure assessment. On the basis of the realistic estimate of exposure for the general population, a possible health risk for children as well as for adults is only indicated in relation with lead and cadmium contaminations of the river banks of the Meuse which are frequently inundated (flooding frequency every two years). Children appear to be a sensitive subpopulation to irreversibie brain damage and learning disabilities resulting from lead exposure because of which a health based standard has been formulated specifically for children (33).

In summary, the emission from a source is the first step in the environmental health chain from source to effect (Figure 10.1) and the uncertainty of the emission (chapter 2) at the beginning of the chain also influences the other steps through the chain and ultimately the assessment of the health risk related to the emission (6). To improve exposure assessment, location-specific measurements in the environmental compartments (chapter 3-5) have been performed. However, there are still uncertainties in the intervening steps from the environmental compartments to human exposure. Therefore, the estimated exposures in part One of this thesis should not be interpreted as the absolute measures of actual exposure. Direct measurements of exposure are the only way to determine actual exposure and to validate and verify the exposure model (6). However, it is very difficult for instance, to measure the additional exposure directly for the general population in relation to the emission of dioxin and PCBS by a WT, because the additional exposure is relatively low and is within background levels. Furthermore, a WI is not the only source which contributes to the exposure to dioxin and PCBs.

The estimated exposures to an environmental agent in part One of this thesis have been compared with established health based standards (e.g. TDI). The TDI refers to the reference dose of a substance that can be taken in without identifiable risk of lifetime exposure. In general, the TDI is derived from a noeffect level in animal studies divided by safety factors (e.g. for intra- and interspecies variation). This creates a safety margin for the most sensitive persons, examples are children, pregnant women and elderly people. Averaged exposure over a lifetime is calculated by taking the daily exposure of children ( 0 - 
6 years) and adults (7-70 years) into account.

The results of the health risk assessment in relation to the soil contamination after the flooding of the river Meuse indicate that incidentally the TDI for $\mathrm{Zn}$ and $\mathrm{As}$ is exceeded by children (chapter 4). Consequences for health of exceeding the TDI during childhood are difficult to interpret (34). However, average $\mathrm{Zn}$ and $\mathrm{As}$ exposures over lifetime are lower than the TDI, which indicates that a possible health risk in relation to these heavy metals is relatively low.

Realistic risk assessments do not only depend on a better characterization of exposure assessment but also on a better characterization of dose-response assessment. Obviously, comparisons of outcomes of exposure assessments with established TDI values can hardly fulfil this requirement. Part Two of this thesis deals with an attempt to study biological responses to low dose exposure, in particular in relation to indoor radon exposure, and concentrates on the last part of the source-to effect continuum from human exposure (chapter 6) to internal dose to adverse health effects (chapter 7-9).

Indoor radon exposure contributes largely (more than 50\%) to the doseequivalent received by the general popullation from all sources of radiation. The major health risk in relation to indoor radon exposure is thought to be lung cancer. The cancer risk for the general population is calculated on the basis of linear extrapolation from epidemiological data of underground miners exposed to high radon levels. The cancer risk estimation in relation to indoor radon exposure indicates that radon exposure may contribute up to $8 \%$ respectively $10 \%$ to the annual lung cancer risk among the general population in The Netherlands and Belgium. However, epidemiological studies on the relation between indoor radon exposure and lung cancer have shown conflicting results and the actual risk for the general population of exposure to low levels of indoor radon is still uncertain (35-39). In addition, it is suggested that indoor radon exposure causes extrapulmonary cancers (e.g. leukaemia, melanoma, kidney and prostate) which indicates that the carcinogenic effect may not be restricted to the lung epithelium (40-42). Although not actually measuring disease, genetic biomarkers provide an alternative to epidemiological studies, because of their potential to improve validity and reducing bias in analyzing relatively smaller size populations. Higher frequencies of chromosome aberrations and hprt mutations in peripheral lymphocytes have been found in populations living in areas with increased background radiation (43-44). For this reason multiple biomarkers, indicative for DNA damage, have been studied along an indoor radon concentration gradient, in populations living in the Dutch-Belgian border region (chapter 7-9).

To establish an exposure gradient from high to low levels of indoor radon, a survey of radon concentrations in soils and dwellings in this region has been 
conducted (chapter 6). The geological structure of the subsoil in this region is characterized by large differences in uranium-rich to uranium-poor rocks and soils. Uranium and radium distributions in soils and rocks are the major sources of indoor radon. In addition, we have studied whether soil gas radon measurements are a suitable indicator to predict the radon potential of this region.

The first study on indoor radon air levels has been performed in February 1992 in 116 dwellings in the township of Vise (radon prone area) by means of a charcoal detector for $24 \mathrm{~h}$. The average radon concentration was $116 \mathrm{~Bq} \mathrm{~m} \mathrm{~m}^{-3}$. A significant relation has been observed between the indoor air concentrations and the geology of the subsoil. As expected, in the low background area, the indoor radon concentrations in dwellings $(n=42)$ determined by the same method, are much lower. Furthermore, in the same region time-integrated alpha-track measurements ( 3 months) of indoor radon exposure show similar results. In addition, the indoor radon levels are lower at higher house floors. Soil gas radon levels surrounding 26 houses, correlate with indoor radon exposure. Soil gas measurements can be used to predict the radon potential of an area. However, the method is not useful to predict small differences in indoor air levels. By this survey of radon concentrations in dwellings, an exposure gradient from low to high indoor radon levels has been established which has been used in the multiple genetic biomarker studies.

Chapter 7 to 9 describe the cytogenetic biomarker studies in relation to indoor radon exposure in populations living in the Dutch-Belgian border region. A pilot study was conducted to test the feasibility of genetic biomarker analysis (e.g. micronuclei, chromosome aberrations, sister chromatid exchanges and hprt mutation frequency) in relation to indoor radon exposure (chapter 7). 11. non-smoking participants with different indoor radon levels were selected to participate in the study. During one day in the spring of 1991, concentrations of radion gas in the living room were determined by means of a charcoal canister. From this study, it was concluded that biomarker analysis in humans in relation with indoor exposure to radon is readily achievable. The follow-up study has been directed at cytogenetic analysis in a larger population and in a combination with more accurate measurements of indoor radon levels by time integrated alpha-track detectors over a 3 months period (chapter 8 and 9). 24 people participated in the follow-up study. The results of the feasibility study and the follow-up study did not demonstrate a relation between indoor radon exposure and the induction of micronuclei, chromosome aberrations and sister chromatid exchanges in peripheral blood of exposed subjects. In addition, in both studies the hprt mutation frequency (logarithmic transformed) in peripheral lymphocytes of the exposed subjects was significantly and negatively correlated to indoor radon exposure. Furthermore, the SCE-frequency significantly correlated with cigarette smoking behaviour in both studies and a 
significant correlation with subject's age has been found for the hprt mutation frequency and for the occurrence of micronuclei (feasibility study) and SCE's (follow-up study).

As mentioned before, Bridges and co-workers found a significant dosedependent increase in hprt mutation frequency in a population environmentally exposed to indoor radon. (44). However, in their follow-up study, which has been recently published, no significant positive or negative association between indoor radon exposure and hprt mutation frequency has been observed (45). This follow-up study exists of three different data sets, which also include the first study by Bridges et al (44). In total 66 occupants of 41 houses have been included into the study. The indoor radon concentration ranges from 18 to $484 \mathrm{~Bq} \mathrm{~m}$. However, in one data set (including 33 participants), a significant negative correlation between indoor radon levels and hprt mutation frequency has been found, which confirms our finding presented in chapter 7 and 9.

Also after combining our hprt mutation frequency data from the feasibility study and the follow-up study (in total 33 participants), a significant negative correlation between indoor radon levels and hprt mutations is observed ( $R=$ $0.46 ; \mathrm{p}<0.011$.

Additionally, a study performed among former uranium miners from the Radium Hill uranium mine in south Australia showed no relation between the hprt mutation rates and previously occupational exposure to radon (46).

There seems to be no biological indication for extrapulmonary effects of radon exposure. It can be concluded from these results that no linear relationship has been observed between indoor radon exposure and genetic biomarkers, which are indicative for DNA damage as early markers for carcinogenesis. Obviously, the current theoretical models for radon cancer risk assessment of linear extrapolation to low dose do not consider these findings.

In general, epidemiological studies report conflicting results. A recently published epidemiological study, in which the data from 11 cohort studies of radon exposed underground miners have been pooled, confirms the linearity of low dose, suggesting that low-level radon exposure in dwellings indicates some risk (47). To date, epidemiological studies on indoor radon exposure of the general population do mostly not show a excess cancer risk (48). Interestingly, Cohen recently demonstrated a negative correlation between domestic radon exposure and lung cancer (49). Furthermore, although in vitro studies indicate that radon can cause cell transformation, changes in chromosome structures and gene mutations, DNA repair processes appear to be important at the low dose range, suggesting a non-linearity at low dose $(49,50)$.

In conclusion, there remains considerable uncertainty in relation to the cancer risk of domestic radon exposure for the general population; our attempt to reduce uncertainties by studying genetic biomarkers instead of cancer incidence, was unsuccessful within this respect. 
In this thesis, several case studies in relation to environmental health risk assessment have been described. The case studies intended to improve exposure or dose-response assessment by replacing some default assumptions. Part One of this thesis deals with exposure assessment. Exposure to the environmental agents has been determined by an exposure scenario model (default method) and by location-specific measurements. In general, the location-specific measurements provide a more realistic estimate of exposure than can be obtained with standard models. The default exposure scenario model can be used as a screening method to estimate exposure and identify important exposure pathways, which can be addressed by location-specific measurements. The NAS committee has recently proposed such an iterative approach of risk assessment (11). An iterative approach to risk assessment will start with relatively inexpensive screening techniques (e.g. exposure scenario models), which are mostly conservative. Refined risk assessments use more site-specific exposure information and reduce the extent to which default assumptions are required. However, the question whether to conduct more location-specific measurements in order to improve exposure assessment, has to be weighed against the value of the information obtained. For instance, in Chapter 5 it has been demonstrated that it is not necessary to perform location-specific measurements in relation to recreational activities, when exposure through ingestion of contaminated fish is not a relevant exposure pathway.

The aim of the case study described in part Two of this thesis, was to evaluate the linearity at low-dose of the dose-response curve of domestic radon exposure and cancer risks. No linear relationship has been observed between domestic radon levels and multiple genetic biomarkers indicative for DNA damage. In the general population conflicting epidemiological data on the cancer risk of radon with respect to indoor exposure have been reported. Furthermore, conflicting results are observed from in vitro studies, and also from genetic biomarker studies in the general population. As a default assumption, linearity of response in low radon exposure ranges may be criticized.

It seems that at low dose the uncertainty in dose-response assessment is larger than the uncertainty in exposure assessment which indicates the major challenge for the science of risk analysis in the future. 


\section{References}

1. Premises of Risk Management, 1989. Annex to the Dutch National Environmential Policy Plan 1990-1994. Second Chamber of the States General, session 1988-1989, 21137, no 5; The Hague, The Netherlands (in Dutch).

2. Committee on the Institutional Means for Assessment of Risks to Public Health. Commission on Life Sciences. National Research Council. Risk Assessment in the federal government: Managing the process. National Academy Press, Washington, D.C.; 1983.

3. Sexton, K, Olden, $K_{\text {; }}$ Johnson, B.L. Environmental justice: the centrall role of research in establishing a credible scientific foundation for informed decision making. Toxicology and Industrial Health wol 9 , no 5: 685-727; 1993.

4. Patton, D.E. The ABCs of Risk Assessment. EPA Journal, jan/feb/mar/ 10-15; 1993.

5. Covello, V.T. Merkhofer, M.W. Risk assessment methods. Approaches for assessing health and environmental risks. Plenum Press, New York; 1993.

6. Sexton, $K_{\text {.; }}$ Reiter, L.W.; Zenick, H. Research to strengthen the scientific basis for health risk assessment? a survey of the context and rationale for mechanistically based methods and models. Toxicology 102:3-20; 1995.

7. Bernard, R.C. Risk assessment: the default conservatism controversy. Regulatory Toxicology and Pharmacology 21: 431-438; 1995.

8. McClellan, R.O. Risk assessment and biological mechanisms: lessons learned, future opportunities. Toxicology 102: 239-258;1995.

9. MoClellan, R.O.CIIT Testimony on updating OSHA permissible exposure limits for air contaminants. Critical issues in developing permissible exposure limits for air contaminants. CIIT Activities, vol 16, no 2: 8-10; 1996.

10. Withmyre, G.K.; Driver, J.H.; Ginevan, M.E.; Rardiff, R.G.; Baker, S.R. Human exposure assessment 1 : understanding the uncertainties. Toxicology and industrial Health vol 8, no 5: 297-320; 1992 .

11. National Academy of Sciences/National Research Council (NAS/NRC) Science and and Judgement in risk assessment. National Academy Press Washington, DC: 1994.

12. Graham, Jn; Walker, K.D.; Berry, M.; Bryan, E.F.; Callahan, M.A.; Fan, A.; Finlley, B.; Lynch, J.; McKone, T; Ozkaynak, H.; Sexton, K. Role of exposure databases in risk assessment. Archives of Environmental Health vol 47, no 6:408-420; 1992.

13. Whitmyre, G.K.; Driver, J.H, Ginevan, M.E.; Tardiff, R.G.; Baker, S.R. Human exposure assessment II: Quantifying and reducing the uncertainties. Toxicology and Industrial Health, vol 8 , no 5: 321-342; 1992.

14. Goddard, M.J, Krewski, D. The future of mechanistic researtch in risk assessment: Where are we going and can we get there from here? Toxicology 102: 53-70; 1995 .

15. Daston, G.P. Advances in understanding mechanisms of toxicity and implications for risk assessment. Reproductive Toxicology, vol 11 no 2/3; 389-396; 1997.

16. Hawkins, N.C.; Jayjock, M.A.; Lynch, J. A rationale and framework for establishing the quality of human exposure assessment. Am. Ind. Hyg. Assoc. J, 53, no. 1: 34-41; 1992.

17. Sexton, K.; Callahan, M.A.; Bryan, E.F.; Saint, C.G.; Wood, W.P. Informed decisions about protecting and promoting public health rationale for a national human exposure assessment survey. Journal of Exposure Analysis and Environmental Epidemiology vol 5, no 3: 233-256; 1995. 
18. Sampson, E.1.; Needham, L.L., Pirkle, J.L.; Hannon, W.H.; Miller, D.T.; Patterson, D.G.; Bernert, J.T.; Ashley, D.L.; Hill, R.H.; Gunter, B.W.; Pascal, D.C.; Spierto, F.W.; Rich, M.J. Technical and Scientific Development in Exposute marker Methodology. Clinical Chemistry 40, no 7 : 1376-1384; 1994.

19. Sexton, $\mathbb{K}$. Estimating exposure and dose to characterize health risks the role of human tissue monitoring in exposure assessment. Environmental Health Perspectives vol 103, supp 3 april 1995.

20. Morgan, M.G.; Henrion, M.; Morris, S.C.; Amaral, D.A.L. Uncertainty in risk assessment; a case study involving sulfur transport and health effects. Environ. Sci.Tech. vol 19, no 8: 662-667, 1985.

21. Finley, B.; Paustenbach, D. The benefits of probabilistic exposure assessment: Three case studies involving contaminated air water and soil. Risk Analysis vol 14, no 1: $53-73 ; 1994$.

22. McKone, T.E.; Daniel.s, J.I. Estimating human exposure through multiple pathway from air water and soil. Regulatory toxicology and pharmacology 13:36-61; 1991 .

23. Hawkins, N.C. Conservatism in maximally exposed individual MEI predictive exposure assessments: a. First cut-analysis. Regulatory Toxicology and Pharmacology 14: 107-117; 1991.

24. Coordination Committee for Measurements of Radioactivity and Xenobiotic compounds. Dioxins in environment and food in The Netherlands. Bil thoven, 1991 (in Dutch).

25. Slob, W.; Troost, L.M,; Krijgsman, M.; Koning, J de.; Sein, A.A. Incineration of municipal waste in The Netherlands. Emissions occurring at incineration. Dispersion and risks of dioxins. RIVM/TNO/VROM, 1992 (in Dutch).

26. Bremmer, $H_{\text {; }}$ Booij, H. PCB Emissions in relation to dioxin emissions. RIVM report no. 601014005, Bilthoven 1995 (in Dutch).

27. Tollefson, L. Methylmercury in fish: Assessment of risk for U.S. consumers. In: The risk assessment of environmental and human health hazards. A textbook of case studies. Eds. Paustenbach, D.J. Wiley, New York, 1989.

28. Great Lakes National Program Office. Risk assessment and modeling overview document. U.S. Environmental Protection Agency, Chicago, IL.

29. Berg van den, M.; Meent van de, D.; Peijnenburg, W.J.G.M.; Sijm, D.T.H.M.; Struijs, J.: Tas, J.W. Transport, accumulation and transformation processes. In: Risk assessment of chemicals: An introduction. Eds. Leeuwen van, C.J.; Hermans, J.L.M. Kluwer, Dordrecht, 1995.

30. Slooff, W. (ed) Criteriadocument mercury, RIVM report no. 710401023. Bilthoven, 1994 (in Dutch).

31. Foster, I.D.L.; Charlesworth, S.M. Heavy metals in the hydrological cycle: trends and explanation. Hydrological Processes 10:227-261; 1996.

32. Bockting, G.J.M.; Koolenbrander, J.G.M.; Swartjes, F.A. SEDISOIL. Estimation of human exposure to sediments. Bilthoven, The Netherlands: National Institute of Public Health and the Environment, 1996 report no. 715810011 (in Dutch).

33. Bowers, T.S.; Beck, B.; Karam, H.S. Assessing the relationship between environmental lead concentrations and adult blood lead levels. Risk. Analysis 14: 2:183-189; 1994.

34. Larsen, J.C.; Pascal, G. Workshop on the applicability of the ADI to infants and children: consensus summary. Food Additives and Contaminants. 15: sup 1-9; 1998. 
35. Pershagen, G.; Åkerblom, G. Axelson, O, Clavensjo, B.; Damber, L.; Desai, G.; Enflo, A.; Lagarde, F, Mellander, $H_{4}$, Svartgengren, $M$ et al. Residential radon exposure and lung cancer in Sweden. N Engl I Med 330: 159-64; 1994.

36. Biberman, R.; Lusky, A.; Schlesinger, T; Margaloit M.; Neeman, E.; Modan, B. Increased risk for small cell lung cancer following residential exposure to low-dose radon: A pilot study. Archives of Environmental Health vol. 28, no. 4: 209-212; 1993.

37. Schoenberg, J.B.; Klotz, J.B; Wilcox, H.B.; Nicholls, G.P.; Gil-del-Real, M.T.; Stemhagen, A., Mason, T.T. Case control study of residential radon and lung cancer among New-Jersey women. Cancer Research vol. 50, no. 15:6520-6524; 1990.

38. Blot, W.J; Xu, Z.Y.; Boice, J.D. Ir.; Zhao, D.H.; Stone, B. ., Sun, J.; Jing, L. B., Faumeni, J.F.Jr. Indoor radon and lung cancer in China. Journal of the National Cancer Institute vol. 82, no. 12: 1025-1030; 1990.

39. Lees, R.E.M.; Steele, R.; Roberts, J.H. A case-control study of lung cancer relative to domestic radon exposure. International Journal of Epidemiology vol. 16, no. 1: 7-12; 1987.

40. Henshaw, D.L.; Eatough, I.P.; Richardson, R.B. Radon as a causative factor in induction of myeloid leukaemia and other cancers. Lancet 335: 1008-12; 1990.

41. Lucie, N.P. Radon exposure and leukaemia. The Lancet vol $2(8654): 99-100 ; 1989$

42. Viel, J.F. Radon exposure and leukaemia in adulthood. International Journal of Epidemiollogy vol 22, no. 4: 627-631; 1993 .

43. Pohl-Ruiling, $J$. Chromasome aberrations in man in areas with ellevated natural radioactivity. Berzelius Symposium XV, 103-111; 1988.

44. Bridges, B.A.; Cole, J.; Arlett, C.F.; Green, M.H; Waugh, A.P.; Beare, D.; Henshaw, D.L.; Last, R.D. Possible association between mutant frequency in peripheral lymphocytes and domestic radon concentrations. The Lancet 18, 337 (8755): 1187$1189 ; 1991$.

45. Cole, J.; Green, M.H.L.; Bridges, B.A.; Waugh, A.P.W.; Beare, D.M.; Henshaw, D.; Last, R.; Liu, Y.; Cortopassi, G. Lack of evidence for an association between the frequency of mutants or translocations in circulating lymphocytes and exposure to radon gas in the home. Radiation Research 145: 61-69; 1996.

46. Shanahan, E.M.; Peterson, D.; Roxby, D.; Quintana, J.; Morley, A.A.; Woodward, A. Mutation rates at the glycophorin A and hprt loci in uranium miners exposed to radon progeny. Occupational and Environmental Medicine 53: 439-444; 1996.

47. Lubin, J.H.; Boice, Jr. D.; Edling, C.; Hornung, R.W.; Howe, R.; Hunz, E.; Kusiak, R.A.; Morrison, H.I, Radford, E.P.; Samet, I.M.; Timarche, M.; Woodward, A.; Yao, S.X.: Pierce, D.A. Lung cancer in radon-exposed miners and estimation of risk from indoor radon exposure. Journal of the National Cancer Institute vol 87, no 11: 817$826 ; 1995$.

48. Lubin, J.H.; Liang, Z.; Hrubic, Z.; Pershagen, G.; Schoenberg, J.B.; Blot, W.J.; Klotz, J.B.; Xi, Z.Y.; Boice, $J \mathrm{r}$. D. Radon exposure in residences and lung cancer among women: combined analysis of three case studies. Cancer Causes and Control 5: 114$128 ; 1994$.

49. Cohen, B.L. Doseresponse relationship for radiation carcinogenesis in the low-dose region. Int Arch Occup Environ Health 66: 71-75; 1994.

50. Jostes, R.F. Genetic, cytogenetic and carcinogenic effects of radon: a review. Mutation Research 340: 125-139; 1996. 


\section{Samenvatting}

De mens wordt via diverse contactmedia (bodem, lucht, voedsel en water) blootgesteld aan verschillende agentia in het milieu. Voor het in kaart brengen van de gezondheidsrisico's gepaard gaande met blootstelling aan deze agentia, kan gebruik worden gemaakt van de "bron-tot-risico" ketenbenadering, en van een model van risicobeoordeling en risicobeheersing. Het eerste gangbare model is ontwikkeld door de National Academy of Science in de VS in 1983. Deze commissie omschrijft het begrip risicobeoordeling als een karakterisering van mogelijke schadelijke gezondheidseffecten in relatie tot blootstelling van de mens aan gevaarlijke milieufactoren. In het algemeen wordt dit proces nader onderverdeeld in 4 fasen: het identificeren van gevaren, het vaststellen van het blootstellingsniveau (aangeduid als "exposure assessment"), het vaststellen van een relatie tussen dosis en effect (aangeduid als "dose-response assessment"), en een karakterisering van het risico op basis van de eerste drie fasen in een vorm die geschikt is voor de risicobeheersing. Voor het beoordelen van risico's is wetenschappelijke kennis nodig, welke eveneens is opgenomen in het model. Het beslissen over de toelaatbaarheid van risico's en het treffen van maatregelen zijn onderdeel van de risicobeheersing.

$\mathrm{Bij}$ de laatste fase van de risicobeoordeling, de risicokarakterisering, worden de onzekerheden inherent aan voorgaande fasen van de beoordeling, in kaart gebracht. Deze onzekerheid is enerzijds het resultaat aan gebrek aan wetenschappelijke kennis en anderzijds het gevolg van gebrek aan gegevens. Bij gebrek aan gegevens en kennis word gebruik gemaakt van plausibele veronderstellingen ("default assumptions") om tot een beoordeling van het risico te komen. Voorbeeld van een plausibele veronderstelling is de lineaire dosis-respons relatie bij lage doses van genotoxische stoffen. Er is veel discussie gaande over het gebruik van plausibele veronderstellingen in de risicobeoordelling; met name de veronderstellingen die conservatief van aard zijn worden bekritiseerd. Men neemt aan dat het gebruik van deze conservatieve veronderstellingen eerder zal leiden tot een overschatting dan tot een onderschatting van het risico.

Het doel van dit proefschrift is om aan de hand van enkele voorbeeldstudies de gezondheidsrisico's van verschillende milieu-agentia te evalueren, waarbij de nadruk ligt op de evaluatie/vervanging van enkele plausibele veronderstellingen bij zowel de blootstellingsbeoordeling (Deel 1) als de dosisresponsbeoordeling (Deel 2).

In de inleiding wordt de "bron-tot-risico" ketenbenadering kort samengevat. Vervolgens wordt het proces van de risicobeoordeling en risicobeheersing beschreven, warbij eveneens wordt ingegaan op de onzekerheid en het gebruik van plausibele veronderstellingen in de risicobeoordeling. Daarna 
word: kort beschreven hoe door middel van wetenschappelijk onderzoek het beoordelen van de blootstelling enerzijds en van de dosis-respons relatie anderzijds kan worden verbeterd. In dit proefschrift is voor de indeling van de hoofdstukken de ketenbenadering van bron naar risico gevolgd.

Zoals eerder vermeld beschrijft Deel 11 van dit proefschrift casuistiek waarbij de gezondheidsrisico's worden geschat in een specifieke blootstellingssituatie. De blootstelling wordt enerzijds geschat aan de hand van een blootstellingsmodel en anderzijds wordt gebruik gemaakt van locatie-specifieke metingen in de werschillende milieucompartimenten. Een blootstellingsmodel of scenario kan worden beschouwd als een plausibele veronderstelling.

Het in de Hoofdstukken 2 en 3 beschreven onderzoek heeft betrekking op de schatting van de blootstelling ten aanzien van dioxinen en PCB's. Voor kwantificering van het gezondheidsrisico in relatie tot de emissie van dioxinen en dioxine-achtige PCB's door een nieuw te bouwen afvalverbrandingsinstallatie, is uitgegaan van een "worst-case" benadering waarbij voor de slechts denkbare situatie het gezondheidsrisico met behulp van een blootstellingsmodel is geschat (Hoofdstuk 2). Uit de resultaten blijkt dat het voorstelbaar is dat bij bepaalde emissiescenario's voor PCB's met een dioxine-achtige toxiciteit de momentane TDI van $10 \mathrm{pg}$ TEQ/ $\mathrm{kg}$ lichaamsgewicht wordt overschreden. Alhoewel in het blootstellingsmodel verschillende onzekerheden een rol spelen, bestaat de grootste onzekerheid in de aanname van de uitworp van PCB's door een afvalverbrandingsinstallatie. Om deze onzekerheid te beheersen wordt aanbevolen om de emissie- grenswaarde van $0.1 \mathrm{ng} \mathrm{TEQ} / \mathrm{m}^{3}$ zoals deze in het Besluit luchtemissies afvalverbranding 1993 is vastgesteld voor de uitworp van dioxinen en furanen, ook te betrekken op PCB's met een dioxine-activiteit.

De kwantificering wan het gezondheidsrisico bij consumptie van verontreinigde aal uit twee beken in West-Brabant wordt beschreven in Hoofdstuk 3. De gemeten concentraties van $\mathrm{PCB}^{\prime} s$, kwik en organochloor-pesticiden in 3 aalmonsters (per monster 25 alen) afkomstig uit deze wateren, zijn relatief laag en vergelijkbaar met aal uit schone binnenwateren. Sportvissers kunnen als een risicogroep worden beschouwd gelet op het feit dat de sportvissers veel en/of vaak zelf gevangen vis die verontreinigd kan zijn, consumeren. Sportvissers die vissen op deze wateren, blijken gedurende de maanden mei tot oktober gemiddeld 10 alen per week te consumeren. Op basis van gemeten gehalten van 3 mono-ortho PCB-congeneren in de bemonsterde aal wordt geen gezondheidsrisico verwacht bij de door de sportvissers opgegeven visconsumptie. De additionele blootstelling als gevolg van de consumptie van verontreinigde vis dragt voor meer dan $80 \%$ bij aan de uiteindelijke blootstelling. 
De mogelijke gezondheidsrisico's in relatie tot een verontreiniging van de onderwaterbodem van twee Maasplassen in Limburg worden in kaart gebracht in Hoofdstuk 5. De onderwaterbodems zijn onder andere verontreinigd met zware metalen en PAK's. De Maasplassen worden frequent gebruikt voor recreatieve activiteiten zoals bijvoorbeeld zwemmen, vissen en surfen. Aan de hand van een gestandaardiseerd blootstellingsmodel is een schatting gemaakt van het blootstellingsrisico in relatie tot deze recreatieve activiteiten. De ingestie van verontreinigde vis blijkt eveneens de belangrijkste bijdrage te leveren aan de totale blootstelling ten aanzien van een verontreiniging van de onderwaterbodem met zware metalen en PAK. Toepassing van het model leidt tot de voorspelling dat de TDI voor $\mathrm{Zn}$ en $\mathrm{Pb}$ wordt overschreden. Naast het meten van het gehalte aan zware metalen en PAK's in de onderwaterbodem zijn eveneens locatie-specifieke metingen in het oppervlaktewater en het zwevend stof uitgevoerd, teneinde de blootstellingsschatting te verbeteren en de onzekerheden te reduceren. Op basis van de zware metalenconcentratie in de contactmedia blijkt de blootstelling tengevolge van de ingestie van verontreinigde vis marginaal in vergelijking met de resultaten verkregen op basis van het gestandaardiseerde model. Het gezondheidsrisico berekend aan de hand van de locatie-specifieke metingen, is verwaarloosbaar. Geconcludeerd kan worden dat overdrachtsfactoren van onderwaterbodem naar oppervlaktewater en het zwevend stof zoals gehanteerd in het gestandaardiseerde model, een grote invloed hebben op de uiteindelijke blootstellingsschatting.

De oevergronden van de Maas hebben voornamelijk een agrarische functie. Inundatie van de oevergronden van de Maas en de daarop verbouwde gewassen vindt variërend in omvang in verschillende periodes en seizoenen van het jaar plaats. In de winter van 1993-1994 zijn grote gedeeltes van de Maasoevers en aldaar voorkomende dorpen overstroomd. Bij overstromingen van de uiterwaarden en oevergronden wordt o.a. slib afgezet dat verhoogde gehalten aan zware metalen kan bevatten. De mogelijke gezondheidsrisico's na de overstroming van de Maas worden nader beschouwd in Hoofdstuk 4. Evenals in Hoofdstuk 5 zijn een gestandaardiseerd blootstellingsmodel en locatie-specifieke metingen gebruikt om de menselijke blootstelling in relatie tot de directe en indirecte blootstellingsroutes te kwantificeren. Toepassing van het model leidt voor het onderzoeksgebied Borgharen-Itteren tot de voorspelling dat de TDI voor $\mathrm{Cd}$ en $\mathrm{Pb}$ frequent wordt overschreden. De belangrijkste bijdrage aan de totale blootstelling wordt geleverd door de consumptie van ter plekke geproduceerde dierlijke voedingsmiddelen.

Kwantificering van transferprocessen van zware metalen van grond naar plant gaat gepaard met grote onzekerheden. Ter reductie van deze onzekerheidsfactor zijn in het onderzoeksgebied proeftuinen aangelegd, waarin aardappelen, stamslabonen en pluksla zijn uitgezet. Gebruik makend van het gestandaardiseerde model blijkt, dat de menselijke blootstelling via ingestie 
van gewassen met $70 \%$ wordt overschat voor de metalen $\mathrm{Cd}, \mathrm{Pb}$ en $\mathrm{Zn}$ en met $27 \%$ wordt onderschat voor het metaal $\mathrm{Cu}$ in vergelijking met resultaten verkregen op basis van de locatie-specifieke metingen. Ook uit dit onderzoek blijkt dat transferparameters in het model een grote invloed hebben op de uiteindelijke schatting van de blootstelling. Op basis van de gemeten zware metalengehalten in de contactmedia (bodem en gewasingestie) en rekening houdend met de achtergrondblootstelling, b]ijkt dat de TDI voor cadmium en de TDI voor lood door kinderen wordt overschreden in gebieden met een overstromingsfrequentie van 1 maal per 2 jaar.

In Deel 2 van dit proefschrift ligt de nadruk op de evaluatie van de lineariteit van de dosis-effect relatie tussen het kankerrisico enerzijds en blootstelling aan radon in het lage dosisgebied anderzijds. Zoals eerder vermeld is de lineariteit van de dosis-respons relatie in het lage dosisgebied van ioniserende straling een woorbeeld van een plausibele veronderstelling. De carcinogeniteit van radon en vervalprodukten is goed beschreven bij uranium mijnwerkers. Sterfte aan longtumoren wordt in het algemeen beschouwd als het belangrijkste effect van blootstelling aan radon. De lineaire dosis-effect relatie dient als basis voor de schatting van het longkankerrisico voor de algemene bevolking. Echter, de onzekerheid in de schatting van het kankerrisico van radon blootstelling in het lage blootstellingsgebied zoals voorkomend in woningen is groot. Resultaten uit epidemiologisch onderzoek naar de relatie tussen binnenhuisblootstelling aan radon en longkankersterfte zijn tegenstrijdig. Voorts zijn er aanwijzingen dat andere vormen van kanker dan longkanker, zoals melanomen, prostaat- en nierkanker, door radon kunnen worden veroorzaakt. In het veld van de moleculaire biologie zijn technieken voor het vaststellen van genetische schade ontwikkeld. Alhoewel met deze technieken geen ziekte wordt gedetecteerd, kunnen ze een alternatief vormen voor epidemiologisch onderzoek. In dit kader is het relevant dat hogere frequenties van hprt mutaties en chromosomale aberraties zijn gerapporteerd in populaties blootgesteld aan verhoogde achtergrondstraling.

Het in Hooldstuk $7 \mathrm{t} / \mathrm{m} 9$ beschreven onderzoek heeft betrekking op het vaststellen van een relatie tussen binnenhuisblootstelling aan radon en het voorkomen van verschillende typen van genetische schade welke beschouwd worden als vroege indicatoren voor de carcinogenese, in verschillende subpopulaties woonachtig in het grensgebied tussen. Nederland en België. De onderliggende doelstelling van het onderzoek is het toetsen van het hypothetische lineaire karakter van de dosis-respons relatie op het biologische niveau.

Om een dosis-respons relatie betrouwbaar te kunnen vaststellen is het noodzakelijk om voldoende variatie in de blootstelling te verkrijgen. Een onderzoek is uitgevoerd on de radonconcentraties in het bodemgas en het binnenmilieu in dit gebied te bepalen (Hoofdstuk 6). Om een indruk te krijgen 
van de radonconcentraties in woningen in de Belgische grensgemeente Visé zijn in eerste instantie in 116 woningen gedurende 24 uur radonmetingen verricht met behulp van actief kool detectie. De gemiddelde radonconcentratie bedroeg $116 \mathrm{~Bq} / \mathrm{m}^{3}$ (range $20-1625 \mathrm{~Bq} / \mathrm{m}^{3}$ ). De oorzaak van de relatief hoge radonconcentraties in sommige woningen in de gemeente Visé kan gezocht worden in de uranium-houdende onderlaag van de bodem. In de grensgemeente Eijsden zijn met behulp van dezelfde methode in 42 woningen de radonconcentraties bepaald (gemiddeld $46 \mathrm{~Bq} / \mathrm{m}^{3}$ ). Aanvullende radonmetingen met behulp van een alfa track detector gedurende 3 maanden leiden tot overeenkomstige resultaten. Het radongas gehalte in de bodem in de gemeente Eijsden is, in tegenstelling tot in de gemeente Visé, te laag en de spreiding te groot om als een goede voorspeller te kunnen dienen voor de radonconcentratie in de woning. Het is mogelijk gebleken om aan de hand van dit onderzoek een blootstellingsgradient van radon in het binnenmilieu te verkrijgen, welke gebruikt is voor het bepalen van de dosis-respons relatie in de Foofdstukken $7 \mathrm{t} / \mathrm{m} 9$.

Uit de resultaten van het haalbaarheidsonderzoek (Hoofdstuk 7) en het vervolgonderzoek (Hoofdstuk $8 \mathrm{t} / \mathrm{m}$ 9) blijkt dat er geen relatie is tussen blootstelling aan radon in het binnenmilieu en de frequentie van SCE's, micronuclei en chromosomale aberraties in perifere lymfocyten. Daarentegen blijkt de mutatie frequentie (logaritmisch getransformeerd) van het hprt gen in perifere lymfocyten van de blootgestelde populaties significant negatief geassocieerd te zijn met de radonconcentratie in het binnenmilieu. Aanvullend blijkt het rookgedrag en leeftijd positief geassocieerd met respectievelijk de SCEErequentie en hprt mutatie frequentie.

Uit deze resultaten blijkt dat er geen lineaire relatie wordt gevonden tussen genetische schade in perifere lymfocyten en binnenhuisblootstelling aan radon. Uit dit onderzoek wordt dus geen verdere onderbouwing gevonden voor de aanwijzing verkregen via epidemiologisch onderzoek, dat blootstelling aan radion een extrapulmonair kankerrisico zou impliceren. Voorts wordt er geen evidentie verkregen voor de juistheid van lineaire extrapolatie naar het lage blootstellingsgebied in geval van carcinogene factoren, waardoor onzekerheid blijft bestaan over de risico's van radon in het lage blootstellingsgebied. Het reduceren van deze onzekerheid vormt een uitdaging voor toekomstig onderzoek. 



\section{Dankwoord}

"Een wan de geheimen van het leven is struikelblokken in springplanken weranderen" (Jack Penn)

Ik wil op deze plaats een aantal personen c.q. instellingen bedanken die direct of indirect betrokken zijn geweest bij de totstandkoming van dit proefschrift. Zonder hen was de weg naar het eindresultat een eindeloos plan geworden als zij de struikelblokken niet bijtijds hadden vervangen voor de noodzakelijke springplanken.

Allereerst wil ik mijn promotor Jos Kleinjans bedanken voor zijn grote bijdrage in de totstandkoming van dit proefschrift. Jos, je hebt mij niet alleen begeleid bij het schrijven van dit proefschrift. De gepaste hulp op tijden dat ik even de draad kwijt was, heeft er onder andere toegeleid dat ik dit proefschrift op tafel heb gekregen, waarbij het woord pragmatisme voor mij een nieuwe invulling heeft gekregen.

De leden van de beoordelingscommissie: prof. dr. Knottnerus, prof. dr. Knipschild, dr. Passchier, prof. dr. Savelkoul en prof. dr. ir. Vrieze ben ik erkentelijk voor het beoordelen van het manuscript en het geven van waardevolle suggesties.

Frits Hendriks (voorheen GGD Streekgewest Westelijk Noord-Brabant, Bergen op Zoom) en Henk Jans (GGD Stadsgewest Breda) wil ik bedanken voor de begeleiding tijdens mijn 'eerste" project. Alhoewel het al een tijd geleden is, heb ik de prettige manier van samenwerken zeer op prijs gesteld en mijn eerste baan als zeer positief ervaren.

Niet onvermeld mag blijven de hulp die ik van de gemeente Visé (Belgiẻ) kreeg voor de uitvoering van het radononderzoek zoals beschreven in de Hoofdstukken $7 \mathrm{t} / \mathrm{m}$ 9. Ik wil in dit verband de heer Puts, met name noemen. De bereidheid om het uitgebreide databestand van radonconcentraties in woningen in de gemeente ter beschikking te stellen, werd bijzonder gewaardeerd. Ook de succesvolle samenwerking met de Universiteit van Luik heeft bijgedragen dat het radononderzoek gelukt is. Prof. Koulischer, C. Herens en mevr Parent will ik daarvoor van harte danken. Zonder de medewerking van de proefpersomen (in zowel Eujsden als Visé) was het radononderzoek zeker niet geslaagd, waarvoor een woord van dank zeker op zijn plaats is. Verder ben ik de heer Vanmarcke en de heer Willeborts (SCK-Mol, België) erkentelijk voor het bepalen van de radonconcentraties. In dit verband ben ik aan Nederlandse zijde dank verschuldigd aan de heer Put (voorheen KVIGroningen), voor het ter beschikking stellen watr radongegevens in woningen in Limburg. Geja Hageman en Irene Welle, voor het "dubbel." scoren van de preparaten en John Engelen voor het analyseren van de chromosomale aberraties. 
Daarnaast wil ik Jurian Hoogewerff bedanken voor zijn medewerking aan het radononderzoek en de verschillende bodemonderzoeken en de hulp bij het maken van de vele mooie 'plaatjes' waarbij de afstand tussen Maastricht en Wenen geen probleem vormde. Tevens gaat mijn dank uit naar Edwin Moonen. Je was altijd bereid om een helpende hand te bieden zowel bij het veldwerk als bij het uitvoeren van de analyses.

Mijn dank gaat verder uit naar Sandra van Leusen en Jean-Paul Rila, Milieugezondheidkunde stagiaires. Jullie hebben een belangrijke bijdrage geleverd aan het onderzoek beschreven in de Hoofdstukken 4 en 5 . Ook deze onderzoeken waren niet mogelijk zonder de hulp van enkele bewoners in Itteren, Aqua Terra, stichting Natuur en Landschap en Rijkswaterstaat afdeling Limburg. Els Rhijnsburger ben ik erkentelijk voor het vertalen in het Engels van de Hoofdstukken 2 en 3.

Tenslotte gaat mijn dank uit naar (ex) collega's van de vakgroep Gezondheidsrisico Analyse en Toxicologie, voor de prettige werksfeer en collegialiteit.

Bijzondere dank ben ik verschuldigd aan mijn ouders, familie en vrienden voor hun belangstelling en support.

Een speciaal woord van dank gaat uit naar Rea. De praktische betrokkenheid, de kritische manier waarop je vaak naar mijn werk hebt gekeken en de manier waarop je jouw ideeën hebt uitgesproken (regelmatig met een typische Reahumor), heeft me er toe aangezet om de dingen ook op een andere manier te benaderen. Mijn waardering gaat vooral uit naar de manier waarop je me iedere keer weer voldoende wist op te peppen en me er door heen wist te slepen, waardoor moeilijke momenten draaglijk werden en bleven.

\section{ALLEMAAL BEDANKT.}

Harma 


\section{Curriculam vitae}

Harmina Jannette (Harma) Albering werd geboren op 21 februari 1965 te Smilde. Na het behalen van het MAVO diploma (aan de Openbare MAVO te Smilde) het HAVO diploma (aan de Dag Hammarskjöld te Assen), behaalde zij in 1985 het VWO (ongedeeld) diploma aan het dr. Nassau-College te Assen. In datzelfde jaar begon zij haar studie Gezondheidswetenschappen met als afstudeerrichting Biologische Gezondheidkunde aan de Rijksuniversiteit Limburg te Maastricht, die zij in januari 1990 voltooide. Van april 1990 tot en met januari 1991 (0.4 fte) was zij werkzaam als projectmedewerkster bij de GGDStreekgewest Westelijk Noord-Brabant te Bergen op Zoom, alwaar het onderzoek werd uitgevoerd zoals beschreven in Hoofdstuk 2. Van mei 1990 tot en met januari 1991 (0.6 fte) was zij eveneens werkzaam als projectmedewerkster bij de Provinciale Raad voor de Volksgezondheid Zuid-Holland te Den Haag, alwaar een gezondheidsrisico-evaluatie naar het microklimaat in auto's werd uitgevoerd.

Vanaf februari 1991 was zij werkzaam geweest als toegevoegd onderzoeker aan de Rijksuniversiteit Limburg (later Universiteit Maastricht) te Maastricht bij de vakgroep Biologische Gezondheidkunde i.o. later Gezondheidsrisico Analyse en Toxicologie. Sinds mei 1993 tot heden is zij werkzaam als universitair docent bij dezelfde vakgroep, alwaar het onderzoek beschreven in dit proefschrift met name werd uitgevoerd. 



\section{List of publications}

\section{Full articles}

- Kleinjans, J.C.S.; Albering, H.J ; Marx, A.; van Maanen, J.M.S.; van Agen, B.; ten Hoor, F.; Swaen, G.M.S.; Mertens P.J.M. Nitrate contamination of drinking water: Evaluation of Genotoxic Risk in human populations. Environmental Health Perspectives vol. 94: 189-193; 1991.

- Albering, H.J.; Hageman, G.J.; Koulischer, L.; Engelen, J.J.M.; Herens, C.; Kleinjans J.C.S. Assessment of cytogenetic damage in human populations in relation to indoor exposure to radon. A feasibility study. The Lancet vol. 340: $8821 ; 739 ; 1992$.

- Albering, H.J.; Jans, H.W.A.; Kleinjans, J.C.S.; Hendriks, H.F.L. Mogelijke gezondheidsrisico's bij consumptie van verontreinigde aal uit twee beken in West-Brabant. TSG 71: vol 4: 203-206; 1993.

- Hageman, G.J.; Welle, I.J.; Stierum, R.H.; Albering, H.J.; Kleinjans, J.C.S. Detection of 6-thioguanine resistant human peripheral blood lymphocytes using 5-bromodeoxyuridine labeling in combination with immunocytochemical staining. Mutagenesis 8 (6): 495-502; 1993 .

- Albering, H.J. DNA schade en celgenetische biomarkers bij lage stralingsdosis. NVS-publicatie 20: 47-50; 1994.

- Albering, H.J., Engelen, J.J.M.; Hageman, G.J.; Koulischer, L.; Vanmarcke, H.; Kleinjans J.C.S. Genetic biomarkers indicative for DNA damage in relation to indoor radon exposure. Annales de l'Association Belge de Radioprotection. vol. 19: $1-2: 15-26 ; 1994$.

- Albering, H.J.; Engelen, J.J.M.; Koulischer, L.; Welle, I.J.; Kleinjans, J.C.S. Indoor radon exposure and extra pulmonary genetic risk? The Lancet 344 (8924): 750-751; 1994.

- Kleinjans, J.C.S; Albering, H.J. Vuilverbranding en gezondheidsrisico's; de dioxine-casus vervolgd. Milieu 9(2): 58-65; 1994 .

- Stierum, R.H.; Hageman, G.J.; Welle, I.J.; Albering, H.J.; Scheurs, J.G.M.; Kleinjans, J.C.S. Evaluation of exposure reducing measures on parameters of genetic risk in a population occupationally exposed to coal fly ash. Mutation Research 319(4): 245-256; 1994.

- Albering, H.J.; Hoogewerf, J.A.; Kleinjans, J.C.S. Gezondheidsrisico Maasslib?. Bodem 5(2): 77-79; 1995.

- Albering, H.J.; Hoogewerff, J.A.; Kleinjans, J.C.S. Survey on Rn-222 concentrations in dwellings and soils in the Dutch-Belgian border region. Health Physics $70(1): 64-69 ; 1996$.

- Kleinjans, J.C.S.; Moonen, E.J.; Dallinga, J.W.; Albering, H.J.; van den Boogaard, A.E; van Schooten, F.J. Polycyclic aromatic hydrocarbons in whiskies. The Lancet $348(9043): 1731 ; 1996$. 
- Albering, H.J.; Rila, J.P.; Moonen, E.J.; Hoogewerff, J.A.; Kleinjans, J.C.S. Human health risk assessment in relation to environmental pollution in two artificial freshwater lakes in The Netherlands. Environmental Health Perspectives (submitted for publication).

- Albering, H.J.; Leusen van, S.M.; Moonen, E.J.; Hoogewerff, J.A.; Kleinjans, J.C.S. Evaluating environmental health risks after the flooding of the river Meuse during the winter of 1993-1994 (submitted for publication).

\section{Abstracts}

- Albering, H.; Marx, A.; van Maanen J.; van Agen B.; Swaen, G.; Mertens P.; Kleinjans J. Genotoxicological evaluation of nitrate contamination of drinking water in exposed populations. Pharmac. Weekbl. Sci. Ed. vol 12: no 2; B4; 125; 1990 .

- Albering, H.J.; Geraedts, J.P.M.; Koulischer, L.; Vanmarcke, H.; Kleinjans, J.C.S. Assessment of cytogenetic damage in human populations in relation to indoor exposure to radon: A feasibility study. Eurotox congress, book of abstracts, Maastricht The Netherlands, p40; 1991.

- Maanen van, J.M.S.; van Dijk, A.; Albering, H.J.; Marx, A.; Swaen, G.: Mertens, P.; Kleinjans, J.C.S. Nitrate contamination of drinking water. A study of possible genotoxic risk in human populations. Eurotox congress, Maastricht The Netherlands, book of abstracts, p41; 1991.

- Albering, H.; Hageman, G.; Engelen, J.; Koulischer, L.; Vanmarcke, H.; Kleinjans, $\mathrm{J}$. Genetic damage in individuals exposed to radon in their dwellings: a feasibility study. Proceedings of the 33rd Dutch Federation Meeting, Rotterdam The Netherlands, book of abstracts p 45; 1992.

- Stierum, R.H.; Hageman, G.J.; Welle, I.J.; Albering, H.J.; Scheurs , J.G.M.; Kleinjans, J.C.S. Cytogenetic monitoring on a population occupationally exposed to coal fly-ash is useful to assess effects of exposure reducing measures. The Joint Meeting BLT-Beltox: Industrial Products: acute and chronic intoxications. Brussels, Belgitum, book of abstracts; 1992.

- Albering, H.J.; Engelen, J.J.M.; Hageman, G.J.; Koulischer, L.; Vanmarcke, H.; Kleinjans, J.C.S. Genetic damage in a human population in relation to indoor racton exposure. First Global and European Conference Environment and Public Health, Antwerp Belgium, book of abstracts p 6; 1993.

- Albering, H.J.; Engelen, J.J.M.; Hageman, G.J.; Koulischer, L.; Vanmarcke, H.; Kleinjans, J.C.S. Genetic biomarkers indicative for DNA damage in relation to indoor radon exposure. Eurosymposium Alma: Radon in our Euregio in workplaces, dwellings and schools, Liege Belgium, book of abstracts 1993. 
- Kleinjans, J.C.S.; Albering, H.J.; Hoogewerff, J.A.; Welle, I.J.; Engelen, J.; Koulischer, L:; Vanmarcke, H. Assessment of peripheral lymphocyte cytogenetic damage in individuals exposed to indoor air radon gas. AACR., Whistler, Canada, 1994.

- Albering, H.J.; Hoogewerff, J.A. Kleinjans, J.C.S. Radononderzoek in ZuidLimburg, NOVEM, Utrecht, 1994.

- Albering, H.J.; Leusen van, S.M.; Hoogewerff, I.A.; Moonen, E.J.C.; Kleinjans, IIC.S. Gezondheidsrisicoschatting van zware metalen na de inundatie van de oevergronden van de Maas in 1993. Ge Nationaal Symposium Bodemonderzoek, Bodem Breed, Lunteren, The Netherlands, book of abstracts p49; 1994.

- Albering, H.J., Hoogewerff, J.A.; Moonen, E.J.C.; Kleinjans, J.C.S. Gezondheidsrisicoschatting van zware metalen in relatie tot een heterogene bodemverontreiniging. 6e Nationaal Symposium Bodemonderzoek, Bodem Breed, Lunteren, The Netherlands, book of abstracts p48; 1994.

- Hoogewerff, J.A.; Albering, H.J.: Moonen, E.J.C. Ruimtelijke variatie van radon in bodemgas bij Visé en Eijsden, Ge Nationaal Symposium Bodemonderzoek, Bodem Breed, Lunteren, The Netherlands, book of abstracts p30; 1994.

- Hoogewerff, J.A.; Albering, H.J. Soil radon variability in the Visé region, Belgium. 3rd International symposium environmental geochemistry, Krakow, Poland; 1994.

- Albering, H.J.; Moonen, E.J.C.; Leusen van, S.M.; Hoogewerff, J.A.; Hageman, G.J.; Helders, E.J.M.; Cools, L.P.C.M.; Kleinjans, J.C.S.; Assessment of human exposure to heavy metals in relation to soil population. Three case studies. Epidemiology 6: S52; 1995.

- Albering. H.J.; Engelen, J.; Koulischer, L.; Welle I.; Kleinjans, J. Domestic radon exposure in relation to genetic damage. Epidemiology 6: S72; 1995.

- Albering, H.J.; Leusen van, S.M.; Moonen, E.J.C.; Hoogewerff, J.A.; Kleinjans, J.C.S. Health risk assessment in relation to soil pollution after the flooding of the river Meuse during the winter of 1.993-1994. Society for risk Analysis, International Society for Exposure Analysis, Annual Meeting. New Orleans, U.S. Book of abstracts p27 (158); 1996.

\section{Reports}

Albering, H.J. Indicatief onderzoek naar chemische belasting van aal in twee beken in Streekgewest Westelijk N-Brabant. Inschatting van het gezondheidsrisico bij consumptie van deze aal. GGD Streekgewest Westelijk NBrabant, Bergen op Zoom, 1991. 
- Albering, H.J. Gezondheidkundige evaluatie van luchtverontreinigende stoffen in auto's. Provinciale Raad voor de Volksgezondheid in ZuidHolland, Den Haag, 1991.

- Albering, H.J.; Kleinjans, J.C.S. Afvalverbrandingsinstallatie Zuid-Oost Nederland. Schatting van humane belasting en de kans op schadelijke gezondheidseffecten als gevolg van chemische emissies. Werkdocument Volksgezondheid. Beleids-MER AVI-ZON. Grontmij, Zeist, 1993.

- Albering, H.J.; Hoogewerff, J.A.; Moonen E; Kleinjans J.C.S. Bodem en gewasonderzoek in tuinen aan de Demertstraat te Maastricht. Gemeente Maastricht, Maastricht, 1994.

- Albering, H.J.; Kleinjans, J.C.S. Estimation of the risk of exposure to tetrachlorodibenzodioxin (TCDD) through food intake. In Food Safety and Toxicology. Open University, Heerlen; 1994.

- Albering, H.J. Kwantificering van de gezondheidsrisico's in relatie tot oevergrondcontaminatie van de Maas. Universiteit Limburg, Maastricht, 1995.

- Leusen van, S.; Albering, H.J.; Kleinjans, J.C.S. The environmental quality of the river Meuse. University of Limburg, Maastricht, 1995.

- Albering, $\mathrm{H}_{\text {J }}$.; Kleinjans, J.C.S. Kwantificering van het gezondheidsrisico voor omwonenden in relatie tot emitterende stoffen door het bedrijf Edelchemie Panheel B.V. Edelchemie Panheel B.V. Panheel. juli 1997. 